\title{
Negotiating multiple identities in educational contexts: stories of Tamil Heritage Language Users as Multilingual Malaysians
}

Thilegawathy Sithraputhran

A thesis submitted to the Victoria University of Wellington in fulfilment of the requirements for the degree of Doctor of Philosophy

Victoria University of Wellington

March 2017 


\section{Dedication}

To my father, Sithraputhran and my mother, Marimuthu, who have always spurred me on and believed in my academic ability. I am what I am today because of you both.You have inspired me to reach for greater heights.

To all Heritage Language Users "The choice of language and the use of language are central to a people's definition of themselves in relation to the entire universe (Ngũgĩ wa Thiong'o, 1986). Let nothing stop you from using your heritage language.

\section{தமிழன் என்று சொல்லடா, தலை நிமிர்ந்து நில்லடா}




\section{Abstract}

Malaysia is a multilingual and multicultural society comprising of ethnic Malays (dominant group) followed by ethnic Chinese, Indians and other indigenous groups. The national language is Malay and English is the second language. Heritage languages such as Mandarin and Tamil are used as the language of instruction in some primary schools. This study explores how a group of Tamil Heritage Language Users from Tamil primary schools (THLU-Ts) at a private university recounted maneuvering through their multilingual world during their early lives at Tamil primary school, at state secondary school (Malay) and then at a private university (English). Nine first year undergraduate participants were selected from a private university in Malaysia where English is the medium of instruction. They were selected as THLU-Ts based on two criteria. Firstly, they were ethnic Tamils and secondly, they had completed six years of primary education at Tamil primary school. I used photovoice interviews to construct their narratives. The participants, prompted by photographs they brought as artefacts, described their language experiences in a multilingual setting. The participants' voices were storied into narratives based on three narrative inquiry strategies of broadening, burrowing and restorying. Two in-depth interviews were conducted over a six month period and these were video-taped and transcribed. The interview transcript from each first interview contributed to a narrative summary or story. This was a general description of the participant and events (broadening stage). The second interview was held towards the end of the semester. During the second interview, participants were asked to reflect on their narrative summaries (which had been distributed earlier) and comment on them. I sought data to reexamine the existing data (burrowing stage) before rewriting a complete and coherent story (restorying) for each participant. This story was also individually reviewed by each participant. Data analysis was an iterative process that included storying and coding. I identified three broad themes and then examined them in the light of relevant literature.

This analysis allowed me to understand how the THLU-Ts shaped their identities during social interactions with different linguistic communities in Malaysia, including THLU-Ms (ethnic Tamils from national primary schools) and non-Tamils (Malays and Chinese). Initially, THLU-Ts faced challenges as they transitioned to secondary school 
coming from a Tamil- medium primary school. At secondary school, they had to adjust to a Malay linguistic environment for the first time. As their proficiency in Malay grew, they felt they were accepted as authentic members of the academic community. When they entered the English-medium university, there was pressure to develop proficiency in English. They repositioned themselves once again and made deliberate language choices during social interaction with other linguistic communities. When the findings were viewed through Blommaert's sociolinguistic scales, it was apparent that participants scaled languages depending on the value assigned to each one (Malay, English and Tamil). This reflected the way language was used in society. As powerful multilinguals who invested in a multilingual repertoire, participants displayed linguistic accommodation. These findings suggest a need for educators and policy makers to reassess the role and importance of HL education. Currently, the Malaysian education policy is silent on its commitment to HL education in Malaysia. Yet, this research supports the One Malaysia concept which stresses unity in diversity and encourages educational policies to take a pro-multilingual stance. 


\section{Acknowledgements}

I thank The Lord for blessing me with wisdom and intellect and from whom I draw spiritual strength which has sustained me throughout my $\mathrm{PhD}$ journey.

I am greatly indebted to two beautiful ladies- my supervisors, Dr. Margaret Gleeson and Dr. Carolyn Tait. I would like to thank you for spurring me on towards completion of my thesis when I had doubts regarding my capability. I am grateful to you both for guiding me with excellent supervisory skills throughout this research process. Working as a team your individual contribution towards this thesis complemented one another. Dr. Margaret Gleeson, your detailed, meticulous scrutiny of my work enhanced its quality and gave it an aesthetic touch and to Dr. Carolyn who continually challenged me to think and widen my perspectives through insightful but hard questions. Both your advices have been priceless and I could not have imagined having better supervisors for my $\mathrm{PhD}$ study.

My gratitude goes to the nine participants who took time to share their stories with me. Thank you for trusting me. You have touched my life in many ways.

I am also very grateful to have a group of fellow $\mathrm{PhD}$ students who provided the laughter and fun and made me aware that I was not the lone traveller in this academic journey. I enjoyed our camaraderie. A special thanks is owing to Sudatip Prapunta with whom I have shared many critical discussions, laughter, and frustrations.

This project is supported by the $\mathrm{PhD}$ Submission Scholarship awarded by Victoria University of Wellington, and the research grant provided by the Faculty of Education. I also want to thank the staff at the Faculty of Education for their help and support in making this three year journey a pleasant one. A special thanks to Susan Kaiser for making time to edit this work, and for her meticulous attention to detail.

Finally, I express my deepest appreciation to my loving husband, Joshua without whom I would not have coped. Thank you for being my sounding board and raising my critical thinking skills. I would not have crossed over each hurdle along the way without your arms continually around me. I am also grateful to my son, Aaron, for chauffering me to the many meetings with my supervisors willingly inspite of his busy work schedule. 


\section{Table of Contents}

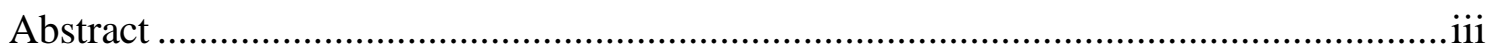

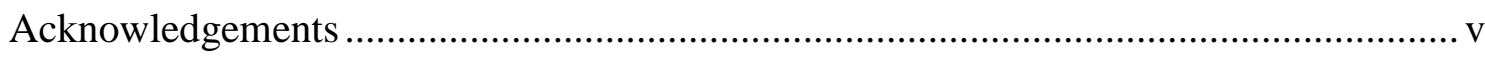

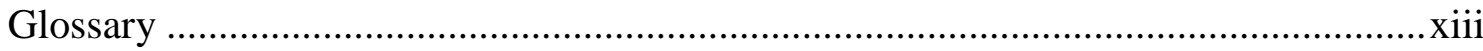

Chapter One Introduction........................................................................................................... 1

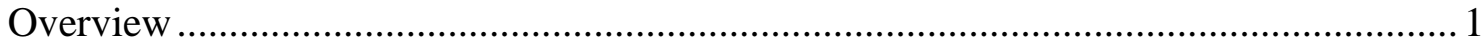

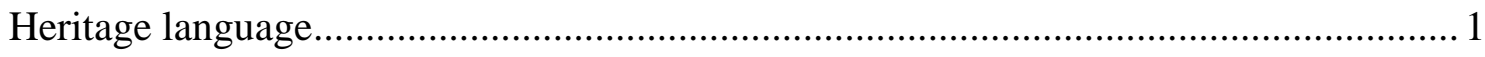

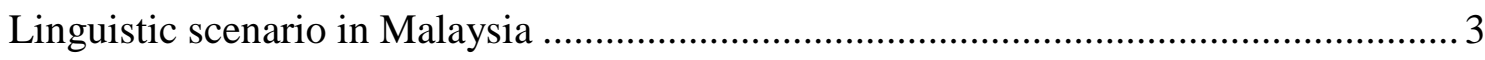

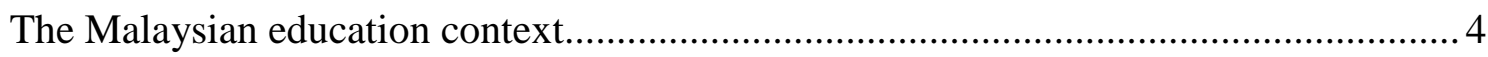

The history and status of Tamil schools in Malaysia ............................................... 6

THLU-Ts (from Tamil primary schools) in Malaysia .................................................. 7

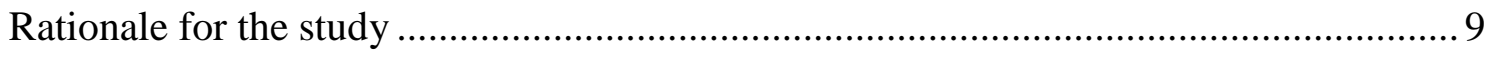

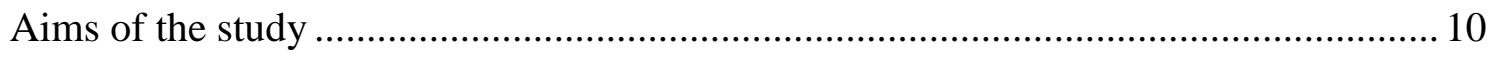

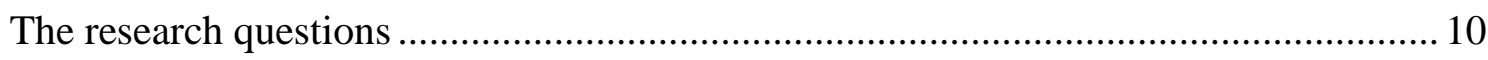

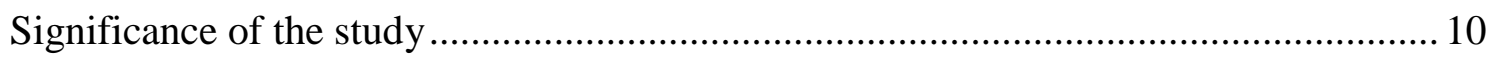

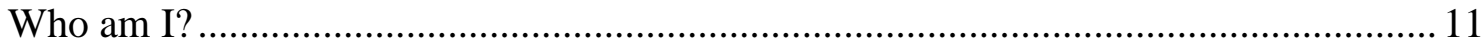

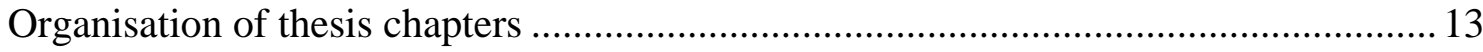

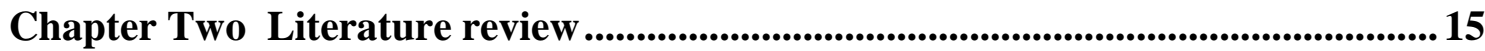

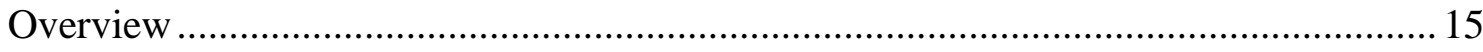

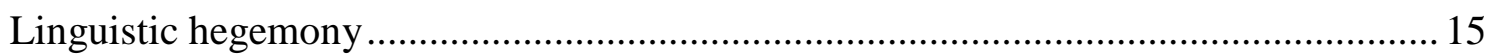

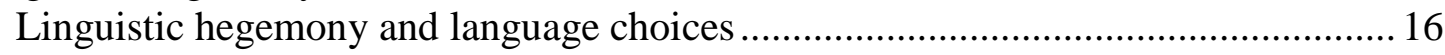

Linguistic hegemony and language boundaries among HLUs ................................ 17

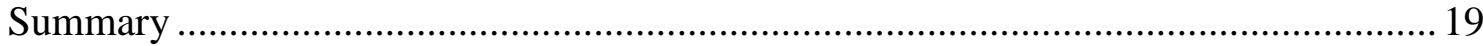

The role of English in a multilingual society ................................................. 19

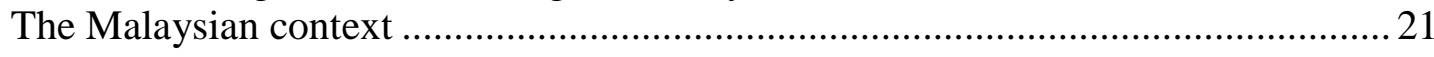

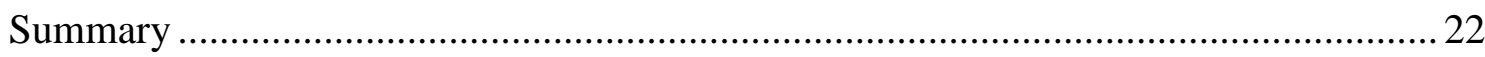

How individuals position themselves and how they are positioned by others............... 22

Language as a form of capital and positioning................................................ 23

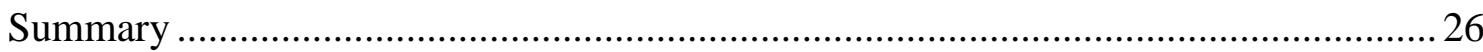

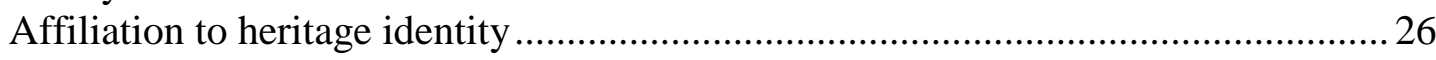

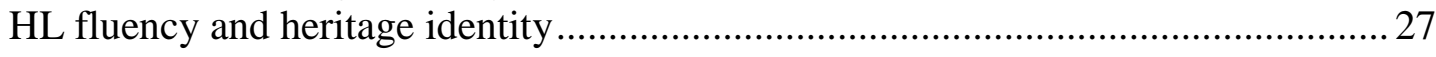

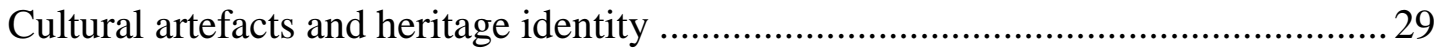

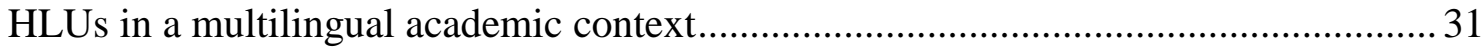

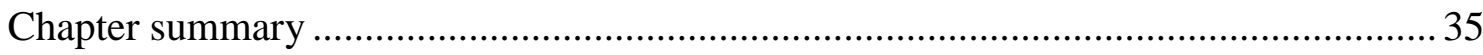


Chapter Three Conceptual Framework.............................................................................. 36

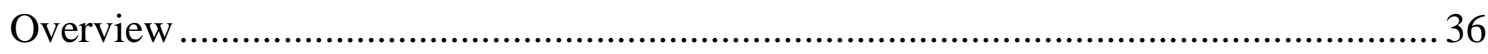

The integration of literature into a conceptual framework............................................... 36

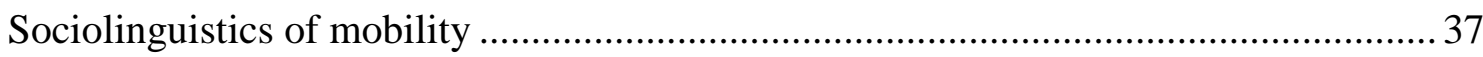

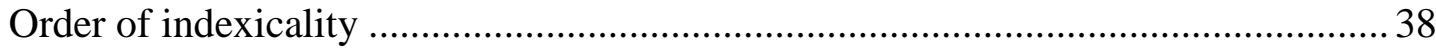

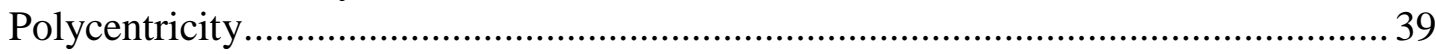

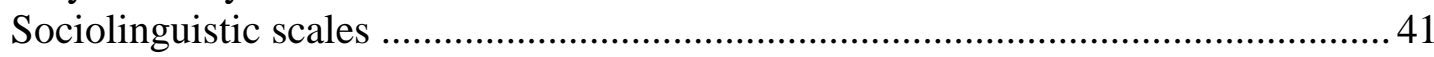

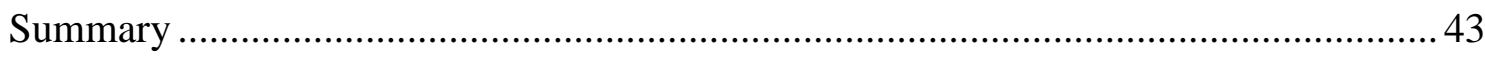

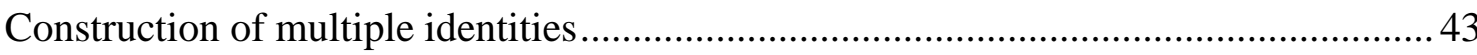

Dynamic identity practices of multilinguals ............................................................ 43

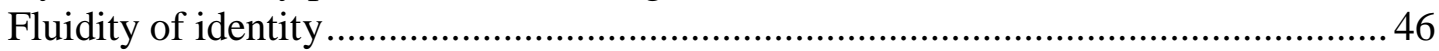

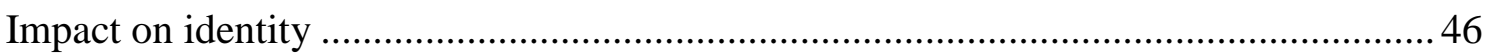

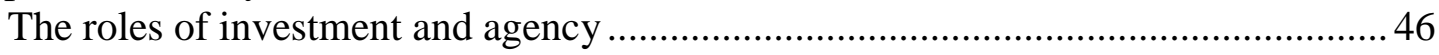

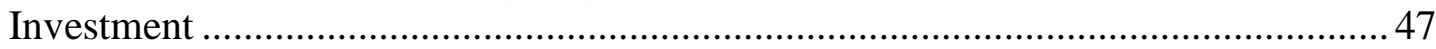

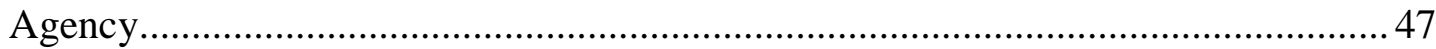

The dynamic interplay of investment and agency....................................................... 47

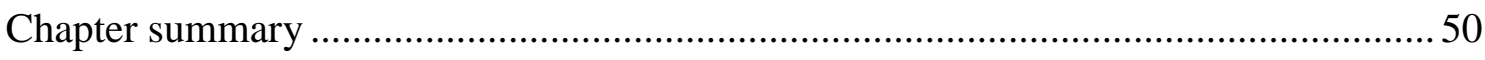

Chapter Four Research Methodology ..................................................................................... 51

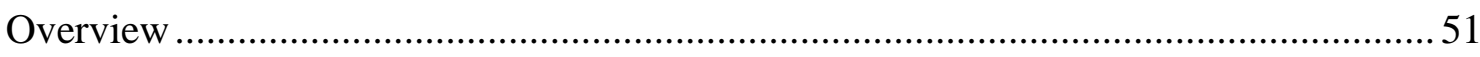

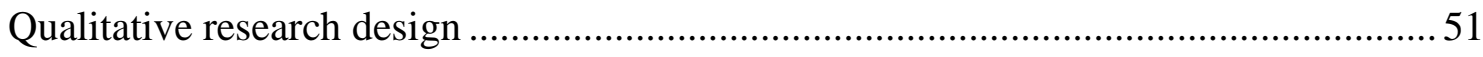

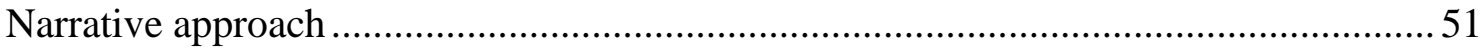

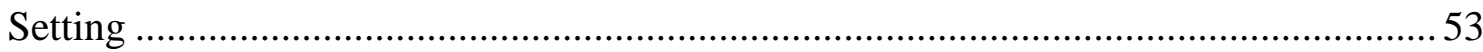

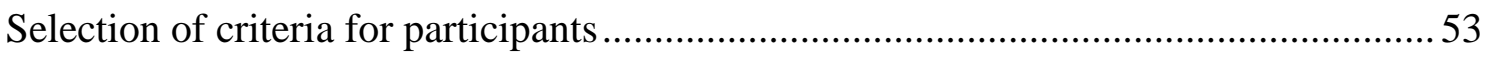

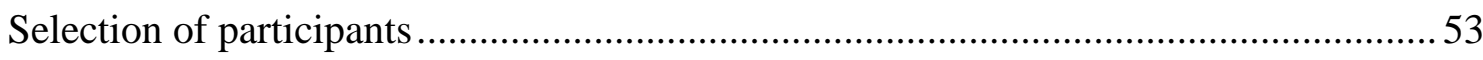

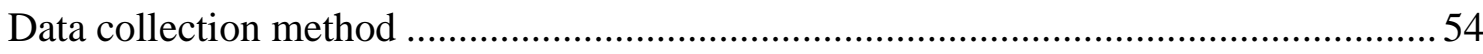

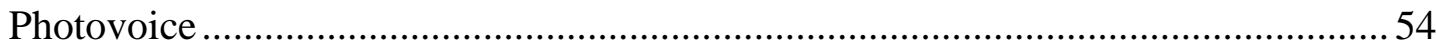

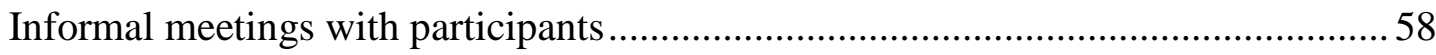

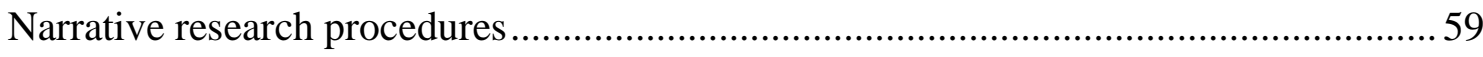

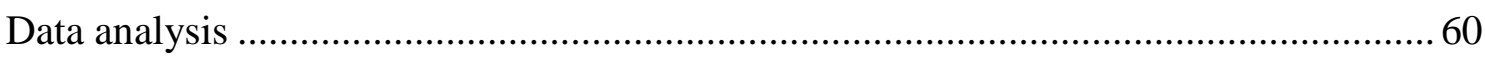

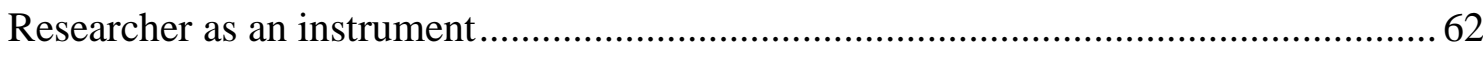

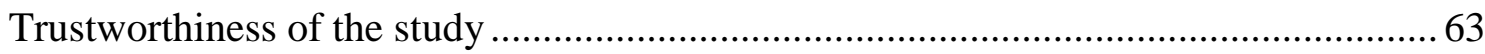

Dependability (or reliability and replicability in quantitative terms)............................64 64

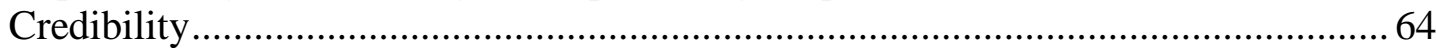

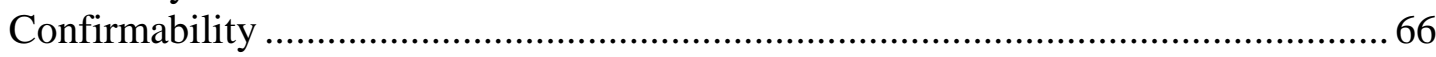

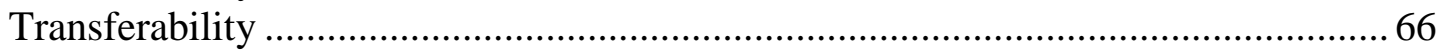

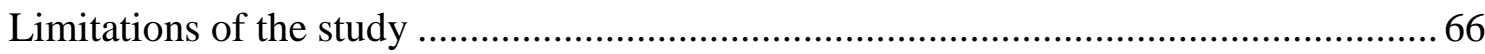

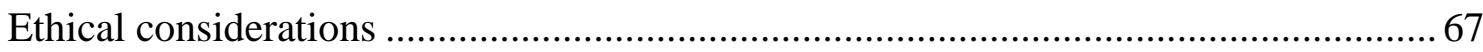

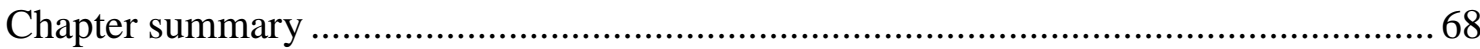


Chapter Five Findings .......................................................................................................... 69

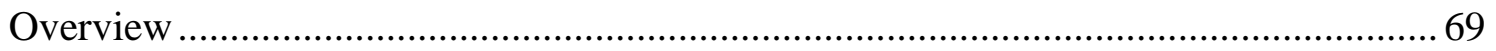

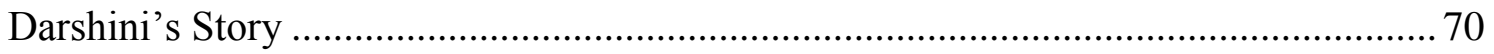

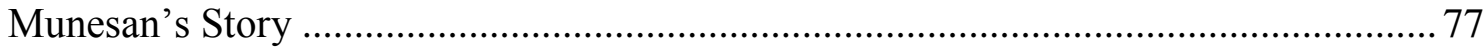

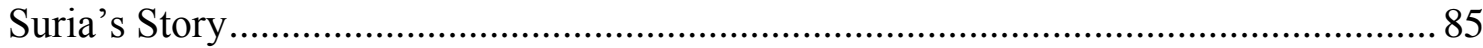

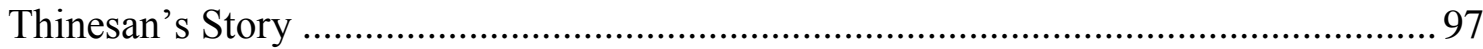

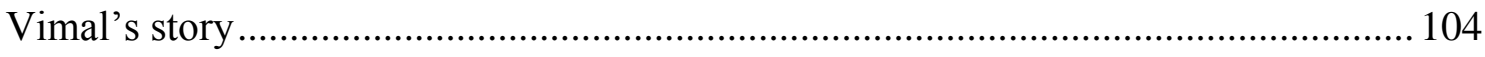

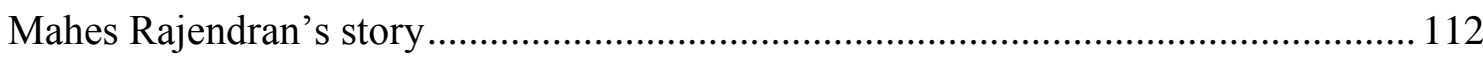

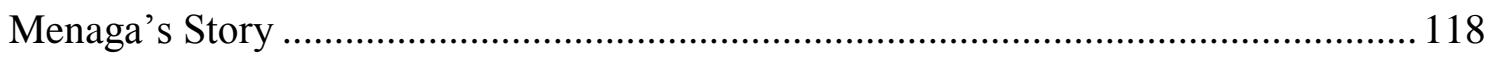

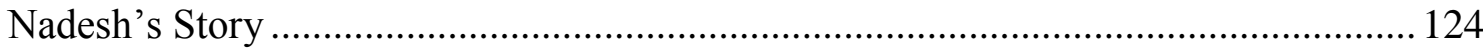

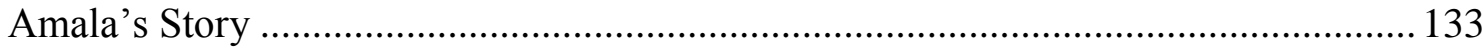

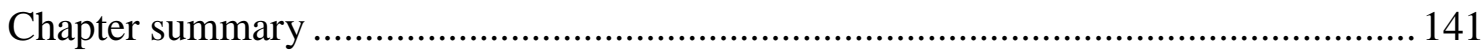

Chapter 6 Thematic Analysis.................................................................................................... 142

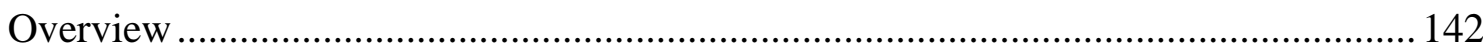

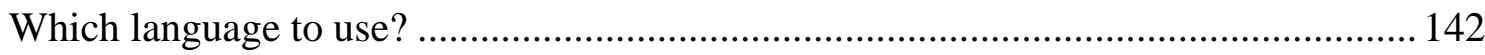

"Different, different people, different, different languages"...................................... 143

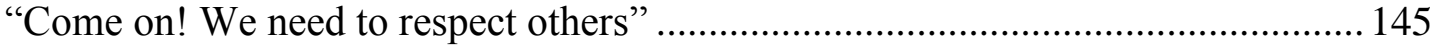

No, Tamil here please! Only English or Malay! ...................................................... 146

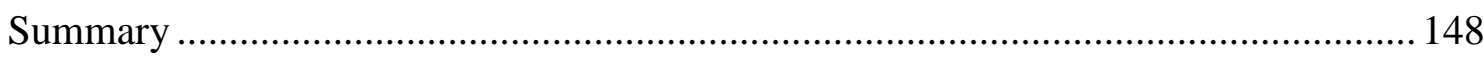

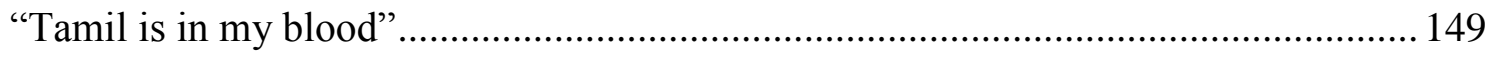

Welcome home-it's time for Tamil now ………………......................................... 150

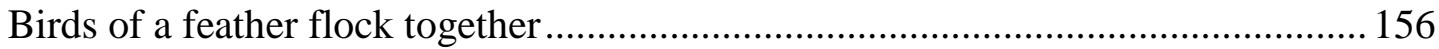

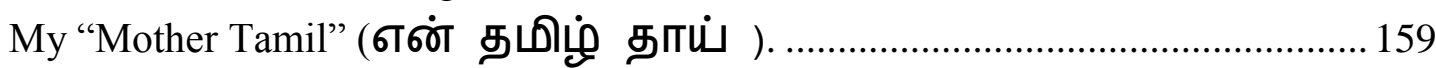

"If we don't speak, who else will?" ......................................................................... 161

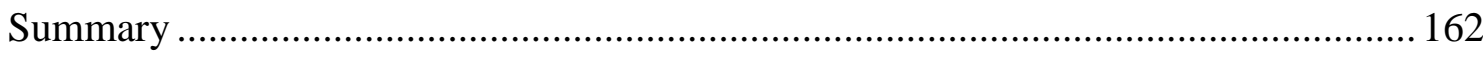

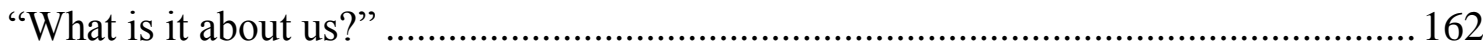

"You don't eat bread and butter. You eat rice and lentils, don't you?" ...................... 163

"Shame on you! After all, we can speak three languages" ............................................... 164

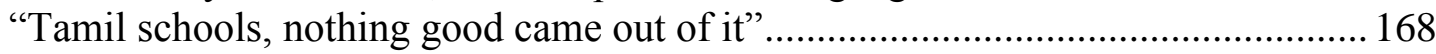

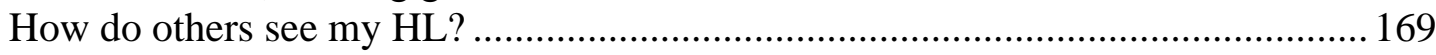

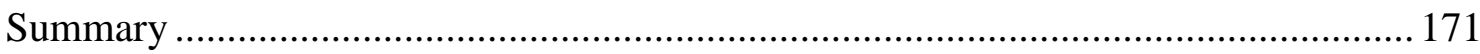

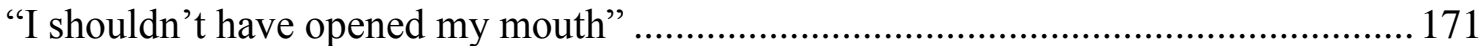

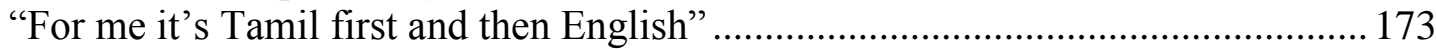

"It's (Malay) not really an important language" ..................................................... 175

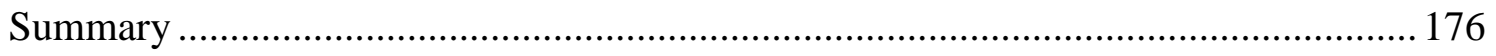




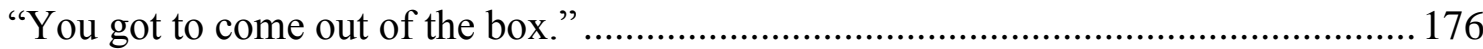

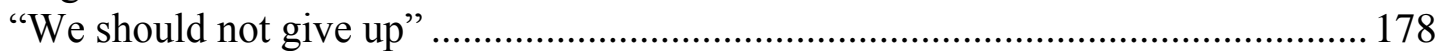

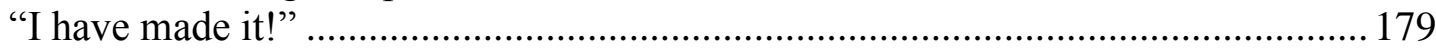

Tamil an international language-“It opened my eyes"............................................ 180

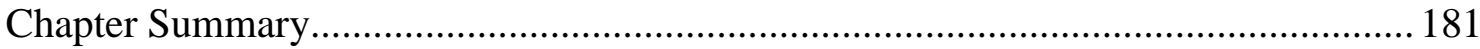

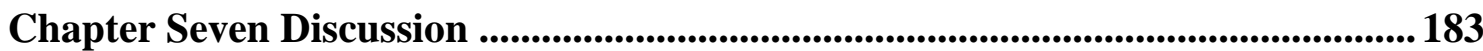

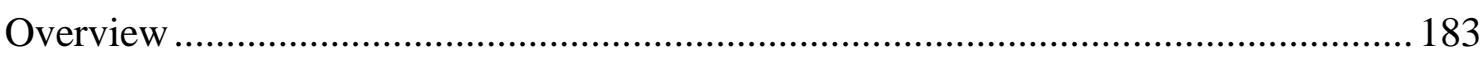

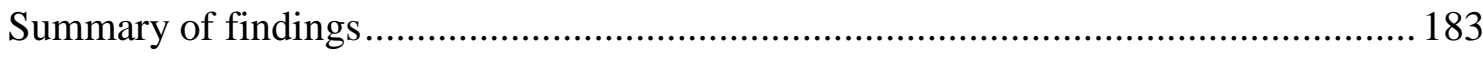

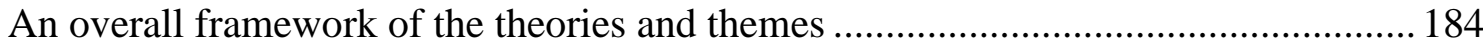

Towards the construction of heritage identities and multilingual identities .................. 185

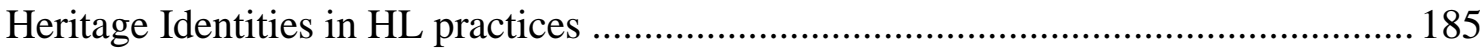

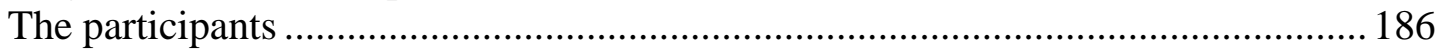

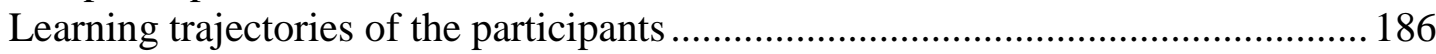

The notion of a linguistic biography of the participants .......................................... 187

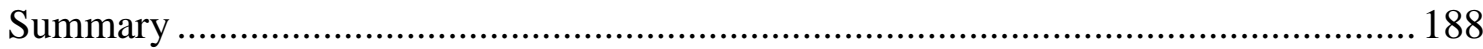

Linguistic hegemony and positioning in relation to identity ........................................ 189

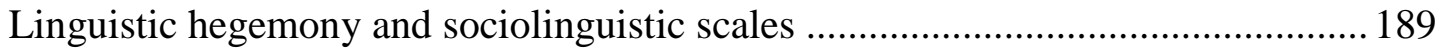

Applying sociolinguistic scales at Tamil primary school ......................................... 190

Applying sociolinguistic scales at secondary school ……...................................... 192

Applying sociolinguistic scales at the international university ................................ 194

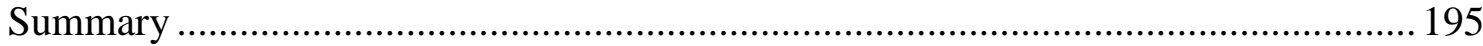

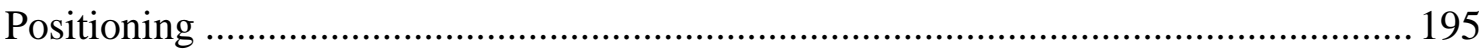

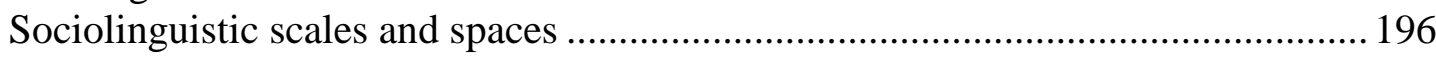

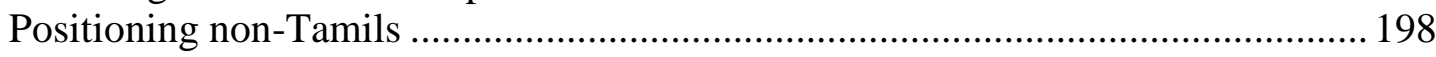

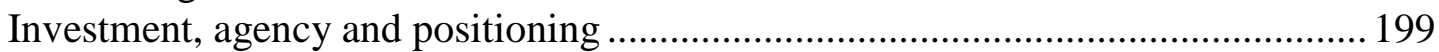

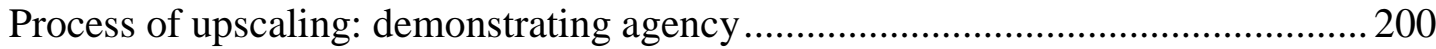

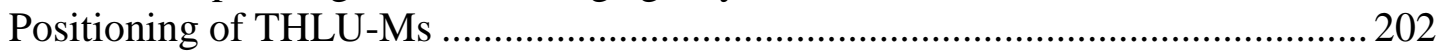

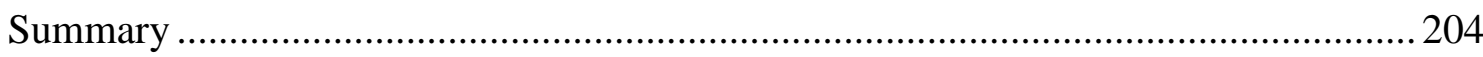

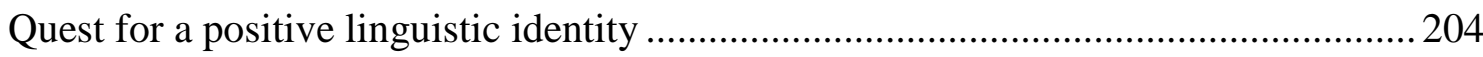

Contemporary identity practices in a multilingual environment................................ 205

Assuming multilingual identities in diverse linguistic practices................................206

Assuming heritage identities in monolingual practices...........................................206

Micro hegemonies and multiple identities (multilingual and heritage identities ..... 208

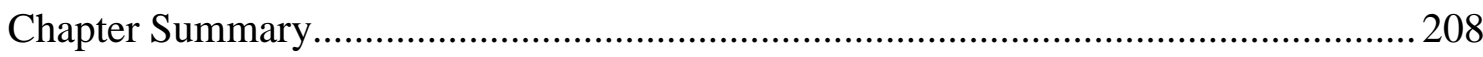

Chapter Eight Conclusion ....................................................................................................... 210

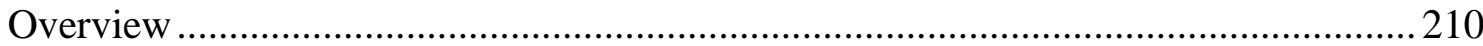

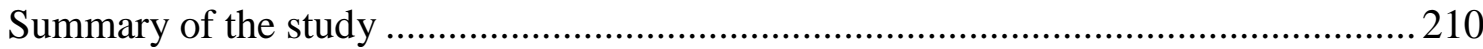

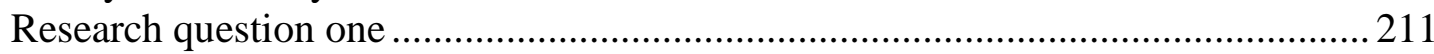

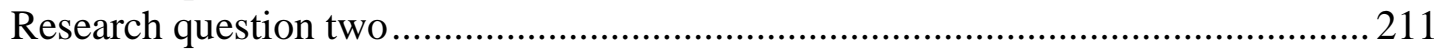

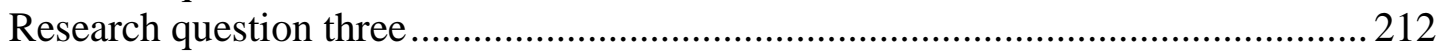




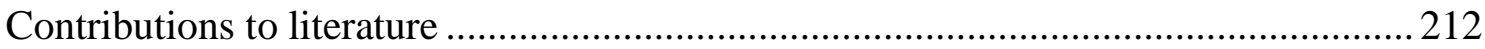

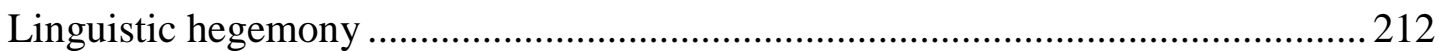

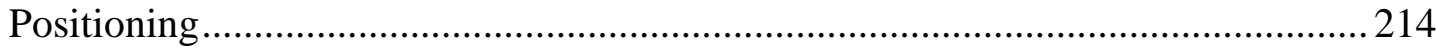

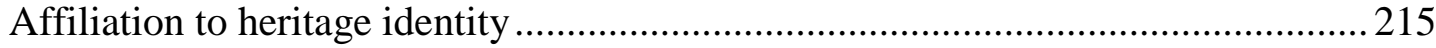

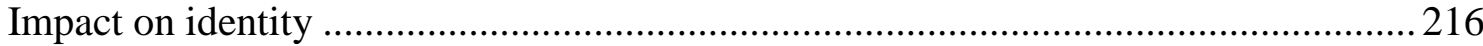

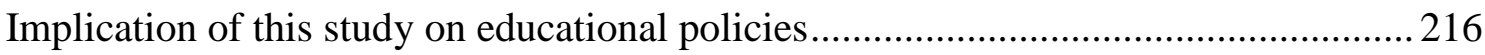

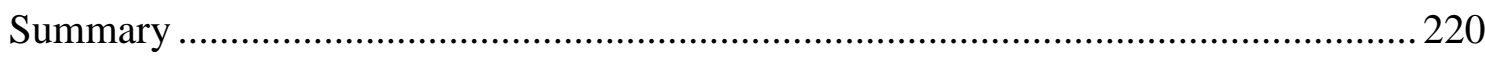

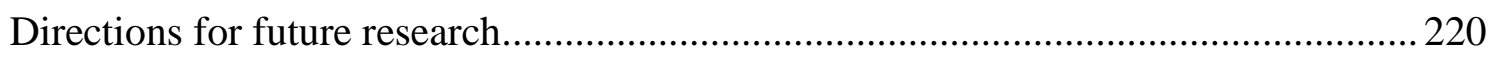

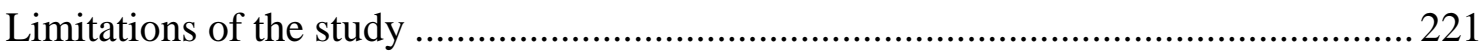

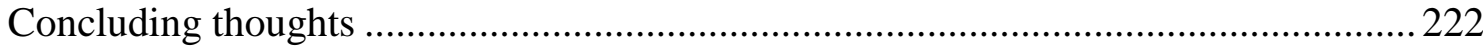

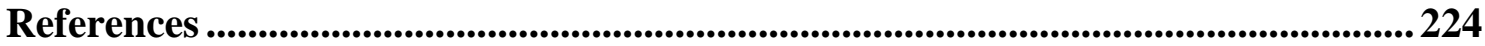

\section{Appendices}

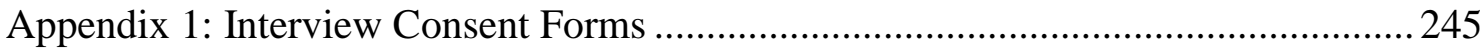

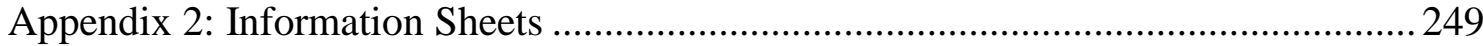

Appendix 3: Sample Interview Questions ............................................................. 253 


\section{List of Figures}

Figure 1. The educational background and medium of instruction of THLUs from Tamil primary schools and THLUs from national primary schools ............ 3

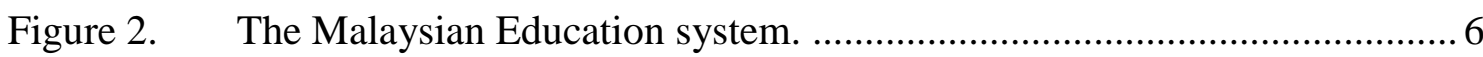

Figure 3. The language of instruction in various academic settings for THLU-Ts.... 8

Figure 4. The language of instruction in different academic settings for THLU-Ms. ....9

Figure 5. Socially situated language boundaries. .................................................... 19

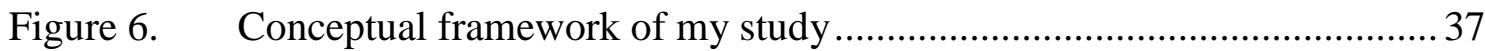

Figure 7. Dynamic identity processes of HLUs .................................................... 45

Figure 8. The dynamic interplay of desire and commitment, investment and agency.. 48

Figure 9. The three narrative inquiry strategies to analyse data collected from the in-depth interviews (Clandinin \& Connelly, 1990, 2000)...........................6 60

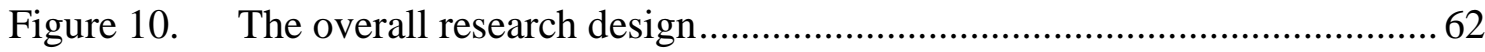

Figure 11. Photograph of Darshini's maternal relatives.............................................. 70

Figure 12. Photograph of Darshini in her father's family house............................... 71

Figure 13. Photograph of Darshini's Tamil primary school teachers......................... 73

Figure 14. Group photograph of participants who had attended the leadership

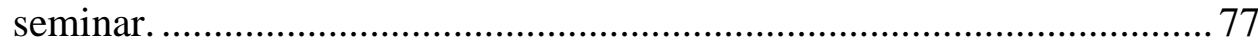

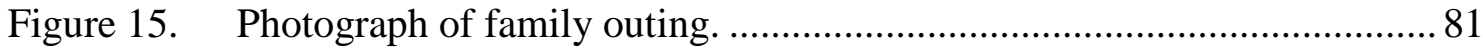

Figure 16. Photograph of Munesan and his friends taken at the university. .............. 82

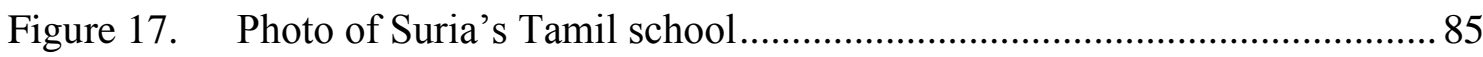

Figure 18. Photograph of Suria receiving trophy at National Oratorical Competition...90

Figure 19. Group photograph of Committee for College Annual Science Exhibition. .. 91

Figure 20. Photograph of Suria receiving award at a singing competition organized by Malaysian Tamil Artistes Society ………………………..... 92

Figure 21. Photograph of Suria making his winning speech.................................... 93

Figure 22. Photograph of Thinesan's Tamil primary school teacher.......................... 97

Figure 23. Photograph of Thinesan's national secondary school............................... 100

Figure 24. Photograph of the university where Thinesan was enrolled. ................... 101

Figure 25. Photograph of Vimal's secondary school. ................................................ 104

Figure 26. Photograph of Vimal with his friends at the university ........................... 107

Figure 27. Photograph of Vimal's Tamil primary school. ......................................... 110

Figure 28. Photograph of Mahes and his friends on a holiday trip. ......................... 112

Figure 29. Photo of Mahes Rajendran's secondary school hall. ................................ 114

Figure 30. Photograph of Mahes and his family at a restaurant.............................. 116 
Figure 31. Photograph of Menaga's Tamil primary school.

Figure 32. Photograph of Menaga with her friends at the university..................... 120

Figure 33. Photograph of Nadesh's Tamil primary school. .................................. 124

Figure 34. Photographs of Nadesh's secondary classroom and classmates. ............ 125

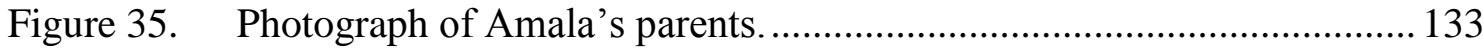

Figure 36. Photograph of Amala and her debating team members. ....................... 137

Figure 37. Photograph of Amala's teacher...................................................... 137

Figure 38. How the identities of the participants are impacted as multilingual speakers

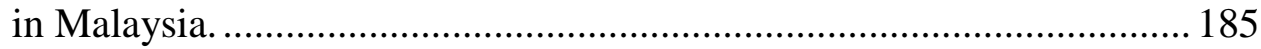

Figure 39. The participants who are THLU-Ts (from Tamil primary schools) ....... 186

Figure 40. Linguistic hegemony and positioning in relation to identity ................ 189

Figure 41. How participants perceived languages were scaled in Tamil primary school. ....................................................................................... 191

Figure 42. How participants ranked languages in secondary school...................... 194

Figure 43. How the participants scaled the languages at the university................. 195

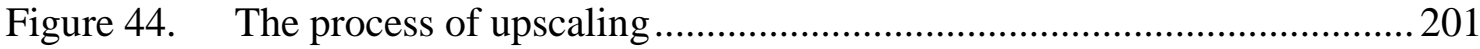

Figure 45. Quest for a positive linguistic identity ............................................. 204

\section{List of Tables}

Table 1. Scaling of language practices across time and space ................................ 41

Table 2. Theme one and its related sub-themes................................................... 143

Table 3. Theme two and related sub-themes ......................................................... 149

Table 4. Theme three and its related sub-themes ............................................... 163

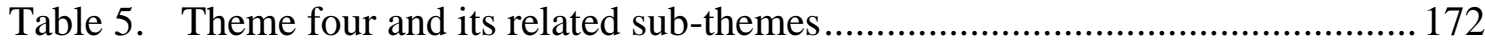

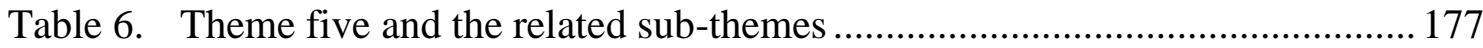

Table 7. Table on summary of findings....................................................... 183

Table 8. Table showing themes, findings and theoretical framework

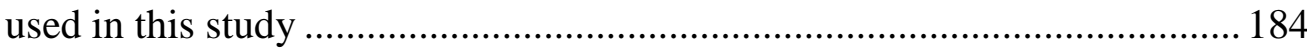

Table 9. The linguistic biographies and practices of the participants...................... 188

Table 10. Using Blommaert's sociolinguistic scales to rank languages in Malaysia ... 190

Table 11. An application of Blommaert and Variis (2013)'s framework of contemporary identity practices to the participants 


\section{Glossary}

\section{Definitions of terms}

A brief definition of terms used in this study is provided .

Term

Agency

Authenticity

Cultural artefacts

Cultural capital

Enoughness

Heritage language

Indexicality

Investment

Linguistic biography

Linguistic capital

\section{Definition}

The human capacity to act in a social transaction (Ahearn, 2001, p. 7).

Having sufficient features of a particular targeted identity to be identified as real authentic members,

Objects or symbols that have meanings for a specific group of people (Bartlett, 2007; Block, 2007).

Having non-financial assets that gives a person social mobility. For example, education, specialized knowledge, speaking skills (Bourdieu, 1986).

Having sufficient features in order to be ratified as a real member of an identity category (Blommaert \& Variis, 2013).

A language other than a dominant language (like English) which is spoken at home. The speaker is ethnically and culturally connected to it.

Societal linguistic attitudes that assign value to different languages and empower the users of prestigious dominant languages (Blommaert, Collins \& Slembrouck 2005a).

Learner's desires and commitment to learn a language of a particular community that is important in their envisioned futures. This would include spending time and energy to improve their linguistic competence in the targeted language as they aspire to be identified with the target community (Norton, 2011).

A chronological account of the formal language learning experiences of the THLUs.

It is a form of cultural capital where the knowledge and skills in a particular language (especially English) places the language user in a privileged position (Bourdieu, 1986). 


\section{Term}

Linguistic hegemony

Language learning trajectory

Linguistic market

Linguistic repertoire

Micro hegemonies

Order of indexicality

Positioning

Polycentricity

Sociolinguistics scales

Symbolic capital

\section{Definition}

The power relationship between a majority and minority language and language groups.

The structure of the language learning path taken by learners.

It is a symbolic market where linguistic exchanges takes place. In this market prestigious languages like English enjoy a higher market value compared to other minority languages (Bourdieu, 1986).

It refers to the sets of language resources available to the language user of certain linguistic community. He or she can choose to use a particular language, in certain social context.

A dynamic and perpetually adjustable linguistic practices and behaviours (Blommaert \& Variis, 2013).

A layered social structure where some forms of registers, codes and styles are systemically perceived as valuable, others as less valuable, and some are not taken into account at all (Blommaert,et. al. 2005a).

During a social interaction, individuals locate themselves and others with rights, duties and obligations in and through talk governed by social rules and order (Harré \& van Langenhove, 1999).

Having multiple centres (academic and social spaces in Tamil and secondary schools and universities), each imposing different codes and norms as to what are accepted as appropriate linguistic practices and behaviours (Blommaert,Collins \& Slembrouck, 2005b).

Linguistic practices based on sociolinguistic scales which are dependent on space and time. When a social interaction takes place in a momentary dimension of time, the linguistic practices within this social context are local and situated and thus ranked lower. Dominant linguistic practices (like English) are ranked higher because they are translocal and widespread (Blommaert, 2010a).

Resources that represents honour, prestige and recognition and serves as value that one holds within a culture (like sococultural values of the THLUs) (Bourdieu, 1986). 


\section{Chapter One \\ Introduction}

\section{Overview}

This study gives voice to a small group of Tamil Heritage Language Users (THLUs) on how they adapted to different linguistic environments during their education. It examines how this adaptation impacted their identities as multilingual Malaysians. It considers how these undergraduate THLU-Ts (Tamil Heritage Language Users from Tamil primary schools) studying at an international university in Malaysia maneuvered their multilingual identities in their academic lives. Their diverse language learning experiences and multilingual interactions with the different linguistic communities (Malays, Chinese and Tamils) highlight how multilingual identities are constructed in Malaysia.

In any communicative event, people express their identities through language choices from their particular linguistic resources. These linguistic resources embody particular socio-cultural histories, and particular sets of linguistic practices, attitudes and values (Hall, 2011). As multicultural language users, the Tamils in Malaysia use Malay, English and Tamil to communicate with different linguistic communities in this country. Language, then, is not only an instrument of communication among the various linguistic communities in Malaysia but also a means of asserting the identities of particular linguistic communities and their distinctiveness from others. Therefore, decisions about when to use their heritage language and the socio-cultural values of their heritage language, contribute to the distinct identity of Malaysian Tamils.

In the next section I define heritage language and the complexities involved in identifying Heritage Language Users (HLUs). As there is no single definition encompassing all HLUs, defining who is a heritage language user can be problematic (Carreira, 2004; Wiley, 2001).

\section{Heritage language}

A heritage language (HL) is the language someone learns at home as a child and is a minority language in a society which uses other dominant languages (such as English) 
(Valdes, 2000). Tamil is considered to be a HL within the Malaysian context. The dominant languages are Malay (the national language) followed by English.

In addition, HLUs are culturally connected to their HL. A HL has a "particular family relevance" to the user (Valdes, 2005, p. 69) and an affiliation with and allegiance to an ethno-linguistic group (Fishman, 2001). HLUs are members of the community where this language is spoken regardless of their levels of proficiency. A HL is also known as a "community language" (Baker \& Jones, 1998; Corson, 1999; Wiley, 2001, 2005), a "home language" (Yeung, Marsh, \& Suliman, 2000), and a "minority language" (Peyton, Ranard \& McGinnis, 2001). These different terms denote the various functions of a HL. For the THLU-Ts in my study, Tamil was their community language and home language, but within the wider Malaysian context, it is a minority language compared to Malay and English which are dominant.

Polinsky and Kagan (2007) classify types of HLUs on a continuum that ranges from fluent users to users who can barely speak the HL. For the purpose of this research, I define THLUs according to their proficiency level and their educational background. THLU-Ts in this study were proficient HL users who had attended Tamil primary schools where Tamil was the medium of instruction. In comparison, the THLUs from national primary schools, THLU-Ms (where Malay was the medium of instruction) did not need to use Tamil for academic purposes. These THLU-Ts' journeys through different languages in different academic environments are explained in the later section of this chapter.

Figure 1 illustrates the different educational pathways taken by THLUs from Tamil primary schools and THLUs from national primary schools. 

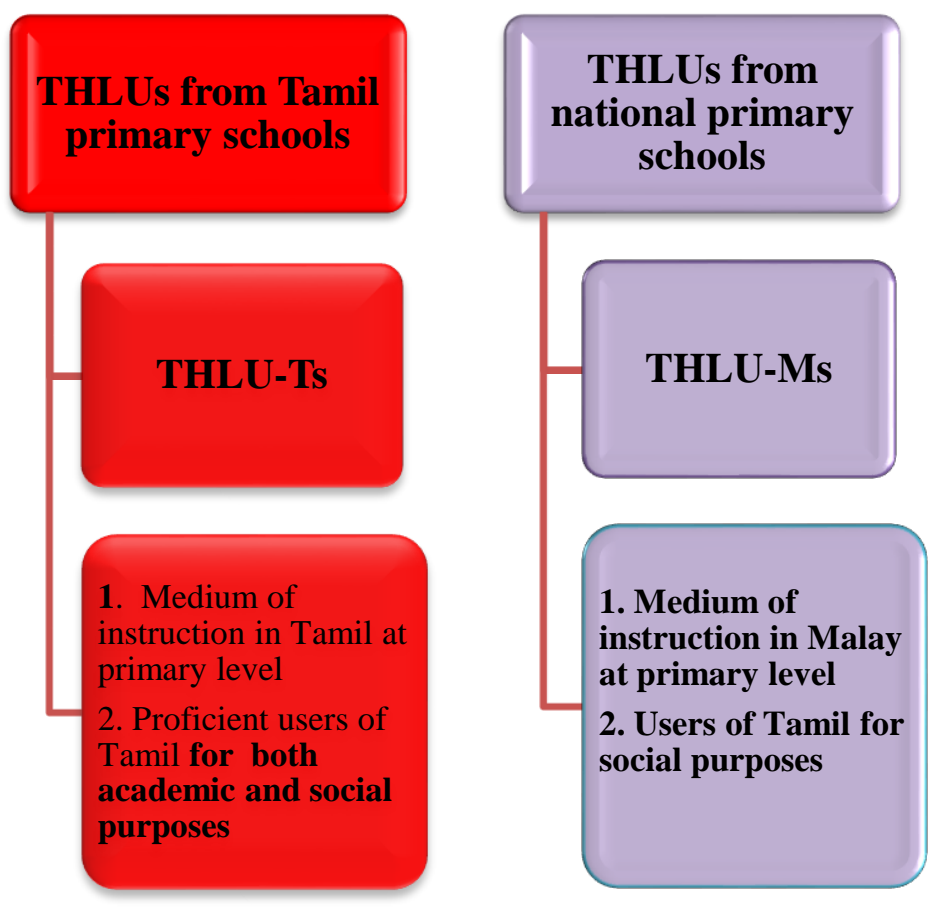

Figure 1. The educational background and medium of instruction of THLUs from Tamil primary schools and THLUs from national primary schools

From now on, the participants of my study will be referred to as THLU-Ts whereas THLUs coming from national primary schools will be called THLU-Ms. To understand how the multilingual practices of THLU-Ts in my study impacted the construction of their identities, it is important to know the rich tapestry of languages in Malaysia.

\section{Linguistic scenario in Malaysia}

Malaysia is a multi-ethnic, multi-lingual and post-colonial nation. The population is about 31 million, comprising Malays (50.3\%), Chinese (21.8\%), Indians (6.5\%) and the remainder consisting of other ethnic and indigenous communities and migrant workers (Department of Statistics, 2014). Malay is the national language and the heritage language of ethnic Malays. English (introduced during the British colonial period) is the second language and alongside these two languages (Malay and English), Mandarin and Tamil are the two major heritage languages spoken by the Chinese and Tamil communities (Asmah, 2007, p. 337). While Malay has been the sole medium of instruction in national schools over the last 30 years, Mandarin and Tamil continue to be used in heritage language schools at the primary level. Due to the increasing economic 
value of Mandarin, Mandarin is now offered as an additional subject taught to nonChinese children in schools, and it is a sought-after language for business and trade with China. However, such is not the case with Tamil language. It is not learnt beyond the Tamil community as, unlike Mandarin, it is not seen to be of economic value. It is not a language that is needed for business, and business deals with India are often conducted in English rather than Tamil. Tamil does not have the economic pull that Mandarin has, but has cultural and literary value among all THLUs living in Malaysia (Azirah, 2009).

In comparison to Malays and Chinese, the Tamils have been less successful economically. They face marginalisation as the smallest minority group in many fields, including: the allotment of business licenses, the awarding of government scholarships, the closure of Tamil primary schools, applying for citizenship, granting of permits for taxis, allotment of land, admission to universities, and the appointment of lecturers or teachers (Lahiri, 2008). In the Ninth Malaysian Plan (2006-2010), it was highlighted that Tamils controlled only 1.2 percent of the corporate wealth in Malaysia, a decline from the 1.5 percent that they controlled previously (Osman, 2007, p.1).

Within this unique linguistic setting, my study explores how using multiple languages (English, Malay and Tamil) in different spheres of the THLU-Ts' daily lives impacts their identities and affects their motivation to maintain their heritage language.

In the next part, I provide an overview of the Malaysian education system highlighting heritage language education. This outlines the Malaysian education context and the different language settings that Tamils encounter in their academic lives.

\section{The Malaysian education context}

There are two types of schools at the primary level, i.e., national primary schools and heritage language schools. Parents have the option to send their children to either national primary or heritage language schools. In the national primary schools the medium of instruction is the Malay language which is the national language, and English is taught as a second language.

On the other hand, in the heritage language schools, the medium of instruction is either Mandarin or Tamil. English is compulsory and is taught as a subject in both Chinese primary and Tamil primary schools. 
Primary education lasts from when children are between six and twelve years of age. After completing primary education in heritage language schools, most Chinese and Tamil students enter national secondary schools where the medium of instruction is Malay. Formal heritage language instruction in Tamil and Mandarin exists only at primary level, although there are Chinese Independent High Schools (privately funded by the Chinese community) which provide secondary education in Mandarin. Both the Chinese and Tamil primary schools receive funding from the government. Allocations for Chinese primary schools are higher compared to Tamil primary schools, for two reasons. Firstly, there are more Chinese primary schools $(1,293)$ compared to the number of Tamil primary schools (523) (Vernacular Schools Report, 2012). Secondly, most Tamil primary schools are located on privately owned estate land and for this reason they receive only partial funding from the government. Under the Education Act 1995, schools located on private land are not eligible for a full grant from the government. Of the current 523 Tamil primary schools only 148 receive complete funding from the government, the rest are partially funded. It is the responsibility of the estate owners rather than the government to maintain school buildings and to provide appropriate facilities. The government pays for teachers' salaries leaving the partiallyfunded Tamil schools to find their own funding for all other expenses. Donation drives are organised by Parent Teacher Associations (PTA) and the Malaysian Indian Congress (MIC) for financial assistance (Janakey Raman, 2010; Tate, 2008).

Tamil education stops at primary level as there are no Tamil secondary schools. Less than one percent of Malaysia's education budget goes to Tamil schools, even though Tamils make up about seven percent of the total population (South Asian Voice, 2008). Tamils also make up less than five percent of successful university applicants (The Economist, 2003). THLU-Ms who have gone through national primary schools have generally fared well economically, while THLU-Ts who went to Tamil primary schools end up in menial jobs, or as factory workers or labourers (Tate, 2008, p. 178). Schiffman's (2002) bleak conclusion of a study of Malaysian Tamils is that since Tamil lacks economic value in Malaysia, it is therefore "maintained by the socio-economically destitute as a last vestige of primordial ethnicity" (p. 168). 
Figure 2 illustrates the Malaysian Education system:

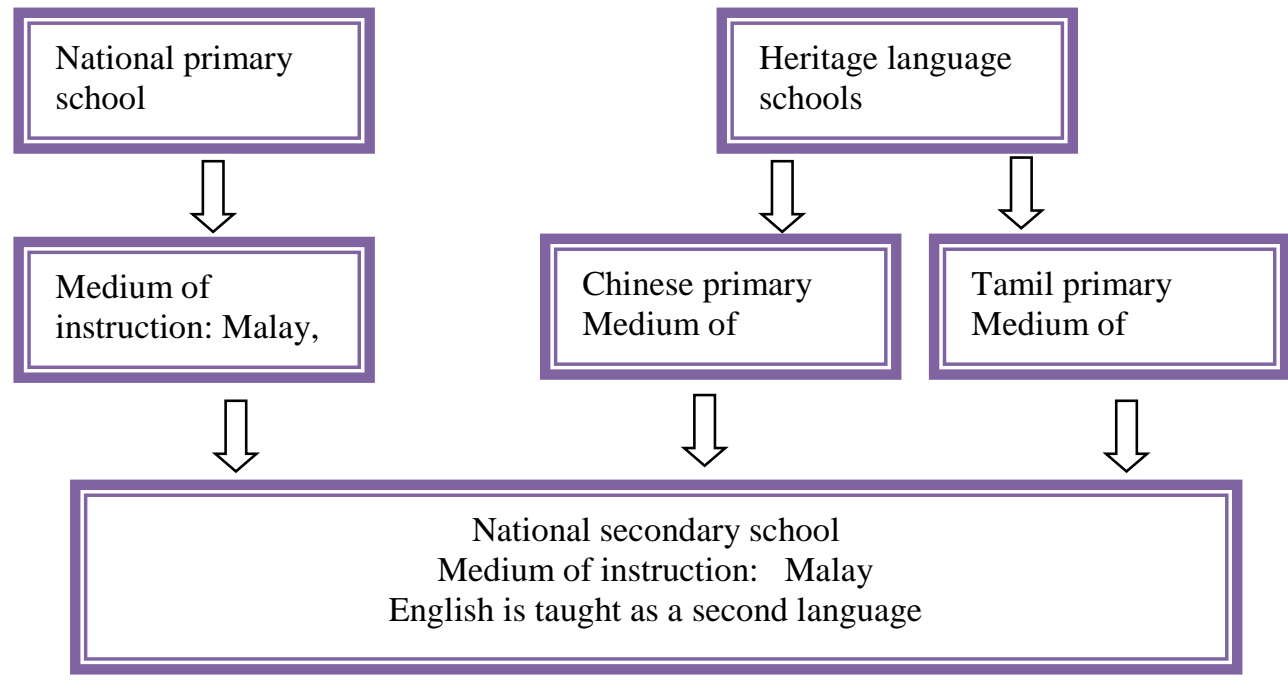

Figure 2. The Malaysian Education system.

The next part focuses on Tamil primary schools where THLU-Ts start their early school life. The development of Tamil primary schools in Malaysia must be understood against the backdrop of the economic and political marginalisation of the Tamil community during the British colonial era. The British recruited Tamils (from Madras Presidency of British India, now known as Tamil Nadu) to work in the rubber plantations under the indentured labour system during the early 1830s. They were settled on rubber estates which were isolated from town centres, which were at that time largely populated by the Chinese community.

\section{The history and status of Tamil schools in Malaysia}

The first Tamil school was set up at the beginning of $18^{\text {th }}$ century. The Penang Free School, set up by Rev. R. Hutchings in 1816, was reported to contain a class for conducting formal Tamil education in the Straits Settlement. The 1912 Labour Ordinance compelled the planters to set up ad-hoc schools for the children of their plantation labour force. The number of schools increased to 333 in 1930, 547 in 1938, and 741 in 1947, and reached its maximum of 888 in 1957. After the country's independence, the shift in education policy and labour migration led to the closing of many schools. Many estates were sold off and this led to the migration of Tamil plantation workers to urban areas, causing an acute drop in the enrolment in the Tamil schools on the plantations. Hence, the enrolment in Tamil schools on the estates dropped 
too, as many plantation workers left the estates to work in cities as factory workers. They brought their families with them and settled in urban areas. In 1963 there were 720 schools in operation on estates. By 2000 there were only 526. The number of Tamil primary schools today stands at 523 (C. Joseph, 2014).

Tamil schools are described as "the Cinderella of the Malaysian Education system" (Marimuthu, 1993, p.478) for three reasons. Firstly, the setting up of Tamil schools was primarily meant to educate the children of the plantation workers. As such, the majority of these schools existed merely to fulfill the statutory requirement rather than to provide a meaningful education. The rubber estates were located in rural areas far away from public amenities (like hospitals, banks, post offices). This provided an isolated environment where there was hardly any contact with the other linguistic communities. Only Tamil language was used and Tamil children had little exposure to Malay or English (Schiffman, 2002).

Secondly, children from the Tamil schools were isolated from mainstream education because they lacked opportunities to interact with other students who attended national primary schools. Thirdly, in terms of teaching quality and infrastructure, Tamil schools lagged behind national primary schools and Chinese primary schools. Tamil primary schools sometimes lacked basic resources such as a proper school building, adequate classrooms, playing fields, toilet facilities and libraries (C.Joseph, 2014). Today, the Tamil schools educate approximately 100,000 children. While middle class Tamils prefer to send their children to national primary schools, almost 75 percent of the Tamil working class still sends their children to the Tamil primary schools (Arumugam, 2014). My study shows the significance of Tamil primary schools through the narratives of successful THLU-Ts who are first year undergraduates at an international university in Malaysia.

Next, I provide a brief description of THLU-Ts who attend Tamil primary schools and highlight the uniqueness of their academic paths in comparison to those of THLU-Ms who attend national primary schools.

\section{THLU-Ts (from Tamil primary schools) in Malaysia}

THLU-Ts in Malaysia undergo six years of early primary education at Tamil primary schools and then move on to national secondary schools. After completing secondary 
education the THLU-Ts enter sixth form (upper secondary for two years) offered at national secondary schools if they meet entry requirements. They then are offered places at public universities if they meet the required Cumulative Grade Point Average (CGPA). They can also choose to enrol themselves in foundation programmes/A levels/matriculation courses offered at private universities. Successful graduates from these programmes then pursue undergraduate courses at private universities. Figure 3 traces the use of language as medium of instruction at the various educational settings.

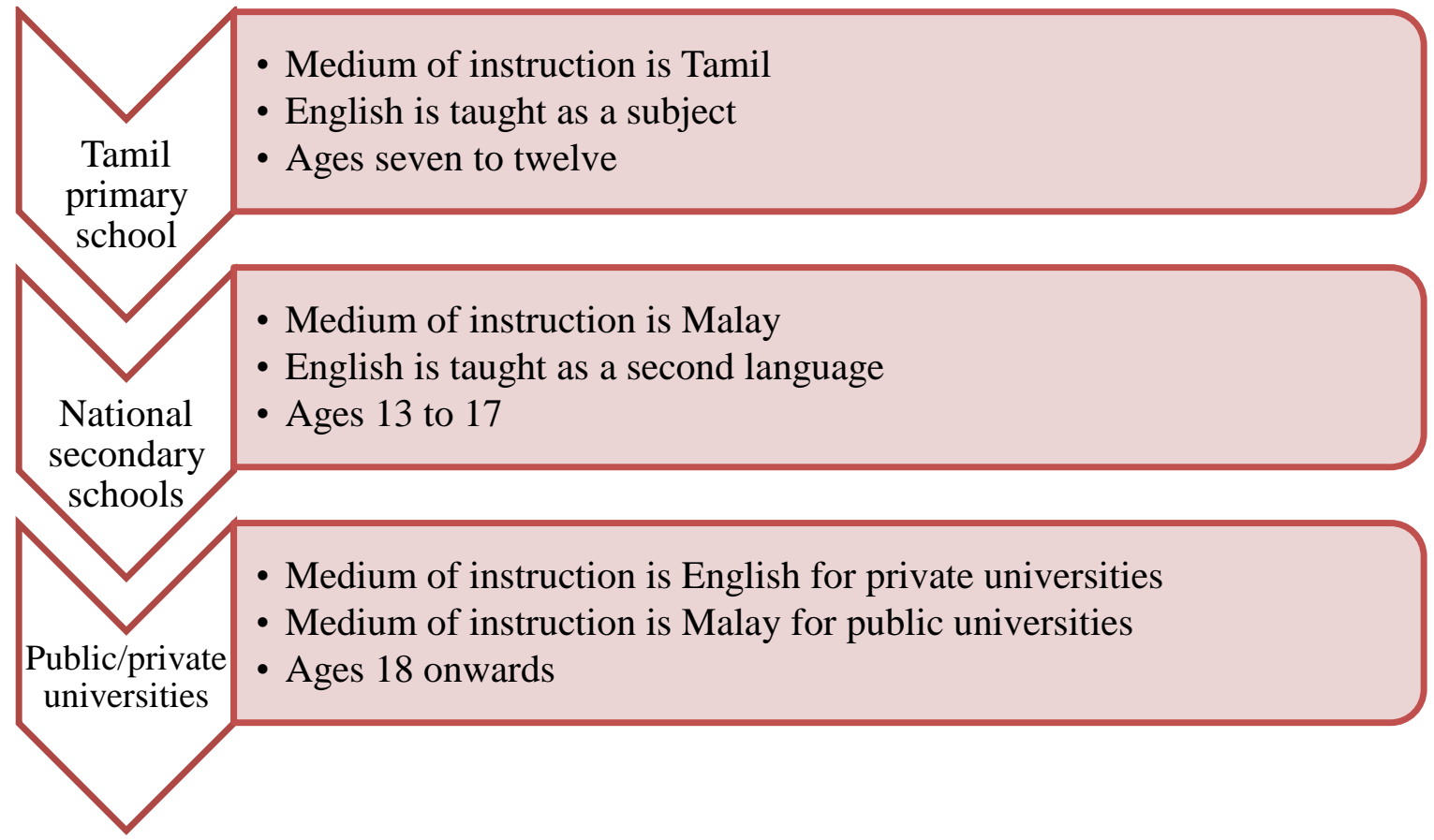

Figure 3. The language of instruction in various academic settings for THLU-Ts.

In comparison, THLU-Ms attend national primary schools, and then proceed to national secondary schools and finally to public or private universities. Figure 4 traces the use of particular languages as mediums of instruction at different educational settings for THLU-Ms. 


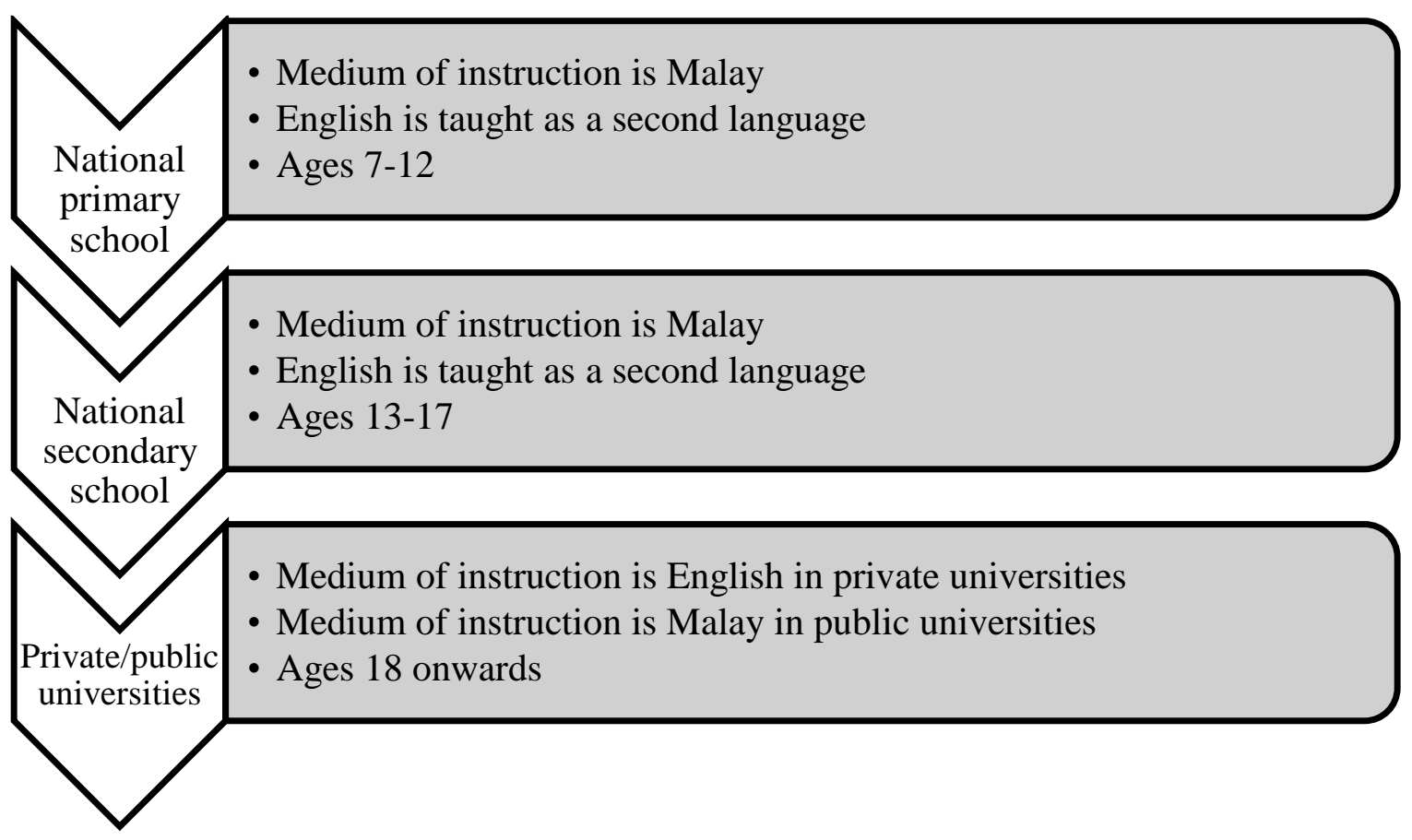

Figure 4. The language of instruction in different academic settings for THLU-Ms.

\section{Rationale for the study}

The maintenance of HLs and cultures is a major challenge for linguistic minorities, whether immigrant, refugee, or indigenous. Almost all societies around the world have witnessed overt or covert suppression of cultural and linguistic difference (Canagarajah, 2004; Fishman, 1991; Weiyun He, 2010; Wong Filmore, 1991). This is a particularly relevant issue in a multilingual country like Malaysia. HL education for linguistic minorities (Chinese and Tamils) in Malaysia is provided by Chinese and Tamil primary schools but HL schools do not enjoy the same status accorded to the national primary schools. Of late there have been calls for the closure of these HL schools in favour of a single school system which uses the national language (Malay) as the medium of instruction. The former Education Ministry Director-General Abdul Rahman Arshad called for the abolishment of HL schools to strengthen national unity (IBN CNN, 2013). Furthermore, the Malaysian Education Blueprint (2013-2025) launched on 6, September, 2013, by the former Deputy Prime Minister, Muhyiddin Yassin has caused grave concern among Tamil and Chinese educators. They feel that the existence of HL schools is threatened as The Blueprint is silent on the maintenance and development of HL schools. There appears to be an absence of national policies and measures to continue and develop heritage language schools (Malaysia Today, Dec.20, 2013). 
The national language (Malay) is mandated for use in all official contexts and is the primary medium of communication between the different linguistic communities. English plays the role of the second most important language, and has become the common language (or lingua franca) in many linguistically diverse regions. Educational reforms as outlined by the Malaysian Education Blueprint 2013-2025 have led to the implementation of a bilingual policy which reiterates Upholding the Malay Language, and Strengthening the English Language (MBMMBI) policy. This difference in the status of different languages in Malaysia is exacerbated for users of heritage languages like Tamil.

\section{Aims of the study}

This study presents the narratives of a small group of successful THLU-Ts who were university students at the time my research took place. It gives voice to their experiences as the THLU-Ts adjusted to new academic and linguistic environments at secondary school and at the international university

This study addresses the following research questions:

\section{The research questions}

How do nine THLU-Ts tertiary students from an international university in Malaysia:

1. perceive the status of their HL in relation to English and Malay?

2. perceive that they are positioned by their peers (non-Tamils and THLU-Ms) when they use Tamil?

3. perceive the role of their families in the language choices they (the participants) make?

\section{Significance of the study}

"One of the most fundamental ways we have of establishing our identity, and of shaping other people's views of who we are, is through our use of language" (Thornborrow, 2004, p. 158). This study expands our understanding of how language choices impacts identity. My study contributes new perspectives on how the multiple language use (Tamil, Malay and English) of THLU-Ts impact their identities in multilingual settings. This study explores how a small group of successful THLU-Ts constructed and negotiated their identities through diverse linguistic practices in multilingual academic settings. 
This research adds further insights into how language choices impact upon identity especially heritage identities. It uncovers how THLU-Ts learn to position themselves within academic settings that are not supportive of their heritage language and social cultural values. Their stories reveal how they responded to tensions created through the imposition of a Malay-only ideology at national secondary schools and English-only ideology at private universities. Their narratives shed some light on the challenges they faced during their academic journey in different educational settings. This may inform educators and policy makers on the problems faced by THLU-Ts during their transition process from heritage language schools to national secondary schools and university. It is timely to undertake a study of this nature, especially as policymakers begin to implement the Malaysian Education Blueprint (2013-2025). The results of this study may be of interest to educators, language policy makers and curriculum planners as well as to families trying to promote HL maintenance and development.

There is very little scholarship focusing on Tamil communities in Malaysia, and the bulk of it reflects a bias towards the histories of Tamil migrant plantation workers and their socio-economic problems (Belle, 2015; Sathisan, 2008). This study is unique because it departs from such a focus and highlights educational issues of Tamil students coming from Tamil primary schools from their perspectives.

The next section describes my personal background and motivation to conduct this study.

\section{Who am I?}

Credible qualitative research needs to address what the researcher brings to the study in terms of qualifications, experience and perspectives (Patton, 1990). The researcher is a key instrument and self-reflections are an integral part of the research process as these determine the way a study is conducted (Creswell, 2012). Thus, the qualitative researcher must be clear about their position in the study (Brantlinger, et al., 2005; Milner, 2007).

I am a THLU-E who came from an English- medium primary school. The first six years of my primary school life was in English and Malay was taught as a subject. Then, in secondary school the medium of instruction was still in English except for 
history and geography which were taught in Malay. This change was brought about by the May 13, 1969 incident which impacted the political landscape in Malaysia during the late sixties and early seventies. The country was reeling from the aftermath of violent racial riots on May 13, 1969. To reduce racial tensions and to unite the different ethnic groups, all English-medium schools were converted to Malay- medium schools (national schools) in January, 1970. By 1984 all Malaysian education was delivered exclusively in Malay language (Gaudart, 1987). I was never exposed to a completely Tamil or Malay academic environment.

I am fluent in Tamil as I can read, write and speak in Tamil well. I owe this to my father who insisted that it was important to know one's mother tongue. So I attended Tamil proficiency classes held on Saturdays at primary and secondary schools. It was not compulsory to attend these classes as it was considered as an extra-curricular activity. Furthermore, not all schools were required to offer HL classes. I chose to learn my HL as an additional language. Hence I would consider myself to be an exception. I scored well in the exams and pursued Tamil language as an elective at university. In addition, I am of Tamil descent and have lived most of my life in Malaysia. Thus I am familiar with the socio-cultural values and traditions of the Tamil community living in Malaysia. This study provided a unique opportunity for me to view the world through the eyes of THLU-Ts.

My professional background as a secondary school English teacher and then lecturer at a public university in Malaysia has given me knowledge and experience in teaching second language learners from diverse linguistic backgrounds. I have conducted research related to ESL teaching and learning and bilingualism and creative thinking skills (Thilegawathy Sithraputhran, 1998).

I have always maintained an interest in the academic welfare of Tamil students in Tamil primary schools. I joined a non-governmental organization, Education Welfare and Research Foundation Malaysia (EWRF), a NGO formed in 1979 to improve the social, educational and economic welfare of Malaysian Tamils, particularly students coming from poor homes. I taught free English classes to Tamil students coming from Tamil primary schools in my home state (Negeri Sembilan). A group of us, professionally trained English Language teachers, helped to prepare these students to sit for their public school examinations. These examinations included PMR (Lower Secondary Examination), SPM 
(Malaysian Certificate of Education) and STPM (Higher School Certificate). It was during this time that I came to know more of Tamil school students and Tamil schools.

I observed that Tamil school students sometimes found themselves in a hostile situation when they proceeded to national secondary schools as they were no longer studying in a culturally and linguistically familiar environment. The transition period from Tamil school to secondary school can be a painful process and it was disheartening to watch the students from Tamil primary schools trying to cope in this new Malay language educational environment (EWRF News, 2013).

I visited some Tamil schools, interacting with the teachers and students there and found that Tamil was used as both a social and academic language in a completely Tamil environment. My interest in the concept of identity among Tamil Heritage Language

Users (THLUs) from then on began to grow. This interest consolidated when I embarked on this PhD journey. I could now pursue something close to my heart and be able to contribute something to my community.

\section{Organisation of thesis chapters}

Chapter One has outlined the purpose of this research and its significance for future THLU-Ts who are emerging from the Malaysian education system and it provides strategies and insights for educators and policy makers concerning THLU-Ts. This chapter also presents the educational, socio-linguistic and historical context of my study. Finally, I have acknowledged how my professional interest and my affiliation to the Tamil linguistic community have shaped my interest in the research problem.

Chapter Two reviews the literature on heritage language users from studies conducted in both international and local contexts. The literature in this study draws on three main areas. These areas of research findings on linguistic hegemony, positioning and affiliation to heritage identity and their relationship to this study are explained. A conceptual framework based on Blommaert's socio-linguistic scales (2010a) is presented in Chapter Three. Important concepts related to heritage identity are highlighted.

Chapter Four describes the research design. A narrative approach employing photovoice interviews was used to gather data from nine THLU-Ts studying at an international university in Malaysia. 
In Chapter Five, the narratives of the nine THLU-Ts are storied from their interview transcripts. I used the narrative research procedures of broadening, burrowing and restorying (Clandinin \& Connelly, 2000) when constructing participants' stories.

Chapter Six analyses the findings of this study. I did a thematic analysis after the interview transcripts were coded using Nvivo 10. Chapter Seven discusses the findings of this study and answers the research questions. The last chapter concludes this study. It summarises the analysis and discussion and considers the implications of this study for educational policies in Malaysia. Finally areas for further research are suggested. 


\section{Chapter Two \\ Literature review}

\section{Overview}

In this chapter I review studies on heritage language users followed by a thematic review of these studies and the implication of these findings for the overall design of my research.

I review research on heritage language users paying particular attention to how HLUs constructed their identities and maintained heritage values in multilingual academic and non-academic contexts. I examine studies that showed how participants (HLUs) negotiated their identities in and out of classrooms in contexts where dominant language ideologies prevailed. This provides insights into HLUs' language learning attitudes, perceptions and their social networking with non-HLUs and other heritage community members.

There are three streams of research that support the frame of my study. They are linguistic hegemony, positioning and affiliation to heritage identity. I begin by briefly defining the key terms before illustrating these three bodies of literature and then show how they are related to my study.

I begin by briefly defining the key terms before illustrating how these issues are developed within the literature.

\section{Linguistic hegemony}

Shannon (1995) defines linguistic hegemony as:

Wherever more than one language or language variety exists together, their status in relation to one another is often asymmetric. In those cases, one will be perceived as superior, desirable, and necessary, whereas the other will be seen as inferior, undesirable, and extraneous. (p. 176)

This concept captures the power relationship between the dominant and the minority languages in a multilingual society.

When particular languages are used in an ethnically diverse society, they often reflect the political, social and economic interests of the governing authority (Kroskrity, 2010). This creates tensions and conflicts between the languages of the ethnic minorities 
and languages spoken by the dominant groups because of the functional importance attributed to dominant languages. Dominant languages play a central role in the national public sphere (such as in educational institutions, government administration and public banking systems). Thus, these languages are valued highly compared to HLs which are often devalued because HL use is restricted to home and heritage communities (Amtaika, 2013; Azirah, 2009).

In the next section I highlight studies that indicated how HLUs were influenced in their language choices by linguistic hegemony.

\section{Linguistic hegemony and language choices}

Blackledge and Pavlenko (2002) argue that language ideologies are rarely about language alone, but are socially situated in the context of power relations in a diverse range of contexts such as academic discourse, language planning, immigrant narratives, education debates and the mass media. Following Blackledge and Pavlenko's argument (2002), linguistic practices appear to be influenced by current political, social, and ethnic conflicts. Thus, how society values particular language uses impacts its users. HLUs are influenced by the values, practices and beliefs associated with language use and the discourse which constructs values and beliefs at state, institutional, national and global levels.

This concept of how linguistic hegemony influences language choices is illustrated in Olsen and Olsen's (2010) study. The researchers conducted a study about how a group of Arab HLUs living in East Jerusalem made language choices that took account of cultural and ethnic differences between the different communities (the Arabs, Palestinians, the Jews and other European minorities). Their language use was also affected by the power play of languages (Hebrew and English versus Arabic). For example, in areas of conflict in East Jerusalem participants preferred using English because they did not want to reveal their Arab identity for fear of being mistreated at Israeli checkpoints. As a result the researchers concluded that their participants used several languages to cope with ethnic, political and social conflicts they faced within their social realms. The participants (72 tenth grade Arabic HL students) switched from their native language, Arabic, to another language, such as Hebrew or English based on the perceived power, importance, and usefulness of these regional languages. For example, they switched to Hebrew while in commercial and entertainment locations 
because Hebrew was the language of commerce and business here. A visit to the doctor and paying bills required them to use Hebrew. Arabic was used to communicate with their parents and grandparents and other heritage community members. Students responded that using Arabic reflected their traditional values and it was used for religious purposes (the language of Quran). They also reported that Arabic shaped their culture and helped to maintain their tradition as they were able to communicate with older members of their community. English was used most often on the internet at home, and for almost every social interaction which included other ethnic groups. Students preferred speaking in English to demonstrate their resistance towards the dominant language group (Hebrew). The researchers concluded that the students negotiated languages within their various social spheres and that languages may shift, depending on location or social and political contexts. This caused these HLUs to create language boundaries.

\section{Linguistic hegemony and language boundaries among HLUs}

The idea of language boundaries in the sense used by HL researchers does not reflect a physical, geographical border that separates areas or regions as seen in a map. Particular ethnic groups determine their membership within the community by observing a common language and a common socio- cultural system and practices (Barth, 1982). They create ethnic boundaries which dichotomise insiders from outsiders. Barth's concept can be extended to include language boundaries which can be seen as a mental boundary that HLUs construct to navigate social spaces during interaction. Within this boundary their HLs can be practised with other heritage community members. It can be seen as the HLUs' efforts to construct and maintain their heritage identities (Jorgensen, 2008).

HL researchers have also used other terms like linguistic demarcation (Jaspal, 2010; Pujolar \& Gonzalez, 2013; Wong \& Xiao, 2010), language division (Wylegala, 2010), public versus private domains or spheres (Pujolar \& Gonzalez, 2013; Wong \& Xiao, 2010) and group boundaries (Gua \& Patkin, 2013) to indicate the concept of language boundaries.

In a qualitative study of 22 Russian HLUs living in Ukraine, Wylegala (2010) found her participants had clear language boundaries. Data from the semi-structured indepth interviews revealed that her participants used Russian at home and in certain 
friendly circles, while Ukrainian was used in the street and in the workplace. Empirical support for this linguistic demarcation also comes from three further recent studies (Jaspal, 2010; Pujolar \& Gonzalez, 2013; Wong \& Xiao, 2010) which reported that there were clear patterns of language use in their participants' language practices. Pujolar and Gonzalez's study was conducted among Catalan speakers in Catalonia where Castilian was the dominant language use. Wong and Xiao's study was conducted with ChineseAmerican undergraduates who were not Mandarin speakers but who spoke different Chinese dialects (Cantonese, Hakka, and Hokkien). They were learning Mandarin at a university in the US. Jaspal's participants were British- born South Asians (Gujeratis and Punjabis) studying in a university in UK. The researchers all found that their participants used their HL in the private sphere (homes, community events, family trips) and the dominant language in the public sphere (formal contexts like government offices, educational institutions). In Wong and Xiao's (2010) study nearly all participants held Mandarin in high esteem even though they felt more comfortable speaking their own dialects. The participants reported that Mandarin was a more worldly and scholarly language and thus suitable for use in public spheres, and their heritage languages were confined to private use at home and with local community members.

In Gua and Patkins's (2013) study, the researchers found that the ethnic minority students (Indians, Nepalese and Pakistanis) studying in a high school in Hong Kong, formed group boundaries where their HLs were practised. The main medium of instruction was English and Cantonese was taught as a second language. The researchers concluded that by establishing group boundaries the participants created opportunities for themselves to use their HL in a dominant society.

The studies cited above illustrate how language boundaries distinguish between two different domains. Figure 5 captures this concept. 


\section{Public Domain (Dominant}

Languages)

- in educational settings

- in government administration

- in public banking systems

- with dominant language groups

\section{Private Domain (Heritage}

Languages)
- in homes

- with family members and relatives

- with other heritage community members

- in community events like cultural and social gatherings

Figure 5. Socially situated language boundaries.

\section{Summary}

Linguistic hegemony thus highlights power, control, legitimacy and influence (which is the exercise of power in the form of language policies) of the dominant language group. All these factors shape the HLUs' beliefs, perceptions and attitudes that affect how HLUs think about themselves, their learning situation, their dominant community, languages (dominant language versus HL) and cultures (dominant culture versus heritage culture) in their environment (J.E. Joseph, 2004; Stavenhagen, 1996).

In most societies, English has become established as a dominant language because of its role as a global language. In many multilingual countries it has become the language of communication (Crystal, 2003; Kushner, 2003). Thus the next section looks at how the linguistic hegemony of English has impacted HLUs in a multilingual society.

\section{The role of English in a multilingual society}

In a discussion of linguistic hegemony, the role of English as a Lingua Franca occupies a unique position as a common tool for communication among various ethnic communities (Crystal, 2003; Kushner, 2003). When HLUs master English speaking skills it is perceived to be as adding value to their linguistic repertoire in the multilingual societies they live in.

Some researchers hold the view that English holds a neutral and culture-free position as a lingua franca (House, 2003; Robinson-Pant, 2005; Skutnabb-Kangas, 2001) because it is seen as a language that is not associated with one particular ethnic group in 
a multilingual society. They argue that when countries (especially post-colonial nations) choose English over all other ethnic languages in an ethnically diverse society, tensions and conflicts over language inequalities may be avoided. When HLUs choose to speak in English to dominant language groups, they add value to their status as members of minority language groups. This view of ELF allows it to cut across different cultures, countries and communities to facilitate communication.

HLUs felt that they regained footing by gaining proficiency in English, the dominant discursive practices of institutions (Coyle \& Jaspal, 2010; Gua \& Patkin, 2013; Preece, 2010). For example, the participants in these studies (above) who were minority language students studying at English- medium universities and high schools felt that using English allowed them to fit in with their peers and make friends. The stigmatisation of their HLs was countered by their increasing competency in English if they were able to socialise well in this dominant language. HLUs in this study appeared to feel empowered when using English as a Lingua Franca because it demanded greater prestige than other dominant languages in a multilingual society. Further empirical support comes from a study conducted by EduBuandoh and Otchere (2012) in a junior high school in central Ghana where English was the medium of instruction. Participants reported that using English in schools was seen as "a mark of the educated" (p. 308) amongst HLUs whose ethnic languages were Dangbe, Twi or Ewe (Ghananian languages). In this study the researchers concluded that the participants equated speaking in English as a "passport to prestige and success" (p. 308). This is similar to the findings of Gua and Patkin's (2013) study. In their study, participants (Pakistani, Nepalese and Indian students) proudly demonstrated their English speaking skills to Chinese students at a high school in Hong Kong to impress their peers. The researchers in both studies concluded that the participants had constructed a counter-discourse to resist the lower social status accorded to their heritage languages and their ethnic minority identity by the dominant group.

English was also found to be the most common language used online (Ben-Rafael et al., 2006; Marshall et al., 2012). The participants in these studies performed online activities such as "chatting," "messaging," and "talking on the net" using English. Digital literacy was in English. This finding supports the view that English is associated with globalising trends. HLUs felt that they belonged to a global community when they used English.

Communication in English elevated their status from at a local level to an international level. 
The concept of English as a neutral language was evident in Coyle and Jaspal's (2010) in-depth qualitative research on L2 undergraduates from a university in London. Participants used a neutral language (English) as the lingua franca among different social/ethnic groups. By using English, the participants were able to socially interact with both native British speakers as well as other Asian ethnic groups. The research findings highlight the significance of ELF as a language that facilitates communication among different ethnic groups and cultures.

Next I reviewed studies on HLUs in Malaysia.

\section{The Malaysian context}

In Lee Su Kim's (2003) study on the impact of using English on the identities of Malaysian undergraduates (from Malay, Chinese and Tamil linguistic communities) in selected private and public universities in Malaysia, three major findings emerged. First, the Chinese Heritage Language Users (from national primary schools) perceived that Chinese Heritage Language Users (from Chinese primary schools) were strongly bonded to their HL (Mandarin). Secondly, Chinese Heritage Language Users (from national primary schools) who could not speak their HL faced disapproval from Chinese Heritage Language Users from Chinese primary schools. They felt that Chinese students from national primary schools had betrayed their heritage identities. Finally both Chinese Heritage Language Users from national primary schools and THLU-Ms (from national primary schools) agreed that English was a language of prestige and empowerment. They preferred to communicate in English with the different linguistic groups at the university.

However, the Malay participants in Lee Su Kim's (2003) study considered otherwise. They preferred to speak in Malay rather than in English. Using English was perceived as an attempt to "show off" or as being "boastful" (Lee Su Kim, 2003, p. 240) by the Malay heritage community. The researcher concluded that Malays were offended if Malay language was not spoken because English was linked to the language of the colonial masters by the Malays. In the case of non-Malays, the researcher concluded that mastering English reduced ethnocentrism because it was seen as a neutral language which facilitated a more reflective and critical attitude towards one's own culture amongst non- Malays who did not come from heritage schools.

In Rajadurai's (2009) study, her participants, who were all Malays, received a hostile reception from their heritage community members if the Malay participants 
spoke in English. This reflects the findings reported in Lee Su Kim's (2003) study. However, in Rajadurai's study her Malay participants responded that they did not earn the disapproval of non- Malays (Chinese and Tamils) if her participants spoke in English. The researcher concluded that it was acceptable to use English with the nonMalays, however within the Malay heritage community this was not so. Both these studies seem to indicate that the Malays were loyal in their use of Malay language which was both the national language and their HL. Hence, the researchers concluded that using English made these Malays feel less patriotic. Neither study included THLU-Ts (from Tamil primary schools).

\section{Summary}

These studies indicate that the prestige attached to English and speakers of English propelled the participants to acquire competency in English. English was considered to be powerful in terms of its usefulness or functionality and enjoyed wider usage compared to other languages. Therefore using English enhanced the social status of HLUs. There was an exception in the Malaysian context. This suggests that if English functions as a global language and international lingua franca, the Malay language functions as a lingua franca within different ethnic groups living in Malaysia because of its status as a national language.

The second area of research findings evident in the literature is the concept of positioning.

\section{How individuals position themselves and how they are positioned by others}

Positioning theory is defined as "the study of local moral orders as ever shifting patterns of mutual and contestable rights and obligations of speaking and acting" (Harré \& van Langenhove, 1999, p. 1). During a social interaction, individuals allocate themselves and others rights, duties and obligations in and through talk governed by social rules and order. Therefore, individuals, through occupying interactionally constructed positions, may implicitly limit or allow certain social actions.

Two relevant perspectives on positioning are important here. One mode of positioning is intentional self-positioning: This is what Davies and Harré (1991) call “reflexive positioning in which one positions one's self" (p. 48). They claim that individuals view the world from a particular position. That is, individuals' self- 
positioning guides the way in which they act and think about their roles, assignments, and duties in a given context. In reflexive or self-positioning, the same person positions himself or herself differently in different contexts.

The other important mode of positioning is interactive positioning or positioning by others, "in which what one person says positions another" (Davies \& Harré, 1991, p. 48). In interactive positioning or positioning by others, the individual takes certain positions in relation to how others perceive them. In this view, positioning people in particular ways limits or extends what those people can say and do (Adams \& Harré, 2001) and inhibits or provides a choice of speaking forms, actions, and thoughts (Harré \& van Langenhove, 1999). That is, if individuals are "positioned as incompetent in a certain field of endeavour, they will not be accorded the right to contribute to discussions in that field" (p. 1). Based on these dynamic relationships of positioning, Harré and Moghaddam (2003) further claim that positioning individuals as deficient may deny them the right to position themselves as academically successful, and positioning them as competent may allow them the opportunity to improve performance.

The concept of positioning enables researchers to make sense of the dynamics of evolving social interactions: how persons position themselves and how they are positioned by others within a specific context (Harré \& van Langenhove, 1999). The contention is that identities of individuals are affected by the positions they take and how they are positioned by others in a social interaction. Positioning becomes even more complex for HLUs as they negotiate their own identities in relation to the different languages, their power relations and the social values attributed to the languages in a society (Peyton, Ranard, \& McGinnis, 2001). The identity of heritage language users is co-constructed and contextualized as they maintain and build connections with both (or multiple) languages and cultures. In order to understand the complexity of these processes, the concept of language as cultural capital (Bourdieu, 1999) and how it affects positioning will be discussed in the following section.

\section{Language as a form of capital and positioning}

Bourdieu, (1999) considers language as a form of capital that communities bring to the "linguistic market" (p. 39). A linguistic market is a symbolic market where linguistic exchanges take place. In this linguistic market certain languages have a higher market value than others. For example, English is seen as a language of power because of its 
global status and thus, is highly valued compared to other languages. Therefore speakers of English have a higher social standing compared to speakers of other languages (like heritage or minority languages).

When HLUs enter this linguistic market they are disadvantaged because the language capital that they bring with them has less value.This plays a significant role in the understanding of the positions taken by HLUs as they navigate within their own linguistic community and among users of dominant languages.This positioning influences the construction of multiple, compatible or congruent identities (Wallace, 2001). Sometimes they find themselves in a struggle trying to position their HL and dominant languages which lead to identity conflicts and tensions (Peyton, Ranard, \& McGinnis, 2001; Val \& Vinogradova, 2010; Weiyun He, 2006).

The identity of heritage language users involves constant negotiation and selfpositioning within a multilingual environment, where language fluency and choices indicate affiliation with and the level of connection to mainstream and heritage language groups. By positioning themselves as insiders or outsiders in relation to heritage and mainstream cultures, HLUs are continuously negotiating their identities. This process demonstrates the complexities and challenges in positioning that influence language choices and type of interaction.

I will now review studies that show how the HLU's positioning is affected by both heritage language and culture and by dominant language and culture. Dressler's (2010) study on German Heritage Language Users residing in Canada suggested that the participants balanced their family heritage identity with identification with their current country of identification. Wallace (2001) terms this as having "feet in both worlds" (p. 125). The heritage language users balanced their identities in both cultures. They felt at ease in both cultural environments and when speaking the dominant and the heritage languages. Further support comes from a study on Cora HL speakers in Mexico. The Cora speakers managed to maintain their heritage identity in the face of pressure to assimilate into mainstream Mexican society (Lopez et al., 2010). These HLUs were able to maintain both their Cora-speaking and Spanish-speaking selves. They adopted dual identity positions or kept "feet in both worlds".

In contrast, there were participants in other studies who took the opposite stance and were reluctant to be labeled as heritage language users. For example Wylegala's 
2010 Russian participants living in Lviv, Ukraine; were reluctant to be labeled as Russian heritage language users because their language was not favourably received by the Ukrainians. Unlike the Cora people, they were not comfortable in presenting themselves as both Russian speaking and Ukrainian speaking. There were clear language boundaries- one for public use (Ukrainian) and another for private use (Russian). The participants stated that they respected the Ukrainian language on the grounds that it was the national language whether they claimed it as their first language or not. (This study was conducted at a time when there was an on-going dispute as to whether Ukrainian should be the national language since Ukraine was once part of Russia). However, participants felt oppressed and uncomfortable when speaking Ukrainian. They were forced to use Ukrainian for all formal communication.

Some of the participants chose to portray themselves as Lvivites (inhabitants of their city) because this identification appeared to be the safest one — nobody could deny their identity because of language or history. This is what Wallace (2001) terms "creating a border culture" (p. 124). They positioned themselves as local Lvivites, not as a result of deep attachment to the city, but because of the impossibility of achieving acceptance from the dominant group with any other identification. They viewed their identities as multifaceted or mixed. The researcher concluded that the participants positioned themselves as living "life on the border" (Wallace, p. 124) because they perceived this as having access to both a Ukrainian identity and a Russian identity.

A recent empirical study examined a participant's self-positioning in an ESL classroom and how his peers and ESL teacher at a university in USA responded to his self-positioning (Aydar, 2014). She described one of her focal participants by the name of Mounir who came from a country in Central Africa. Mounir was a nineteen year old undergraduate who was a multilingual. French was his native language and English was his second language. Mounir also studied Arabic and German. His proficiency in English enabled him to participate in class discussions more actively than his classmates. While Mounir positioned himself as someone who was knowledgeable, his selfpositioning seemed to bother his peers and teacher over time. They started to interpret his participation as showing off. They positioned him as an outcast- someone who was inconsiderate and showed off his linguistic abilities. This negative positioning by others limited his participation and access to learning opportunities. His peers became less 
willing to collaborate with him in classroom activities. As a result Mounir's participation in classroom activities fluctuated depending on his self-positioning and response to the positioning by others. The researcher concluded that positioning can be powerful in terms of allowing to participate in a classroom context.

\section{Summary}

These studies indicate that positioning may be significant when HLUs (THLU-Ts) construct their identities in a multilingual setting.

Findings from these studies revealed that HLUs responded to the way they were positioned by their peers, teachers and heritage community members by adjusting their language use in different contexts. By doing so they were continually making modifications to the way they perceived themselves in relation to the society around them. Their deliberate choices and actions during social interactions both in and out of classrooms demonstrated their positioning.

The final theme is HLUs' strong attachment to their HLs and how this attachment impacted their identities. This affiliation to their heritage socio-cultural values differentiated them from monolingual users.

\section{Affiliation to heritage identity}

The concept of identity generally refers to who we believe we are and how we think we are perceived by others. Our sense of who we are depends crucially on what others think of us (Kanno, 2000; Norton, 2000). Identities are expressed through our language attitudes, language choices and behaviors when we interact with people around us. For the HLU, culture, ethnicity and heritage language are seen as markers of in-group membership within a particular linguistic community (Edwards, 1988). These markers influence the way HLUs perceive themselves and how they are perceived by others.

Phinney (1990) defines heritage identity as "a dynamic, multidimensional construct that refers to one's identity or sense of self as a member of an ethnic group" (p. 63). Kanno (2003) emphasises group membership within a particular linguistic community as being essential in shaping heritage identity. Affiliation to heritage identity is based on shared history, descent, belief systems, practices, language and religion all associated with a cultural group (Block, 2007a). Heritage communities identify themselves through a set of socio-cultural values and practices that distinguish them 
from other communities and which hold special meanings for them. These socio-cultural values enable and facilitate social and cultural connections, networks, within their community members. These shared values and practices build an affiliation to their heritage communities.

Most HL researchers have identified HL fluency and cultural artefacts (or cultural resources) as two key elements that denote a strong bonding to heritage culture and traditions (Block, 2007a; Cho, 2000; Leung et al., 1997; Phinney et al., 2001; Soto, 2002; Tse, 1997).

I will first review studies on HL fluency and heritage identity before discussing how cultural artefacts are associated with heritage identity.

\section{HL fluency and heritage identity}

A HL serves its speakers as an identity marker because the HL functions as a medium through which the culture, history and social values of a heritage community are conveyed (Castells, 2004; Coulmas, 2005).

Studies conducted on HL proficiency and heritage identity throughout the world (Chinen \& Tucker, 2006 (Japanese-American); Cho, 2000 (on Korean American); Phinney et al., 2001 (on Mexican, Vietnamese, and Armenian immigrants in the US, Russian and Ethiopian immigrants in Israel, Surinamese and Turkish immigrants in Netherlands and Vietnamese and Turks in Finland); Shibata, 2000 (Japanese-American); Soto, 2002 (on Peurto Rican-American); and You, 2005 on (Korean-American)) indicated that those with greater heritage language proficiency have a stronger ethnic identity or show a more positive attitude toward their ethnic group. They also found that those with high levels of heritage language competence make meaningful connections to their own group of people. The researchers concluded that that the ability to speak the heritage language can help members of ethnic minorities develop a better sense of who they are as ethnic individuals.

Many studies have identified a positive relationship between HLU's heritage identity and their degree of heritage language fluency (Cho, 2000; Phinney et al., 2001). Cho (2000) studied second-generation Korean Americans and found that participants with heritage language competence showed a strong sense of who they were. In the same vein, Soto (2002) concluded that bilingual Puerto Rican children in the US who had high 
levels of competence in Spanish demonstrated a strong sense of ethnic identity as Puerto Ricans.

Other research that investigated the impact of weekend heritage language schools on heritage identity concludes that there are close links between HL schools and heritage identity. Japanese American students (Chinen \& Tucker, 2006; Shibata, 2000) and Japanese Canadians (Oketani, 1997) demonstrated a stronger sense of heritage identity after attending Japanese Saturday school in contrast to those who did not. These studies also reported that the self-esteem of these children significantly increased after they enrolled in a heritage language programme teaching their HLs. Similar findings were also reported in You's (2005) study of young Korean children enrolled in Korean weekend school. The researcher found that participants' reported a stronger heritage identity after attending weekend HL schools.

Further support comes from Oriyama's (2010) study of Japanese high school students studying in Australia. Oriyama's participants chose to display their Japanese heritage identity by speaking in Japanese to their Japanese school mates although they were fluent in English. Oriyama concluded that by using their HL, her participants demonstrated affiliation to Japanese heritage identity.

The participants in Dressler's (2010) study reported that acquiring HL proficiency was important in supporting the participants in appreciating heritage sociocultural values. In her case studies of six HLUs of German studying in a Western Canadian university she found that her participants were proud of their German heritage although they assimilated well into Canadian society. They wanted to master their HL (German) because they wanted to know more about their heritage history and culture and so they enrolled for HL programmes at the university. One participant reported that she was aware of the deficiencies in her HL competence, but took pride in her accomplishment of relearning a language that had been lost as a result of societal pressure to assimilate. Subsequently, she chose to learn German at university to "open pathways to older members of the family" (p. 22). She felt that interacting in German with her grandparents who were not proficient in English would allow her to reconnect to her ancestral ties. Other participants also reported that the desire to know more about their cultural heritage was motivated through stories related by their grandparents who came from Germany and had settled in Canada. One of the participants explained that 
her knowledge of German cultural traditions came from "the stories my mother would tell about what my grandfather told her or the ones he would tell us about what they would do" (p. 27). These participants were proud to be identified as HLUs and attributed their choice of German as a language of study at least partially to their familial and affective connections to the language. This motivation to study their heritage language is consistent with the motivation of HLUs found in other studies (Carreira, 2004; Noels, 2005).

However, not all of Dressler's participants were proud of their heritage status. Three participants in Dressler's (2010) study rejected the label of HLU because of the negative connotation carried by the term heritage as "pointing to the (ancient, primitive) past rather than to a (modern, technological) future" (Hornberger \& Wang, 2008, p. 17). Another reason given was that they perceived that their connection to the country and culture would not be acknowledged by others, thus they chose not to identify with the term HLU. They also reported that German was rarely spoken at home.

Finally, research on HL fluency and heritage identity seemed to indicate that HLUs identified best with the concept of inheriting the language tradition that they were born into. For the HLUs in the reviewed literature, this was the most commonlyexpressed aspect of heritage identity. While a sense of an inherited identity did not serve to predict how HLUs responded to the label of HLU, it provided insight into the relationship between feelings of inheritance and membership of this group. Most participants in these studies felt connected or bonded to their heritage communities when they spoke in their HL.

Next I define cultural artefacts and review related literature on how cultural artefacts are associated with heritage identity.

\section{Cultural artefacts and heritage identity}

Cultural artefacts or resources (Bartlett, 2007; Block, 2007b), also known as non-verbal participatory practices (Canagarajah, 2012), refer to objects or symbols that have meaning for a specific group of people. They can "assume a material aspect (which may be as transient as a spoken word or as durable as a book) and/or an ideal or conceptual aspect (such as a label, like good girls and bad boys)" (Bartlett, 2007, p. 217) that gives meaning and a sense of heritage identity in the everyday lives of the HLUs. Cultural artefacts are objects, symbols, narratives, or images and popular stories and folklores. 
These include religious rituals and traditional practices observed during ceremonies and festivals which denote the collective attribution of meanings and representations for a specific heritage community.

In the section that follows, I reviewed studies on how cultural artefacts bond heritage communities culturally together.

In Dressler's (2010) study, participants referred to German artefacts such as Christmas traditions and punctuality as cultural values. On the other hand, lack of holiday traditions like not observing Christmas celebration in a religious and traditional way and tolerance of diversity were referred to as Canadian artefacts. These artefacts were perceived as part of Canadian culture. Three participants in her study (Canadians of German descent) made reference to traditions as cultural artefacts or markers of a “classic German household" (p. 44). These traditions, especially those around Christmas time, and the stereotypical values or characteristics such as punctuality and orderliness, are just some of the cultural artefacts that the students referred to in this study. For the Coras, (an indigenous people of the Mexican Sierra del Nayar, in Northwestern Mexico), their sacred agricultural rituals were considered cultural artefacts (Lopez et al., 2010). The Coras continued practising their agricultural rituals so that their traditional way of life would not be threatened by the dominant language and culture of Spanish speakers in Mexico.

In Canagarajah's (2012) study of Sri Lankan Tamils living in England and Canada, Niranjan, one of the participants in this study, first said that he did not speak Tamil, following the traditional assumption of full proficiency. He later acknowledged that he used gestures and body language as a resource to understand Tamil. Canagarajah (2012) explained that Niranjan might not always have understood the meanings and terms used in Tamil. However, these words were often associated with habitual and regular practices at home in specific interactions, with specific participants, and in specific contexts. Therefore, he was still able to communicate with older members of the family and participate in community gatherings. Thus, certain cultural rituals practised during weddings and religious events acted as cultural artefacts or non -verbal participatory practices. Through these procedures, the Tamil youths in this study could enjoy in-group status with their community in events that were culturally important. 
The next study is important as it takes place in an educational setting in contrast to the previous studies. The context was a primary class which is very different from a university context as in the context of my study. This study suggests ways teachers can make connections to HLUs and encourage their participation in class.

Budach (2013) conducted a study of primary school children aged between six and seven years from four German-Italian bilingual classrooms in Frankfurt, Germany. Besides German and Italian, children also came from Polish, Croatian, Turkish, Frisian and English heritage language backgrounds. She used cultural artefacts from the different heritage communities to teach German and Italian languages. The participants actively participated in classroom discussion because the culturally rich artefacts were used as pedagogical tools. She concluded that cultural artefacts were valuable pedagogical tools that had the capacity to create links to a multilingual learner's life worlds and their academic journey. Participants felt that they were culturally connected and this helped them to reshape their social roles and identities in a multilingual classroom.

In the next section I highlight studies that show the issues and challenges faced by HLUs in a multilingual academic context.

\section{HLUs in a multilingual academic context}

In formal academic contexts, the multilingual practices of HLUs are seen to be a challenge against dominant language ideologies. The linguistic norms and practices in educational institutions in multilingual societies do not encourage the construction of heritage identities. Hence linguistic minority students use their HLs to contest hegemonic language policies and practices in academic institutions (Heller \& MartinJones, 2001). Jaspers (2004) reported that Moroccan students in Antwerp often used their heritage languages (principally Moroccan Arabic and Berber) if they wished to project a 'tough-guy' or threatening persona. HL use was seen as challenging school authority. This is an example of the extensive literature on language maintenance and heritage language use in schools illustrating how children and adolescents use the heritage language as a 'secret language' in order to exclude others (Gibbons \& Ramirez, 2004; Jaspers, 2004; Ncoko, Olsen, \& Cockcroft, 2000). 
The HLUs' multilingual resources often appear to be suppressed within the classroom context owing to the tensions between language and education policy, teacher attitude and school ideology. Surveys and interviews were done on K-12 teachers (from kindergarten to year twelve) in the US on their attitudes toward children's HL (Lee \& Oxelson, 2006). The researchers powerfully found that mainstream teachers tended to express negative or indifferent attitudes toward their students' HL. The teachers reported that they did not see a role for themselves and schools in maintaining HLs. When teachers and schools treated children's HL lightly and considered HL use at schools a problem, it was hard for HL students to value their HL as a resource (Zhang \& Slaughter-Defoe, 2009).

Some studies revealed that HLUs' multilingual practices during interactions were discouraged. HLUs are were discouraged from code switching in formal academic contexts and reprimanded for using their HL (Palmer, 2009). Thus, this separation of languages (HL versus dominant language) may contribute to identity conflicts and tensions among HLUs. Brown (2010) reported that negative stereotyping of four Korean-American participants within a college context by their white American classmates contributed to identity conflicts. Her participants struggled trying to maintain a Korean identity and an American identity. Similar findings were also reported among Italian Canadians in Toronto (Giampapa, 2004). Surveys on their language choices indicated participants' struggles, trying to negotiate within, across and between their different cultural worlds, creating "centers" and "peripheries" of identity. They included or excluded themselves during social interactions through their language choices as they moved among different groups within their multilingual environment (p. 192).

Researchers highlight conflicting views of the impact of ethnic diversity on the second language acquisition of HLUs (He, Phillion, Chan, \& Xu, 2008; Martin, 2010). On one hand, research has shown that heritage language users bring linguistic, cultural and ethnic diversity to academic institutions. On the other hand, this linguistic heritage and cultural knowledge is largely ignored, and HLUs are seen as problematic. In contexts where English monolingual ideologies are influential, HL students experience difficulties using and studying in English (Cummins, 2000, 2005). Cummins' (2005) study describes the problems faced by four fifth grade Pakistani girls studying English in an elementary school in Canada. During their interviews they talked about their 
struggles to express themselves, not just linguistically, but also culturally. They felt left out and rejected by their peers because of their limited English proficiency and the way they spoke and dressed. Their accent and their traditional attire represented cultural artefacts that were not recognised by their white Canadian classmates.

Language barriers and challenges from acculturation processes may exacerbate HLUs' academic, emotional and social development and limit their access to programmes (Lee, 2008). In Lee's study 12 Korean undergraduates studying in an American university were interviewed and observed in their English classrooms. Participants in this study perceived language barriers as one of the greatest obstacles to achieving academic goals, primarily because of the time-consuming process of language translation from Korean to English. Participants said that at the beginning of their studies, they required more time to read and write assignments in English and for oral presentations than they would have needed in their HL. Participants also reported that they felt limited in various academic activities because of their limited English proficiency especially their listening skills. The most common complaint among participants was that they could not express themselves in an articulate and precise manner like they could in their HL. They found that it was easier to interact with heritage members and other minority groups in English compared to Caucasian Americans. A sense of shame or inferiority emerged as a result of this. Participants described their English language inadequacy as a barrier to communication with native speakers. They reported that they were hesitant to initiate discussions in the classroom and rarely socialised with native speakers outside class. The researcher concluded that the participants felt powerless during social interaction with the dominant group which impacted their self-confidence negatively.

HL schools in Britain (also known as supplementary or community schools) are voluntary institutions set up by linguistic minority communities, often with the aim of teaching literacy in heritage languages to the British-born generations of minority ethnic children (Creese \& Martin, 2006; Martin et al., 2004). Studies examining the impact of language, language ideologies, culture and identity on HL students' educational experiences in these HL schools (Francis et al., 2009; Toohey, 2000) revealed that HL schools were seen as playing a pivotal role in the transmission of language and culture. For example in Francis et al.'s (2008) study, sixty British-Chinese 
"participants from five Chinese HL schools in UK were interviewed about the purposes and benefits of learning a heritage language in a HL school in UK. The researchers concluded that participants' heritage languages and the culture of their country of origin constructed a heritage identity. Studies of multilingual practices in HL schools in the UK (Blackledge \& Creese, 2008; Creese \& Blackledge, 2011; Li, 2011; Li \& Wu, 2009) revealed that immigrant children manipulated their multilingual proficiencies to construct new identities to contest the heritage identity imposed on them by HL schools. The researchers concluded that the young people were flexible and adaptable in response to the multilingual environment they lived in, as they negotiated identities which were more complex and sophisticated than the heritage positions ascribed to them by their HL teachers. For example, in Creese and Blackledge's (2011) study, the participants (Bengali HLUs) rejected some heritage symbols and challenged their teachers' insistence on the use of HL (Bengali) only in the classroom.

Further empirical support for multilingual learners' construction of multiple identities and their navigation of their multilingual resources comes from $\mathrm{Li}$ and $\mathrm{Wu}$ 's (2009) study. The participants (Chinese-English bilingual immigrant students) in a Chinese HL school in UK, creatively utilised code-switching to push back or break down the boundaries between the traditional way of learning (using one language only) and the new (encouraging students to make use of their multilinguistic resources). These schools were set up to teach Chinese literacy to British Chinese children and their policy was to use Chinese only. However, the researchers found that the pupils used a great deal of English and they codeswitched frequently and regularly in and out of the classroom. The researchers concluded that through the participants' multilingual practices, they were able to contest institutional ideologies imposed upon them. This was seen as one way that multilingual learners adjusted themselves in a multilingual learning environment.

The studies conducted in UK's HL schools indicate that multilingual students felt comfortable within the HL school setting and carried out multilingual practices as they were confident about their multiple identities and ability to use multiple languages. This contrasts with their behaviour in mainstream schools where participants did not feel comfortable codeswitching. The researchers believed that this was because of the safe environment provided by the HL schools. Furthermore, the researchers concluded that 
HLUs constant codeswitching from their HL to English reflected gaps in their HL proficiencies.

In contrast, other studies have indicated that teachers' language ideologies and attitudes toward linguistic and cultural diversity may influence immigrant children's language practices and identity formation differently. Researchers discovered that teachers' negative attitudes toward linguistic and cultural diversity had the potential to disempower bilingual immigrant children at school (Cincotta-Segi, 2011; Cummins, 2000; Gkaintartzi \& Tsokalidou, 2011). For example, Gkaintartzi and Tsokalidou (2011) revealed that although teachers in a mainstream Greek school advocated diversity at a theoretical level, they actually categorised their Albanian immigrant students' HL as problematic and burdensome. The teachers were not happy if the participants used their HL in the classroom. HL use was discouraged during classroom interaction.

Similar findings were reported in Martin's (2010) study of how dominant English speakers disapproved of the use of HL amongst ethnic minority undergraduates at a university in UK. Tracing the language learning experiences of his participants, he concluded that the use of heritage language may trigger social exclusion and racism. The participants who came from India, Pakistan and Bangladesh found themselves socially excluded within this English speaking environment and were ridiculed for low proficiency in English.

The researchers in both these studies concluded that HLs were not valued in formal academic settings (both in school and university) and because of this HLUs felt disempowered.

\section{Chapter summary}

So far, I have discussed studies that provided empirical findings on how the sociocultural values of heritage languages, linguistic hegemony and positioning have impacted the identities of HLUs in different countries. Their identities are projected through the language choices they make and their attitudes, values and beliefs regarding language use.

In the next chapter I provide the theoretical framework used in my study. 


\section{Chapter Three \\ Conceptual Framework}

\section{Overview}

This chapter elaborates the theoretical underpinnings of my study. I explore three main concepts upon which my study is based. They are:

- the diverse linguistic practices of multilinguals (Kumaravadivelu, 2008; Spolsky, 2009; Zakaria, 2011).

- the construction of multiple identities in multilingual contexts (Bucholtz \& Hall, 2005; Kang \& Bodenhausen, 2015; Marshall, 2009; Pavlenko \& Blackledge, 2004; Norton, 2000).

- the impact of identity on multilinguals (Blommaert, Creve, \& Willaert, 2006; Pavlenko, 2001).

I draw on the work of (Blommaert, 2010a) on sociolinguistics of mobility or languages-in- motion to support the diverse linguistic practices and construction of multiple identities. I explain how Blommaert's language mobility patterns which are order of indexicality, polycentricity and sociolinguistic scales; highlight the multiple identities THLU-Ts take on during multilingual interactions (with THLU-Ms, Malays and Chinese students).

Next, I look at the dynamic identity process of Blommaert and Variis (2013) to explore how HLUs constructed multiliple identities. I touch on the dynamic interplay between investment and agency to examine their roles on identity construction (Deters et al., 2015; Garcia, 2012; Toohey \& Norton, 2011). I integrate the constructs and theories and show how they relate to the framing of my study. Finally, I conclude this chapter highlighting the uniqueness of my study.

\section{The integration of literature into a conceptual framework}

The conceptual framework for this study draws upon three major concepts (multilingual practices of HLUs, multiple identity construction and impact on identities) and corresponding theories (sociolinguistics of mobility, dynamic identity process and dynamic interplay of investment and agency).This is represented diagrammatically in the 
metaphor of a frame. Figure 6 illustrates how the three constructs from reviewed literature correspond to the theories discussed on the right.

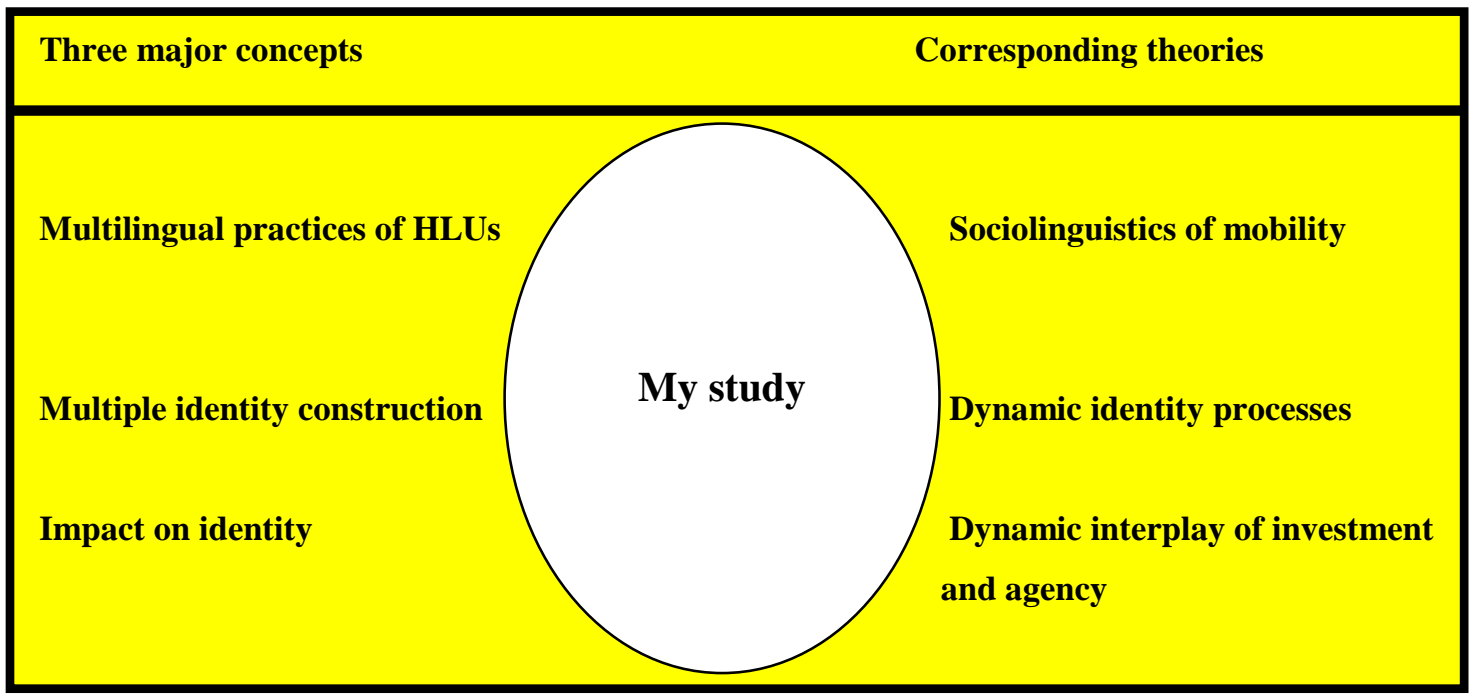

Figure 6. Conceptual framework of my study

In the next section I begin with sociolinguistics of mobility and show how they address the multilingual practices of HLUs with support from literature

\section{Sociolinguistics of mobility}

Blommaert (2010a) describes sociolinguistics of mobility as language - in - motion, where the movement of people is also seen as a movement of language resources. People carry familiar linguistic repertoires with them as they move from villages to cities (local contexts) and from country to country at a macro-level. These mobile language resources are ascribed different values by communities in different contexts. Therefore sociolinguistics of mobility is seen as "a trajectory through different stratified, controlled and monitored spaces in which language gives you away" (p. 14).

Empirical studies on Korean migrants have highlighted the complexities of language choices arising from tensions among transnationalism, language ideologies, and negotiations of identity (Kang, 2012; Park, 2009; Song, 2012). For example, Kang (2012) found that South Korean students and their parents in Singapore negotiated and redefined the values of Mandarin, English, and Singlish (Singaporean English) used in Singapore in an attempt to forge their own transnational identities. The participants tended to emphasise speaking these languages appropriately. They did not want their 
language choices to give them away as non-Singaporean. Similarly, in research on the language practices of Korean students studying in the US, Song (2012, p. 40) illustrates that language ideologies were adopted in a "contextually specific" manner. Participant observation revealed that they aligned themselves differently to speakers within different language contexts and these choices impacted their identities. Heritage language speakers negotiate their own identities in connection to these different languages and their power relations and social distributions in society (Vinodgrova, 2010).

In a multilingual and multicultural nation like Malaysia, language contexts are even more complex and contested. The participants in my study have to negotiate between the dominant languages (Malay and English) and also their HL context. The sociolinguistics of mobility offers a unique angle from which to investigate THLU-Ts' language use and identity construction in movements across academic spaces and time during their language learning trajectories. It is the sociolinguistics of mobility from the Malaysian perspective.

In the next section I describe the language mobility patterns, (order of indexicality, polycentricity and sociolinguistic scales) in detail. Blommaert offers three theoretical concepts for consideration: sociolinguistic scales, orders of indexicality and polycentricity. Together they provide a descriptive frame for sociolinguistics of mobility.

\section{Order of indexicality}

Languages are ranked depending on their function, context and meaning. Languages and varieties of languages are assigned values and social meanings by the society in which they are used (Blommaert, 2010a). The ranking of languages is also referred to as regimes of language (Kroskrity, 2000). A "particular environment organises a particular regime of language, a regime which incapacitates individuals" when they lack the resources to interact in that particular environment (Blommaert, Collins, \& Slembrouck, 2005a, p. 198). As people move from context to context, the ranking or ordering of languages may shift. The language resources that people bring with them may have to be reevaluated depending on what is acceptable in that particular context. Linguistic resources are assessed using different orders of indexicality in each new context, and every move involves a different set of indexical potential for the resources. What works well in one context may not work at all in another. Thus, order of indexicality reflects 
power, hierarchy and dominant language ideologies (Canagarajah, 2013a). As a result dominant languages supersede over minority languages which are deemed as inferior because it is less functional in the public sphere.

For HLUs, identity negotiation becomes more complex since it is tied to expectations of different language choices held by different language communities (Bailey, Canagarajah, Lan \& Powers, 2016). In a study exploring the multilingual practices and experiences of ten young professional Korean immigrants living and working in Hong Kong, the researchers found that participants faced tensions caused by conflicting language ideologies. Participants often spoke of language hierarchies (a Korean-English versus American-English or British English) in their workplace. In multilingual contexts outside their workplace, participants preferred using English because they saw English as a global language in contrast to Cantonese which was the local language. However, some participants reported that learning Cantonese would be important if they chose to stay longer in Hong Kong. Some participants also reported that being able to speak in Cantonese improved social connections with Cantonese speaking colleagues at work place. Researchers concluded that participants re-ordered their multilingual language patterns according to social context.

The next language mobility pattern that Blommaert introduces is polycentricity.

\section{Polycentricity}

Blommaert explains polycentricity in terms of the micro and macro structures of people's everyday world. Micro structures refer to individuals (teachers, parents, role models) and collective groups (peer groups, local community). Macro structures refer to organized structures like church, educational institutions, local authorities and community organisations. These structures are seen as social and cultural bodies of authority which form patterns of power. These structures act as evaluating authorities over social communication. This would include content of conversation, places, people (roles, identities, relationships), and language styles. Blommaert calls these evaluating authorities as centres.

These centres are diverse depending on place, people and time which Blommaert refers to as being polycentric. These centres impose different codes and norms as to what are accepted as appropriate linguistic practices and behaviours (Blommaert, 2005; Blommaert et al., 2005b). As such, people using different spaces need to orient 
themselves towards very different sets of norms and expectations. A move from one centre to another requires indexical reordering.

Darvin and Norton (2014) refer to these centres as "systemic patterns of control" (p 42). In an educational context schools, colleges and universities are examples of centres. Darvin and Norton are concerned with how these educational institutions control language use and may accord or deny multilingual users the right to use their HL. Language policy makers and educators assume that language minority students reach a higher level of majority language competence if other language skills are suppressed, and improving their skills in the majority language is the most effective way of fighting school failure (Heller \& Martin Jones, 2001). An ethnographic study of 10-12 year old HL students in mainstream schools in Denmark who came from Turkish and Arabic backgrounds indicated that these participants rarely used languages other than other than standard Danish in both in and out of classroom settings (Karrebæk, 2013). Classroom observations indicated that the teachers disregarded minority languages as suitable for learning purposes. Interviews with the school principals revealed that there was a lack of explicit language policy. The researcher concluded that her participants' trajectories of socialisation were oriented to different norms operating at different centres (school and homes). Participants believed that there was no appropriate context for using their HL within the school context. This study was of primary school children. My study explores how this linguistic polycentricity (different language norms operating in different academic centres) impacts the identities of my participants in educational contexts.

Using a single case study approach Zentz (2015) found that her participant (a Javanese university student) learnt to negotiate his multilingual resources to project a positive self-image. His use of Javanese was confined to his home village. He used Indonesian and English with his high school and university classmates to develop a strong collaborative relationship. The researcher concluded that as her participant encountered different orders of indexicality operating at different centres; it was not the indexical value of languages that posed a problem for him. It was instead the language resources that he had transplanted from one community of practice into another that caused conflict. For example, his heritage community members were offended by the 
way he projected an English identity (voicing his opinions strongly). His university friends ridiculed his Javanese accent whenever he spoke Indonesian.

The research context in Malaysia is different because of the strong presence of ethnic Chinese and Tamil linguistic groups. Also, HL education (Mandarin and Tamil) is part of the Malaysian education system.

The final concept under sociolinguistics of mobility is sociolinguistic scales.

\section{Sociolinguistic scales}

Using the notion of scale as a theoretical sociolinguistic concept, Blommaert (2007) connects it to the important dimensions of space and time. I will explain how space and time are deeply connected to scales and how scales are constructed based on these two important dimensions. I will then illustrate how the linguistic resources of HLUs are deployed across time and space according to the scales constructed (refer to discussion chapter for a detailed explanation).

Blommaert (2010a, p. 34) defines scales according to space and time in the following way:

Table 1. Scaling of language practices across time and space

\begin{tabular}{lll}
\hline & Lower scale & \multicolumn{1}{c}{ Higher scale } \\
\hline Time & Momentary & Timeless \\
Space & local, situated & trans-local, widespread \\
\hline
\end{tabular}

Table 1 shows how language practices move and develop in space with the strictly local (micro) and the trans-local (macro) as extremes, and with several intermediary scales in between (Geertz, 2004). When a social interaction takes place in a momentary dimension of time, the linguistic practices within this social context occur temporarily in brief intermittent periods. As such the space in which this communication takes place is local and situated. For example, when the HLUs communicate in HL with their family members in the home context or whenever they meet other members of their heritage community. These acts of communication are all uniquely contextualized, individualized and personal. Blommaert (2010a) places such language practices within the lower scale. In comparison, language practices which are more global in context, like dominant linguistic practices, take place in social contexts that are more widespread and 
transcend the local. These are ranked higher on the scale, for example, when the HLUs use dominant languages in academic settings; they are observing institutional and the academic community norms and rules. The linguistic value attached to such social interactions is higher as dominant languages enjoy greater power and prestige when compared to minority languages.

Sociolinguistic scales show how the linguistic resources that enjoy power and prestige in certain local contexts receive lower status as linguistic minorities move within social contexts where the language of the majority is used. Blommaert (2010a) presents scales as "a metaphor that suggests that we have to imagine things that are of a different order, that are hierarchically ranked and stratified" (p. 33). He goes on to state that "scales offer us a vertical image of space, of space as stratified and therefore powerinvested; but they also suggest deep connections between spatial and temporal features" (p. 34). From this perspective, the metaphor reminds us that the movement of people with the linguistic resources they carry with them is not across neutral social and geographical spaces. These spaces assign values and statuses to the codes that people take with them. Because languages are measured according to scales, every move up the scales denotes that HLUs that the language they use is more highly valued by the specific target community. Whenever they move down the scale, this means that the language they use is devalued by the dominant language users because it is not functional within formal settings. For example, HLs which are only valid in localized contexts within heritage communities.

Next, I review some studies that used sociolinguistic scales to explore HLUs multilingual practices.

Gu and Tong (2012) investigated identity construction among a group of mainland Chinese, cross-boundary students by analysing their language choices and linguistic practices in a multilingual university in Hong Kong. Chinese students who were born in Hong Kong (their parents are from mainland China) and study in Hong Kong but live in mainland China are referred to as cross-boundary students. The researcher used sociolinguistic scales to demonstrate how movement across spaces (from China to Hong Kong) indexed the value of languages (English, Mandarin and Cantonese). The participants joined the group of students who spoke Mandarin. They 
also projected multilayered identities and gained legitimacy in peer interactions by using English and Cantonese.

In another study using scales, Lin (2012) discusses the multilingual patterns of cosmopolitan Beijing. The researcher conducted ethnographic fieldwork in downtown areas of Beijing observing shop names, menus, promotion posters, clothes, locations and its inhabitants. For example, more multilingual signs with English signage were visible in areas where international hotels and embassies were located. These were the more affluent areas with a large expatriate population, local and foreign professionals involved in international business activities. The language regime became strictly monolingual in areas which were predominantly populated by the local communities like, local government administrative centres and business districts. Lin concluded that for these reasons there were social inequality and uneven power distribution which were demonstrated by these multilingual signages. English signage indicated a cosmopolitan Beijing. The sociolinguistic scales revealed local societal structure and language use.

\section{Summary}

Most studies reviewed under sociolinguistics of mobility explored participants multilingual practices within a migrant context. One study reviewed the social distribution of language use in geographical spaces. My study is unique because it looks at the language practices of Malaysian Tamils within a Malaysian multilingual context.

In the next section I explain how HLUs construct multiple identities based on Blommaert and Variis's (2013) dynamic identity processes.

\section{Construction of multiple identities}

In this section I first illustrate the schematic general framework for investigating the complex and dynamic identity processes by Blommaert and Variis's (2013). Using this framework I explain further the dynamic construction of identities among HLUs in a multilingual context incorporating the sociolinguistic scales. (Refer to figure 7 which illustrates this).

\section{Dynamic identity practices of multilinguals}

Blommaert and Variis (2013) identify four points in this framework for examining construction of identities in multilingual societies. They are: 
- $\quad$ sets of features representing particular identities

- attachment to these features which displays particular identities

- having enough of these features to become legitimate members of the desired community of practice

- process of acquiring sufficient sets of features involves conflict and contestation.

Blommaert and Variis (2013) view identity practices as orientations towards sets of features that are (or can be) seen as emblematic of particular identities. These identity practices encompass the cultural artefacts described by Bartlett (2007) and Block (2007a) that symbolise the heritage identity of particular ethnic communities. For example, religious practices, rituals, the way people dress, cultural greetings, food preferences or habits, art and literary forms, music and other cultural practices which are unique to specific heritage communities. These sets of characteristics help to distinguish between heritage identities and multilingual identities. Multilinguals may express attachment to a particular set of emblematic features. This desire to belong to a specific identity spurs multilinguals to acquire sufficient emblematic features that represent the targeted identity. This notion of "enoughness" (Blommaert \& Variis, 2013, p. 148) plays a central issue in construction of multiple identities for HLUs. They may become legitimate members (Blommaert and Variis use the term authentic members) when they successfully project sets of characteristics/ socio-cultural values and attitudes of the specific group or community.

Integrating Blommaert's sociolinguistic scales and Blommaert and Variis's identity framework (figure 7) describes how HLUs construct multiple identities (either a heritage identity or multilingual identity). 


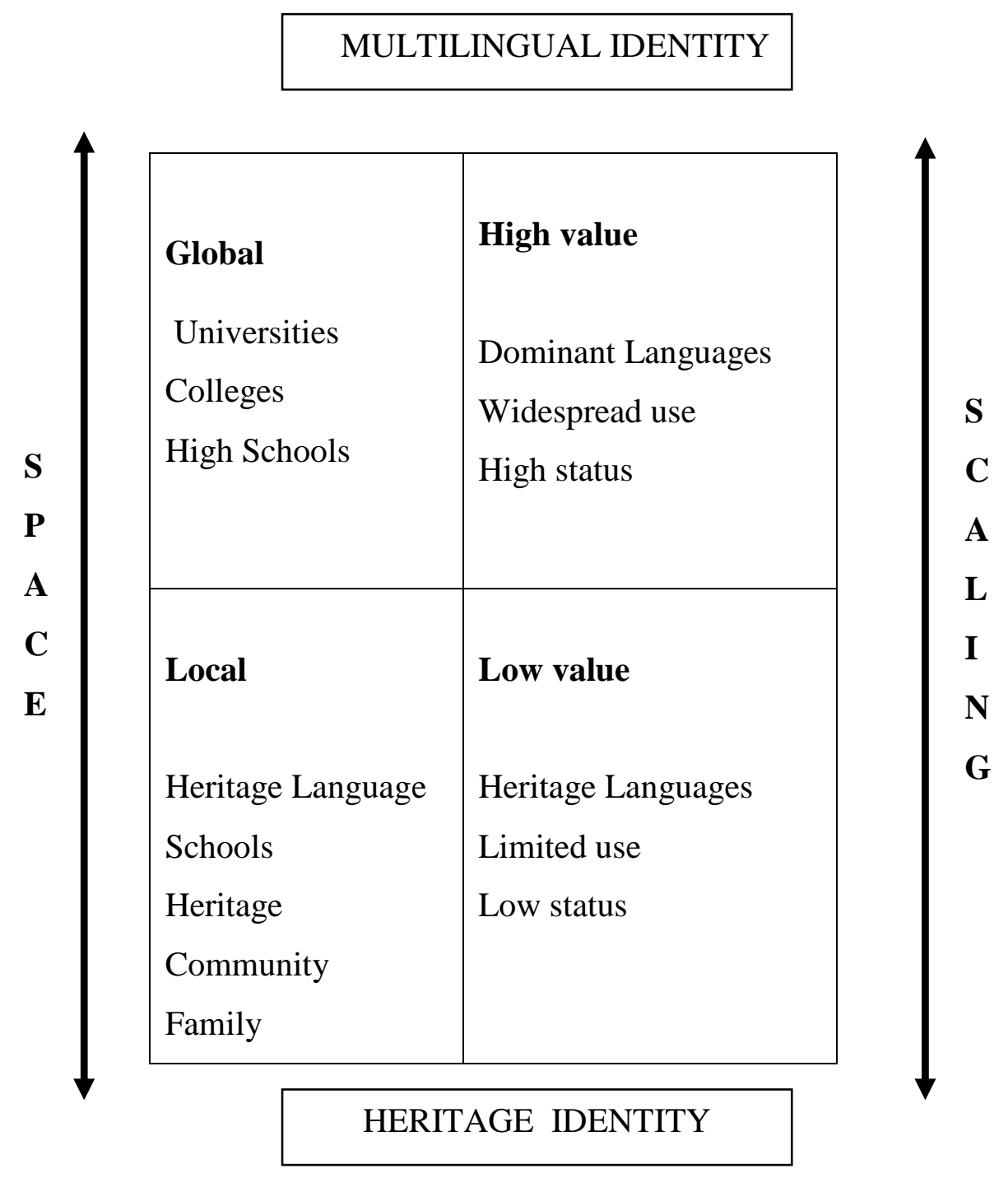

Figure 7. Dynamic identity processes of HLUs

Figure 7 highlights the dynamic identity construction of HLUs in a multilingual context. As HLUs move up the scales from local to global context they acquire sets of features emblematic of a multilingual identity which can be seen over time and space. For example, this set of features could include becoming a competent dominant language user in tertiary context. In contrast, when HLUs move down the scale they project emblematic features that represent a heritage identity; becoming a proficient HLU within local community network. This moving up and down in turn impacts their identities. They are positioned high on the sociolinguistic scales if they project a multilingual identity because of the high linguistic value attached to dominant 
languages. If they project a heritage identity they are positioned low on the scales because heritage languages are not valued. This reflects how languages are ranked in multilingual societies. Competence in changing the parameters of identity categories from heritage to multilingual or vice-versa rests on their attachment to these particular identities. Conflict and contest are evident in such a shifting and dynamic identity process as HLUs move up and down the scales. In their attempt to acquire sufficient sets of features which makes them an authentic member of the targeted community (whether multilingual or heritage identities), HLUs face a lot of struggles. In such dynamic identity processes they are always adjusting and readjusting sets of features so that they project sufficient characteristics of a particular identity. This highlights the fluidity of identity during this process.

\section{Fluidity of identity}

Blommaert and Variis's dynamic identity processes revolve around the notion of enoughness. HLUs constantly adjust, reconfigure and amend sets of emblematic features in the process of being accepted as authentic members of the desired community. HLUs are always redefining their identities through their multilingual practices when they move from context to context. Blommaert and Variis, (2013), Norton (2013) and Darvin and Norton (2014) view identity construction as multifaceted, changing and a site of struggle as multilinguals attempt to understand their relationship to the world around them across space and time.

Next, I illustrate how identities are impacted.

\section{Impact on identity}

In this section I show how the dynamic interplay of investment and agency impacts the identities of HLUs. I draw support from Norton's concept of investment and agency to explain how identities of HLUs are impacted during construction of multiple identities.

\section{The roles of investment and agency}

Dynamic identity practices include Norton's work on investment and agency which emphasises the fluidity of identities. To begin with I define the concepts of investment and agency and then show how they enhance the fluidity of identities through their dynamic interplay. 


\section{Investment}

Norton (2011) builds her construct of investment using metaphors from economics. Inspired by the work of Bourdieu (1991) she refers to two important concepts that illustrate investment. In a linguistic global market, a multilingual's cultural capital and symbolic capital contributes value to their language as a commodity. Cultural capital of multilinguals refers to the forms of knowledge, educational backgrounds, and modes of thought that characterise different language communities. It has differential exchange value (or 'currency' in economic terms). Besides cultural capital, multilinguals also bring symbolic capital to the linguistic market. According to Bourdieu (1991), symbolic capital refers to resources available to an individual on the basis of honour, prestige or recognition and represents the value that one holds within a culture. This "provides the means for a non-economic form of domination and hierarchy, as classes [language communities] distinguish themselves through [cultural and symbolic capital]" (Gaventa, 2003, p. 6).

In their desire to increase the value of their cultural and symbolic capital, multilinguals invest in dominant language proficiency (English) (Darvin \& Norton, 2013). These investment strategies would include spending time and energy to improve their linguistic competence in the targeted language as they aspire to be identified with the target community. Norton believes that it is through desire and imagination that learners are able to invest in linguistic practices that can transform their lives $(2000,2011)$.

\section{Agency}

Duff (2012) defines agency as “people's ability to make choices, take control, selfregulate, and thereby pursue their goals as individuals leading, potentially, to personal or social transformation" (p. 417). Norton's notion of investment intensifies the role of agency for multilinguals. According to Kramsch (2013, p. 195), investment "accentuates the role of human agency, in accumulating cultural and symbolic capital". Seen from this perspective, agency can be viewed as a fundamental force driving multilinguals to make choices with regard to how they relate to the social world (Ahearn, 2001).

\section{The dynamic interplay of investment and agency}

Investment seeks to make meaningful connections between a learner's desire and commitment to learn a language and the ability to respond or act through appropriate 
and competent language use (Toohey \& Norton, 2011). Investment in a particular language choice is demonstrated through a learner's agency. HLUs spend time, money and energy (such as attending language proficiency classes, private tuition and buying language resources) to gain proficiency in target/ dominant languages because they are propelled by their desire and commitment to invest in the desired language. Once their investment pays off, that is when they have acquired linguistic proficiency in the target language; they exercise their agency by participating more confidently in classroom discussions and also interacting socially outside the classroom with the target community. As their need and desire to invest in a specific language grows so does their capacity to act purposefully and reflectively in social relationships with others. The greater the investment made by the learners, the greater their agency in displaying confident use of the desired language. Deters et al. (2015) further suggest that during social interaction learners "enhance their agency giving them a sense of power over their environment and thereby increasing their investment in language learning" (p. 206). The point here is that when an increased investment in language learning occurs, this activates a higher degree of agency as language learners now realise that they have become more proficient in the use of the target language.

This can be illustrated in the following diagram in Figure 8:

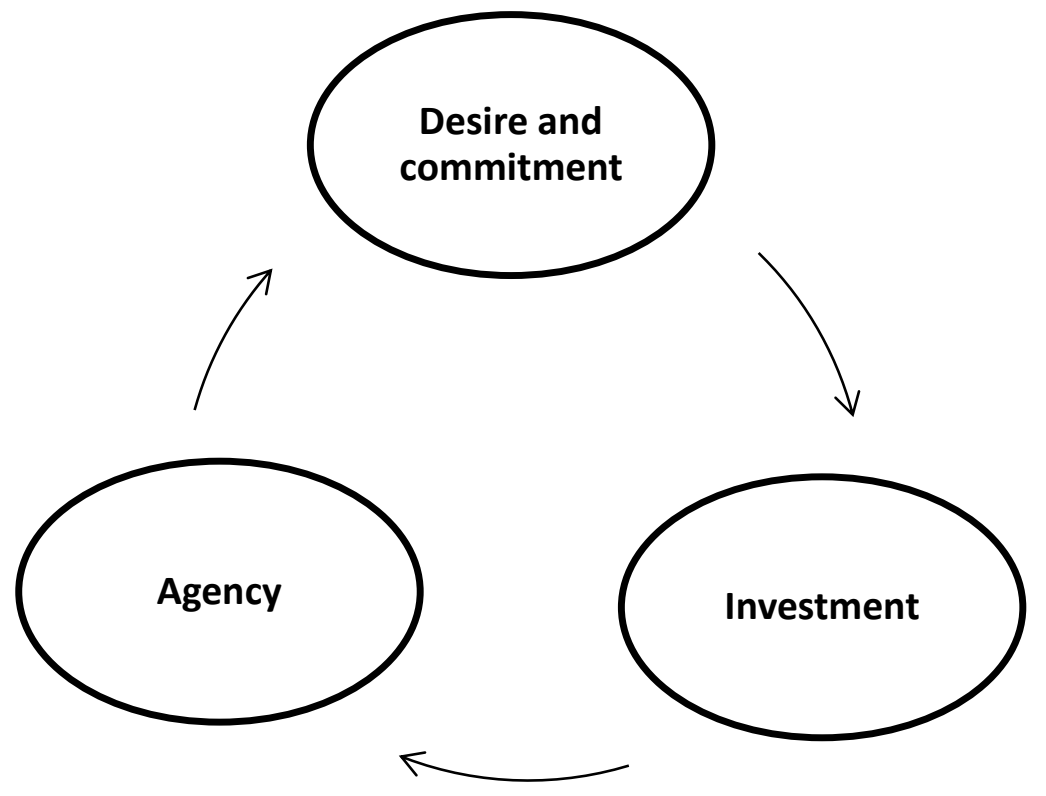

Figure 8. The dynamic interplay of desire and commitment, investment and agency 
Desire and commitment to acquire competency in the desired language trigger HLUs to invest their time, effort and money in gaining proficiency. This investment then is displayed through their capacity to interact meaningfully using their invested linguistic resources during social interaction with others (Garcia, 2012). This is a dynamic process. When the HLUs are able to demonstrate their linguistic competency (agency) during social interaction with others, their desire and commitment increases as a result of confident display of competent language use. This in turn causes them to invest more in acquiring further proficiency in the desired language.

I highlight a few studies related to this concept.

Researchers noted that mainland Chinese participants studying in a university in Hong Kong used English during club meetings at the university to practice English skills (Gao, Cheng, \& Kelly, 2008). Club meetings were held after lecture hours and usually on weekends. Their attendance appeared to demonstrate the participants' investment and agency in developing their English skills.

De Costa (2010) drew on the construct of investment and agency to understand why his participant strived to use standard English during interactions in a secondary school in Singapore. Jenny was a Chinese student from China who wanted to be perceived as an academically able student through her willingness to communicate in English with her Singaporean classmates. When she arrived in Singapore she had a reasonable level of proficiency in English. Findings from a year long ethnographic study revealed that even in the face of overwhelming forces, Jenny was able to exercise her agency and to do so in ways complementary to prevailing ideologies which subsequently bolstered her learning.

In another study Chang (2011) examined two doctoral international students on their learning trajectories studying in US through the lens of investment. Chang argued that the students were able to exert their own agency "to fight their academic battle" (p. 228) and selectively invest in areas that would increase their market value in their current communities.

Findings from research discussed earlier showed that investment and agency are closely linked to identity construction. In sociolinguistics of mobility HLUs exercise their agency to invest in powerful identities (increasing proficiency in dominant languages). 


\section{Chapter summary}

In the Malaysian context the linguistic practices of my participants become more complicated as participants have to negotiate between two different language ideologies. Malay, which is the national language in Malaysia, is the lingua franca between the different ethnic communities within Malaysia and in public spheres. English is the international lingua franca which is used for communicating with international communities. Within this hierarchy of languages, the participants now have to position their HL (Tamil). The challenge for my participants is to retain their sense of self while also appropriating new linguistic norms and practices when using the different languages (Canagarajah, 2004). 


\section{Chapter Four \\ Research Methodology}

\section{Overview}

In this chapter I begin by describing the rationale for adopting a qualitative methodology. I explain why a narrative approach is appropriate for this kind of research which focuses on the voices of linguistic minority students as they make meaning in a multi-educational context. My description of the study design also includes an explanation of the research site, selection of participants, data collection methods, and data analysis procedures. Finally, I explain my position as a researcher; discuss validity issues related to a qualitative study, and outline limitations and ethical considerations.

\section{Qualitative research design}

Qualitative research aims at providing an in-depth and interpreted understanding of the social world of the research participants. It seeks answers to questions that stress how social experience is created and given meaning (Denzin \& Lincoln, 2000). I used a qualitative research design because it was suitable to address the research questions of my study. It enabled me to focus in depth on a small group of participants (nine THLUTs) and to understand their perspectives on how social interactions within a multilingual society impacted their identities as HLUs.

As a qualitative researcher, I looked into how the participants' socio-cultural histories and values shaped their language choices, values, attitudes and beliefs. Their stories gave me a window through which to view their worlds. Qualitative research provides a unique tool for me to study "what lies behind, or underpins, a decision, attitude, or behavior or other phenomena. It also allows associations that occur in people's thinking or acting - and the meaning these have for people - to be identified" (Lewis \& Ritchie, 2003, p.28).

\section{Narrative approach}

I will now highlight the reasons why a narrative approach suited my study. Firstly, many researchers have found narratives are particularly appropriate for identity studies (Block, 
2007b; Pavlenko \& Blackledge, 2004; Pavlenko \& Lantolf, 2000; Reissman, 1993, 2008; Ricento, 2005). "Tapping into issues of identity, how one views oneself and relates to the world around one, requires an inquiry into people's experiences and meaning making, and an inquiry into those areas calls for the use of narrative" (Kanno, 2003, p. 11).

When participants tell their life stories, they reveal who they are, their beliefs and values (Bastos \& Oliveria, 2006). Identity is constructed through the stories we narrate and re-narrate to ourselves as well as to others through personal experience in relation both to the other and to a social milieu (Clandinin \& Connelly, 2000).

Secondly, narratives capture the complexities of peoples' lives in response to the world they live in. When people talk about what they have said and done, they attempt to create a link to explain events and experiences in their lives. The process of narrating experience is not merely a tool for communication, but also one that allows individuals to negotiate and/ or make meaning out of it (Bell, 2002).

Finally, Canagarajah (1996) argues that narratives function in opposition to elitist scholarly discourses, and that their use in research offers an opportunity for marginalised groups to participate in knowledge construction in the academy. A narrative approach deliberately seeks out the voices of marginalised or minority groups. In addition, issues that directly affect the ways in which learners experience immigration, settlement, and language learning are wrapped in the stories they hold (Bell, 2002). For these reasons, narrative seems a natural tool to use as the participants of my study are ethnic Tamils (a linguistic minority group in Malaysia). In addition they are also THLU-Ts, a sub-group within the ethnic Tamil minority.

These are the strengths of a narrative approach; they align with my research questions and the purpose of my research:

How do nine THLU-Ts tertiary students from an international university in Malaysia:

1. perceive the status of their HL in relation to English and Malay?

2. perceive that they are positioned by their peers (non-Tamils and THLU-Ms) when they use Tamil?

3. perceive the role of their families in the language choices they (the participants) make? 


\section{Setting}

The study was conducted in a private university in Malaysia in the state of Selangor. This university offers courses in engineering, information technology accounting and business management at both undergraduate and post-graduate level.

This particular research site was selected for the following reasons. Firstly, public universities in Malaysia conduct most of their programmes in Malay which is the national language. Being a private university, the medium of instruction at this site is English. This enabled the researcher to select participants who had undergone formal instruction in their Heritage Language (Tamil) at primary level, attended national secondary schools where the medium of instruction was Malay, and finally enrolled at a university where the medium of instruction is English. These experiences had the potential to impact the participants' multilingual choices (Tamil, Malay and English) which my study investigates. Lastly, the research site was chosen because of its proximity to the researcher's residence. Considering the frequent visits I had to make to build a rapport with my participants, conduct interviews and possibly meet participants at short notice, this research site was convenient.

\section{Selection of criteria for participants}

I used the following criteria in selecting prospective participants (THLU-Ts) for my study:

1. They have been educated in Tamil primary schools for six years.

2. They have been educated in national secondary schools where the medium of instruction is Malay and English is taught as a second language.

3. They are enrolled in a university which uses English as the medium of instruction.

4. They are ethnic Tamils.

5. They come from homes where Tamil language is spoken.

\section{Selection of participants}

The process of selecting participants required the use of both purposeful sampling and snowball sampling techniques to gain access to THLU-Ts for the study.

After seeking permission from the Registrar of Student Affairs at the university, I obtained a list of first year Indian students who had enrolled at the university from the 
Deputy Registrar for Enrolment. The list did not provide the information I was looking for (refer to section on selection of criteria for participants). I was then introduced to the student leader (incidentally a THLU-T) who agreed to help me identify the first year THLU-Ts at the university. With his help I was able to recruit ten participants who met the criteria of THLU-Ts for my study.

A group of this size has been suggested as an ideal size for studies using photovoice (Wang, 1999). Wang advocates that if the total number of participants exceeds ten they should be divided into separate groups, so that each group has a maximum of no more than ten participants. Initially I recruited ten potential participants and briefed them regarding details of the study including their roles as participants. I then gained their informed consent. (Refer to the ethics section in this chapter). However, one participant did not turn up for our scheduled meeting and we did not maintain further contact. I conducted the interviews with the remaining nine participants. Recruiting only nine participants allowed me to take time to ensure that individuals felt listened to and enabled me to respond to each one in a sensitive and respectful way.

\section{Data collection method}

Narrative inquiry research methodology uses multiple data collection methods to access multiple perspectives and digs deep into participants' experiences (Connelly \& Clandinin, 1990). Connelly and Clandinin (1990) urge narrative inquirers to collect "a rich data source with a focus on the concrete particularities of life that create powerful narrative tellings" (p. 5). The rich and detailed field texts can be any forms of narrative texts or artefacts such as participant's stories, journal writing, conversations, interviews, field notes, and documents (Clandinin \& Connelly, 2000). I used photovoice interviews which offer an innovative way to triangulate research results: visual and verbal information; and individual reflections on the photos themselves (Goodhart et al., 2006). By documenting aspects of their lives through photography, participants create artefacts that can be used to express their lives on their own terms.

\section{Photovoice}

Photovoice is a participatory action research strategy in which individuals take and discuss photographs as a catalyst for personal, communal, and policy change (Bogdan \& Biklen, 2007; Kemmis \& McTaggart, 2003; Whyte, 1991). The three major goals of this 
methodology are (a) to allow participants to document their lives through photography, (b) to raise critical consciousness among participants, and (c) to reach policy makers with project outcomes (Wang \& Burris, 1997). Photovoice as a research method has often been used with participants in educational research ranging from primary students to those in tertiary contexts (Chio \& Fandt, 2007; Strack, Magill, \& McDonagh, 2004; Wilson, et al., 2007; Zenkov \& Harmon, 2009). This method was effective in drawing out participants' perceptions of what it meant being a THLU-T in a multilingual Malaysian society. It presented the perspectives of this marginalised group whose future seemed uncertain in the context of the Malaysian Education Blueprint. Participants were not just passive data providers but actors whose choices of photos influenced the results and outcome of this study. This established a sense of ownership of data through the participants' active engagement in the study.

Participants were asked to take photos which had impacted them and reveal their language experiences. These photos could be of objects, scenes, events or places that had impacted them and which tell a story about their language experiences. They were also reminded that none of these photos should have any facial images to protect privacy and confidentiality of people. They were informed that the photos will be used to facilitate the discussions during the in-depth interviews. Participants were provided with an initial time frame in which to bring these photos to the in-depth interview sessions. I began the interview sessions once the participants had confirmed that they were ready with their photo collection.

During our informal meetings I discussed my research project and answered any questions or doubts that they had. The participants were briefed on the aims of the study and what was required of them. They were informed of the photovoice method including ethical considerations of picture-taking to ensure that they did not include the face or other identifying features of any person in their photos and also to gain the written consent of those photographed. They signed forms confirming their consent to be interviewed once they agreed to participate in the research.

Although participants were informed of the protocols for using photovoice, they chose not to bring recent photographs; instead they chose photos to illustrate their past experiences. These photos were of their Tamil primary school, national secondary school and of family members, relatives and friends. They wanted to share their personal 
stories as THLU-Ts as they moved from one new linguistic environment to another. Therefore these photos captured events and experiences that had already taken place. Furthermore, the participants did not have the written consent of those people whom they had photographed. Neither were the facial images in the photos blurred or blocked.

These decisions made by the participants as to how the photos were presented during our interview sessions gave rise to methodological issues related to photovoice. Thus, I used the term "photovoice interviews" instead of photovoice methodology (as initially planned) to indicate that it was a technique used to collect data for my study rather than a methodology.

Having decided that it was a photovoice interview, I also needed to highlight the fine distinction between photovoice and photo elicitation. I chose to refer to my data collection method as photovoice interviews and not photo elicitation because the data collection method adhered to the fundamental elements of photovoice more than photo elicitation. "Photovoice, at its most basic level is the use of photographic equipment, usually digital, to capture a visual image then to transform this image into a vehicle for generating information and discussion" (Delgado, 2015, p. 7). The photos the participants brought to the interview provided a start-off point for them to explore their multilingual experiences.

In comparison, photo elicitation studies employ any visual images, including archival photos or those generated by the researcher or participant (Hurworth, 2003). Since the visual images may be produced by either the participant or the researcher, the question arises as to who controls the images and the interpretation of the images. It could be the researcher, the participant, or both (True, 2015). In my study, the participants chose the photos and talked about them. They and not I assigned meaning and interpretations (Chio \& Fandt, 2007). Keeping in line with the goals of photovoice methodology (Wang \& Burris, 1997), the photovoice interviews allowed participants to reflect on their multilingual experiences and in this way they sharpened their awareness of the challenges they faced as multilingual THLU-Ts living in Malaysia (Goodhart et al., 2006).

I chose not to publish the photos in my thesis. Instead, I used picture frames describing the photos my participants brought for the interview session. By doing so, I 
protected the privacy and confidentiality of both my participants as well as the people in the photos.

Moreover, being regarded as an older sister by the participants throughout the research process further added to my responsibility as a researcher. I was entrusted with the role to protect the confidentiality of my younger siblings (the participants).

In their description of photovoice, Wang and Burris explicitly state that the technique should be "creatively and flexibly adapted to the needs of its users" (1997, p. 383). This is what I chose to do to address both methodological issues and the ethical implications related to the use of photovoice in my study.

The researcher used the participants' photographs as prompts to interview each participant individually. Participants were prompted to discuss their photographs using "experience questions", "opinion questions", "feeling questions" as they related to the participants' past, present and future based on Patton's (1990) interview probes (as cited in Maykut \& Moorehouse, 1994, pp. 90-91). I outline below some interview questions that I used:

- Experience questions to begin interviews: Tell me something about yourself, your family, your educational background, what courses you have taken at the university? Tell me something about this photo which you have taken.

- Opinion questions: How do you see yourself as a Tamil user at this university?

- Feeling questions: What kind of feelings have you experienced when you used your HL in the classroom?

I video-recorded our interview sessions which were then later transcribed. Each interview session took almost an hour. Two in-depth interviews were conducted, one early in the semester and the second one towards the end. During the first interview session, participants began narrating their stories based on the photos they had brought. I built a general description of the participants' background and their life events based on experience questions (refer to examples shown earlier). The inquiry into events as depicted in the photos taken by my participants helped me to broaden or "list... events into a schematic whole" (Polkinghorne, 1988, p. 19) or a continuous and unified "plot". Broadening is also about making "a general comment of a person's character, values, way of life or, perhaps, about the social and intellectual climate of the times" [as they narrate their experiences revolving around these events]" (Clandinin \& Connelly, 2000, 
p. 11). I wrote out narrative summaries or stories for each participant after our first interview.

During the second interview the participants reflected on the narrative summaries or stories which had been e-mailed earlier. At this point I focused on the reconstruction of a specific event from the participant's point of view at a certain time and place, and tried to understand why the participant felt and experienced these events in particular ways. I sought additional data to reexamine the existing data before rewriting a more complete and coherent story for each participant. This story was also individually reviewed by each participant. This was referred to as "burrowing" (Clandinin \& Connelly, 1990, p. 12). Finally, this led to "restorying" (Clandinin \& Connelly, 1990, p. 12). Participants' stories were retold a third time capturing the meaning of the events and their significance for the larger life story of the participant as a THLU-T.

These three narrative inquiry stages are explained in detail under narrative research procedures (refer to Figure 9).

\section{Informal meetings with participants}

Before conducting the in-depth interviews, I met the participants at the university a few times to build a rapport. We also communicated through e-mails, short messaging texts and whatsapp. The participants felt that they could trust me to share their thoughts and stories. At first, they addressed me as "madam" as they saw me as an older, professional woman from their community. They showed admiration and respect for my status.

However, this reaction towards me changed once they felt that they could trust me with their personal stories. The numerous visits I made to the campus seemed to engender confidence and trust. I spent time with them before the interview sessions began. We sat and chatted in the university cafeteria and the waiting lounge. Sometimes we also met outside the campus at restaurants and at other times in my home. I got to know them better. Having myself experienced the Malaysian university academic environment greatly strengthened this relationship and built a bond of trust between us. I could speak to them in Tamil fluently and shared the same socio-cultural values. This relationship built during the research process appeared to change the participants' perceptions of me. They started addressing me as “அக்கா” (a term used to address an older female sibling in the family). This suggested that they were then seeing me as one of them (an insider in their community) who shared their concerns as a fellow Tamil 
living in multilingual Malaysia.This high level of trust informed and contributed to the sharing of their stories through the photos.

\section{Narrative research procedures}

I used the three narrative inquiry strategies (Clandinin \& Connelly, 1990, 2000) to analyse data collected from the in-depth interviews.

The first experience questions provided a social and contextual backdrop for participants' stories (broadening phase). The feeling and opinion questions helped me to reconstruct particular events which had impacted the participants. I paid particular attention to the feelings the participants associated with these events and dug deep to explore their beliefs, values and attitudes (burrowing phase). Finally, individual participant's stories were retold chronologically and coherently with a description of the meaning and significance of these stories to their lives (Ollerenshaw \& Creswell, 2000). Using this narrative procedure, I wrote out their individual stories under various subheadings which reflected emerging themes (language and bonding, linguistic hegemony of languages and how they felt they were positioned during social interaction). Figure 9 illustrates how the participants' stories were analysed, interpreted and written up through a process of broadening, burrowing and restorying (Connelly \& Clandinin, 1990). 


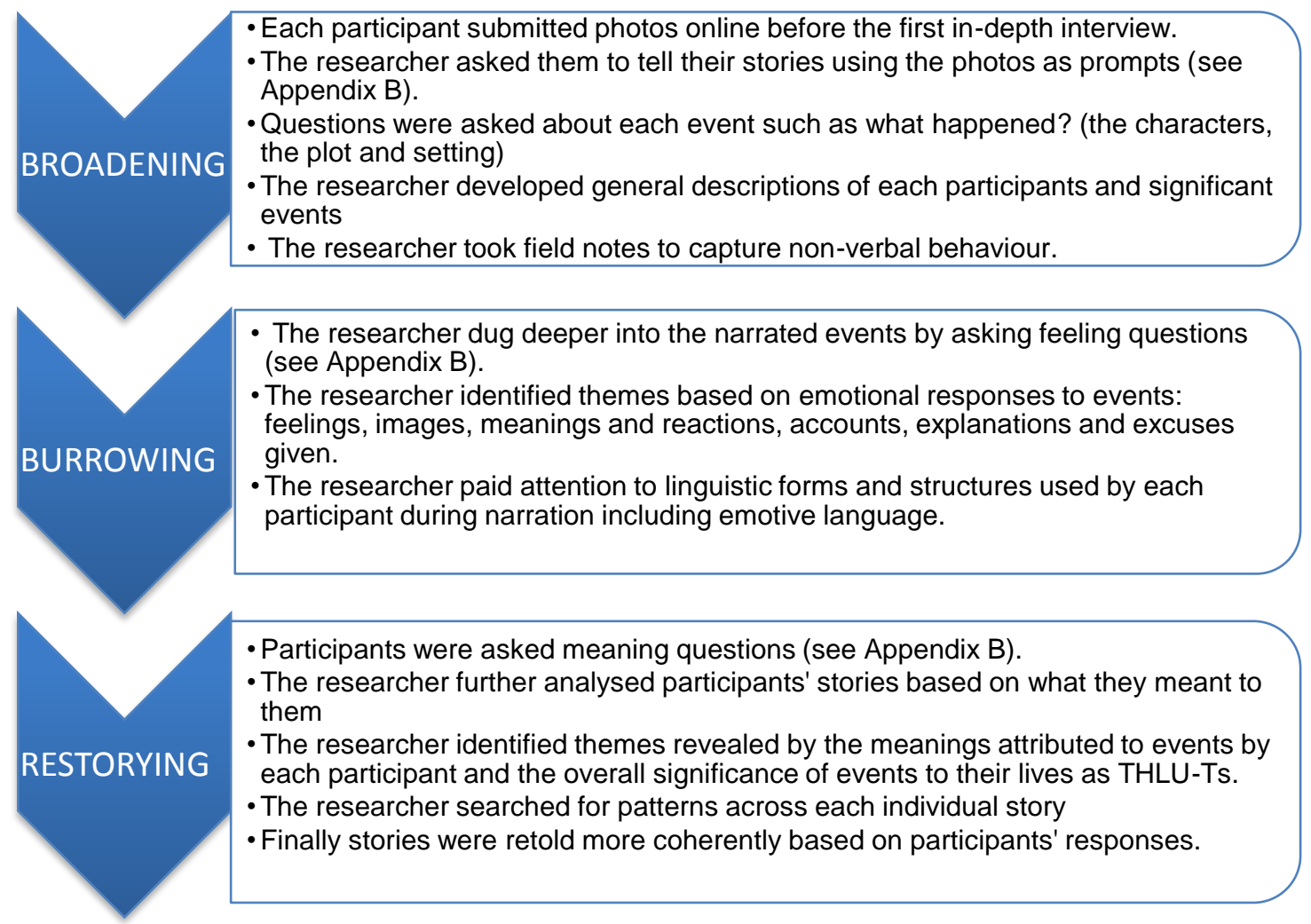

Figure 9. The three narrative inquiry strategies to analyse data collected from the indepth interviews (Clandinin \& Connelly, 1990, 2000)

\section{Data analysis}

I used NVivo Version 10 to code the interview transcripts and also to manage data. I

followed the six coding stages of (Braun \& Clarke, 2006) which I outline as follows:

1. I read and reread the transcribed data and, in addition, I listened to the videorecordings several times to ensure the accuracy of the transcription. In this way I immersed myself in the data.

2. Next I wrote out participants' stories using narrative research procedures. I then identified features of the data that I considered as relevant to the research questions and began initial coding using NVivo. I gave equal attention to both the interview transcripts and participants' narratives during the initial coding process. During this iterative process I continually refined insights and sharpened the focus for analysis by identifying gaps in my understandings of what was going on in each case. Hence, I could return to the data with a clearer understanding of how to categorise them thematically. 
3. I grouped all initial codes relevant to the research questions into themes. For example, to address research question one (How do nine THLU-Ts tertiary students from an international university in Malaysia perceive the status of their HL in relation to English and Malay? I labeled it under NVivo coding (parent node) "how do others see us?" (Refer to chapter on Thematic Analysis). I used the NVivo software to create thematic maps which helped in the generation of themes. There were altogether 95 nodes that represented codes; out of which 16 were parent nodes and the rest child nodes.

4. I refined the coding process by discarding themes that did not have enough data to support them or were too diverse (not related to research questions). I also made sure that no coding had been missed by going through iterative process again. The 16 parent nodes were classified into nine categories and after further scrutiny were then collapsed to five themes. (Refer to Thematic Analysis chapter).

5. I looked for transition between themes and examined the interview transcripts and participants' stories based on different kinds of transitions for example, from a family setting, to academic setting, and identified the phrases which expressed specific themes. Extract taken from participant's transcript:

It happened when I was in Form 4. I was speaking with my friends in Tamil when this group of Malay students scolded and made fun of us. There was also a teacher who reminded us that we must not speak in Tamil as this is not a Tamil school. (Munesan, Transcript, Dec. 2014)

The bold phrases indicated that the participant was relating an incident at national secondary school. It also reflected competing language ideologies (HL use versus dominant language use) at national secondary school. In addition, emotive language imagery or passages that expressed feelings and metaphors were identified. The following quote from a participant's transcript illustrates this: "Being a Tamil, it is close to my heart. I was born with it. It is in my blood" (Thinesan, Transcript, Dec. 2014). The bold phrases highlighted the theme affiliation to heritage identity.

6. Finally I connected all the coded thematic ideas to broader literature and theories in chapter six. I chose examples from the transcript to illustrate elements of the themes.

The thematic analysis proved to be a flexible and useful research tool which provided a rich, detailed and complex account of data that helped in my analysis process (Braun \& Clarke, 2006). A detailed discussion is found in the Thematic Analysis chapter. 
An overview of the research procedure is illustrated in Figure 10.

Research Questions

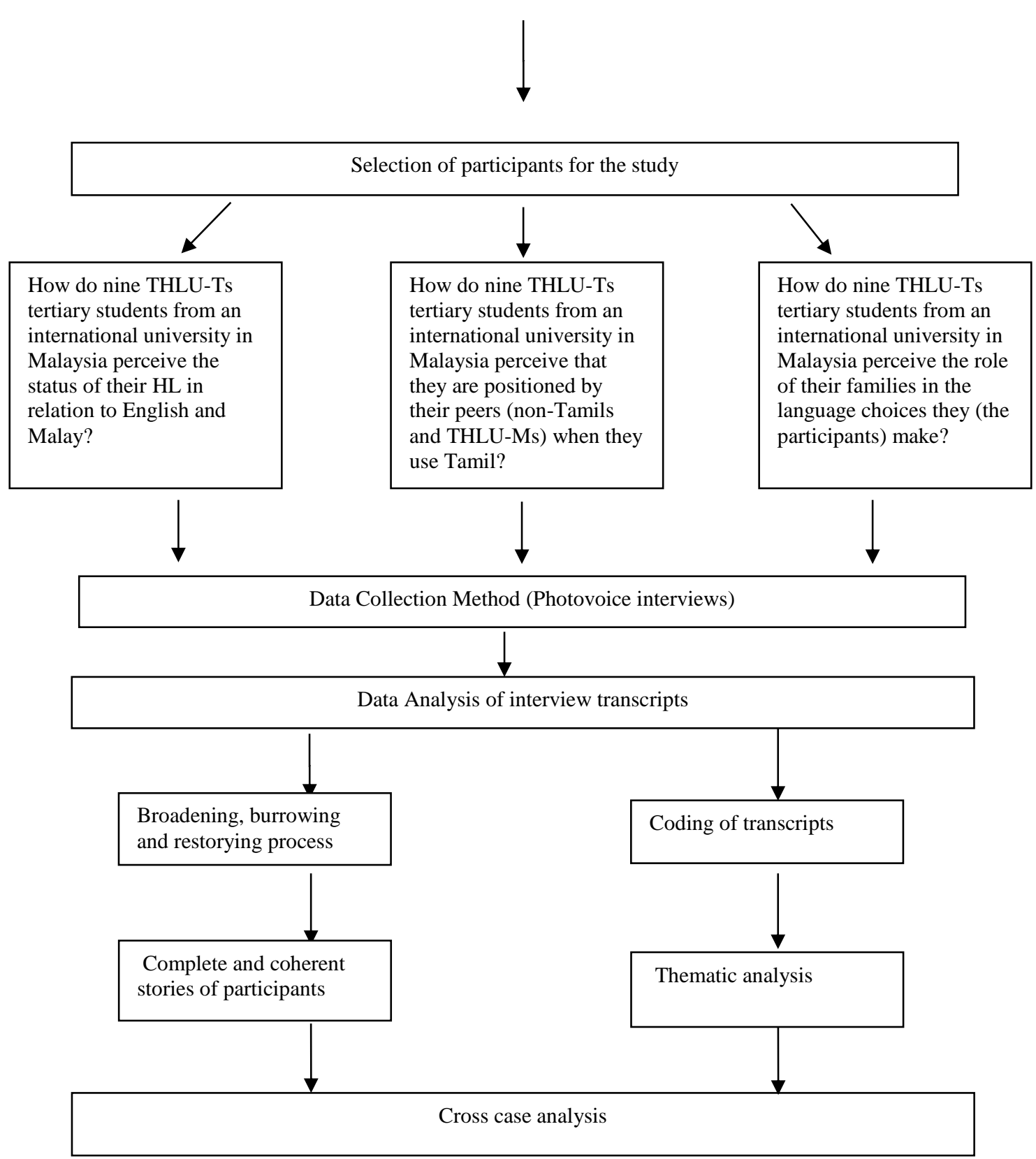

Figure 10. The overall research design

\section{Researcher as an instrument}

I discussed my positioning and credibility in the Introduction chapter. In this section I touch on the reflexivity processes. Reflexivity is an attitude of attending systematically 
to the context of knowledge construction, especially to the effect of the researcher, at every step of the research process (RWJF Qualitative Research Guidelines Project).

Reflexivity enabled me to engage with my research in a way that assisted in guarding against unwarranted assumptions coming from my own background (Barbour, 2008). I continuously examined my own experiences and biography and its impact on the research process. I recorded my personal thoughts, insights, hunches, or ideas that emerged in a journal throughout this whole research process. These field notes were a written account of what I experienced, observed, and thought as I collected data in the study. During the period of this study, my research journal provided a record of the research process and allowed me to reflect on the process, my findings and my personal responses.

In my research journal I was able to document some of my struggles and have conversations with myself in order to clarify my own thinking. Entries such as the one below show evidence of how I questioned my ontology of THLU-Ts behavior and attitudes. I was certainly influenced by the literature I had read.

Were they expecting too much that all Tamils must speak in Tamil? Who does the inclusion or exclusion? Sometimes I feel they do not want to be associated with THLU-Ms not the other way round. I need to rephrase this question. What are heritage identity markers? Which they would priotise? Did they see HL use as the only connection to a heritage identity? Is this a fair assumption to make?

Canagarajah notes that affiliation to heritage identity can also be demonstrated through participatory cultural and religious practices. There was so much that I needed to learn, ask and understand. I begin to realise that it is not just impossible to solve the problems I see around me, it is also presumptuous and arrogant to think that I might do so. Yet walking away and pretending that the issues do not exist seems even less ethical... (Research Journal, 20 Dec. 2014)

In visiting and revisiting data from both interview transcripts and participants' stories I engaged in a deeply reflexive process.

I also interviewed a family member who had gone through Tamil primary school and who was now enrolled in a private institution before conducting interviews with my participants. This helped me to understand participants' stories.

\section{Trustworthiness of the study}

It is important that any study is evaluated according to its underlying research methodology paradigm. This chapter has demonstrated that the methodology used to answer the research question fits within a qualitative, narrative paradigm. Although there 
is debate about how best to assess the rigour of qualitative studies (Morse, Barrett, Mayan, Olson, \& Spiers, 2002; Rolfe, 2006), Guba's (1981) overarching idea of trustworthiness seems most fitting. Trustworthiness includes other qualities necessary

for rigour in research such as: dependability, credibility, transferability and confirmability (Creswell, 2009; Shenton, 2004).

\section{Dependability (or reliability and replicability in quantitative terms)}

This is achieved by repetition logic (Yin, 1994) or repeating the same procedures across all cases. The steps taken during the research process must be "logical, traceable and documented" (Schwandt, 2007, p. 299). This was achieved in my study by ensuring that during the interview sessions the photos that participants brought initiated all discussions. The researcher began all interviews by asking what the photos were about and what they meant to the participant. The interview prompts elicited the participants' experiences of the same major issues in each case (multilingual experiences during social interaction). Furthermore, this chapter includes a comprehensive description of research design, its implementation, and the data gathering process. This allows the reader to assess the extent to which proper research practices have been followed.

\section{Credibility}

This relates to ideas of validity or authenticity (Creswell \& Miller, 2000). Lincoln and Guba (1985) argue that ensuring credibility is one of most important factors in establishing trustworthiness. In order to promote confidence that I have accurately recorded the phenomena under scrutiny I observed the following:

- the adoption of research methods that are well-established in qualitative research. Narrative inquiry captured information on how THLU-Ts interpreted certain events that impacted them; the values, beliefs and experiences that guided those interpretations; and their hopes, intentions and plans for the future (Etherington, 2000). These studies might be represented in a variety of creative ways including art, photography and other audio and visual means, or performed through poetics, stories, theatrical and dramatic presentations, (Ellis, 1995; Bochner \& Ellis, 1996, 2002; Ronai, 1995). I used photovoice methodology to construct participants' stories. 
- the development of an early familiarity with the research site and participants before the first data collection takes place. I made frequent visits to the university, getting to know the registrar and student administration staff. I also met the participants individually and, at other times, in groups. This was done to gather an adequate understanding of the organisation and to establish a relationship of trust.

- providing a thick description. Participants' narratives included a detailed description of events, characters and places that impacted them. The use of photos helped to capture the visual effects. This promoted credibility as it helped to convey the actual situations that were investigated and, to an extent, the contexts that surrounded them.

- background, qualifications and experience of the researcher. Alkin, Daillak and White (1976) go so far as to suggest that a scrutineer's trust in the researcher is of equal importance to the adequacy of the procedures themselves. I have described my professional and personal background in Chapter One and under the heading Researcher as an instrument in this chapter. In addition to this, as a mature professional Malaysian teacher and educator I was able to confirm the authenticity of participants' descriptions of the socio-economic, education and political climate in Malaysia. In this respect, my credibility as a researcher is strengthened.

- member checks are considered the single most important provision that can be made to bolster a study's credibility (Guba \& Lincoln,1989). Participants reflected on summaries of their narratives which were distributed after the first round of interview sessions. Another element of member checking involves verification of the researcher's emerging theories and inferences. The researcher analyses and verifies data while data is being collected, not after (Van Maanen, 1983; Shenton, 2004). During the second interview we discussed their comments and I asked participants if they could offer any reasons for particular patterns that I had observed. This strategy is recommended by (Miles \& Huberman, 1994). To ensure that I had accurately captured participants' stories from their perspectives, the revised coherent stories were also individually checked by the participants.

- keeping a reflective journal to record initial impressions of each data collection session, patterns appearing to emerge in the data collected and theories generated. These reflections play a key role in "progressive subjectivity" (Lincoln \& Guba, 
1985). I monitored my own developing constructions, which are considered critical in establishing credibility.

\section{Confirmability}

This is another aspect of validity comparable to objectivity in quantitative studies (Shenton, 2004). This is where I acknowledge that my own experiences and beliefs are part of the research process, in direct contrast to approaches taken by quantitative researchers. In order to carry out this study it was necessary for me to play an active role, for example, in selecting and interpreting data. In fact, it is not possible or desirable for the researcher to be objective in a qualitative enquiry. Photovoice methodology helped to reduce researcher bias because participants initiated discussions based on photos which they chose. This process helped to ensure as far as possible the research findings are the result of the experiences and ideas of the participants, rather than the characteristics and preferences of the researcher. Engaging in the photovoice process asks participants to showcase elements of their lives while promoting an inclusive format to express their own realities (Chio \& Fandt, 2007; Novak, 2010; Ornelas et al., 2009).

\section{Transferability}

This is related "to the extent to which the findings of one study can be applied to other situations" (Merriam, 1998). Since the findings of a qualitative project are specific to a small number of particular environments and individuals, it is difficult to demonstrate that the findings and conclusions are applicable to other situations and populations. This study is defined by its specific context which highlights its uniqueness. However, I have provided sufficient contextual information (in Chapter One) and rich description of data to allow readers to have a proper understanding, thereby enabling them to compare the instances of the findings and conclusions described in my research with those that they have seen emerge in their situations.

\section{Limitations of the study}

The results of this study may not be transferrable to all HLUs studying in universities in other research contexts. The findings will only be relevant to this particular research setting. However, a thick description of the data captured in the participants' narratives will allow readers to make connections to their particular context. Secondly, time is 
another limitation. The study deals with identity construction among THLU-Ts, which is fluid and dynamic. The study only captures identity construction during the period of data collection. Finally, the analysis of interview data depends on the interpretation of the researcher but mitigated by the narrative research process which includes participants in the reflexive process. My reflective field notes allowed me to maintain reflexivity.

\section{Ethical considerations}

Victoria University of Wellington's (VUW) Human Ethics Policy (2007) indicates that participants have the right to be well informed about the research project and how their rights will be protected, for instance, privacy, confidentiality, anonymity and withdrawal from the project, before they agree to participate. The following procedures were followed based upon these guidelines:

1. I wrote a formal letter to obtain permission from the university which included the details of the study. In the letter, I guaranteed to respect the site, its people and its facilities. I assured the administrators that the identity of the university will not be disclosed. A detailed account of the ethical protocols as prescribed by Victoria University of Wellington was included in the application including details of ethical approval granted for conducting this study.

2. Consent forms were given personally by the researcher to the students who volunteered to participate to ensure that their decision to participate was informed by accurate information. The participants were assured that they could withdraw from the project at any time during the data-collection process.

3. In order to protect the participants' privacy, confidentiality and anonymity, the participants were asked to choose "research names" for this study.

4. The participants were also informed that only the researcher and her supervisors would have access to the original data and documents. They were assured that, the collected data will be archived securely and later destroyed. 


\section{Chapter summary}

In this chapter, I have discussed the issues that flowed from the process of identifying the beliefs and rationale that underlay the choice of research methodology. I have explained how a narrative approach suited my study, and data collected through photovoice helped to construct participants' narratives. I also discussed how the data was analysed through storying and coding iteratively. My positions as a researcher and as an instrument were also highlighted. Finally, the trustworthiness of my study, limitations and ethical considerations were included. This leads to the findings which are presented in the next chapter. 


\section{Chapter Five \\ Findings}

\section{Overview}

This chapter presents the findings of my study which were derived from data collected through individual in-depth interviews with nine THLU-Ts (the participants) studying at an international university in Malaysia. The interviews took place at a meeting room designated by the university authorities. Two interviews were conducted for each participant; one at the beginning of the semester and the second one towards the end of the semester. The first round of interviews were conducted in late August, 2014 and the second round of interviews were conducted from early January, 2015 till early February, 2015.

I tried as far as possible to minimise researcher interpretation so that the voices of my participants would be heard. When writing their stories I retained grammatical inconsistencies and half thoughts so as not to change the vocabulary or phrasing in my transcription and to let the spoken voice to come through. The interviews were all conducted in English. It was only necessary to translate Tamil idioms and proverbs into English to try and capture the essence of what the participants intended. These translations were affirmed during member-checking.

I present the photos in picture frames due to methodological issues and ethical implications related to the use of photovoice (refer to chapter on Research Methodology). I present below the stories of my nine participants. The sub-headings capture the chapters within each story. I retained some of these sub-headings for in vivo codings (refer to chapter on Thematic Analysis). 


\section{Darshini's Story}

This is Darshini's story a first year, female chemical engineering student. She spoke well in English. She showed keen interest in sharing her language experiences with me. This was quite evident in the way she detailed each event that impacted her.

\section{Tamil brought us close together}

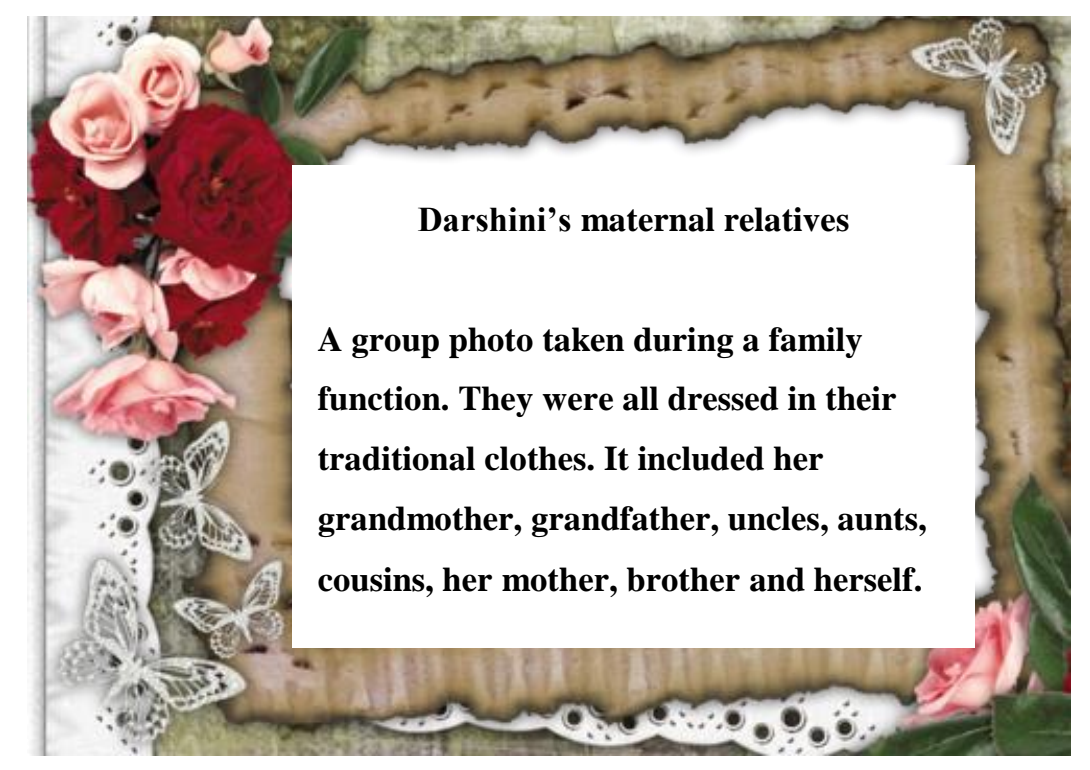

Figure 11. Photograph of Darshini's maternal relatives

Darshini told me that when she looked at this photograph of her maternal relatives it brought to mind Tamil use (refer to Figure 11). Every year they organised outings and it was a special time of family bonding. The whole family would spend time together "eating, talking, laughing and having fun" (Darshini, Transcript, Dec. 10, 2014).They would be speaking in Tamil most of the time. She informed me that these outings fostered a greater relationship among the maternal side of the family. "So our bond grew closer and closer" (Darshini, Transcript, Dec.10, 2014). When she said this she slowly brought her palms closer and cupped them, "your family is like this? ... very close together?" (Darshini, Transcript, Dec.10, 2014).

I asked if at any time during these outings they spoke any other languages besides Tamil. She replied that amongst her cousins they tended to use English a little but with her aunts, uncles and grandparents it was always in Tamil. "You see the older generation, they don't speak in English. So we have to speak in Tamil to them especially my grandmother" (Darshini, Transcript, Dec. 10, 2014). So Darshini said she took it 
upon herself to ensure that her cousins spoke in Tamil to the older generation. Because she enjoyed a close relationship with her maternal cousins and was the eldest, she commanded respect from the rest. "I will make sure that they speak in Tamil and they listen to me as I am the eldest grandchild" (Darshini, Transcript, Dec.10, 2014). It was important for her as she saw this as one way of keeping the language alive. "This is a good opportunity for them to use Tamil. So they won't forget” (Darshini, Transcript, Dec. 10, 2014).

\section{Not good enough}

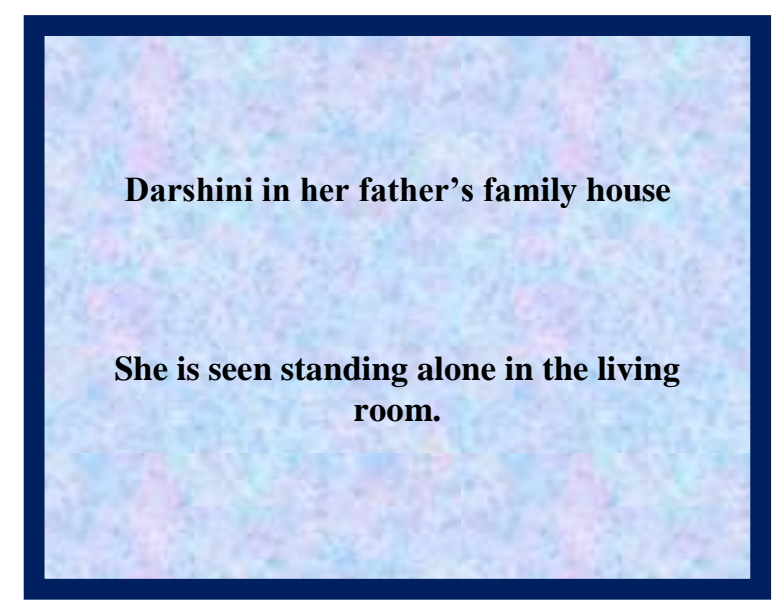

Figure 12. Photograph of Darshini in her father's family house.

When Darshini talked of her paternal relatives, her expression changed. She frowned and threw her hands up in the air. It signaled despair. (Researcher's Field Notes, Dec. 10, 2014). They did not like the idea of her studying in a Tamil school. They considered anyone studying in a Tamil school had "no status" (Darshini, Transcript, Dec. 10, 2014). They felt that if you came from Tamil primary school, you will be weak in Malay and English and that "everyone will look down" on you (Darshini, Transcript, Dec. 10, 2014). She told me that she was the only one among her paternal cousins who had gone to a Tamil primary school.

She told me that she did not like to attend any family gatherings held in her father's family house. "I will always be sitting alone” (Darshini, Transcript, Dec. 10, 2014). Her paternal cousins did not talk to her much. "You see they come from national primary school but I come from a Tamil primary school. So I have no standing" (Darshini, Transcript, Dec 10, 2014). Every time her parents were invited to attend a 
function she made up excuses not to go. "I feel so down. The youngsters will group together" (Darshini, Transcript, Dec. 10, 2014). She said that she always felt “demotivated" (Darshini, Transcript, Dec. 10, 2014), in their company. Her relationship with her paternal cousins was not close when compared to that with her maternal cousins. "The bond from my father's side is not close compared to my mother's side" (Darshini, Transcript, Dec. 10, 2014).

\section{I have shown them}

Darshini told me that she did not like the expression on her paternal cousins' faces when she spoke in Tamil. "I feel so hurt" (Darshini, Transcript, Dec. 10, 2014). She said that her cousins always spoke in English to her. However, this was in the beginning. "But now I have come up" (have done well), "they are normal" (behave normally) (Darshini, Transcript, Dec.10, 2014). I asked her what she meant by normal. She replied that they included her in their conversation and even spoke in Tamil to her sometimes. "If I talk to them in Tamil, they will also talk to me in Tamil. Last time they refused to talk in Tamil they only replied in English. But now it is different" (Darshini, Transcript, Dec. 10, 2014).

She described to me her "coming up" (Darshini, Transcript, Dec. 10, 2014). She was the only one of her generation from wither side of the family who had performed excellently in all her public examinations. These included UPSR (Primary School Achievement Test), PMR (Lower Certificate of Education) and SPM (Malaysian Certificate of Education). She scored straight A's. "My cousins all ... They all did not perform well", she said with great relish (Darshini, Transcript, Dec. 10, 2014). Now she is a first year undergraduate at an international university majoring in mechanical engineering. "Seeing my achievements, her cousins all start talking to me" (Darshini, Transcript, Dec. 10, 2014). She told me that from a young age she was very determined to succeed, this was fuelled by her desire to prove herself to her paternal cousins.

Furthermore, her parents had played a great part in motivating her. Her father knew that his relatives were not happy that he had chosen to send his daughter to a Tamil school. "They did not like us (his children) studying in Tamil School". So he continually reminded her that she had to do well in order to prove them wrong. Now she proudly claims that, "I have achieved and I have shown" them. She is thinking of furthering her studies abroad just like her cousins. She felt this would further elevate her status as a 
THLU-T. "People will respect me more if I study in Australia or England" (Darshini, Transcript, Dec. 10, 2014).

\section{Building a strong base}

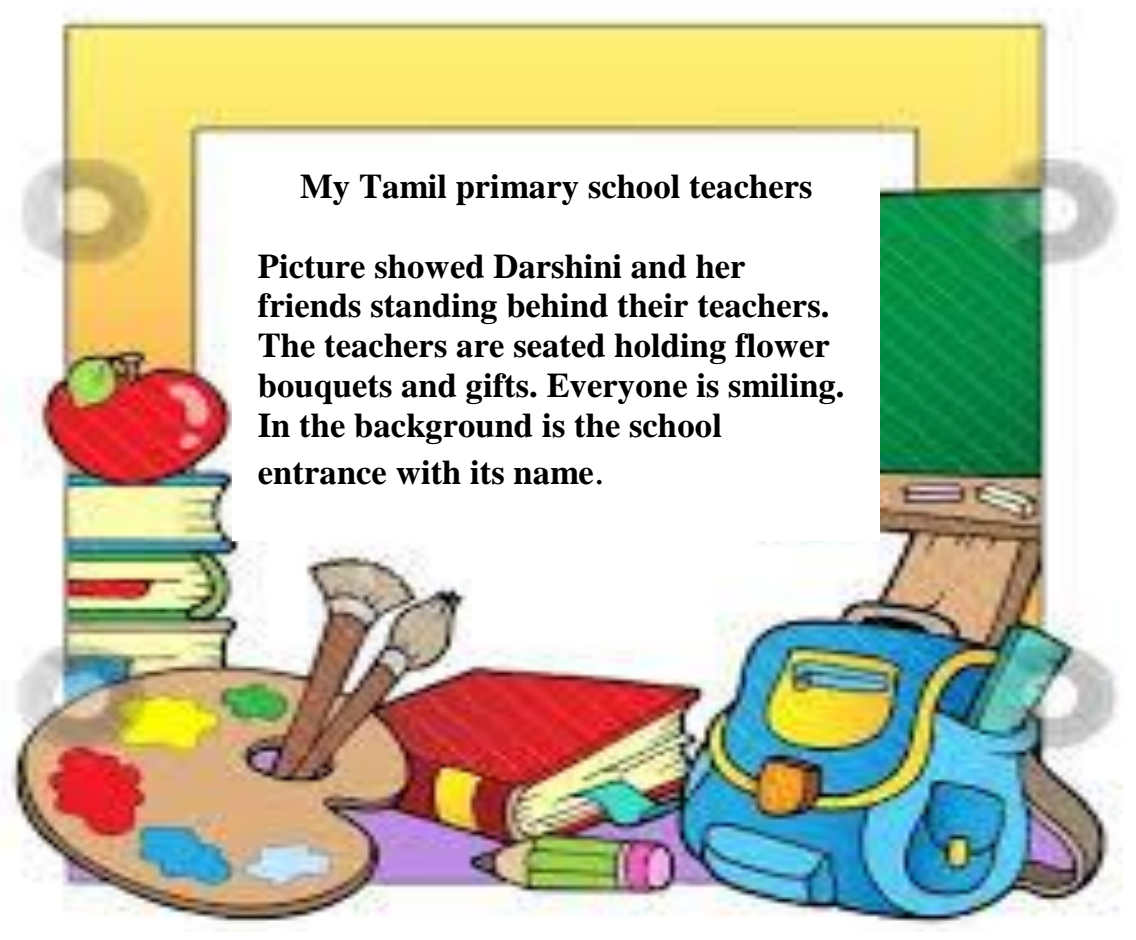

Figure 13. Photograph of Darshini's Tamil primary school teachers.

Darshini told me that she and her friends revisited their Tamil primary school after five years to thank their teachers who had played such a big role in their academic achievement. (Refer to figure 13). This batch of students had done extremely well in UPSR, PMR and SPM. In fact, her Tamil primary school was ranked second in Malaysia for UPSR. They also managed to score a minimum of six A's in SPM. She informed me that they owed this to their Tamil primary school teachers who according to her had built a strong foundation. She told me a building can collapse if the foundation was not strong. "Everything will come down if the base is not strong" (Darshini, Transcript, Dec. 10, 2014).

There was so much joy and pride in her voice when she recalled the moment. Their teachers were so touched by their gesture and told them that they brought great pride to the school. She told me there was a featured article in the local Tamil daily newspaper on this. This included the photo which she had showed me. She told me that 
when she narrated this incident to her friends at national secondary school, they were amazed. She felt that this amazement was due to the fact that students from national primary schools did not enjoy such a close relationship with their teachers. "But those who studied at Malay School (national primary school) there won't be a bonding of this sort. I don't think so" (Darshini, Transcript, Dec. 10, 2014).

\section{Let them say what they want, we do not care}

She talked about her national secondary school experience. When she first entered secondary school, she used to receive cold and unfriendly stares from the Tamils who had come from national primary school when she and her friends were talking in Tamil. She noticed that they were saying things about them which were not nice. "I think they were trying to tell us to break off and go away" (Darshini, Transcript, Dec. 10, 2014). In

time, she did not care. She asked me, "Why must we stop talking in Tamil? Let them say whatever they wanted" (Darshini, Transcript, Dec. 10, 2014).

She told me it was difficult to adjust to the new environment in secondary school. When she saw another Tamil, she immediately spoke in Tamil but the response was usually in Malay accompanied by "weird looks" (Darshini, Transcript, Dec 10, 2014). She soon realized that these Tamils were from national primary schools. She informed me that to distinguish those Tamils from Tamil primary school and those from national primary schools, she spoke in Tamil first. "I could always tell from the look on their faces", (Darshini, Transcript, Dec. 10, 2014). She would immediately switch to Malay if they gave her "weird looks". She told me she did not expect Tamils to behave like this. This happened initially. Later on, when she got to know more Tamils from Tamil primary schools, she did not care. "We came from Tamil school, so we will speak in Tamil” (Darshini, Transcript, Dec.10, 2014).

With the non-Tamils, she said that they accepted her and her Tamil friends from Tamil primary school if they spoke in Malay or English. However, if she and her friends spoke in Tamil, they did not mind either. She felt that this was because they (she and her Tamil friends) could speak well in Malay, English and Tamil. She informed me that the non-Tamils changed their initial perception of students coming from Tamil school which was that they would be weak in Malay and English. Once the non-Tamils found out that they could converse well in both Malay and English, the Malays and Chinese accepted them. 
She described an incident that had happened to her friend which showed that Darshini was not bothered by what others think. On this occasion, her friend was ridiculed because she had said something incorrectly in Malay. Her friend was depressed after this. Darshini advised her friend not to give up but to improve her proficiency. She said that the only way to become proficient is to continue speaking even if mistakes are made. She told me that if we withdraw and do not speak at all, then we will never improve. She further elaborated that during situations like this, some may mock at your mistakes yet some may correct them. "We got to move on and not feel ashamed. If we don't talk, we won't learn at all” (Darshini, Transcript, Dec. 10, 2014).

\section{Language use at the university}

Talking about her university experience, she found that she was using a lot of English compared to secondary school. She also used Tamil when she spoke to her Tamil friends. However, she was cautious when she wanted to use Tamil. She began first in English because she was afraid that her course mates would look down if she were to talk in Tamil. Furthermore, she felt that being in an international university, it was always safer to use English as it was an international language. She started using Tamil once she got to know the person well. With the rest of her non-Tamil classmates she used English. She commented that the Malays in the university spoke fluent English unlike the Malays in her secondary school.

Darshini spoke of an incident which left an indelible mark in her life as a THLU-T. One of her lecturers who was an Indian national explained Mathematical concepts in Tamil when she approached for help. Suddenly there was complete silence and she realised that the others (non-Tamils and THLU-Ms) were observing what was going on. "I think they must have thought can Tamil be used to explain Math at university level" (Darshini). She held her head high overcome with intense pride.

\section{The need to speak in Tamil}

Besides being her mother tongue, she said that she was proud to speak in Tamil as "Tamil is giving" her "rice" (Darshini, Transcript, Dec. 10, 2014). Rice has the property of sustaining life. Tamil was seen here as a life-giver. Darshini explained that coming from a Tamil school had taught her to be industrious and disciplined and to value success. This kept her striving for excellence. 
Darshini felt sad because she noticed that most Tamils at the university rarely conversed in Tamil, even among themselves it was always in English. She commented that it was only those from Tamil school who spoke in Tamil. She strongly felt it was essential for every Tamilian to speak in Tamil to preserve their culture and their identity. "If we do not speak the language, in time to come, we would have lost everything (Darshini, Transcript, Dec. 10, 2014). This statement made Darshini realise the gravity of the situation. 


\section{Munesan's Story}

Munesan was studying mechanical engineering at the university. This was his first year. He was very friendly and approachable throughout our interview session. $\mathrm{He}$ communicated well in English.

\section{I lost touch with Malay at the university}

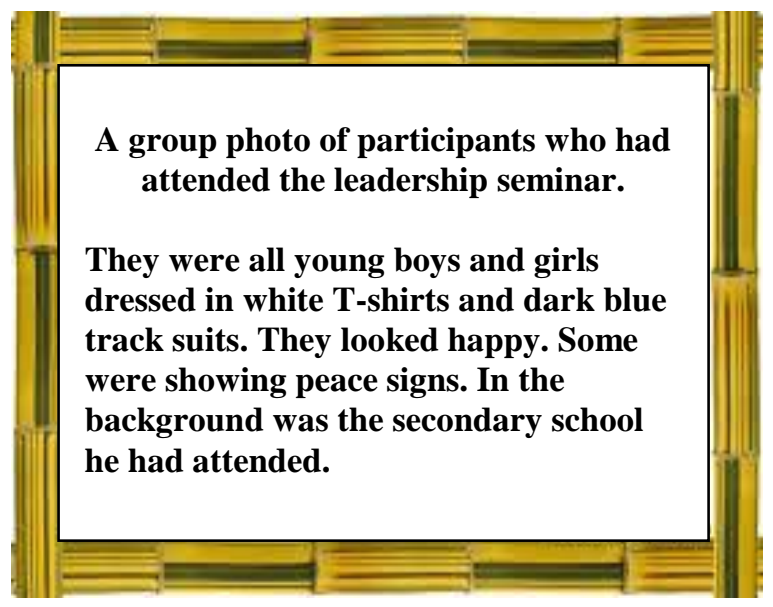

Figure 14. Group photograph of participants who had attended the leadership seminar.

Munesan started talking about his language experiences at the university. $\mathrm{He}$ showed me a photograph which was taken during a leadership seminar where he was enlisted as one of the student facilitators. He described the difficulties he faced when he was asked by his former secondary school authorities to help conduct a leadership seminar for school prefects and class monitors. He had to conduct the programme in Malay. Although he felt proud to be selected as one of the student facilitators, he felt nervous because of his lack of proficiency in Malay. He told me his proficiency in Malay was not good as compared to Tamil and English. Of the three languages, Malay was his "poorest" (Munesan, Transcript, Dec.19, 2014). When I asked him why his proficiency in Malay was poor, he replied that since coming to the university, he hardly spoke any Malay. "I lost touch with Malay. I had more Tamil friends and I spoke in Tamil more. In class we used English all the time. The subjects were taught in English" (Munesan, Transcript, Dec. 19, 2014). 
He managed with the help of his friends, with a lot of practice and after numerous rehearsals. He smiled as he related this to me. He shook his head in disbelief. "I used to be good in Malay, you know" (Munesan, Transcript, Dec. 19, 2014).

\section{I became good in Malay at secondary school}

Then he started reflecting on how good he was in Malay while at secondary school. Things were different at secondary school. Malay was the "number one" (Munesan, Transcript, Dec.19, 2014) language that he used. He told me that he had a good relationship with his Malay school mates. I was interested in finding out how this happened. It all began in Form One when he found himself surrounded by Malay students except for another Tamil boy. So he found himself talking more in Malay and less in Tamil. This endeared him to his Malay friends. "The Malay students were very happy when I spoke in Malay to them" (Munesan, Transcript, Dec. 19, 2014). He chose not to speak in Tamil in class, even to his Tamil friend. He informed me that the Malay students were sometimes very unhappy when we spoke in Tamil with them around as they were suspicious that "we (the Tamil students) are saying something bad about them" (Munesan, Transcript, Dec. 19, 2014). So he decided to speak either in Malay or English. This was the reason why he was able to build a good relationship with the Malay students. "We cooperated very well together. There was no problem at all.”(Munesan, Transcript, Dec. 19, 2014). When he was in Form Five there were four Tamil boys in his class and they sometimes spoke in Tamil. His Malay classmates did not mind this. They often asked him to translate their conversation into Malay or English. "We got along fine and it was never an issue. I really enjoyed and had fun with my form five classmates” (Munesan, Transcript, Dec. 19, 2014).

During this time he formed a close relationship with his Malay classmates and they knew he was proficient in English and Malay, so they did not really mind if he spoke in Tamil occasionally. In fact, they admired him for being fluent in three languages.

\section{Moments of English}

I asked him about the occasions he had spoken in English to his Malay friends. He told me that from Form One to Form Four, he used to speak in Malay to them. However in Form Five, he used more English. The reason was in Form Five the students were 
ranked according to their academic performances in Form Four. The top scorers were placed together. He found himself in the top class together with other Malay students who had done well. He told me that these Malay students preferred to converse in English. There were four other Tamil students in his class and all of them chose to speak in English although they had come from Tamil primary school. He hardly ever spoke in Tamil in class. He spoke Tamil during break time and also during Tamil cultural events which were organized by the Tamil society. Otherwise he spoke in English or Malay as he was always in the company of his Malay school mates.

\section{The struggling years}

Munesan told me that it was not always an enjoyable secondary school life. His happy memories were marred by the first two years. "I suffered a lot during my first and second year" (Munesan, Transcript, Dec. 19, 2014). He found it difficult to adjust to the new environment as he had been immersed in Tamil for six years. The subjects were now taught in Malay and English. It was tough especially during the English class as he did not understand some of the things his English teacher said. He told me that in the beginning his English grades were poor. He was so frustrated because he was unable to communicate with his teacher in English and asked for help.

Some Tamil friends (THLU-Ms) helped him a lot. His Tamil friends explained in Tamil if Munesan did not understand what was being said in English. Munesan used to convey his doubts in Tamil to his friend who then translated this into English to the teacher. That was when he decided to improve his English because "this translation was taking too much time" (Muneasn, Transcript, Dec. 19, 2014). He went for English and Malay tuition. By the time he was in Form Three, he was able to converse reasonably well in both these languages. He improved his Malay by "hanging out" (Munesan, Transcript, Dec.19, 2014), with his Malay friends in school.

His proudest moment was when he represented his school at a national drama competition in English and was awarded the best actor for the role he portrayed as 'the phantom' in the 'Phantom of the Opera'.

\section{Help from home}

Munesan informed me that his father motivated him to use English more even though the language spoken at home was Tamil. His father was aware of the importance of 
English as he had come from an English medium school. So he bought a lot of reading materials in English. "My father insisted that I read the English newspaper daily. He subscribed to The Star (an English local newspaper)" (Munesan, Transcript, Dec.19, 2014). In fact, when he was in a "serious mood", Munesan had to talk to him in English. His father became serious when he was discussing topics centering on politics, education and world affairs.

Another person who motivated him to speak in English was his sister-in-law. She reminded him that if he wanted to continue his studies in a university, he needed to be proficient in English. "Every time we met, I had to speak in English" (Munesan, Transcript, Dec. 19, 2014). In addition, he also spoke in English to his elder siblings who had gone to national primary and secondary schools. Therefore he told me that he had ample opportunities to practise speaking English at home.

\section{Why then Tamil primary school?}

I was interested to know why his father had sent him to a Tamil primary school when the rest of his siblings had gone to national primary schools. He told me that his third brother had gone to a Tamil primary school and had done well academically compared to his two elder brothers. He achieved better scores in UPSR, PMR and SPM. So Munesan being the youngest was sent to Tamil primary school. His father felt that the teachers at Tamil primary schools were more dedicated and concerned than those at national primary schools.

\section{She was so harsh}

Once he got into trouble for speaking in Tamil. He was reprimanded by the teachers. He told me he did not mind being scolded because the teachers also scolded the Chinese students for speaking in Mandarin. The teachers reminded them that they were no longer in Tamil or Chinese schools. However, he felt embarrassed and upset when one of the teachers asked him and his Tamil friends to disperse. "Do you think this is an MIC meeting? (Munesan, Transcript, Dec.19, 2014). MIC is the acronym for Malaysian Indian Congress which is one of the coalition partners of United Front which is the ruling party in Malaysia. He told me that this remark was uncalled for as he felt that the Tamils were being associated with a political party. He found this to be distasteful. 
“There was no need for this. She could have just told us to break off" (Munesan, Transcript, Dec.19, 2014).

\section{A family outing}

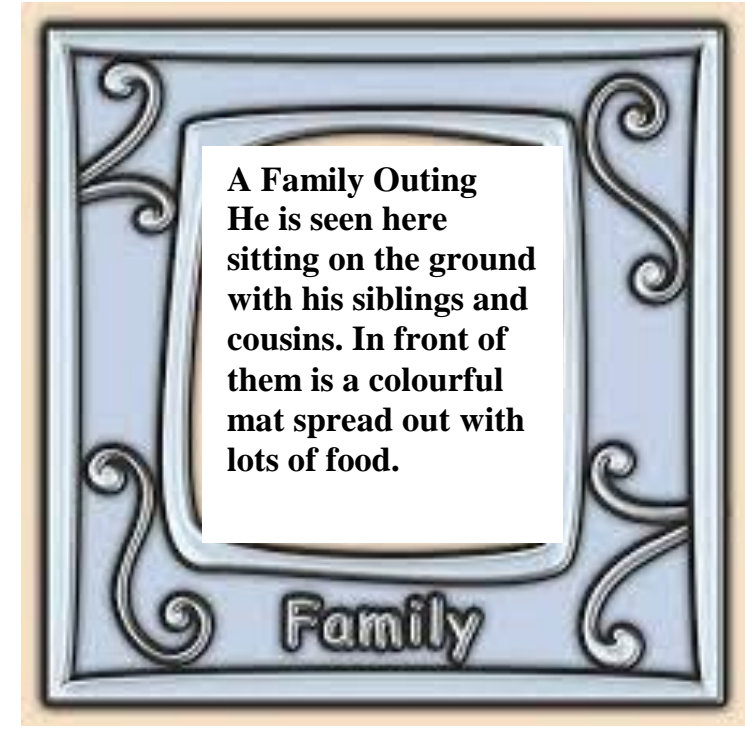

Figure 15. Photograph of family outing.

He told me how he enjoyed himself on a family outing to a popular hill station in Malaysia. It was a time of joy and laughter spending time relaxing with "your loved ones" (Munesan, Transcript, Dec. 19, 2014). His happiness was intensified because "it was a time of great excitement speaking in Tamil” (Munesan, Transcript, Dec. 19, 2014). He treasured every moment because he could freely speak in Tamil. "I felt free. I was being myself” (Munesan, Transcript, Dec. 19, 2014).

He laughed when he related a funny incident that happened during this event. Munesan had a call from one of his Malay friends and he was responding to him in English. This spoilt the mood for his cousins as he was speaking in English for some time. "My cousins were quite upset I was speaking in English but they had no idea that I was speaking to a Malay friend. They started to mock me as I was on the phone for quite a while" (Munesan, Transcript, Dec.19, 2014).

Munesan told me that it gave him a lot of joy when he spoke in Tamil which was why he could understand why not all Tamils felt the same. The Malays and Chinese were not embarrassed to use their mother tongue; however the Tamils were hesitant to speak in Tamil. He noticed that most Tamils used English even when they spoke to another Tamil. He said that he often got upset when they replied in English although he 
had spoken to them in Tamil. He felt that one should be able to speak their mother tongue. He further added that he could not help but ask them (THLU-Ms) why they chose to speak in English. "They just smile and walk away", he told me. (Munesan, Transcript, Dec. 19, 2014). He reasoned that perhaps they felt that speaking in Tamil would affect their image negatively. They felt that since people looked down at them when they spoke in Tamil so this would lower their dignity.

\section{Oops, I made a blunder!}

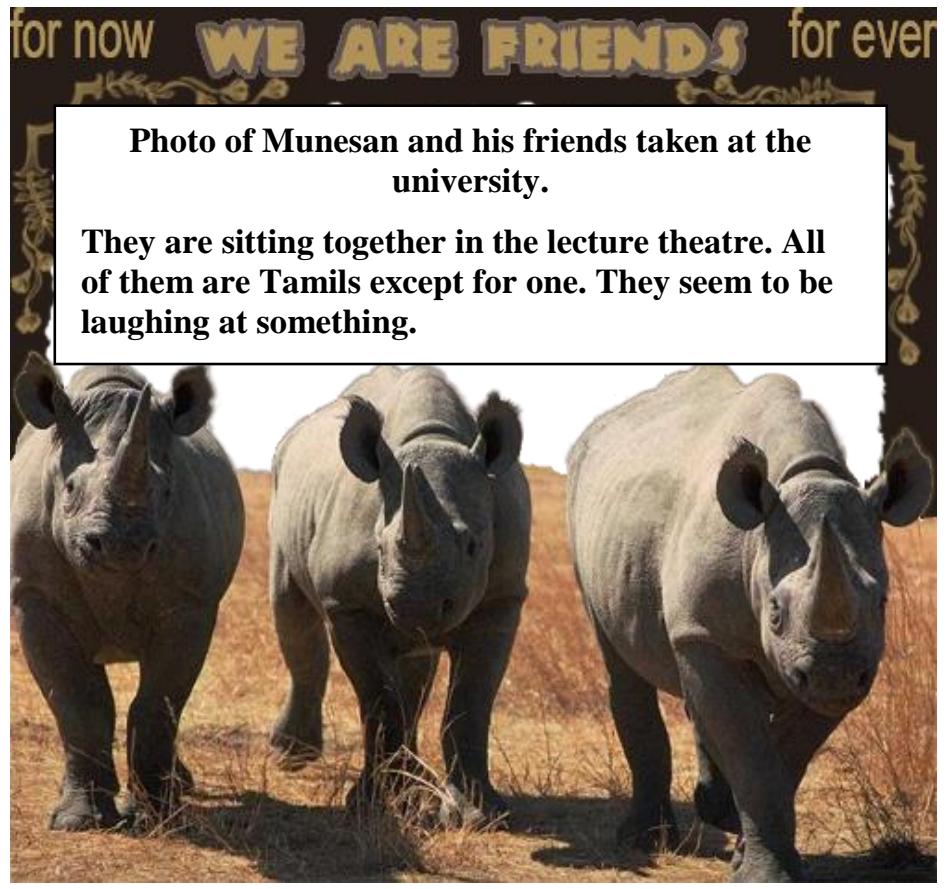

Figure 16. Photograph of Munesan and his friends taken at the university.

He showed me a photograph taken during the second semester at the university. It was during a sports day organised by the co- curriculum department. Munesan told me that he was in charge of the registration and the bowling competition. When he began the briefing the participants during registration, he told me that he used Tamil because the participants were all Tamils or so he thought. However, on second glance, suddenly he realised that there were a few Chinese and Malays. "I felt so embarrassed. I saw the agitated looks on their faces. I don't know what they thought of me then" (Munesan, Transcript, Dec. 19, 2014). He apologised and immediately switched to English. That was why he showed me this photo as a reminder to himself to be cautious to use English 
or Malay during formal occasions. He added that it did not matter if there were Tamils present during these occasions.

\section{There were two groups}

Munesan had observed that there were two groups of Tamils on the campus. The first group of Tamils loved to speak in Tamil when they met another Tamil. Naturally most of them came from Tamil primary school (THLU-Ts). However, there were a few who came from national primary schools (THLU-Ms). They (THLU-Ms) were interested in learning the language so they often hung out with him. He admired their motivation and determination to know their mother tongue.

On the other hand, there were many Tamils (THLU-Ms) who refused to speak in Tamil. They chose to speak in English even among themselves. When he spoke in Tamil, he noticed that they were uncomfortable and responded in English. "They don't mix much with us" (Munesan, Transcript, Dec. 19, 2014). However when he got into a conversation with them, he would speak in English because he thought it was not fair to make them feel stressed. "Why make things difficult? It's better to speak in English as everyone understands it” (Munesan, Transcript, Dec. 19, 2014).

He said that he had friends from both these groups. Though, he usually went out with the Tamil-speaking group (THLU-Ts). They normally spoke in Tamil outside the classroom like for example in the cafeteria. I asked him how people around him reacted when they saw his friends and him using Tamil. He replied that he was more concerned that they would label them (his friends and him) as noisy and loud. He was not bothered about what language they used.

Sometimes if he spoke in English to the Tamil speaking group, they made fun of him. "Hey, why have you become a "Peter" now?" (Munesan, Transcript, Dec. 19, 2014). So, he had to switch to Tamil as he did not want to offend them. He told me by now he could distinguish the two groups by the way they spoke. He had friends from both these groups. "I am flexible. I am comfortable with both groups" (Munean, Transcript, Dec. 19, 2014). He believed that he was able to adapt because of his fluency in both English and Tamil.

When he was explaining to me how easily he was able to adapt, he suddenly talked about his friend (a THLU-T) who spoke fluently in Tamil whenever they were alone. This friend would immediately switch to English if other Tamils were present. 
Munesan said that probably his friend wanted "to show off" that he, too, could speak English well. Furthermore, talking in English commanded more respect.

\section{Language status}

Munesan ranked the languages according to its importance of use especially in the campus and functionality in terms of career advancement. However, it was Tamil that brought him great pleasure. "I love listening to Tamil music, reading Tamil novels and watching Tamil movies and drama" (Munesan, Transcript, Dec. 19, 2014).

Next came English because of its function and wide use and lastly Malay. According to him Malay is not important now as compared to in secondary school. "There is hardly any need to use it now" (Munesan, Transcript, Dec. 19, 2014). 


\section{Suria's Story}

Suria was doing first year chemical engineering. He spoke confidently and expressed his views very clearly in English. He engaged certain issues during our interview sessions in a logical manner, supporting and justifying his views.

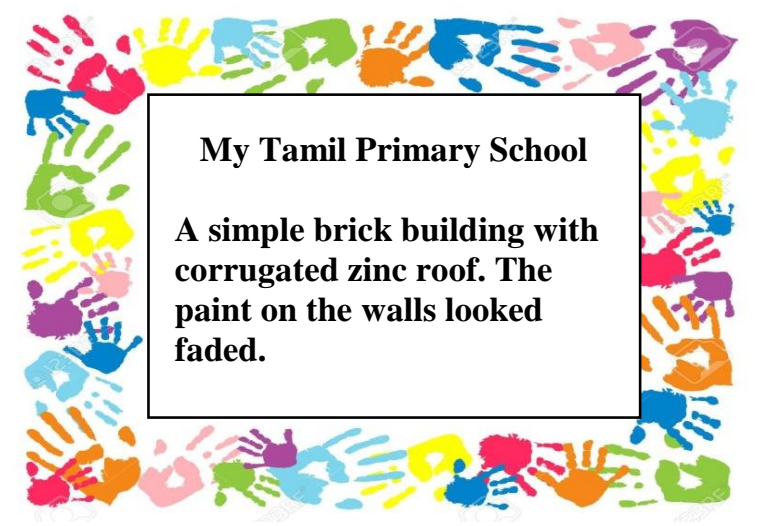

Figure 17. Photo of Suria's Tamil school

\section{Being loyal}

Suria told me that his father sent his younger brother and him to Tamil primary school to keep the language alive in the family. Since his two elder sisters had gone to national primary school, both his parents thought that "at least two of us need to study in Tamil school so that we will not forget our culture and our language" (Suria, Transcript, Dec. 10, 2014). He did this "out of loyalty to Tamil language" (Suria, Transcript, Dec. 10, 2014).

\section{The barrier}

Suria enjoyed his primary schooling days. He was a very active person and took part in lots of competitions representing his school. He participated in events like storytelling, drama, poem recitals, and debates and won many prizes. During these competitions he met Tamil students from national primary schools (THLU-Ms) and made friends with a few of them. Some of these boys lived in the same neighbourhood. He used to visit them in their homes and most of the time their conversation would be in English. Suria informed me that they came from English speaking homes so he was expected to speak in English as well. Although he spoke in English to them, he admitted that his fluency in English was not as good as theirs. However, he said he tried his level best. 
During the evenings, they used to spend their time together cycling in the park close by their housing area. There were also some Tamils from his Tamil primary school in this group (THLU-Ts). His Tamil primary school friends and he (THLU-Ts) used to feel offended because the other Tamil boys (THLU-Ms) always spoke in English. Whenever they met these boys in their homes, their parents also expected them to talk in English, "knowing that we came from Tamil school and it would be a bit hard for us, did not matter" (Suria, Transcript, Dec. 10, 2014). He felt that his Tamil school friends and he (THLU-Ts) were respected if they spoke in English. He used to wonder why they behaved in such a fashion. He confided in me that this friendship did not last. They soon stopped going out on their cycling rounds together with the Tamil boys from national primary schools (THLU-Ms). "We stopped cycling together because we did not enjoy their company" (Suria, Transcript, Dec. 10, 2014). Suria said a "barrier” (Suria, Transcript, Dec.10, 2014) existed between them. When I asked him what sort of a "barrier", he replied that those who spoke in English belonged to one group and those who spoke in Tamil belonged to another. There was not much communication between these two groups in their neighbourhood.

\section{Why the barrier?}

Suria explained that the reasons behind the existence of these two groups. He told me it was the fault of the parents. According to him parents overemphasised the importance of English at the expense of Tamil language. Parents were so concerned that their children become proficient in using English that they forced them to speak in English even at home. He said that most Tamil parents felt that if their children spoke in English others would perceive them as being smart. "If you speak in Tamil you are an average student" (Suria, Transcript, Dec. 10, 2014). He argued that knowing one's own mother tongue was equally important and it was the responsibility of parents to instill the love for Tamil. He also believed that teachers at Tamil school also had an important role to play. Tamil should not be seen as just another subject to be taught; instead teachers should strive to create a passion for this language by extolling its beauty and virtues. However, he felt that Tamil teachers were just interested in completing the syllabuses. 


\section{Well done!}

When discussing the role of teachers, Suria remembered two teachers who were responsible for his successful achievement in school. The first one was his teacher in Tamil primary school. According to him she laid the foundation for a strong proficiency in Tamil writing skills. It was this teacher who had helped him so much that he managed to do well. He called this a "miracle" (Suria, Transcript, Dec. 10, 2014).He spoke so fondly of her. "She taught me like a mother would. She pampered me with sweets and presents if I did well” (Suria, Transcript, Dec. 10, 2014).She instilled a reading habit by buying story books which had lovely, colourful pictures and read to him after class hours.

The second one was his English teacher in national secondary school by the name of Kamala (of Tamil descent). "She brought my English to a different level" (Suria, Transcript, Dec. 10, 2014). Suria proudly told me he scored A's for English in the PMR and SPM examinations. He owed his success to his English teacher. She trained him so well that he topped the class for English. Soon his classmates approached him for help if they had any problems in English. Suria informed me that his Malay friends approached him for help in Chemistry, Physics and Additional Math as these subjects were taught in English then. He also helped them improve their writing skills on argumentative topics in the MUET examination (Malaysian University English Test).

His confidence in English grew and he started taking part in both Malay and English debates, spelling competitions, poem recitals and essay writing competitions. He also held several responsible positions like the President of English Language Club, Student Disciplinary Head and a school prefect.

\section{Great English teachers}

He told me he was fortunate that he had Ms Kamala as his English teacher in national secondary school, and his Tamil primary school teacher. Both of them were not only responsible for his proficiency in Tamil and English but for also having contributed to his character development. "They taught me to be disciplined and hard-working" (Suria, Transcript, Dec. 10, 2014). Under their tutelage he found that success comes to those who never give up. He considered both of them mother-figures. "They took care of me like my own mother" (Suria, Transcript, Dec. 10, 2014). In addition, Ms Kamala was also concerned over the welfare of Tamil students in national secondary school. "She 
helped Tamil students a lot” (Suria, Transcript, Dec. 10, 2014). She monitored closely the behaviour of Tamil students in the school and was quick to reprimand any misbehavior.

\section{Help from dad}

Suria believed that in addition to the guidance of his teacher, his proficiency in English increased because he spoke in English to his father at home. Furthermore, two of his elder sisters had gone through national primary schools. He told me that his father used to check his English homework while he was in Form Five. He also checked on his conversation skills. Suria told me that he learnt to speak well because every weekend, he used to accompany his father to play badminton. During these moments they spoke in English because the rest of the players were Chinese. "So during these trips, I spoke in English to father's friends and also to their children" (Suria, Transcript, Dec. 10, 2014).

\section{My Malay and Chinese friends in national secondary school}

When Suria first came to national secondary school, he did not find it difficult to adapt to the new environment as he had many Tamil friends who had studied together with him at Tamil primary school. This was because his secondary school was located just opposite his Tamil primary school. For the first three years in secondary school he moved around with his Tamil friends and spoke mostly in Tamil. However, things changed in the fourth year.

Students were streamed according to their academic achievements in PMR and the subjects they took. His Tamil classmates were separated and he had more Malay and Chinese classmates. As a result, he hardly ever met his Tamil friends except outside class during break time. He started spending more time with his non- Tamil classmates and spoke mostly in Malay or English. He told me that he rarely used Tamil with the only Tamil student in his class. Thus his Tamil use decreased.

The rare moments when he spoke in Tamil in class were not frowned upon by his non-Tamil classmates. In fact, they were interested in learning Tamil. According to Suria, his classmates were very friendly and they even used to watch Tamil movies together. Although in the beginning whenever he spoke in Malay, he was teased by his Malay classmates because of his accent, he never felt offended. Slowly, his pronunciation improved because he was constantly speaking in Malay. 
He spoke English mostly with his Chinese classmates as his Malay classmates preferred talking in Malay. He told me that he did not want to offend his Malay friends by speaking in English as they were happy if he spoke in Malay to them. When I asked him why he thought his Malay friends preferred to use English, he replied that they were not used to speaking in English and that they were more comfortable using Malay. Since he was proficient in both English and Malay, he did not mind at all. He wisely asked, "Why talk in English and make their lives uncomfortable?"(Suria, Transcript, Dec. 10, 2014).

\section{The two groups again}

I was interested in finding out about his relationship with Tamil students who did not come from Tamil primary school (THLU-Ms). He said that although he spoke in Tamil to them they chose to reply in English even if they understood Tamil. So the two groups also existed here- the Tamil only group and the English only group. He informed me that he generally had little to do with those Tamils who came from national primary schools (THLU-Ms) and who chose to speak in English. "I was not interested in mixing with them" (Suria, Transcript, Dec. 10, 2014). These Tamil students also did not talk to him much. However, he offered his help if they approached him.

\section{I lost touch with Tamil}

While he was in national secondary school, Suria said that his Tamil proficiency decreased whereas proficiency in Malay and English increased. He only managed to get a $\mathrm{C}$ for Tamil language at PMR level. The reason was the school could not get a properly qualified teacher to teach Tamil. The teacher who taught them was not familiar with the PMR exam format as she was used to teaching Tamil for primary school students. Suria told me that his proficiency level dropped and so did his confidence level in Tamil. He was able to get a $\mathrm{C}$ because he went for Tamil private tuition and this was only available to him in Form Three. By then it was too late to catch up with the Form One and Two syllabuses. Most of his Tamil friends did not do well either. As a result, he was afraid to sit for Tamil at SPM level. He thought that his performance in Tamil might pull down his overall scores for SPM. So, he decided to drop Tamil as a subject even though his parents were not happy with his decision. They told him to go for private tuition again; however he was unwilling to follow their advice. Besides his 
former tuition teacher was no longer available. He told me that his poor performance in PMR had affected him badly.

\section{Birds of a feather flock together}

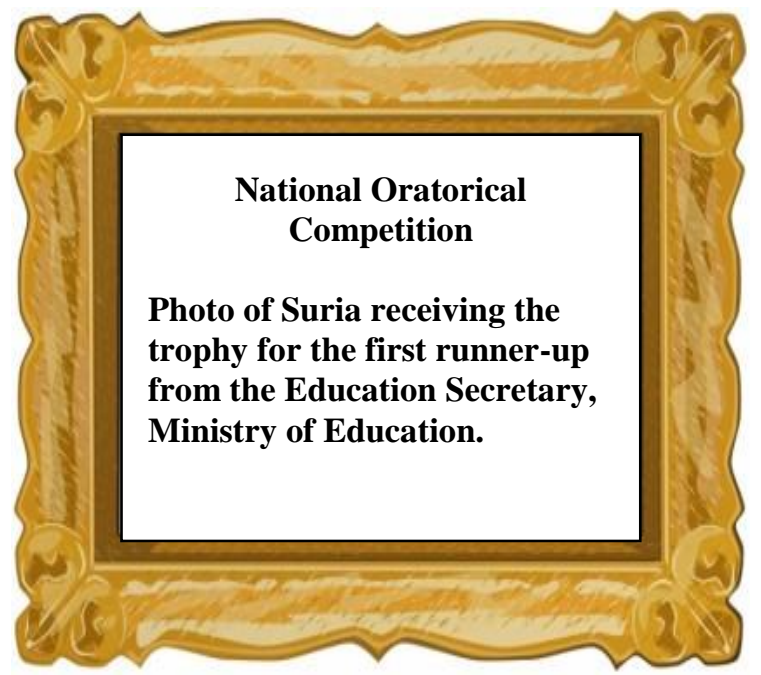

Figure 18. Photograph of Suria receiving trophy at National Oratorical Competition.

Suria recalled an event which took place while he was in secondary school. He called this "a motivating episode in [his] life" (Suria, Transcript, Dec. 10, 2014). He was selected to represent his college at a Malay oratorical competition at national level. He was trained well by his lecturer and received a lot of support from the academic staff. However, he told me that he was disappointed by the lack of support and motivation from his non-Tamil and THLU-Ms (from national primary schools). "They showed no interest at all" (Suria, Transcript, Dec. 10, 2014).

There were many contestants from the different schools throughout Malaysia and he was overwhelmed by all this so much so that his confidence was badly affected. However, he was greatly moved by the huge turnout of Tamil students (THLU-Ts) from his school. They boosted his self-confidence. "They cheered and applauded and I felt so good" (Suria, Transcript, Dec. 10, 2014). They were members of the Tamil Cultural Society at his school. He managed to become the first runner-up which was a great achievement being a non-Malay speaker. He received tough competition from excellent Malay speakers. After this event, he informed me that the bond among the Tamils (THLU-Ts) in the school became strong. "We were united as Tamils" (Suria, Transcript, Dec. 10, 2014). 


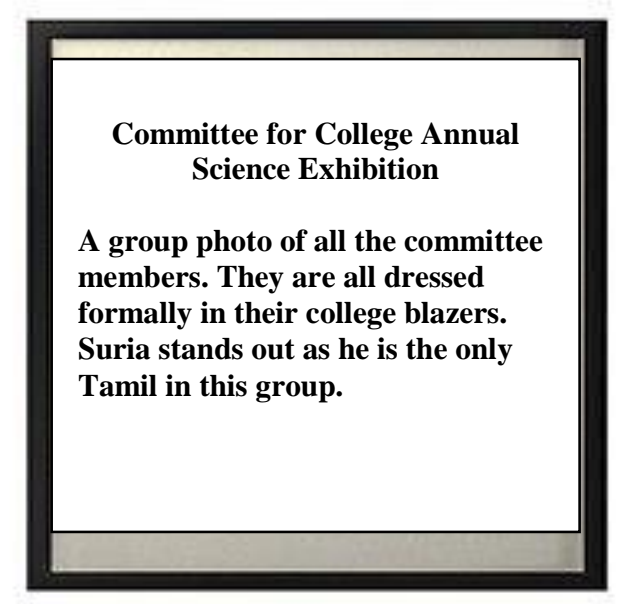

Figure 19. Group photograph of Committee for College Annual Science Exhibition.

Another event that brought together all the Tamils (THLUs) in the school was during the College Annual Science Exhibition. Suria was the Event Manager of the exhibition. He informed me that it was difficult to work together with the organising committee for this event. He was the only Tamil and so did not receive much support from the non-Tamil committee members. "They were not committed because I was a Tamil. Most are Chinese. When I conducted the event they didn't give much cooperation" (Suria, Transcript, Dec. 10, 2014). He was frustrated and almost wanted to give up and this was when, once again, he found help and support from his Tamil friends who came from Tamil school (THLU-Ts). They were not even on the committee, he told me. They helped him a lot even to the extent of decorating the hall, going out with him to look for sponsorship and helping him to get the science equipment needed to conduct experiments. "I was in tears and cried after the event was over" (Suria, Transcript, Dec. $10,2014)$. He told me the event would not have been a success if the THLU-Ts in his school had not come to his rescue.

I asked him why the committee members did not help him out. "Probably I was not a Chinese" (Suria, Transcript, Dec. 10, 2014). He felt that it would have been different had he been a Chinese. They hardly got involved at all and left him to manage alone. He could not control his emotions when the Head of School for Science patted him on the back for a job well done. "I excused myself and went out to cry. They were tears of joy, you know" (Suria, Transcript, Dec. 10, 2014).

Suria told me how lonely and isolated he felt when he first came to the college to do his STPM (Higher School Certificate). "I felt lost among my non-Tamil and Tamils 
who came from national schools (THLU-Ms). They were talking in either Malay or English in class" (Suria, Transcript, Dec. 10, 2014). They hardly ever mixed with the Tamils from Tamil schools (THLU-Ts). Then, when more THLU-Ts started coming to his class, he felt better. "We (Tamil students) sat together and started talking in Tamil" (Suria, Transcript, Dec. 10, 2014). He was comforted by the strength in numbers. They celebrated birthdays together, helped each other if problems arose. Thus, a "special bond" existed among them. Some of his Tamil friends from national primary schools (THLU-Ms) also started talking in Tamil and respect grew between these two groups of Tamils (THLU-Ts and THLU-Ms). "I guess we had no choice but to group together as we were a minority" (Suria, Transcript, Dec. 10, 2014).

\section{A different world}

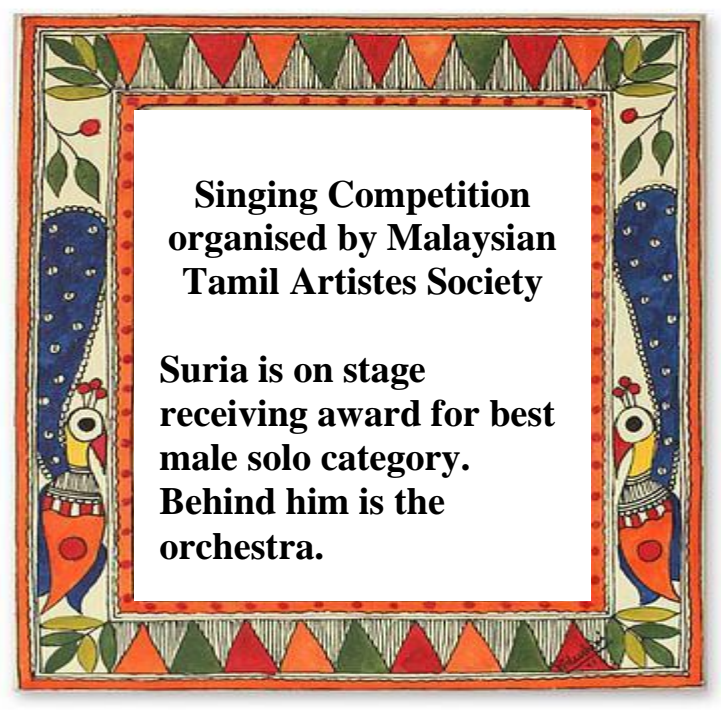

Figure 20. Photograph of Suria receiving award at a singing competition organized by Malaysian Tamil Artistes Society

Suria narrated to me an interesting event which took place just before he came to the university. He had taken part in a singing competition organised by Malaysian Tamil Artistes Society. He told me since young he had been singing "bhajans" (Hindu religious worship songs) and as he became older he was interested in singing Tamil cinema songs. So he grabbed the opportunity when it came to showcase his singing talent. Sure enough, he beat ten other opponents after a few rounds to grab the first spot. There was so much pride and joy in his face and voice when he told me this. 
He told me he was completely immersed in a beautiful and exciting world of Tamil. Everyone around him was speaking in Tamil. People were singing Tamil songs to Tamil music played by a professional orchestra. At this point, Tamil seemed so important to him. "I didn't want this experience to end".

This event reignited his love for Tamil. He admitted that after Form Three in national secondary school, his proficiency in Tamil had dropped. In his own words, "I lost the touch I had for Tamil" (Suria, Transcript, Dec. 10, 2014). This was because he had dropped Tamil as a subject at SPM and STPM (Higher School Certificate). During his time at the competition he was trained in Tamil pronunciation. The meaning of the song lyrics were also explained so that he would be able to express the feelings the lyricist wanted to convey to the audience. He told me that the competition impacted him greatly. "I was exposed to pure and classical Tamil" (Suria, Transcript, Dec. 10, 2014).

\section{It was English at the university}

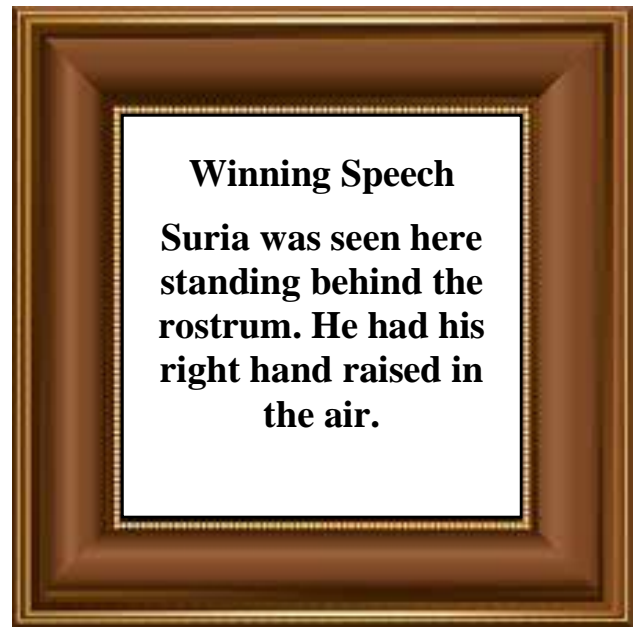

Figure 21. Photograph of Suria making his winning speech.

Suria showed me some photos taken during election campaign for Student Head. In this photo he was seen addressing the student body after winning the election. He informed me that at the university he used a lot of English and Tamil. Though he spoke in Tamil to his Tamil friends, in his official capacity as the Student Head, he used English during official functions. From here, he slowly started to talk to me about his life in campus. 


\section{The divide-revisited}

Suria told me that even in campus there were two groups of Tamils (the THLU-Ts and THLU-Ms). The former spoke in Tamil most of the time while the latter hardly spoke any. I asked him how one would distinguish these two groups besides the language they used. He told me that "the English only group" was easily identifiable because they were the "out-going type" (Suria, Transcript, Dec. 10, 2014). I asked him to explain what he meant. According to him, they were more "sociable" and often loved "partying and drinking" (Suria, Transcript, Dec. 10, 2014). He felt that speaking English "gives them more freedom". They hardly associated themselves with the Tamil-only group. They often looked down at students who spoke in Tamil because they felt it was not fashionable to use Tamil in public.

On the other hand, the Tamil only group did not like to mix much with the English only group because of the former's attitude and outlook towards life. "We are not used to this kind of life style. There are boundaries that we should not cross. We speak English too, but we know what's decency. Like respecting elders and knowing how to behave in public" (Suria, Transcript, Dec. 10, 2014).

So, Suria spoke in Tamil more in the university compared to when he was in secondary school. He told me that sometimes when he spoke in English to his Tamil friends in the university from Tamil primary school (THLU-Ms) he got ticked off. They were not happy about it. He received remarks like "you eat lentil curry, don't you, why the need to speak in English?" (Suria, Transcript, Dec. 10, 2014).

They used English if they had any doubts regarding their lectures. So English was used for academic purposes and Tamil was used for social purposes.

\section{Some blurred lines}

Though most Tamils fell into these two groups in the campus, there were some (THLUMs) who had learnt to speak in Tamil although they came from national primary schools. He told me that they adapted themselves well and often talked in Tamil to him. They were willing to learn and showed interest in acquiring proficiency in their heritage language. He had respect for them.

He gave an example. A course-mate of his could not speak in Tamil when she first came to campus. However, she could now speak, read and write in Tamil reasonably well because of Suria and his friends. He was quite proud of this. "She was 
willing to learn and so we took turns to teach“(Suria, Transcript, Dec. 10, 2014).

Another friend of his who did not come from Tamil primary school also showed interest in speaking Tamil and so hung out with him and his friends and had picked up a lot of Tamil words. She was especially interested in Tamil cinema songs because of the catchy tunes. She often asked him the meaning of the lyrics and so in the process was exposed to Tamil vocabulary. Suria had many friends like this who often went out with the Tamil-only group to watch Tamil movies. He said it was good to see Tamils showing an interest and getting to know their mother tongue.

Suria felt that some of his course mates had realised that it was important for Tamils to stick together, because "being a Tamil, we can depend on one another, should a problem crop up" (Suria, Transcript, Dec. 10, 2014).

\section{Which language to use?}

English was spoken in the classroom as lectures were conducted in English. However, sometimes during group discussions some of his Tamil friends used Tamil. Suria had often heard remarks like "Stop being a racist"(Suria, Transcript, Dec. 10, 2014) from the Chinese and Malay course mates whenever they overheard them talking in Tamil. He was quite aware that his non- Tamil course mates were offended whenever his Tamil friends spoke in Tamil in class. So he stopped his friends and insisted that they should speak in English so that everyone understood. Sometimes he even translated what was being said into English so that the others who did not understand Tamil would know.

Whenever he went out with his friends, he made sure that they used a language that everyone was comfortable with. In the company of Tamil friends who spoke Tamil, he used Tamil. If there were Chinese or Malays present he switched either to English or Malay depending on whichever was convenient to the other person.

Suria felt that "mutual respect" (Suria, Transcript, Dec. 10, 2014) was important when deciding which language to use. He told me that just because he came from a Tamil primary school, he could not expect every Tamil he met to speak in Tamil as they might have attended national primary schools. At the same time, the other party (THLU-Ms) should also realise that he did not come from national school, so it would be more likely that he would be using Tamil more. He added that problems could be avoided if both parties (THLU-Ts and THLU-Ms) understood the language backgrounds they were coming from. "Then no one will feel hurt" (Suria, Transcript, Dec. 10, 2014). 


\section{It takes time}

It was a long process getting readjusted to a new language environment. When he had to switch for the first time from Tamil to Malay in national secondary school and then to English in the university, he said it was like "a culture shock" (Suria, Transcript, Dec. 10, 2014). He felt alienated, lonely and lost. This feeling went on for some time. So for the first few months he would not talk much, remained quiet and kept to himself. Then, he started to look out for Tamil friends and moved around with the Tamil speaking group. Later on he needed to make new friends from other racial groups as his Tamil friends were not in the same class with him anymore. To avoid being lonely he told me that he started speaking in English or Malay. When he was doing his STPM, most of his classmates were Chinese. He had no choice but to speak in English. He felt that "there was no point being isolated just because of language. If "English can break barriers and bring more friends", he was willing to use it. (Suria, Transcript, Dec. 10, 2014). It took time to adapt but he was glad now as he had many good Chinese and Malay friends too. 


\section{Thinesan's Story}

Thinesan was a quiet young man who spoke softly. At first, he appeared to be hesitant and unsure. However, he slowly opened up when I assured him that he can express his thoughts and feelings without fear. I stressed on maintaining confidentiality.

\section{Never give up on Tamil}

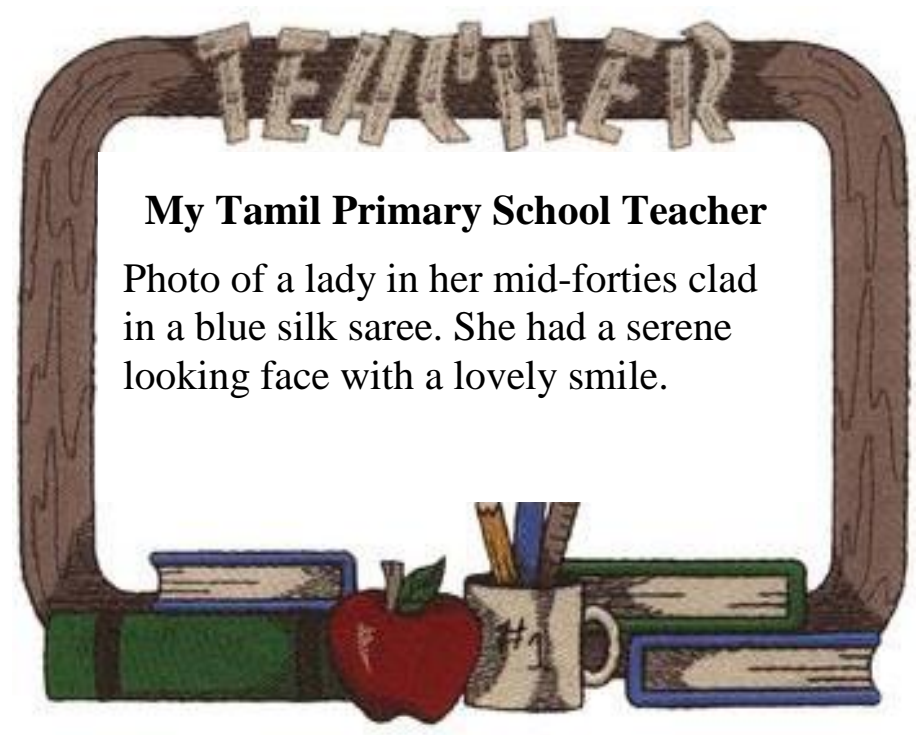

Figure 22. Photograph of Thinesan's Tamil primary school teacher.

As Thinesan held the photo in his hands and started describing his teacher whom he called "my Mother Tamil” (Tamil Tāy) (Thinesan, Transcript, Dec.10, 2014), there was so much awe and respect in his voice. "Mother Tamil", is a personification of the Tamil language. In Tamil culture, the intimacy between the language and its speakers is that of a bond between a child and its mother. Tamilttāy is looked upon, as their mother who gave birth to them and raised them to be loyal and devoted Tamil speakers.

Thinesan was inspired to increase his knowledge in Tamil because of her. "I still remember her for her concern, care and love for Tamil which inspired me" (Thinesan, Transcript, Dec.10, 2014). He informed me that although he spoke Tamil at home and both his parents came from Tamil primary school, yet it was this teacher who instilled the love for Tamil language. "She was like a mother to me" (Thinesan, Transcript, Dec.10, 2014). According to him she was the only one in the school who spoke Tamil flawlessly. "She never used Malay or English words while speaking in Tamil like the 
other teachers. "It was so pure" (Thinesan, Transcript, Dec.10, 2014). He told me he had yet to come across someone like her. A lot of teachers had come and gone but she still remained in his memory. She insisted that he should not give up learning Tamil even in secondary school. He had heeded her advice to continue learning Tamil.

He told me that he still read a lot in Tamil even after coming to the university: "I just came from the library where I was reading some Tamil newspapers" (Thinesan, Transcript, Dec.10, 2014). He read novels and short stories in Tamil by famous Tamil authors. Besides, he took a keen interest in knowing the history and latest developments in Tamil language. "This helps me to keep in touch with Tamil" (Thinesan, Transcript, Dec.10, 2014). He was proud to use his heritage language in public areas knowing that Tamil is one of the oldest languages. He was grateful to both his parents for having made the choice to send him to Tamil primary school and to his teacher for inspiring him to love the language and appreciate its beauty.

\section{For the love of Tamil}

Thinesan said he loved to speak in Tamil whenever he met another Tamil. This was why I realised that although he began speaking in English, he often crept back to Tamil. I was a Tamil. Once he realised that he was speaking in Tamil, he quickly reverted back to English as the interview was conducted in English. He added that he always responded in Tamil even though they (Tamil speakers) spoke in English. I asked him if they did not speak Tamil, then would he choose to respond in English. He cut me short by saying, “They are Tamils, aren't they?” (Thinesan, Transcript, Dec.10, 2014). All his Tamil friends could converse well in Tamil and some of them did not even come from Tamil primary school. However, they were united by their love for Tamil. In fact, he admired Tamils who took the trouble to speak their mother tongue although they had never formally learnt the language. At this juncture he recalled what his Tamil teacher had told him. Since it is not compulsory to enrol Tamil kids in Tamil primary school, how could one keep the language alive? For the language to thrive, Tamils must speak in Tamil to one another. "If not the language will be lost" (Thinesan, Transcript, Dec.10, 2014). To emphasise this fact, he drew an analogy.

Just like an English man who speaks English which is his mother tongue, so we Tamils should speak in our mother tongue also. You can't expect the English man to 
speak Tamil, only a Tamil can speak Tamil. But if a Tamil chooses to speak in English, how do you think the language can survive? (Thinesan, Transcript, Dec.10, 2014)

\section{A different opinion}

However, he realised that there were people who still think that learning Tamil was a waste of time. He had no time for people like this and refused to be associated with them. At this point, he recalled one of his relatives who had a very poor opinion of Tamil primary school. He had sent all his children to national primary school, even though there was a Tamil primary school nearby. When asked why, he (Thinesan's relative) explained that Tamil schools lagged behind national schools in terms of academic performance of the students. Education was of poor quality and that there was a lack of care and concern shown towards students' academic performances. In addition, he commented that the male students from Tamil primary schools often misbehaved and caused a lot of disciplinary problems when they entered national secondary schools. However, Thinesan did not think this was true. There were lots of boys from Tamil primary school who had made it to the university. These boys had done well in both Tamil primary and secondary schools.

He told me that based on his own experiences there was no constant supervision or guidance in national secondary school unlike Tamil primary school. He said he had more freedom in national secondary school compared to Tamil primary school. He was taught to be disciplined and hardworking in Tamil primary school. "I was afraid of being reprimanded if I did not attend class". To illustrate how concerned his Tamil primary school teachers were, he said that even though UPSR was not an important public examination as compared to SPM, they received intensive training so that they would be well prepared. He said that there was no such motivation at national secondary school. "I did not receive such care and attention in secondary school. Yet I managed to perform well. How come, I thought to myself? Was it because of the previous training given by my Tamil school teachers?” (Thinesan, Transcript, Dec .10, 2014) 


\section{Becoming proficient in Malay}

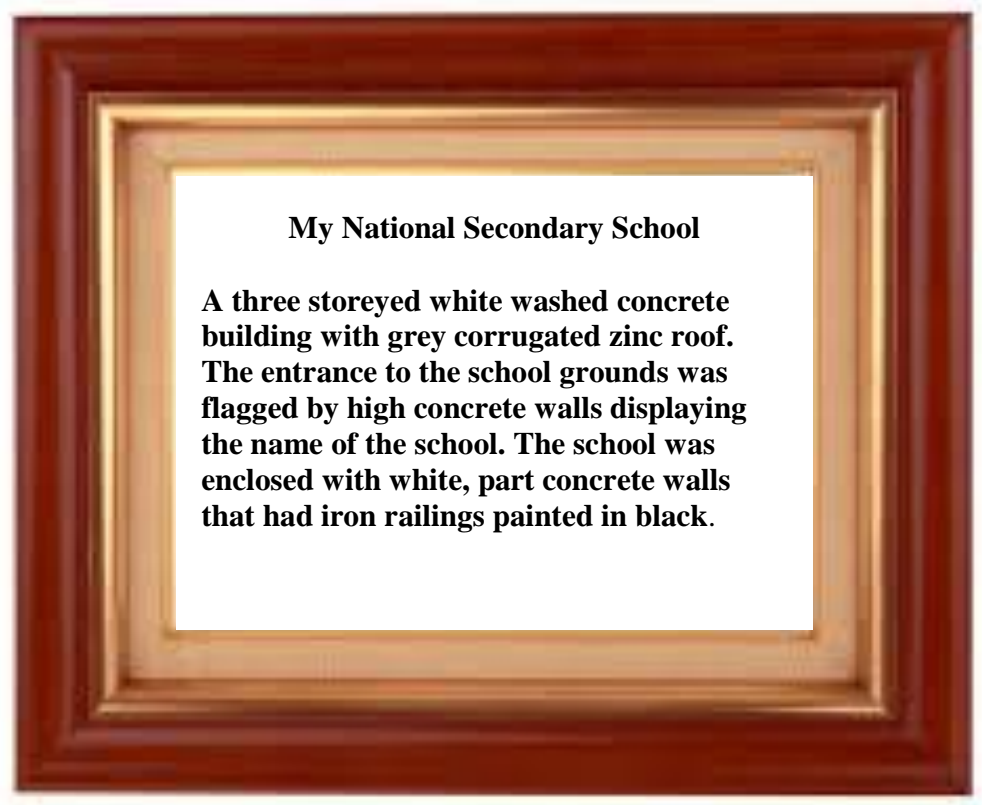

Figure 23. Photograph of Thinesan's national secondary school.

Thinesan told me that this was where he started picking up Malay. It was a challenge for him, having come from a Tamil medium school. He was not used to having Malay and Chinese school mates. At first he mixed with Tamil students who had come from Tamil primary school only. However, he soon made friends with students from other races. In particular, he spoke of a Malay friend by the name of Helmi who helped him a lot to polish up his conversation skills in Malay language.

He agreed that in the beginning he had a few problems adjusting to the new environment but confessed they were nothing serious. There were times when he was teased by his Malay friends for having used the wrong word or for mispronouncing. However he informed me it was done light-heartedly. "I did not feel offended. They did not mean any harm." (Thinesan, Transcript, Dec. 10, 2014). He told me that he wanted to learn new words and improve his pronunciation thus he was not affected much.

As time progressed he became better in spoken Malay because he spoke more in Malay now with his Malay friends in secondary school. "I used to observe them and started to speak better" (Thinesan, Transcript, Dec.10, 2014). In the beginning he had a few friends, but later on, when he became more competent in Malay, he had no problem mixing with the others. "I had good friends from other races" (Thinesan, Transcript, Dec. 10, 2014). 
When he first came to secondary school, he was weak in both Malay and English. He did not score A's in either of these subjects in UPSR and PMR. To highlight how much progress he had made in Malay, he informed me that he managed to score an A at SPM level. There were a few reasons for his success. Firstly, his hard work, secondly he felt that it was easier to learn Malay when compared to Tamil or English. Thirdly, he mentioned that his Malay teachers were struggling to teach Math and Science in English. This was the year when there was a change in language policy, where Math and Science were taught for the first time in English. He realized that struggles were not new to him alone. Even teachers can face problems struggling to become competent in a language that they are not familiar with. "They found it difficult to explain concepts in English. I was not alone" (Thinesan, Transcript, Dec. 10, 2014).

\section{English everywhere}

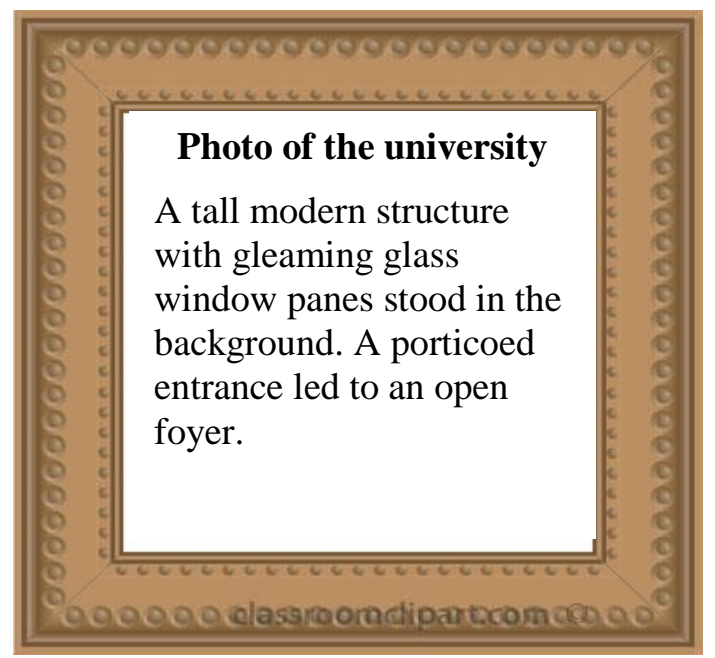

Figure 24. Photograph of the university where Thinesan was enrolled.

Thinesan told me that when he first entered the university, he was shocked to find everyone talking in English including the security guards. What amazed him even more was the fact that Malays were also conversing fluently in English. At secondary school, the Malays were reluctant to speak in English; they always used Malay with the rest of the students. "I had this perception that Malays were not fluent in English" (Thinesan, Transcript, Dec. 10, 2014). He had to revise his opinion after this. He was impressed by a Malay lecturer who spoke English with a near native-like proficiency.

He was so afraid at first, wondering whether he could cope in this new English environment. He felt very uncomfortable because he was aware that his English 
proficiency level was low. He told me that most of the Tamil boys were also able to speak fluently in English. The first thought that came to his head was to quit. However, he told me he stayed on because his father had paid up the tuition fees. "I was determined to make it. I had no choice" (Thinesan, Transcript, Dec. 10, 2014).

In the beginning he struggled a lot but he told me that his friends were very helpful so he did not feel embarrassed. He told me that it would have been different had he been in secondary school. He recalled an instance when some Chinese students had given him and his friends disapproving looks when they were speaking in Tamil. However, he had a lot of support from his non-Tamil friends at university, who according to him were very friendly and approachable. He felt that the students in the university were perhaps more mature as they were older. They were not offended if he spoke in Tamil to his Tamil friends. He improved his speaking skills by conversing with non-Tamil friends. "I became better conversing daily in English. This is the place where my English improved" (Thinesan, Transcript, Dec.10, 2014). In addition, he improved his speaking skills through social media. Facebook and Whats App helped him to make use of expressions and commonly used phrases when talking to people. "I used short phrases to aid me in spoken English" (Thinesan, Transcript, Dec. 10, 2014). He wrote these expressions down and learnt to use them in conversations. He turned to his friends for help when he had problems constructing sentences in English. Sometimes he translated the sentences into Tamil and tried to gauge the meaning so that he could understand. He checked this out with his friends.

He told me that he loved the environment in the campus now because he could now talk both in English and Tamil. He was happy that his English proficiency has improved compared to before. He attributed part of this success to the internet. He often surfed for articles to complete his assignments and projects. These were all done in English. He was more confident when talking to his lecturers. He used to be very quiet in class before as he had problems communicating in English. So, even when he had doubts he was afraid to approach his lecturers. However he felt good at this point of time because he was able to voice his problems in English. "I have become braver, because I like the atmosphere here and feel free" (Thinesan, Transcript, Dec. 10, 2014).

He gave two examples that attested to his improved English proficiency. The first one was when he did a presentation in English. After the presentation his lecturer 
commented that his presentation skills had improved tremendously. The second episode was when his parents praised him for speaking completely in English over the phone to his university friend. Thinesan informed me that before this he had hardly ever spoken in English. Both his parents and siblings always spoke in Tamil at home.

He also found that he was using more English now. Recently he went on a holiday to Langkawi and to his surprise found himself talking in English to the hotel staff and tour operator "just like a tourist" (he smiled) (Thinesan, Transcript, Dec. 10, 2014). Even when he was talking to his Tamil friends, he found that some of his sentences in Tamil were interspersed with some English words. Now that he was in the university, he found no necessity to use Malay.

\section{Tamil is still close to my heart}

Although Thinesan felt good speaking in English, yet, his love for Tamil has never diminished. He said that if he saw any Tamil he would still use Tamil first. "Tamil is in my blood. I was born with it" (Thinesan, Transcript, Dec. 10, 2014). He felt that his proficiency in English was not as good as in Tamil because Tamil had become a part of him. He was exposed to Tamil since birth, so it was only natural for him to be better in it. However it was different with the other languages (Malay and English). He told me that he learnt these languages (Malay and English) "in stages" (Thinesan, Transcript, Dec.10, 2014). He became proficient in Malay while in secondary school and in English at university. Perhaps that was why according to him he was still improving his English proficiency as it was the latest language addition to his multilingual proficiency. 


\section{Vimal's story}

Vimal was a quiet and soft- spoken young man. He studied chemical engineering at the university. He seemed rather embarrassed talking of his language experiences at secondary school especially regarding class presentations in Malay and English.

\section{Transition period}

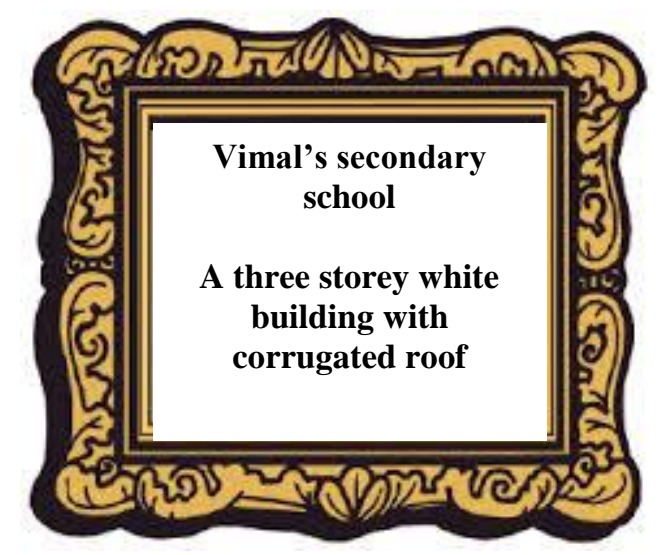

Figure 25. Photograph of Vimal's secondary school.

Vimal was a 20 year old male undergraduate from the School of Chemical Engineering. The first photo he showed me was of his secondary school. After having spent six years in a Tamil primary school, going into the national secondary school was

a different and difficult experience for him because he was going to "a new environment where there were Malays and Chinese students" (Vimal, Transcript, Dec. 19, 2014). While he was in Tamil primary school, his classmates were all Tamils and they would speak in Tamil. He told me that there was no problem communicating as they would all be speaking in Tamil which was their mother tongue. However, this was not so in the national secondary school. He informed me that he got into some problems as he could not adapt to the Malay culture which was the dominant culture in the national secondary school and the majority of his school mates were Malays. "I couldn't adapt to their (Malay) culture" (Vimal, Transcript, Dec. 19, 2014).

\section{Problems faced at national secondary school}

Then he started telling me the problems he faced initially at national secondary school. He found language to be the main barrier. It was difficult for him to switch from Tamil to Malay. As all his classmates spoke in Malay, he found it difficult to communicate 
with them. He was so used to speaking in Tamil both at home and with his Tamil friends. As a result, he claimed that he was not fluent in Malay as he lacked exposure to using Malay. "My Malay was weak as I did not have enough opportunity to use Malay" (Vimal, Transcript, Dec.19, 2014).

Due to his low proficiency level in Malay he was not able to cope with his lessons as the medium of instruction was in Malay. He told me that he could not understand his teachers and performed badly especially during oral presentations. "Because I was weak in Malay, I used to stammer a bit and that made everyone laugh. I was so embarrassed. I was always afraid of having to go up to the front of the class to answer questions or do some activities" (Vimal, Transcript, Dec. 19, 2014).

He shared with me that even now, at university, he was still afraid of making presentations in front of the class because he remembered being teased and laughed at when he made mistakes speaking in Malay at secondary school. The idea of standing in front of the class evoked a lot of bad memories for him. "It's not just the language also just standing in front of the class is fearful because of the bad experience in secondary school. I have the same problem here in university" (Vimal, Transcript, Dec. 19, 2014). He related to me an incident which happened in semester one at the university. He was so afraid to present that he walked out of the lecture theatre and did not come back. Later his lecturer reprimanded him and advised him to practise his presentation skills as this was important if he wanted to have a successful career later on. When I asked him how his oral presentation skills were now, he told me that he has made a lot of improvement. He realised that he had to do it whether he liked it or not. Furthermore, it was less stressful because he had come to know most of his course mates.

\section{Reaction from his classmates at national secondary school}

Vimal informed me that most of his negative experiences were while he was studying in national secondary school especially during the first three years of his secondary school life. He told me that he "struggled a lot" (Vimal, Transcript, Dec. 19, 2014). When I asked him to explain his struggles, he told me that firstly it was his heritage language use (Tamil). Whenever he spoke in Tamil to his Tamil friends, some of his Malay and Chinese classmates would mimic some of the Tamil words spoken by them to poke fun and tease them. This made him feel embarrassed as his non-Tamil classmates did it in front of everybody else. He said he would not have minded if the non -Tamil classmates 
had teased them (his Tamil friends and him) privately. So I asked him how he coped with this problem. His reply was they would speak in Tamil softly in class so that the rest of his non -Tamil friends would not hear. "Now we speak softly and also look around first to make sure it is safe to speak in Tamil" (Vimal, Transcript, Dec. 19, 2014).

Secondly, he had to get used to speaking in Malay as there were only one or two Tamils in his class. The majority of his classmates were Malays. He told me that it was difficult in the beginning. He had to learn to communicate in an unfamiliar language. To make matters worse, he was often teased by some of the Malay students because of his poor command of the Malay language and pronunciation. As a result those Tamil students coming from Tamil primary school tend to stick together. "We were either with other Tamil students or alone" (Vimal, Transcript, Dec. 19, 2014). He said that most of the time they kept to themselves. When I asked him the reason for this behavior, he said that the transition into a new environment posed a lot challenges and problems. "We were thrown into a new environment where everything was different" (Vimal, Transcript, Dec. 19, 2014).

Vimal informed me that he was sad that he could not communicate as well as his classmates in Malay and because of this he could not mix freely with the rest of his nonTamil classmates. So overcoming initial fear and embarrassment of being ridiculed he started to move around more with Malay students. "I tried to mix with Malay students and talked to them to improve my Malay. I will listen carefully to what they say, observe the way they speak and try to copy the way they speak. I tried to learn from my Malay classmates as much as I could" (Vimal, Transcript, Dec 19, 2014).

This was difficult at first because when he made mistakes, they often laughed at him. However, later on when they realised that he was serious in learning the language, they started to talk to him more. Some of his Malay classmates used to correct his mistakes and checked his pronunciation. He worked hard and by Form 2 (second year of secondary schooling) he was able to adapt to this new environment. He performed well in Malay for both PMR and SPM. It was a proud moment for him when he did better than some of his Malay classmates in Malay. 


\section{Language choice}

Vimal reported that he spoke mostly in Malay to his Chinese and Malay classmates and Tamil to his Tamil friends while in secondary school. He spoke very little English outside the classroom. English was spoken only during English class.

At university, he spoke mainly in English and Tamil. He spoke in English to the Malays and Chinese, and Tamil to his Tamil friends. Malay was hardly ever spoken as the medium of instruction in the university was English. "All the courses are in English, so there is no need to speak in Malay" (Vimal, Transcript, Dec. 19, 2014). Furthermore, there were fewer Malay students when compared to national secondary school. He told me that he used Malay when he went shopping outside the campus. "Only when I go shopping, I speak some Malay" (Vimal, Transcript, Dec. 19, 2014).Whenever he went out with his Tamil friends to public places he spoke in Tamil and he informed me that he was not bothered even if the people around him were non -Tamils, they still continued speaking in Tamil.

What language he used depended on who he was talking to. In his own words, "I change according to situation" (Vimal, Transcript, Dec. 19, 2014). He told me that at first it was difficult to switch languages. "I would take some time to comprehend and answer in English" but later on when he became more proficient in English and Malay he could switch easily (Vimal, Transcript, Dec. 19, 2014). He considered himself to be a multilingual now.

\section{Life in the university}

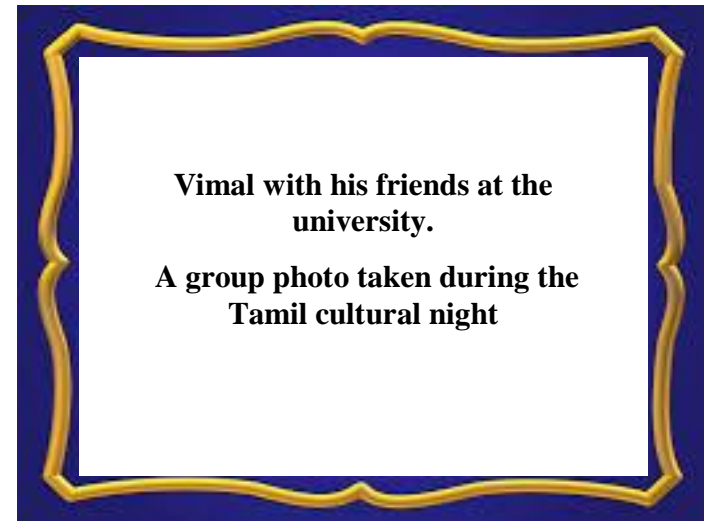

Figure 26. Photograph of Vimal with his friends at the university 
Vimal found it easier to adapt to university life compared to his secondary school. He seemed to be happier when he recalled the good memories he had at the university. He showed me a photograph taken with his Tamil friends at the university. Looking at the photo he said, "Although I had difficulties in the beginning but not like when I first entered secondary school. There were more Tamils and I can speak Tamil freely" (Vimal, Transcript, Dec. 19, 2014). He informed me that he found it easier "to pick up English compared to Malay “as everyone was speaking in English including the Malays. Furthermore, his Tamil friends who had come from national primary schools used to correct him if he made mistakes in English. He did not mind this at all. "I did not feel bad. It was a learning experience and they were all my friends" (Vimal, Transcript, Dec. 19, 2014). This speeded up his learning process. "Initially I found it difficult and struggled a lot. But now I have improved and am able to speak more confidently" (Vimal, Transcript, Dec. 19, 2014).

He described two occasions in the university which had impacted him greatly. One was the Indian Cultural Night organised by the Tamil students. He told me he was so happy talking in Tamil all the time to his friends and guests. He was thrilled taking part in a traditional dance. "I really enjoyed myself. It was great" (Vimal, Transcript, Dec. 19, 2014).

The other occasion was when he had to struggle speaking in English. His friend was a non-Tamil so Vimal could not use Tamil as his friend would not have understood. He had to speak in English and at that time he was not fluent enough. "My friend spoke in English fluently and I struggled. My friend did not say anything but I felt embarrassed. That's when I decided to improve my English” (Vimal, Transcript, Dec.19, 2014). This event took place during his foundation year at the university. He told me that he has improved a lot since then. "Now I speak better and am not nervous" (Vimal, Transcript, Dec. 19, 2014). He told me that he spoke to the same friend again continuously in English for more than three minutes without any hesitation and he felt really proud of himself. "I just felt proud that I have learned to speak quite confidently in English" (Vimal, Transcript, Dec. 19, 2014).

\section{Status of Languages (Tamil, English and Malay)}

Vimal thought that more Tamil parents should send their children to Tamil primary schools and not to national primary schools as Tamil was their mother tongue. He 
believed that this would give the Tamil children more opportunity to use their mother tongue. According to him it was easier learning Tamil than Malay or English. As a result of his Tamil primary school experience, he said that he did well in the Primary School Assessment Test." I have come from a Tamil School and fully realise the benefit of studying in a Tamil School" (Vimal, Transcript, Dec. 19, 2014).

Even in national secondary school, he scored well in Tamil which helped to raise his overall score for PMR and SPM. "I found it a lot more easier than Malay or English" (Vimal, Transcript, Dec. 19, 2014).

Furthermore, he felt that all Tamils should know their mother tongue and learn to speak it well as this was their identity. "The Malays and Chinese have their ethnic languages and we have ours" (Vimal, Transcript, Dec. 19, 2014). He ranked Tamil first followed by English and then Malay. The reasons he gave were firstly, as Tamils it was important that Tamil language was learnt first before learning other languages. At the same time he realised that learning Tamil alone was not sufficient. He ranked English second because English was an international language, was spoken everywhere and especially important in the workplace. He considered Malay not as important as Tamil and English because its use was only limited to communication with the Malays. Moreover, the medium of instruction at university was English and he used English to communicate with non-Tamils. "You need Malay to talk with the Malays only because we can use English when talking to the Chinese or other races" (Vimal, Transcript, Dec. 19, 2014). He found Malay not to be relevant at this point of time in the university. I asked him about his national secondary school experience where he had found that it was necessary for him to be proficient in Malay. He informed me that at that point in time it was important to be fluent in Malay to gain acceptance amongst his classmates who were mostly Malays and also to comprehend the lessons which were taught in Malay. However, he reported that after leaving school there was no need to be competent in Malay. "Now I hardly speak any Malay" (Vimal, Transcript, Dec. 19, 2014).

Now at university, he said that he wanted to improve proficiency in English because it would help in his academic writing and also later on in the workplace. "I want my written English to be that of a level of a degree-holder not that of a school boy level" (Vimal, Transcript, Dec. 19, 2014). According to him, it would give a professional 
touch to his writing. He also added that proficiency in English might win him a scholarship.

\section{I love Tamil school}

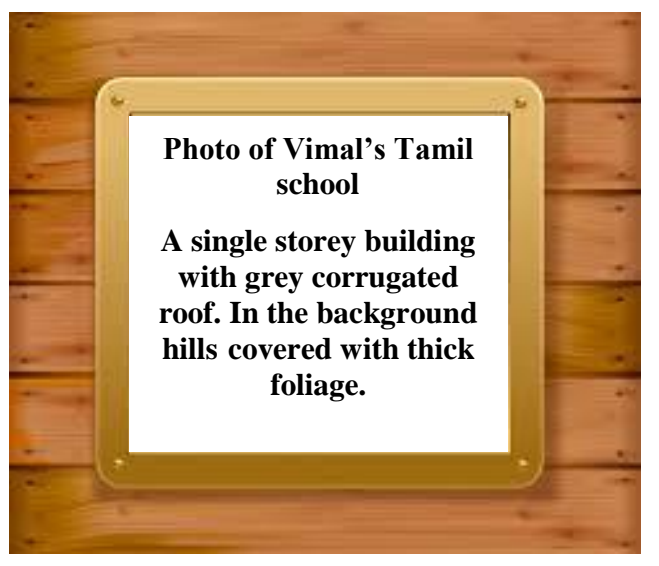

Figure 27. Photograph of Vimal's Tamil primary school.

Next Vimal showed me a photo of his Tamil school. He told me that he loved his school. Vimal felt that coming from a Tamil primary school, had given him an advantage over the Tamils who did not have a Tamil primary school education. He was able to speak and write Tamil well and he said that many Tamils were unable to do so. "I have learnt proper grammar and literature and this is an advantage" (Vimal, Transcript, Dec.19, 2014). He said Tamil was close to his heart and that he expressed himself better in Tamil compared to Malay or English. "I can say exactly what I mean speaking in Tamil” (Vimal, Transcript, Dec. 19, 2014). He was also more accurate in describing things. "I don't feel that I am able to express my feelings or describe something accurately speaking in English or Malay" (Vimal, Transcript, Dec. 19, 2014). He said that he felt comfortable speaking in Tamil however, he did not feel that speaking Tamil was anything special as speaking in Tamil was something normal to him as he had been using Tamil since he was a child.

Whenever he saw a Tamilian speaking English fluently to another Tamilian, he felt that he or she was trying to show off. When I asked him why he thought so, he replied that firstly they were embarrassed to speak in Tamil. Secondly, they perceived that speaking in English would make them appear "more educated" in front of other people (Vimal, Transcript, Dec. 19, 2014). He thought that they felt that English was better and more important than Tamil and there was nothing to be gained by learning Tamil. 
He felt that it was not necessary to speak in English to another Tamilian.

"Among Tamils we must speak Tamil" however when speaking to other races "we must show off our English to them" (Vimal, Transcript, Dec. 19, 2014). So he felt that speaking fluently in English would earn respect and admiration from people. "I also think that people will have more respect if we speak good English" (Vimal, Transcript, Dec. 19, 2014).

\section{Tamil schools versus national schools}

Vimal noticed a few differences between students who came from Tamil primary schools and those Tamils who came from national primary school. Generally those coming from Tamil primary school kept a low profile at the national secondary school. They were quiet and reserved. He felt that limited proficiency in Malay and English could be one reason. However, he noticed that once they become proficient in the languages, they became bolder and were more active. This happened usually after the first two years in national secondary school. Furthermore they were easily identified as coming from Tamil primary school from the way they spoke Malay and English. "If you observe how they speak with the Malay students, the difference between those from Tamil school and those from national school is very obvious" (Vimal, Transcript, Dec. 19, 2014). He told me that Tamils coming from national primary schools spoke in Malay fluently. Even when they spoke in Tamil to them, it was interspersed with a lot of Malay words. He also noticed that in the university, girls coming from Tamil primary schools were more conservatively dressed compared to those who came from national primary schools. For example girls from national schools were often dressed in jeans and T-shirts while girls from Tamil schools usually wore traditional clothes or long skirts and blouses.

He felt that in order to maintain a heritage language identity, he would send his children to Tamil primary school in future. When I reminded him of his struggles having had to adjust to the new environment in national secondary school, his reply was "I know it will be difficult but I will do the necessary to prepare them well so that they won't have to struggle" (Vimal, Transcript, Dec. 19, 2014). So in spite of the problems they may face, he still thought that it was better to send them to a Tamil school. 


\section{Mahes Rajendran's story}

Mahes Rajendran was a first year mechanical engineering student. He was quite happy sharing his language experiences with me. This was especially evident when he recalled those moments when he spoke in Tamil.

\section{Language experiences in the university}

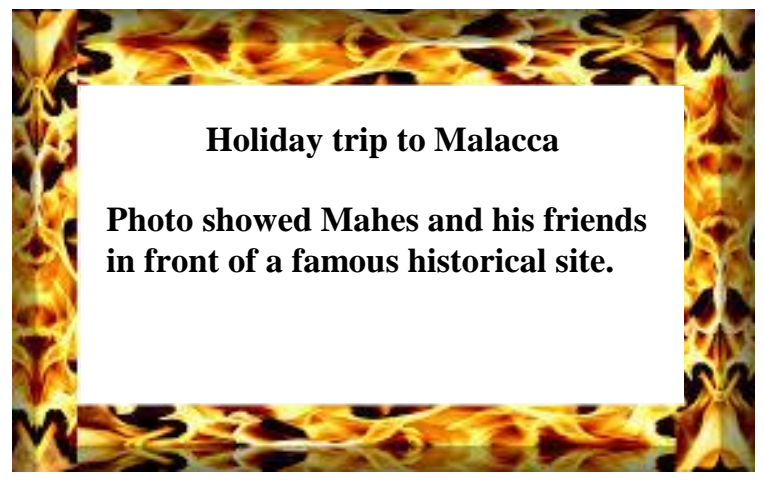

Figure 28. Photograph of Mahes and his friends on a holiday trip.

Mahes began by relating four different events that happened in the university which revolved around his language use. The first event was a holiday trip to Malacca. He showed me a photo taken during their excursion. There were five of them, all travelling together in a car they had hired. Out of this group, four (including Mahes) were Tamil students who had attended Tamil primary school. The driver was an international student from Iran. Mahes told me that most of the time the conversation in the car was in Tamil. Hardly any English was spoken. Mahes suddenly realised that it was rude to talk in a language that the Iranian friend could not understand. The Iranian remained quiet most of the time, "he did not understand and I felt guilty at this" (Mahes Rajendran, Transcript, Dec. 16, 2014). So he reminded the rest of his Tamil friends to talk in English. Mahes informed me that "We tried our best to speak in English but slowly we crept back into Tamil" (Mahes Rajendran, Transcript, Dec. 16, 2014). When I asked him the reason for this, he replied that it was only natural for them to speak in their mother tongue (Tamil) as they were surrounded by Tamils. "We simply forgot" (Mahes Rajendran, Transcript, Dec. 16, 2014). Mahes further added that although whenever they remembered they were in the presence of an Iranian friend, they spoke in English; it was mixed with Tamil words. "Even our pronunciation had a Tamil slang" (Mahes, Transcript, Dec. 19, 2014). He also mentioned that if it was something discreet, 
they spoke in Tamil otherwise they used English. "If it was a personal question, it will be in Tamil. Like open group question it will be in English" (Mahes Rajendran, Transcript, Dec. 16, 2014).

The next occasion was a surprise birthday party thrown by his university friends. He remembered speaking completely in Tamil with his friends. "They were all Tamils. So I could confidently talk in Tamil" (Mahes Rajendran, Transcript, Dec. 16, 2014). He told me it was such a memorable moment for him. He felt happy and carefree as he did not need to speak in English. "I felt confident and didn't feel guilty. I was not concerned because I knew they were all Tamils and they understood what I was saying” (Mahes Rajendran, Transcript, Dec. 16, 2014).

The third event took place in a sports complex during a Futsal tournament. His team comprised some international students who were from Africa. They were representing their university. He told me that he felt awful during the match as his team members were communicating in their language to each other. "I felt I was being isolated, it was not a good feeling at all” (Mahes Rajendran, Transcript, Dec. 16, 2014). He said that they should have communicated in English as they were all part of the same team. When I asked him would this not be the same feeling the non-Tamils would feel if he were to speak in Tamil to his Tamil friends. His response was it would have been okay to use Tamil amongst people whom you did not know well, however it was not okay if you were in the company of friends. "I would have been disappointed if my nonTamil friends spoke in a language that I don't understand. Because you are my friend. It's ok if this happens when you don't know the person well” (Mahes Rajendran, Transcript, Dec. 16, 2014).

Then he told me about his participation in the project to clean the national zoo. During this event he spoke in English and Malay as most of his team members were Malays and Chinese. Furthermore, he did not know them well although they were his course mates. "They were not people I know well. They were still my classmates but not that friendly" (Mahes Rajendran, Transcript, Dec. 16, 2014).There were only two Tamils in his group. Sometimes they could not understand Mahes when he spoke in English and they would ask him to repeat. He told me this could be because of his Tamil accent. "I was not confident the way I spoke English" (Mahes Rajendran, Transcript, Dec. 16, 2014). This affected him so badly that he often had to pause and ask himself 
whether he had made any mistakes as he was so afraid that the rest of them would ridicule him "I felt guilty within me. Have I made any mistakes, have I said anything not right or might even say something not correct? Would they say aloud my mistakes?"(Mahes Rajendran, Transcript, Dec. 16, 2014).

At this juncture, he narrated to me an incident which happened while he was travelling in a car with his friends. He said he had mispronounced the word "Tutti Fruitti" and to his embarrassment his friends (who were THLUs-M) laughed aloud. At that instant he felt that he should not have opened his mouth.

\section{Language experiences in national secondary school}

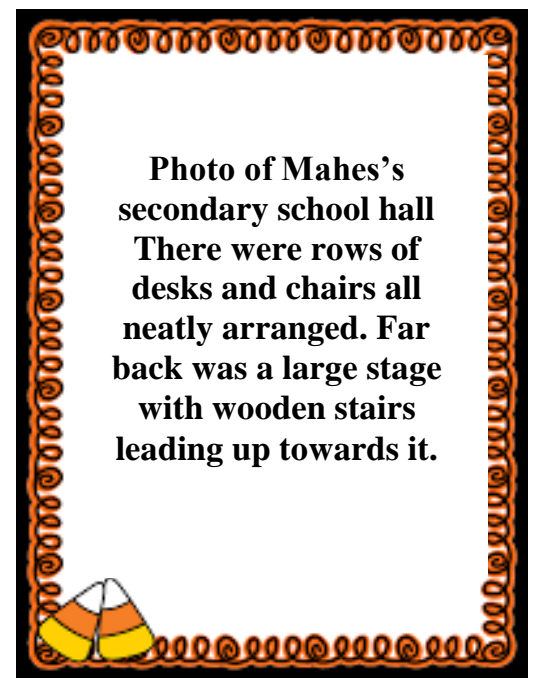

Figure 29. Photo of Mahes Rajendran's secondary school hall.

He showed me a photo of his school hall which reminded him of a Malay debating competition he had taken part in while he was in Form Two. He informed me that at that point he was still learning to speak Malay and English better. It was difficult for him to let go of his Tamil accent. He did not speak well as he was so nervous because of his lack of proficiency in Malay. I asked him what the audience's reaction was. They listened silently but he did not know whether they had understood him. He panicked when a member from the opposition team asked him a question. He stood silently for a few moments. "It took some time to come back to my normal self" (Mahes Rajendran, Transcript, Dec. 16, 2014). Somehow he managed to give an answer. He confided in me how at that time how he wished he had stayed back in his Tamil primary school. "I should have continued studying in Tamil school. I wanted my Tamil school environment back" (Mahes Rajendran, Transcript, Dec. 16, 2014). 
He had difficulties in communicating to his classmates in English or Malay while in national secondary school. His Malay and Chinese classmates would often ask him to repeat if they did not understand what he was saying. He told me sometimes they would laugh at him and ask him to speak clearly. He often felt embarrassed and stayed in the company of his Tamil friends who had come from Tamil school. This affected his selfconfidence. It was only during the last two years of his secondary school life that he made some improvements in proficiency in Malay and English with the help of his close Tamil friends. He said, "it was important that I improve my Malay and English if I wanted to do well in my exams" (Mahes Rajendran, Transcript, Dec. 16, 2014). He said he practised speaking English and Malay with his Tamil friends and this is probably why he felt that he could not let go of his Tamil accent.

Mahes described another incident in his secondary school life which brought a lot of good memories for him. It was a time when he had stayed over at his Tamil friend's house playing video games. They were joined by another classmate of theirs who was Malay. He told me that his Malay classmate spent the night together with them. During this episode they spoke in Malay most of the time as their friend was Malay. He said they did use English, however very little because Malays preferred to speak in Malay. "My Malay friend is uncomfortable using English. It does not bother me. I can speak Malay too" (Mahes Rajendran, Transcript, Dec. 16, 2014). Sometimes he informed me that he spoke in Tamil to his Tamil friend if it was something personal. His Malay friend reminded them to speak in Malay and he told me that he only translated jokes or interesting topics only not everything. It was such a happy moment for him and he was still in contact with this Malay friend. 


\section{Language experience with family members}

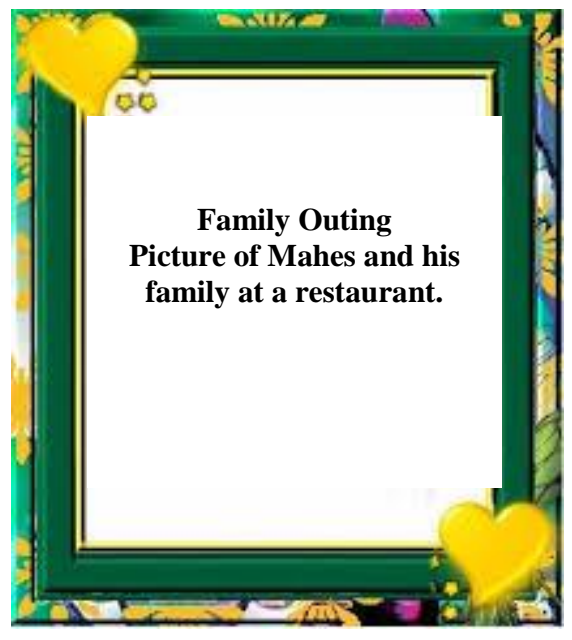

Figure 30. Photograph of Mahes and his family at a restaurant.

He spoke of a family trip they had made a year ago. The photo he showed was taken at a restaurant. Mahes informed me that his family members were speaking in Tamil most of the time. They did not speak any English or Malay at all. He said he felt happy, comfortable and relaxed. "There were no guilty feelings like watching over what I had to say" (Mahes Rajendran, Transcript, Dec. 16, 2014).

Another time, the family had an evening out in a restaurant. They spoke completely in Tamil. "It was 100\% all the way", he said (Mahes Rajendran, Transcript, Dec. 16, 2014). He told me that he felt free to express his thoughts. "No feelings of guilt or lack of self- confidence" (Mahes Rajendran, Transcript, Dec. 16, 2014).

I was curious to find out why he used the word "guilty" so often when he spoke in a language other than Tamil:

Researcher You often use the word "guilty". Could you tell me what you mean by this?

Mahes Rajendran I will perspire. My heart beats faster .... Very afraid (fear). Like they might say something. (Transcript, Dec. 16, 2014)

He was so afraid of what others might say when he spoke in English or Malay.

He spoke Tamil at home with his siblings and parents. However, his second brother spoke more Malay and English compared to Tamil. When I asked him why since all of them had gone to Tamil primary school, he explained that Math and Science were taught in English then. However, these subjects were reverted to Tamil later on. 
"Therefore it is only my second brother who uses more English compared to me and my youngest brother. We speak mostly Tamil at home. Every one of us" (Mahes Rajendran, Transcript, Dec. 16, 2014). Whenever his younger brother spoke to him in English Mahes cut him short and asked him to speak in Tamil. Mahes insisted that as a Tamil, one should always speak in their mother tongue at least at home. "You are a Tamilian aren't you? Why are you speaking in English? Don't become a Peter" (Mahes Rajendran, Transcript, Dec. 16, 2014). .

Mahes informed me that although he mainly used English at university now, he was still afraid that he might make mistakes and embarrass himself. Especially in the classroom, when questions were asked in English, he stammered and hesitated. He felt that his English was not fluent enough. His lecturer often asked him to speak clearly. This was when his "guilty” (Mahes Rajendran, Transcript, Dec. 16, 2014) moments began. "I start having doubts whether I had answered correctly even though the answer may be correct but because of the language problem I start doubting" (Mahes Rajendran, Transcript, Dec. 16, 2014).

However, his proficiency in English was slowly improving, he told me. "It is becoming better now. Not like before" (Mahes Rajendran, Transcript, Dec. 16, 2014). For most of our interview, he spoke in English. He switched to Tamil when he wanted to express his emotions.

On his language use now, he said he spoke in English to his non- Tamil friends and also in the classroom and with his lecturers. He spoke in Tamil to his Tamil friends outside the classroom. He found that there was no need to speak in Malay now as all of his friends including his Malay friends spoke in English.

Whenever he made language switches he said he felt the safest when he was speaking in Tamil. He identified this as his "comfort zone" (Mahes Rajendran, Transcript, Dec. 16, 2014). When he spoke in Malay it was okay but he always felt unsure and slightly hesitant when he was speaking in English. 


\section{Menaga's Story}

Menaga appeared to be a confident young lady who held herself well throughout our interview session. She was quite vocal and articulated her views very strongly.

\section{Tamil primary school experience}

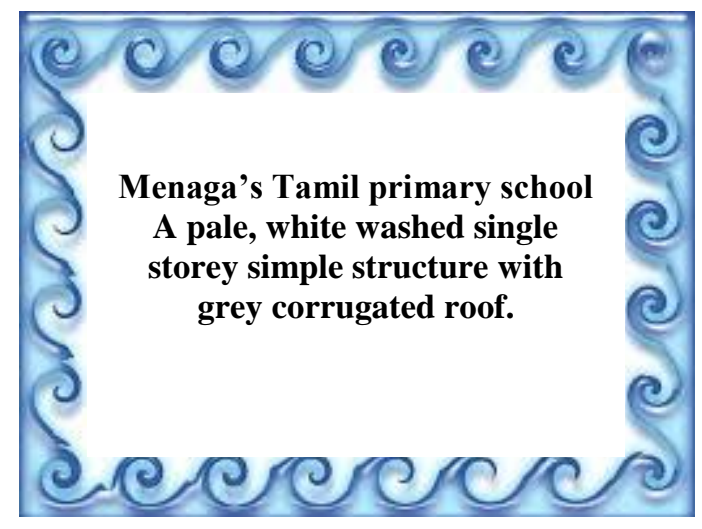

Figure 31. Photograph of Menaga's Tamil primary school.

Menaga showed me a photo of the Tamil primary school she had studied. Although it was a small school with poor facilities, it held a lot of good memories for her. She told me her teachers were very concerned over the students' academic progress. "They always gave 100\% effort to help the students succeed" (Menaga, Transcript, Dec. $8,2014)$. The teachers also emphasised hard work and discipline. This paid off. She proudly informed me that she had scored 7 As in UPSR). She had also competed in many competitions and won many prizes. According to her if she had been in national primary school, she would not have won so many awards. She felt that being part of a minority group, she might not have been offered the same opportunities as the majority Malays. "We (the Tamils) won't have the same support" (Menaga, Transcript, Dec. 8, 2014). However, this was not so in Tamil school. The best among the Tamils were selected to take part in competitions. Furthermore, Tamil school students received a lot of cash awards if they did well in UPSR. The Malaysian Indian Congress awarded Menaga RM 500 and a book prize for being a top scorer. She said this was "the beauty of Tamil school. All you got to do is do well and you will get a lot of opportunities to win scholarships and awards" (Menaga, Transcript, Dec. 8, 2014). She believed that this was part of the drive to recruit more Tamil students to attend Tamil primary schools to 
increase the enrolment. MIC wanted to encourage more parents to send their children to Tamil schools.

\section{Not much English here}

When she was in Tamil primary school, she did not speak much English since all of her friends were Tamil so they preferred to speak in Tamil. However in the classroom she spoke in Malay during Malay lessons and English when English was taught. She told me the teachers were very strict and punished them if they were to speak in Tamil when English and Malay languages were taught. The teachers wanted them to improve their proficiency in Malay and English. She did not remember speaking in English outside the classroom because the environment was such that they only spoke in Tamil.

\section{New environment at secondary school}

It was difficult at first for Menaga to adapt to the new environment. She told me that she was the only one from Tamil school in her class, the rest of the students were from national primary schools. All her classmates would speak in Malay and English. She felt left out. Later on, she confided in me that she realized that if she wanted to survive and succeed, she needed to improve her fluency in Malay and English. "It was like learning another subject just like Maths or Science" (Menaga, Transcript, Dec. 8, 2014). She prepared herself mentally to take this on as a challenge. "I worked very hard. I just observed and remembered the words they used and I copied the way they spoke to one another" (Menaga, Transcript, Dec. 8, 2014). She even took a notebook around with her and jotted down words and phrases which she would memorise later. Over time she soon got used to the new environment and managed to adapt quite well.

\section{It was different at secondary school}

Since she was the only Tamil in her class, she had no opportunity to use Tamil. However she spoke in Tamil with her other Tamil friends when they attended Tamil class together. She also spoke in Tamil to her Tamil friends outside the classroom. She said she did not mind if the other non-Tamils teased them whenever she and her friends spoke in Tamil. She did not take them seriously. Her argument was if the Malay students spoke in their ethnic language (Malay) and the Chinese students spoke in Mandarin (their ethnic language), then what was wrong about Tamils speaking in Tamil. 
The Tamils from national primary school spoke in English initially. After some time they too started to speak in Tamil to her. It was interesting to hear that there were some Malays who tagged along with her and her Tamil friends to learn Tamil. She and her Tamil friends would teach her Malay friends and converse in Tamil with them to help their speaking skills.

She used English and Malay depending on the context she found herself in. In the classroom it was either Malay or English. Outside the classroom she spoke in Malay to her Malay friends and sometimes in English to her Chinese friends. "I would use whichever language comes easy to the other person either Malay or English" (Menaga, Transcript, Dec. 8, 2014).

She further added that if she went out shopping with her friends she would use Malay. When she attended tuition classes which comprised different races she would use either English or Malay depending on the situation.

Overall she found that she spoke a lot in Malay while she was in national secondary school as most of her classmates were Malays and furthermore the medium of instruction was in Malay. She even took part in many competitions like essay writing and won prizes.

\section{Fluent in English at the university}

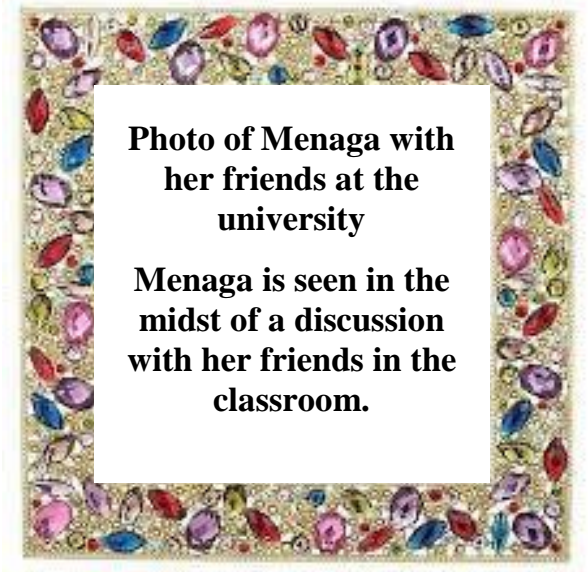

Figure 32. Photograph of Menaga with her friends at the university.

Menaga spoke of her life now at the university. She shared with me a photo her friends had taken while she was busy explaining a concept discussed earlier by their 
lecturer. She was proud that she explained very well in English as some of her friends were non-Tamils.

Menaga informed me that she currently spoke a lot in English and used Tamil only when she met her Tamil friends in the university. She used English in the classroom and with her lecturers as lectures and tutorials were conducted in English. When I asked her whether she spoke in English to her Tamil friends, she replied that sometimes she did. However, this was dependent upon the speakers. If they started the conversation in English, then she communicated in English. On the other hand, if they started conversing in Tamil, then she switched to Tamil. She also noted that even though they might start talking in English at first, it always eventually ended up in Tamil. This was especially so if the topic of their conversation was related to Tamil cinema, songs and cultural events.

Menaga felt happy that she had become quite fluent in English and was well accepted by her friends in the university. "I think all of us are in the same proficiency level. I think we are able to understand one another and that should be enough for proper communication (Menaga, Transcript, Dec. 8, 2014).

\section{Feeling proud}

Menaga was not particularly embarrassed or anxious when she spoke in Tamil in public places with her Tamil friends. She said she hardly noticed the reactions of other nonTamils around her. She said, "I think we should be proud to speak in our mother tongue" (Menaga, Transcript, Dec. 8, 2014). To prove her point she related to me an incident which happened in the bus she was travelling in. A Chinese passenger, who was travelling at the same time, was speaking in Mandarin to his friend so loudly throughout the whole journey. "Nobody said anything. There were a lot of other races too in the bus. But why we Tamils are so embarrassed to talk in Tamil?” (Menaga, Transcript, Dec. 8, 2014).

In fact, she could not remember any incident that she regretted speaking in Tamil. On the contrary, she could only feel proud when she used her mother tongue. When she compared herself to other Tamils who could not read, write and speak in Tamil, she felt that she was a more "accomplished person" (Menaga, Transcript, Dec. 8, 2014). She was quick to tell me that she was not criticizing them but she was disappointed when Tamils did not give importance to Tamil and instead tried to master 
another language like English at the expense of losing their mother tongue. "It is like losing your culture, your race" (Menaga, Transcript, Dec. 8, 2014).

She told me firmly that a Tamil who cannot speak his mother tongue is not appreciative of his identity. This is actually "a shameful thing” (Menaga, Transcript, Dec. 8, 2014), as it does not enhance his image at all. However if he was fluent in both Tamil and English this would greatly improve his image. She felt that it was the duty of every Tamil to learn their mother tongue and continue using it to preserve their identities as Tamils. "No one else is going to do this for us, except ourselves" (Menaga, Transcript, Dec. 8, 2014).

She also commented that she felt "blessed" (Menaga, Transcript, Dec. 8, 2014) in the sense that she could read, appreciate and enjoy the treasures of Tamil literature like The Bhagavadgita and the great Tamil epics. "They don't know what they are missing. They miss the opportunity to be enlightened and appreciate these great works" (Menaga, Transcript, Dec. 8, 2014).

She observed that at university those who came from Tamil primary school were very hardworking and almost always were able to complete any assignments given on time. Even if they were not able to do a good job at first, they tried very hard to overcome any problems and succeed. She attributed this characteristic to the training they received at Tamil primary school. On the other hand, she noted that those Tamils who came from national primary school certainly had one advantage over them, which was they were more competent in English and Malay compared to those who came from Tamil primary school.

\section{Status of languages}

Menaga ranked English first as it was an international language. She said that it was a global language and thus not comparable to other languages. It can be used in any part of the world. Next, she ranked Tamil followed by Malay.

These were her reasons. Tamil was used around the world where there were Tamil diasporas. However, she noted that as an academic language, its use was quite limited. Yet she still felt motivated to continue using the language because she said that it was her identity. "English cannot be part of our identity because by race we are Tamils. We are not whites" (Menaga, Transcript, Dec. 8, 2014). She contended that if the Tamils themselves did not learn and propagate the Tamil language who else would. 
Besides this, she was also very proud of the fact that Tamil was one of the most ancient languages in the world and had such a long history.

Her take on Malay was that its use was limited mostly to countries like Malaysia, Indonesia and Singapore. Beyond these borders, it had no relevance as it was not spoken at all. She used Malay when she talked to sales-persons at supermarkets, retail outlets and restaurants. She also used Malay when she was talking to her Malay friends. She told me she had spoken Malay for fun with her Tamil friends when they had made a trip to India last year. It was used as a sort of "coded language" (Menaga, Transcript, Dec. $8,2014)$ so that the Tamils in India would not be able to understand them. She told me that they had so much fun as people were trying to figure out what their nationality was. "We looked like them but we spoke in a strange language" (Menaga, Transcript, Dec. 8, 2014). 


\section{Nadesh's Story}

Nadesh was an expressive young man who spoke fluently in English. He was studying for business administration. He exuded an air of confidence when he spoke to me.

\section{Tamil school experience}

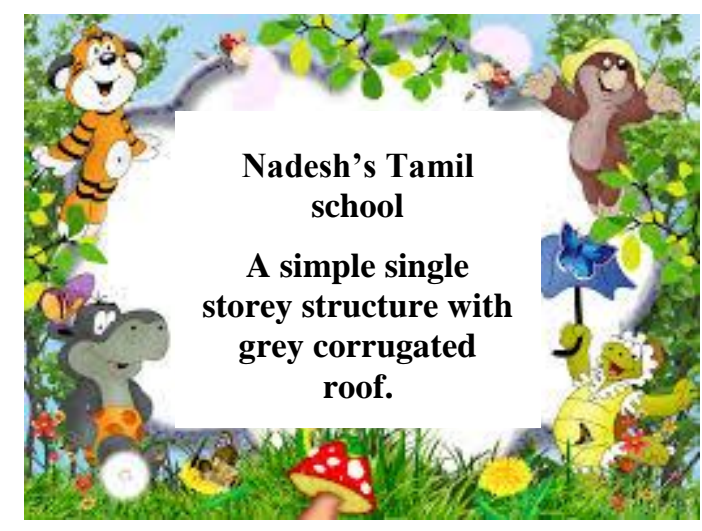

Figure 33. Photograph of Nadesh's Tamil primary school.

Nadesh showed a photo of the Tamil primary school where he had studied. I could see from his expression that he must have spent six happy years here. When he recollected his primary school experience, his eyes glowed and there was a lilt to his voice as though yearning for those long gone years (Researcher's Field Notes, Feb. 9, 2015). "I really enjoyed my primary school years. You know the environment was more like a home. Everywhere there were Tamil-speaking people" (Nadesh, Transcript, Feb. 9, 2015). He told me how his teachers were extremely concerned about their academic welfare. A month before the Standard Six public examinations started, his teachers organised weekend extra classes to expose students to exam strategies and answering techniques. The students stayed at school over the weekend. The teachers took turns to prepare food for them. "They were more like our parents" (Nadesh, Transcript, Feb. 9, 2015). Two classrooms were turned into dormitories where the students slept. "We ate together, studied together and slept together. It was like a one big happy family" (Nadesh, Transcript, Feb. 9, 2015). These classes were so useful to him that he managed to score all A's. Talking about his language experiences in the Tamil primary school, he stated that he used Tamil almost all of the time except during classes when English and Malay were taught. Even then the teacher had to force the students to use either Malay or English. "If the teacher forced us to talk in English we used English. Otherwise we preferred using 
Tamil” (Nadesh, Transcript, Feb. 9, 2015). When I asked him why he preferred using Tamil even during English classes, he informed me that he felt there was no need as every one of them spoke Tamil better and it was easier using Tamil to learn English. I could see how this might have landed him in trouble when he went to national secondary school.

\section{Language experiences at secondary school}

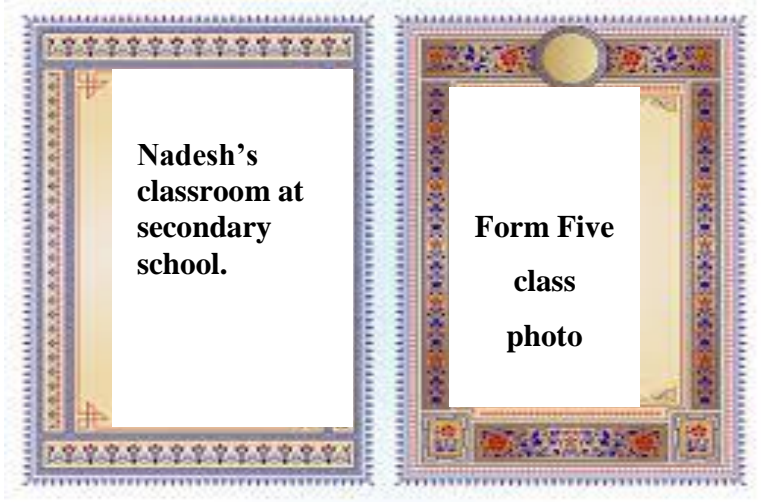

Figure 34. Photographs of Nadesh's secondary classroom and classmates.

The next two photographs were pictures of his national secondary school classroom and his class photo. The medium of instruction was no longer Tamil, it was Malay; his classmates were no longer all Tamils, there were Malays and Chinese too. In addition, there were many Tamils who did not come from Tamil primary schools but who came from national primary schools.

I could tell from the tone of his voice that it was a difficult time for him. He frowned when he described the first three years of trouble which lasted from Forms 1 to 3. The major problem he faced was communicating with the Malays and Chinese. If he was used to speaking in Tamil before, he had to switch to English or Malay now. As if this was not enough, the Chinese were also speaking in their heritage language. He threw up both his hands in the air and made a swirling motion signalling it was all beyond him (Researcher Field Notes, Feb. 9, 2015):

Researcher: Can you tell me how you felt?

Nadesh : It was all so confusing that I was not interested in talking to anyone. We in Tamil school, we were always with the Tamil people and when we moved to secondary school there were Malay people and Chinese people who were talking in their own language. I tried to avoid them as much as possible. I didn't feel like I wanted to talk to them. (Nadesh, Transcript, Feb. 9, 2015) 
Nadesh managed to find five other Tamil students who were from Tamil primary school and they formed a group of their own. He told me that they moved around together and did not mix with the rest of their schoolmates. This lasted for a few weeks until the school orientation took place. The school organised some activities which brought students from various races together. Participation in sports and competitions opened doors for him to get to know students of other races better. He made some new friends. Luckily, they were very friendly as well (Nadesh, Transcript, Feb. 9, 2015). In particular, he mentioned the names of two Malay friends and three Chinese friends with whom he started talking in the classroom and also during break. He started to speak in Malay more now because his Malay friends preferred talking in Malay. Since Malay was the medium of instruction in national secondary school, the Chinese understood it as well. His eyes lit up when he talked of the good times they shared together playing football. "We had good memories. Till now I still remember their names and faces" (Nadesh, Transcript, Feb. 9, 2015). Proudly he shared with me that he was still in touch with them after all these years.

The class teacher also helped foster better relations between students by ensuring that they were seated beside a student of different race. This helped, he said. The school forbade their students from using mobile phones in the classroom so this encouraged more interaction. The roles of the teachers and school management actually helped to build better interracial relations amongst the students.

\section{Early troubles}

In the beginning, when I was getting used to the new environment, I made lots of mistakes. At that time I had to think in Tamil and then translate into English and then talk. This was a problem. (Nadesh, Transcript, Feb. 9, 2015)

Nadesh used to make a lot of grammatical errors and had problems constructing sentences in English. Reflecting on those moments, he told me that his written English was much better than the spoken form. When I asked him why this was so, he replied that he had basic knowledge of English grammar and writing structures which he had learnt while in Tamil primary school. However, using these in conversations meant that he needed to use them immediately, and translating from Tamil to English slowed down the process. Thus, he was often teased by his classmates. He grimaced at how his classmates kept on repeating the word or phrase that he had spoken wrongly. 
Researcher: So, how did this affect you?

Nadesh So, I told myself I should not speak in English in front of them or to them. I better speak in a language that comes easier to me.

Researcher: What were these languages?

Nadesh : $\quad$ Malay and Tamil. I spoke in Malay to the Malays and Chinese, and Tamil to my friends who came from Tamil school. (Nadesh, Transcript, Feb. 9, 2015)

Nadesh informed me that his proficiency in Malay increased during his secondary school years. This was no surprise as this was the medium of instruction in national secondary school. Another reason was most of the students were Malays and Malays preferred talking in Malay as it was their ethnic language. However, with the Chinese it was a different story, they preferred using English more than Malay. At the same time, Tamils coming from national schools also preferred to talk in English. So he concluded that English was one language that everyone understood. Besides people were not offended because "English was not the mother tongue of Malays, Chinese or Tamils" (Nadesh, Transcript, Feb. 9, 2015).

So I now asked Nadesh what happened to his English use in national secondary school. The next paragraph follows Nadesh's story as he outlined steps taken to improve his proficiency in English and the result of his success.

\section{The breakthrough}

Nadesh informed me he did not know exactly when the turning point came when he decided that enough was enough. He could not go on any longer like this. He thought this could have happened by the end of first year in the secondary school. "I realised that I should not be too much concerned over what they say. It should not affect me this way" (Nadesh, Transcript, Feb. 9, 2015). He decided that speaking more in English would help to gain respect and admiration from those who had teased him earlier. There was a tone of determination in his voice. His voice became louder and there was so much emphasis in the way he spoke (Researcher's Field Notes, Feb. 9, 2015). He started reading books, articles and news in English. He listened to programmes in English and at the same time surfed the internet completely in English. He reduced reading in Tamil and started reading more books in English. He even memorised useful expressions in English. He tried speaking in English to his close friends first. He said he did not mind if they teased him because they corrected him immediately and encouraged his efforts. 
His hard work paid off. "My close friends started noticing the changes first" (Nadesh, Transcript, Feb. 9, 2015). They said he spoke well without any pause or hesitation. His voice was filled with pride and satisfaction when he related this to me. (Researcher's Field Notes, Feb. 9, 2015). What followed next brought even greater joy and pride to Nadesh. He must have spoken so well that his other classmates (the ones who used to tease him before) to his amazement, questioned him whether he had actually memorized a script. He stared at me for a few seconds as if wanting me to believe the ridiculousness of their statement (Researcher's Field Notes, Feb. 9, 2015). The pinnacle of his success came about when he started scoring higher marks than his classmates who came from national primary schools. He stated that his classmates grudgingly admitted he had improved a lot. "I think they could not accept this knowing that I had come from Tamil school. Later on, they did not isolate me and accepted me as part of their group. I felt I had proved something” (Nadesh, Transcript, Feb. 9, 2015).

Looking at him now, I would not have thought that he had any fluency problem in English. Throughout the entire interview he spoke to me in English. He did not falter and expressed himself well.

\section{The later years (Forms 3 to 5)}

The last three years of his secondary school life brought him success, admiration and respect from his schoolmates because of his proficiency in English. This impacted him positively and he grew to be more confident.

He related an incident during his fifth year in secondary school (Form 5) which highlighted this. After a group presentation in English, he was congratulated by his teacher and his group members for an excellent job done. He was commended especially for being able to present without looking at the script. He told me that he would not have been able to do this had it been the first few years (Forms 1 to 3). "At this time I was able to think in English straightaway. So there was no problem. I liked the feeling when I can speak without translating" (Nadesh, Transcript, Feb. 9, 2015).

By the time he left secondary school, he was no longer the same boy who had kept to himself and refused to speak to his schoolmates in English for fear of being teased. His circle of friends had grown. They were no longer just Tamils who came from Tamil primary schools and who spoke Tamil. "Before, I used to have a lot of Tamil friends and I spoke in Tamil. But now I have friends from all three races and I can use 
English or Malay to communicate to all of them" (Nadesh, Transcript, Feb. 9, 2015). He was not able to do this before as he could only communicate in Tamil with his Tamilspeaking friends.

\section{Life at the university}

Nadesh constantly spoke in English in the university and had a lot of non-Tamil friends. When I asked him why, he replied that since the medium of instruction was English, he found it necessary to use English more. "Group assignments and presentations were in English so it was natural that I should use English more" (Nadesh, Transcript, Feb. 9, 2015).

I was interested to find out why he had a lot of non-Tamil friends. He gave two reasons. The first being there were fewer Tamils doing the course that he was doing as compared to Chinese and Malays. The second reason was that the Tamil speaking students kept away from him thinking that he could not speak Tamil as he was seen in the company of Chinese and Malay most of the time. "They thought I was arrogant and did not want to speak in Tamil" (Nadesh, Transcript, Feb.9, 2015). Ironically this was the same thought he used to have of the Tamils who did not come from Tamil primary school while in secondary school (Researcher's Field Notes, Feb. 9, 2015). At this juncture, he smiled and said reflectively, "I used to think the same too, you know" (Nadesh, Transcript, Feb. 9, 2015).

However, this perception changed when he participated in class discussions where some of the THLU-Ts were his group members. More THLU-Ts got to know that he was a friendly and helpful person and he could converse in Tamil too. Soon he was accepted as one of them and his popularity grew until he became their class project leader. "I was the sort of guy who liked to ask a lot of questions in class so they looked up towards me as someone who can take care of them" (Nadesh, Transcript, Feb. 9, 2015). Furthermore, when the Tamils found out that he could speak in Tamil fluently; this endeared him to them even more. "I became their spokesperson" (Nadesh, Transcript, Feb. 9, 2015). They found in him someone who could hold his ground among his other non-Tamil course mates because he spoke English fluently and in addition, here was someone whom they could be proud of because he too had come from a Tamil primary school. 
Nadesh said he used English in the classroom and Tamil outside with his Tamil friends. With his Chinese friends he spoke in English. However, with his Malay friends he spoke in Malay and English whichever language his Malay friends preferred. He seemed to know when and where to use the three different languages (Malay, English and Tamil). Where Tamil use was concerned, he was drawn towards it as it was a symbol of his ethnic identity that bonded him with other Tamils. "As a Tamil, I make it a point to speak in Tamil to other Tamils because this is my mother tongue. I use English with my Chinese friends because they prefer this. My Malay friends almost always end up speaking in Malay even though I start in English" (Nadesh, Transcript, Feb. 9, 2015). I was interested in finding out how he coped and fitted in a multilingual environment.

\section{Living in different worlds}

Nadesh came from a home where Tamil was spoken most of the time. Both his parents came from Tamil primary schools. He was very comfortable speaking Tamil because it was a language that he had been exposed to since birth. He told me that he felt being proficient in Tamil had always been an advantage to him. His overall examination scores had been boosted by the excellent scores he received in Tamil both in secondary school and also at university. "I always felt proud speaking Tamil because this is my identity, why should I be embarrassed speaking it" (Nadesh, Transcript, Feb. 9, 2015). His language experience in Tamil primary school was a continuity of his language experience at home. That was why he saw the Tamil primary school culture as an extension of his home culture.

However, his world came crashing down when he entered national secondary school. He found that his school mates did not take to him kindly if he spoke in Tamil. What was worse, even the Tamils who did not come from Tamil primary school teased him. He knew that if he wanted to fit in he had to improve his English proficiency. From our interview sessions, I discovered here was a young man who was aware of the distinct expectations of national secondary school and the different roles and responsibilities of a national secondary student. I believe this was what motivated him to acquire English and Malay proficiency. Talking about the importance of Malay, he said "all subjects were taught in Malay and it was necessary to be fluent in it if I wanted to perform well in my exams" (Nadesh, Transcript, Feb. 9, 2015). 
As for English it was seen as a language which "brought respect and status. I think they thought a Tamilian who spoke Tamil did not know much. They judged me the way I spoke and what language I spoke. Once they knew I could speak English... well their perceptions changed" (Nadesh, Transcript, Feb. 9, 2015):

Researcher: How did their perception change?

Nadesh: $\quad$ They started to respect me. (Nadesh, Transcript, Feb. 9, 2015)

Nadesh saw English as a language of knowledge and mastering it yielded power to the speaker:

Researcher: Why is English important?

Nadesh: It's a language of knowledge so it is a must. If you don't know English it's a great disadvantage. If you know than it becomes an asset and it makes you powerful. (Nadesh, Transcript, Feb. 9, 2015)

The last two years of his secondary school were "smooth sailing" (Nadesh, Transcript, Feb. 9, 2015). He earned the admiration and respect of his classmates. He was able to break the fixed identity imposed on him by others. In the beginning he was positioned by others as someone whom they did not want to be associated with but that did not deter Nadesh from taking a stance to be accepted as one of them through increasing language proficiency in English and Malay. "If before I had only Tamil speaking friends, now I had friends from all races” (Nadesh, Transcript, Feb. 9, 2015).

As a university student he adjusted successfully into the multilingual environment. He was proficient in all three languages and was able to use them depending on the context he found himself in. As a heritage language speaker, I saw him being able to balance his heritage language use and dominant language use (English and Malay) with ease.

\section{Where is Tamil in all of these?}

As a researcher I was curious to find out towards which end of a continuum he leaned: to a heritage language identity or a non-heritage language identity. He outlined the reasons why he gave greater importance to English compared to Tamil and Malay:

Researcher: How would you rank the three languages English, Malay and Tamil?

Nadesh: $\quad$ To me English comes first followed by Tamil and then Malay.

Researcher: Why in this order?

Nadesh: Because a lot of information which is up-to date is in English especially in the field of business and technology. I find it so relevant to what I'm doing now. 


\section{Researcher: What about Malay? \\ Nadesh: $\quad$ I don't use Malay a lot now except to my Malay friends. When I was in secondary school I used to speak more. (Transcript, Feb. 9, 2015)}

Furthermore, he said that English broadened his perspectives as it has helped him to keep abreast with current issues. He also commented that appearance and the language one speaks commands respect in society. He elaborated on this. "Wearing western clothes and speaking good English gives you a high status" (Nadesh). According to him, this is not the same with Malay.

When I asked him where I could place him on the continuum, his answer was "slightly leaning towards non-heritage language identity" (Nadesh, Transcript, February 9, 2015). The reason he gave showed how serious he was in his quest for knowledge. "I am afraid I might be overtaken and left behind if I don't keep on reading in English. In all areas like IT, business, academically, technologically I may be left behind. Because current knowledge in these fields is in English" (Nadesh, Transcript, Feb.9, 2015).

He informed me that Tamil is reserved for culture and family values. It is a language that fostered bonding among family and community members. "Tamil language teaches me more about my culture and family values. It is a language which teaches respect for elders" (Nadesh, Transcript, Feb.9, 2015). He explained how specific honorific terms were attached to pronouns and verbs when addressing someone which was related to age and status. I also sensed pride and loyalty towards Tamil when he described to me what an ancient language it was and how some of its great epics like Thirukkural which was written almost 2000 years ago still had relevance in today's society. Thirukkural is a collection of 1330 Tamil couplets organised into 133 chapters. It is a moral code of ethics that a man should live by.

I threw in a question towards the end of our interview which drew an unexpected answer. Which primary school would he send his children to? A Tamil primary or national primary? "I would send my children to an international school where the medium of instruction is English" (Nadesh, Transcript, Feb. 9, 2015). When I asked him why he informed me that he did not want his children to face the same problems he had faced in national secondary school. However, they would be sent for private tuition classes in Tamil. This, he said would ensure that his children would become proficient in English and at the same time did not forget their mother tongue. 


\section{Amala's Story}

Amala began the interview rather hesitatingly but grew more confident as we progressed. She appeared to be quiet and unassuming in the beginning. However, she became quite passionate on topics that revolved around HL use.

\section{Goodness! Why Tamil primary school?}

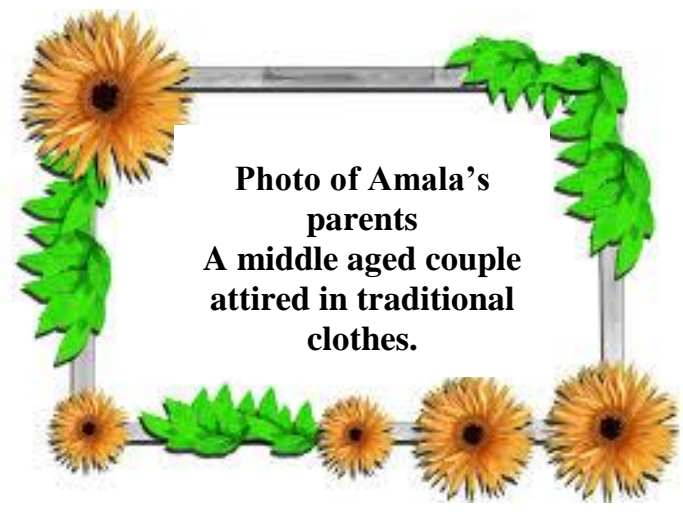

Figure 35. Photograph of Amala's parents.

Amala showed me a photograph of her parents and started talking about their decision to send her to Tamil school. She told me that the reason she was sent to Tamil primary school was because of her elder brother who had a physical handicap. "He was using a wheel chair" (Amala, Transcript, Dec 8, 2014). She informed me that she was the youngest and the only daughter in the family. Her eldest brother was already attending national primary school and it was her second brother who was in Tamil primary school and needed looking after. "So that I can help him, so any emergency or anything. So because of that, my parents said never mind, we send you to Tamil school, also" (Amala, Transcript, Dec 8, 2014). Although her father was quite hesitant initially, later on he agreed to her mother's wishes.

However, her parents received a lot of objections from her father's side of the family. She narrated to me how her paternal uncles tried to dissuade her parents especially her mother from sending Amala to Tamil primary school. Her paternal relatives had all studied in English medium schools. "Why Tamil school? Just send her to Malay school (national primary school). Like we did with our children. Look they are all doing well" (Amala, Transcript, Dec. 8, 2014).

Her uncles were of the perception that nothing good came out of a Tamil education. She still remembered the gestures they had made when they found out that 
she was going to a Tamil primary school. She raised her hands upwards and told me “you think she is going to go up like that?”(Amala, Transcript, Dec. 8, 2014). Her father's comment was "let's see how she fares" (Amala, Transcript, Dec. 8, 2014).

However, her mother put her foot down and insisted they should give Tamil primary school a try. She reasoned that no one in the family had gone to a Tamil primary school except for her second brother. Amala informed that her parents had sent her brother to Tamil primary school because it was convenient for the family. The school was close to their house and because of his handicap, the family felt less apprehensive as they could easily reach him should the need arise.

\section{Let's see how she fares}

Amala informed me that she did very well academically when she was in Tamil primary school. She was very proud of her achievements. She was one of the top scorers for UPSR. Right from Standard One she was one of the high performers. "We used to be a gang. All of us who topped the class. Like the first, second and third" (Amala, Transcript, Dec. 8, 2014).

Every year they represented their school for national competitions for poetry, writing and debates in Tamil and Malay. "We made our school proud and brought a lot of trophies" (Amala, Transcript, Dec. 8, 2014). She laughed when she told me that she and her friends were monopolizing these competitions. Her teachers had requested them to take part in other extra curricular activities like drama and sports to give the rest of her school mates opportunities to participate.

\section{Oh those difficult years at secondary school!}

Amala faced a lot of communication problems when she came to national secondary school. I asked her to tell me more about these problems. Most of the students came from national primary school and there were students from different racial backgrounds. There were four Tamils in her class and out of this only two came from Tamil primary school including her. The other two Tamils came from national primary school. The rest were Malays and Chinese who were also from national primary school.

She told me she was placed in the top class. In the beginning, she said she did not talk at all. She sat together with her Tamil friend finding comfort and strength. "We don't know how to begin, what to say" (Amala, Transcript, Dec. 8, 2014). They sat 
quietly for some time until a few of their classmates noticed them and tried to make friends. They came over and introduced themselves and where they were from. "We started to talk a bit then but never too much. I won't begin a conversation. I'm like that you know, very quiet" (Amala, Transcript, Dec. 8, 2014).

She related to me an incident during school assembly which had affected her badly. She was bullied by some Malay school mates. They used to intimidate her. "Oh so you are from Tamil school, aren't you?'(Amala, Transcript, Dec. 8, 2014). She did not like the tone they took up with her. She felt that to them Tamil school spelt inferiority. She was quite hesitant at first to say the derogatory term they used on her:

Amala: $\quad$ You know they called me..... (she looked at me, expecting me to know the word)...you know the word...

Researcher: What is it?

Amala: $\quad$ The word ... Tamils hate to hear.

Researcher: You mean 'keling'?

Amala: $\quad$ Yes. 'Keling'. (Nadesh, Transcript, Dec. 8, 2014)

No Tamil likes to hear this term being used to refer to them. It is kind of a racial slur used in Malaysia only. Like the word 'negro'.

She told me that she was so scared after this incident that she went back home and told her father that she did not want to go back to that school again. She begged her father to transfer her to a Tamil secondary school. I asked her if there was one. She replied there was only one private Tamil secondary school in Kuala Lumpur. "Please send me there. I will survive there. I really cannot take it" (Amala, Transcript, Dec. 8, 2014). Her father advised her to stick with it and told her to be strong. Furthermore, it was not practical as they were living in Johor which was quite far from the Tamil secondary school and it was also expensive. He encouraged her to polish her English and Malay skills so that she could hold her own. "So, I went back again. I had no choice. What to do?" (Amala, Transcript, Dec. 8, 2014).

\section{Somehow I managed}

I asked her how she coped with this problem. She replied it was very difficult at first. "It was hard with the Malay girls" (Amala, Transcript, Dec. 8, 2014). She and her Tamil friends would move in a group trying to make friends with the Malay girls especially during break time. "This happened day by day" (Amala, Transcript, Dec. 8, 2014). 
When they said something unpleasant, she just kept quiet. This went on for some time until they themselves realised that they should not be "fighting" (Amala, Transcript, Dec. 8, 2014) with her and instead should just make friends.

There were a few things working in her favour. She was in the top class and performed well academically and this earned her respect. In addition, there were not many Tamils and she had to quickly adapt to the new environment. With her father's help she managed to improve her proficiency in English and because of this the others looked up to her. "My father told me: since you are moving around you need to speak English more" (Amala, Transcript, Dec. 8, 2014).With the Chinese girls, she told me she did not encounter such problems. According to her "the Chinese did not care as long as you worked hard and did well in your exams" (Amala, Transcript, Dec. 8, 2014).

When she was in her second year at national secondary school, things began to become better. She rarely spoke in Tamil as most of her classmates were Malays and Chinese. It was always either in Malay or English. She told me her trying or difficult moments were over in Form One. The icing on the cake was when a Chinese friend chose to sit beside her in the class when she was in Form Two. They became close friends. By the time she was in Form Three, she confessed that she was one of the noisiest in her group. Her group was often ticked off by the teachers whenever they got noisy during class. The teacher would ask them to stand up. "You guys are too noisy" (Amala, Transcript, Dec. 8, 2014). She herself marveled at the transformation. "I can't believe that this is me" (Amala, Transcript, Dec. 8, 2014).

\section{Relationship with Malays and Chinese schoolmates}

Amala said she had a good relationship with her non- Tamil friends in national secondary school. "They did accept me finally" (Amala, Transcript, Dec. 8, 2014). She believed that first impressions could change if you got to know people better and that was what she did. "First, I thought, you know how the Chinese and Malay are. They have different impressions of us Tamils" (Amala, Transcript, Dec. 8, 2014). She told me that she invited her non-Tamil school mates for Deepavali an Indian cultural festival. "They came and were not shy. They were friendly" (Amala, Transcript, Dec. 8, 2014).

However, her Malay friends were not too keen because of their religious convictions. Muslims could only consume 'halal' food. She told me it was difficult to cope with Malays compared to the Chinese. According to her the Malays held 
"stereotyped" views of Tamils compared to the Chinese who were more "open minded" (Amala, Transcript, Dec. 8, 2014).

\section{The debate}

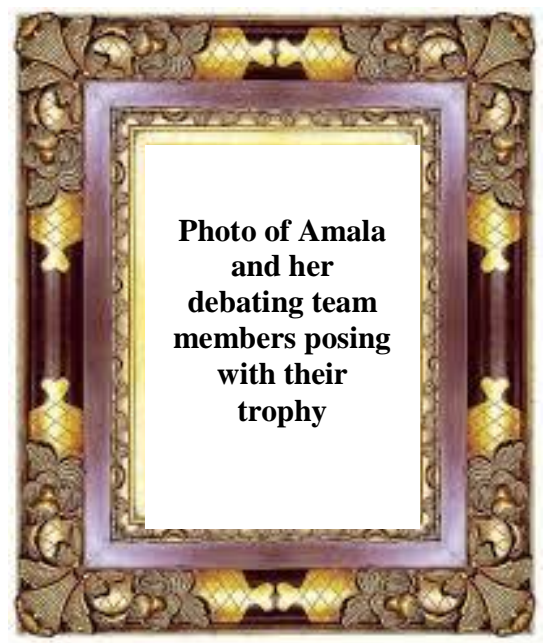

Figure 36. Photograph of Amala and her debating team members.

Amala told me that she took part in a Tamil debate at international level during her fourth year in national secondary school which made her aware of the importance of Tamil. She showed me a photo of her with her team members taken after the debate. She said that she suddenly realised there was a whole, new exciting Tamil world out there. "There were lots of things that can be done using Tamil, lots of exciting opportunities" (Amala, Transcript, Dec. 8, 2014). During that event everyone spoke in Tamil, a lot of knowledge was shared in Tamil. It made her appreciate that Tamil could be useful. Her team managed to walk away with the second prize. This boosted her confidence.

\section{A remarkable man}

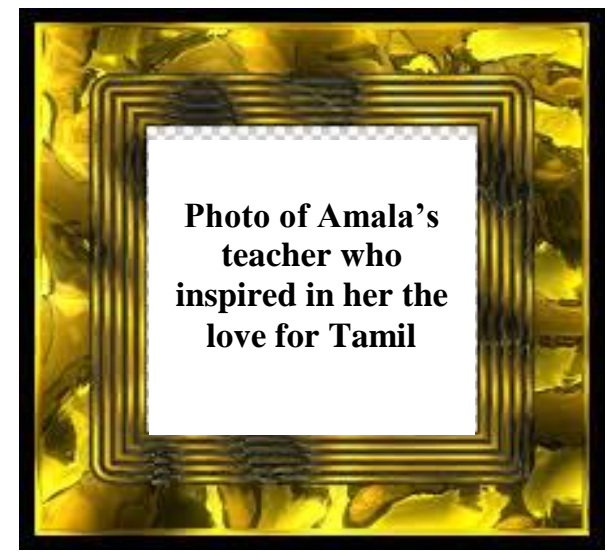

Figure 37. Photograph of Amala's teacher. 
She had great respect and admiration for this particular teacher who taught her Tamil in national secondary school. She showed me a photo of this teacher. She called him "my Tamil sir" (Amala, Transcript, Dec. 8, 2014). He inspired her to take pride in her heritage identity. He encouraged her to value Tamil culture and values. She learned to appreciate Tamil literature which she said was "so beautiful". His love for Tamil was so great that he had named his children Tamil Choodar (Tamil Flame) and Tamil Kathir (Tamil Grain). "Look the names of his children... shows how patriotic he is towards the language" (Amala, Transcript Dec 8, 2014). When they visited his home, they were so impressed at what they saw. There was a mirror on the wall which had great Tamil proverbs written on it. His study was full of Tamil books. "It was Tamil everywhere" (Amala, Transcript, Dec. 8, 2014). She was inspired to learn more about Tamil.

\section{What is it about us?}

Amala said that she was not embarrassed speaking in Tamil but she often regretted that she had come from a Tamil primary school. She was quick to inform me that her life at Tamil primary school was good and she had enjoyed her years studying there. It was because of the stigma attached to it. When her Tamil friends at university found out that she came from Tamil school, they asked her, "Oh, you are from Tamil school, is it?" "Why? What's wrong with that?"(Amala, Transcript, Dec. 8, 2014), she asked me. She told me that they often thought that if you came from Tamil school you would not want to mix with other people. She said this was not true. She said those who came from Tamil school often grouped together because they loved talking in Tamil.

\section{You are different too, you know}

Amala felt that there was a difference in the way those who came from national primary school perceived the world around them as compared to those who came from Tamil primary school. "We have different mind sets" (Amala, Transcript, Dec. 8, 2014). She cited a few examples: in the way these two groups (THLU-Ts and THLU-Ms)) moved with others; their behaviours; and the way they dressed. She felt that individuals need to conduct themselves appropriately according to the situation. One should not just do or say as he pleased. She said that those Tamils who came from a national primary school were "modern" and did not conform to Tamil culture and values. She said, "you 
should know your level". I asked her what she meant by this. She explained that as THLU-T there are certain traditional values that need to be observed. For example being appropriately dressed as a lady, the way a female conducted herself when talking to a male. "It is not nice if you talk loudly and laugh (Amala, Transcript, Dec. 8, 2014).

\section{Aren't you proud of your mother tongue?}

Amala did not mind if others ranked Tamil lower than English or Malay but she said that she was disappointed when Tamils themselves did not value their mother tongue. She informed me that some Tamils on campus refused to speak in Tamil even though they could. If Tamils themselves did not respect their mother tongue, she pointed out that the other races will not be bothered to. "We have lost", she said. "There's no point" (Amala, Transcript, Dec. 8, 2014).

She compared this situation with the Chinese and Malays. For them their mother tongue came first even though they came from national schools. The Chinese and the Malays gave priority to their heritage languages unlike the Tamils. She felt that Tamils who came from national schools gave more priority to English. "This is the problem I see among Tamils". The general feeling is she said, "It's only Tamil after all" (Amala, Transcript, Dec. 8, 2014).

\section{Life as a multilingual}

Amala informed me that as a multilingual, she used Malay, English and Tamil according to the speaker's comfort and fluency. She said if she moved with Malays and Chinese, she spoke in Malay and English. However, with Tamils she usually started with Tamil. But, the moment they started replying in English, she switched to English. She sighed, "I give up. What's the point?" (Amala, Transcript, Dec. 8, 2014).

In comparing her use of English and Tamil, she had this to say. She was quite uncomfortable when she used English because she was afraid that she might make mistakes especially with the tenses. "Supposing we make a mistake, I feel so embarrassed. Oh dear what have I said now?” (Amala, Transcript, Dec. 8, 2014). However, this was not so with Tamil. "I have spoken the language for so long that I am comfortable with it as it is part of me" (Amala, Transcript, Dec. 8, 2014). 
I asked her whether she felt discouraged if she made mistakes in English. Her reply was even though she made mistakes, she still continued because she wanted to correct her mistakes. "I want to learn. I want to become better" (Amala, Transcript, Dec. 8, 2014).

\section{"Wow" moments}

Her face lit up when she told me of a Nigerian friend on campus who was learning to speak Tamil. Every time he saw her he greeted her with a "vanakam" (greetings in Tamil) "you feel so proud that someone is learning your language. It's nice to hear someone coming up and talking to you in Tamil" (Amala, Transcript, Dec. 8, 2014). Another of her "wow" moment was in national secondary school. Her Chinese classmate was impressed with Tamil script and wanted Amala to teach her to write in Tamil.

\section{Coming out of the box}

She was happy with her life at university. She felt that she has made it. "I have come out of the box"(Amala, Transcript, Dec. 8, 2014) when she compared herself to some of her friends in Tamil primary school who dropped out after Standard Six and got married. "My friend is 20 now and she is married and has a kid" (Amala, Transcript, Dec. 8, 2014). Amala considered herself to have moved beyond the stereotyped role of a traditional Tamil woman who is seen as a caregiver who is totally dependent upon her husband.

Amala was a first year Chemical Engineering student. She told me that one needed to have good scores to do this course especially in Math and Chemistry. "So this is all like a motivation for me that makes me to study well and have a future and take it as a challenge" (Amala, Transcript, Dec. 8, 2014). This programme was her chance to prove herself academically.

\section{I can do something}

She told me that she took up Chemical Engineering for two reasons. Firstly, she wanted to prove to her mother that as a female she was no less intelligent than her brother. Her mother always praised her eldest brother for his intelligence and achievements. He was a Mechanical Engineer by profession. "I took up this course because it is tough and has more males in this field" (Amala, Transcript, Dec. 8, 2014).

She told me she was upset when her mother told her to take up teaching and become a Tamil school teacher just like her. Secondly, her maternal uncles this time 
discouraged her from taking up this course. She informed me that they ridiculed her and joked about the course she wanted to do. "They asked me whether I wanted to make bombs being a girl" (Amala, Transcript, Dec. 8, 2014). She said she could not be bothered with all these comments and was determined to go ahead with her plans to become a successful Chemical Engineer. "I want to show them I can do something" (Amala, Transcript, Dec. 8, 2014).

\section{Chapter summary}

The findings from the in-depth interviews provided data to address the three research questions. How do nine THLU-Ts tertiary students from an international university in Malaysia:

1. perceive the status of their HL in relation to English and Malay?

2. perceive that they are positioned by their peers (non-Tamils and THLU-Ms) when they use Tamil?

3. perceive the role of their families in the language choices they (the participants) make?

The following common issues arose from the participants' in-depth interviews. They were:

- $\quad$ participants' reasons behind language choices they made both in formal and informal contexts.

- $\quad$ participants' love for the Tamil language and how it bonded them to their families and heritage community members.

- $\quad$ participants' perceptions of how using Tamil, Malay and English influenced the way how non-Tamils and THLU-Ts perceived them in a multilingual academic environment.

- the roles played by Tamil schools and families of participants in encouraging them to use Tamil and retain Tamil socio-cultural values.

These themes are further refined and explored in the following chapter through in vivo coding. 


\section{Chapter 6 \\ Thematic Analysis}

\section{Overview}

This chapter presents the main themes that emerged after coding the interview transcripts of my participants. Once the themes were identified, I analysed the similarities, differences and conflicts and peculiarities. This analysis is the focus of this chapter.

I grouped the relevant sub-themes under separate themes and used participants' words to label them. They are presented in this style to closely reflect the participants' responses. Altogether five major themes emerged and they were: "Which language to use?", "Tamil is in my blood", "What is it about us?", "I shouldn't have opened my mouth" and "You got to come out of the box". I ordered the themes and relevant subthemes moving from the general to the specific. The rationale was by exploring the theme on "Which language to use?" (language choices), I was able to peel off the different layers or themes and uncover participants' journey as a THLU-T in multilingual academic context in Malaysia. This theme is centrally placed in this study as it foregrounds the processes that underlie how these THLU-Ts constructed their identities.

The following sections outline the main themes and subthemes emerging from analysis of the interview transcripts. I explored each of these themes and expounded the commonalities and differences between my participants. Quotations from my participants emphasised their voices and were data to support the analysis.

\section{Which language to use?}

I begin with the first major theme "Which language to use?" Table 2 illustrates this theme and its relevant in vivo sub-themes. 
Table 2. Theme one and its related sub-themes

\begin{tabular}{ll}
\hline Theme One & Sub-themes ( in vivo coding) \\
\hline $\begin{array}{l}\text { Which language to use? } \\
\text { Language choice in formal and informal } \\
\begin{array}{l}\text { contexts. Drawifferent, different people, different, } \\
\text { ethnic lines. }\end{array}\end{array}$ & $\begin{array}{l}\text { "Come on! We need to respect others" } \\
\text { - No, Tamil here please! Only English or } \\
\end{array}$ \\
\hline
\end{tabular}

The THLU-Ts used three languages (Malay, English and Tamil) in their daily interactions with students from different ethnic groups. They stated two reasons underpinning their language choices. They knew which language to choose as they had a multilingual repertoire, and they took into account the ethnicity of their interlocutor. Hence, the theme "Which language to use?" reflects the language choices that the THLU-Ts made in a multilingual context. None of the nine participants reported feeling uncertain or confused over their language choices in their daily interactions with different communities.

I will now illustrate how the participants made their choices by drawing examples from their interview transcripts. I begin with the first sub-theme.

\section{"Different, different people, different, different languages"}

Almost all participants interviewed responded that they made language choices according to the ethnicity of the other person. One participant reflected on her language experiences this way:

Since we are living in a multiracial country we have learnt three languages. We have to adapt and change ourselves according to situation. If I am with the Malays, I speak in Malay. If with the Chinese I speak English. With The Tamils I will speak in Tamil. This is the way of life. People are like this. My life experiences have taught me.... Different, different people different, different languages. (Darshini, Transcript, Dec. 10, 2014)

This was reiterated by another participant, Amala who said that she spoke in Malay, English or Tamil according to the ethnicity of the speaker. "I usually separate the three languages according to the speaker's race" (Amala, Transcript, Dec. 8, 2014). For the participants, language choices were made based on the ethnic group they are interacting with. "What language I use depends on whom I am with. With my Tamil friends I speak in Tamil while with my Chinese friends I speak in English and Malay 
friends I speak in Malay. It all depends on whom I am mixing with" (Vimal, Transcript, Dec. 19, 2014).

So most participants switched languages based on the people they were interacting with. Participants continuously adjusted their multilingual repertoire depending on the ethnicity of their interlocutors not the languages they speak. However, in the case of THLU-Ms it was different.

The participants expected the THLU-Ms to speak in Tamil. Language choice along ethnicity meant that Tamil language was the default mode whenever the participants met another Tamil. But this was not so with THLU-Ms. Participants talked of adjusting to the THLU-Ms' comfortability and fluency in using languages. "Let's say if the person (THLU-M) is comfortable like talking in English with me, I will talk in English and let's say they want to talk in Malay I will continue in Malay" (Suria, Transcript, Dec. 10, 2014). Munesan shared the same view. "When I feel that in that situation no one would be able to understand Tamil I would speak in English or Malay. If I feel that they can understand Tamil I will speak in Tamil” (Munesan, Transcript, Dec. 19, 2014). Their decision implied that the participants were operating from a position of control, although most participants were unhappy that they had to switch to either English or Malay when interacting with THLU-Ms. "You are a Tamil. Why don't you speak in Tamil" (Munesan).

The participants used similar approaches when selecting the appropriate language for THLU-Ms. "I would test out first by speaking in Tamil. If they choose to answer in Tamil, I would then continue. If not I would switch to the language of their choice (Malay or English).

For Suria, it was a matter of "mutual respect". He told me that "it was not fair" to expect all Tamils to speak in Tamil because they came from schools with different medium of instructions. Likewise, THLU-Ms should "understand our (THLU-Ts) problem. "If people understand this, then no one will be offended. This is how we learn to adapt" (Suria).

Making language switches was no easy task. However through continuous practice they developed fluency slowly. "Starting it was difficult. I was forced to switch. But as days went by it became easier. It became natural" (Vimal). 
When participants made the language switches, they assumed a powerful multilingual identity position without relinquishing their heritage identity. This is echoed in Darshini' statement, "I only change the language I speak "I'm still the same Dharshini. Not three different Dharshinis" (Dharshini). Being multilinguals, the participants were prepared to use multiple languages for effective communication with the other linguistic groups living in Malaysia.

The second sub-theme explored language choice in informal contexts.

\section{“Come on! We need to respect others"}

During their interaction with the non-Tamils, participants observed language preferences. The Malay students almost always spoke in Malay while the Chinese students preferred English. "Because I felt that Malays do not speak English much. I know that even if I were to speak in English, my Malay friend is going to reply in Malay. So might as well talk in Malay" (Mahes Rajendran, Transcript, Dec. 16, 2014). Nadesh felt that the Malays were offended if they chose to speak in English. "They insist in talking in Malay" (Nadesh, Transcript, Feb. 9, 2014).

On the other hand, with the Chinese it was different. The Chinese preferred using English. "They speak in English most of the time. If I were to speak in Malay, they made no comments. However, the response will be in English. So I'll continue talking in English” (Menaga, Transcript, Dec. 8, 2014).

The participants were sensitive to the language preferences of the non-Tamils. They went out of the way to include the non-Tamils in their conversations by making conscious language switches (to Malay or English) even though there were THLU-Ts

present. Darshini reflected on those times when she had Malay, Chinese and as well as her Tamil friends travelling together with her in her car:

This is like this. I'm driving and I'm bringing some friends in my car. I won't switch on the radio because we need to respect others. If I am alone or with my Tamil speaking friends, I switch on the Tamil channel. So if Chinese and Malay friends are in my car, I won't switch on the radio at all. Even with my Tamil friends I will talk in English if they (Malays, Chinese and THLU-Ms) are there because I don't want others to think that we are talking about them in Tamil. It's not polite. So in this kind of situation I will talk in English. (Darshini)

Suria reprimanded his Tamil friends (THLU-Ts) if they spoke in Tamil whenever Malays or Chinese were present. For Mahes Rajendran it was his feeling of "guilt" that stopped him from using Tamil when in the company of non-Tamil friends. For Mahes 
Rajendran it was his feeling of "guilt" that stopped him from using Tamil when in the company of non-Tamil friends. He felt that he had broken social convention of language use. It was important that the others understood what he said. "They won't know what I'm saying because they don't know Tamil" (Mahes Rajendran).

Most of the participants took it upon themselves as sort of a moral obligation or duty to make sure that the language rights of the different communities during social interaction in an informal context were respected. In their social interactions with the different ethnic groups, respect seemed to be the common thread that ran throughout their narratives. They took great care not to offend their Malay and Chinese friends. This earned them a lot of Malay and Chinese friends.

It was more common for the participants to speak in Tamil to other THLU-Ts outside the classroom than in class, for example at the cafeteria or when they gathered together in the lounge area. They also used Tamil when they went out with other THLUTs. During occasions like this, their topics were usually centered on Tamil movies and music. "We enjoy talking in Tamil, discussing the latest Tamil movie hits. Our favourite heroes... and love finding out popular Tamil songs. We even exchange and listen to Tamil ringtones" (Menaga). They were able to relate to the Tamil pop culture using Tamil. This suggested that the participants made connections with the international Tamil community through the social media.

So far, I have illustrated how my participants selected a particular language from their linguistic repertoire in an informal context. Now, their linguistic practices in a formal context are discussed.

\section{No, Tamil here please! Only English or Malay!}

The participants did not use Tamil when they were in formal classroom context in secondary school. During class discussions, they used Malay since this was the medium of instruction. On the few occasions when they happened to use Tamil in class, they were reprimanded by their teachers. For example, Munesan said that his teachers reminded them (the THLU-Ts) that they were no longer in Tamil schools. Dharshini commented that the teachers considered speaking in Tamil "a taboo" in the classroom. The participants felt apprehensive to use Tamil in the classroom as they feared open ridicule from their teachers who were Malays, Chinese and Tamils. 
In contrast, Thinesan said that he did not feel intimidated as his teacher helped him to see the reason. He explained, "My teacher told me that it was disrespectful to the others as they did not understand my HL. She also reminded the Chinese not to use Mandarin. We must remember we are in secondary school" (Thinesan). Thinesan accepted the reasoning given by his teacher. He was grateful to his teacher who had educated him on appropriate social etiquette. Interestingly, this seemed to suggest that participants did not feel that their HL was compromised if teachers were willing to provide logical reasons why HL was not encouraged in the classroom context as they were attempting to make sense of the new academic language and literacy practices in secondary school.

Most of the participants struggled the first few years of transition from Tamil school. The medium of instruction which was now in Malay posed communication problems. When Nadesh first came to secondary school he told me he felt like a stranger. "I was not used to seeing so many races together. There were so few Tamils" (Nadesh). Vimal felt he was “out of place. I don't think I belonged here” (Vimal). Suria described his initial experience as a "culture shock" (Suria).

Some participants spoke of how they managed their language problems in the classroom. Munesan sought the help of his Tamil friends who translated what the teacher was saying into Tamil. Munesan then managed to grasp the gist and answer in Malay. "It was so frustrating. It took a long time" (Munesan). Nadesh felt the same. He complained of the long tedious process of translation. "I think in Tamil and then translate into Malay or English. And then tried to understand what the teacher said back into Tamil" (Nadesh).

Now that they were at the university, English had become important as all subjects were taught in English. So participants spoke in English to their friends and lecturers in the classroom.

Even when they met their lecturers outside the classroom, they spoke in English too. They told me that they hardly ever used Malay with them, unless the lecturer was a Malay. Even then, this was rare. Thinesan and Darshini were actually surprised that the Malay lecturers spoke in English so well. They informed me that this was not the case when they were in secondary school. "Because in secondary school, it was not like this - 
we spoke Malay and more Malay. So when we came here when they speak so fluently in English it is good to see" (Darshini).

On the other hand, there were times when the participants used Malay in a formal context at university. Suria mentioned that he talked in Malay to the librarians and administrative clerks who were mostly Malays. Amala said that she used Malay in her transaction with the accounts clerk. In both these cases the people with whom they interacted were Malays. Besides this, Malay was occasionally used during official functions which Suria was required to attend in his capacity as a student leader. However according to Suria such official functions were very few and most official functions were conducted in English. In fact, nearly all of the participants lamented that since coming to the university their Malay proficiency had dipped.

My proficiency went very bad, was not as good as before. Used to write essays. My Malay language teachers used to photostat my essays and distribute to other students as samples. It was that good. But when I came here, my Tamil and English proficiency increased because all the time I used Tamil and English. I lost my touch with Malay. (Suria)

Participants described how their linguistic repertoire extended (from Tamil to Malay to English) when they moved from Tamil school to national secondary and to university. The essence of their language growth was cleverly captured by one participant. Stretching her arms wide horizontally, she said, "if we go to this side (pointing to her far left) it was Tamil. Then in the middle, it was Malay and now (pointing towards her right) it is English" (Darshini). For Thinesan it was learning languages "in stages" (Thinesan, Transcript, Dec. 10, 2014). For Munesan, Malay was the "number one" language that he used at secondary school (Munesan). Suria "lost touch with Tamil" once he left Tamil school. He also "lost touch with Malay" once he was at the university.

\section{Summary}

So far, it can be seen that the THLU-Ts knew when to use a specific language from their linguistic repertoire in order to achieve effective communication with the different communities they interacted with. They learnt to orient themselves differently, accommodating the language preferences of the different communities that they interacted with daily. They also observed the language norms in different educational 
contexts. In short, they were able to maneuver through their multilingual world through their language choices.

\section{"Tamil is in my blood"}

The second theme that emerged was a strong bonding to Tamil which reflected a strong affiliation to their heritage language identity. Table 3 shows the second theme that emerged from the data analysis and the relevant sub-themes associated with it.

Table 3. Theme two and related sub-themes

\begin{tabular}{|c|c|}
\hline Theme Two & Sub-themes (in vivo coding) \\
\hline $\begin{array}{l}\quad \text { "Tamil is in my } \\
\quad \text { blood" } \\
\text { Homes, Tamil } \\
\text { schools and } \\
\text { heritage } \\
\text { community } \\
\text { members - bastions } \\
\text { of Tamil language } \\
\text { and culture }\end{array}$ & $\begin{array}{l}\text { - Welcome home-it's time for Tamil now } \\
\text { - Birds of a feather flock together } \\
\text { - My "Mother Tamil" } \\
\text { - If we don't speak who else will }\end{array}$ \\
\hline
\end{tabular}

The participants' love for their heritage language and culture influenced the way they perceived themselves in relation to their heritage language community. By using their HL they were able to access and identify with their heritage community. This was evident in the way they projected themselves as THLU-Ts in their social interactions with their HL community. The THLU-Ts' deep emotional attachment to Tamil language impacted their identities.

A strong bonding to their Tamil school, their families, and the wider Tamil community enabled my participants to actively participate as a member within their heritage community. In this way, they were also able to maintain familial and communal relationships and stay connected to their heritage identity. Tamil schools, homes of participants and heritage community members were seen as the custodians of Tamil language and culture. 


\section{Welcome home-it's time for Tamil now}

There were three elements in the participants' lives which played a significant role in contributing towards the growth and maintenance of heritage identities. These are: the participants' homes, the Tamil schools and the Tamil heritage community.

All the participants stated that they used Tamil at home with their family members and relatives. They felt that they were able to stay connected to their heritage language by communicating in Tamil whenever they went back home during semester breaks. Nadesh's account exemplified this:

When I got back home I had this urge to speak in Tamil. I was always using English or Malay in the university and in schools. Very little Tamil only with my Tamil friends. But at home I will use Tamil almost all the time about 90 percent. (Nadesh)

The desire to speak in his heritage language was fulfilled at home.

My mother is a Tamil school teacher and I always talk to her in Tamil. This helps me to maintain my fluency. I also use Tamil with my siblings. We have to continue talking in Tamil otherwise we may forget certain words, how to use them. I think home is the best place to practise. (Amala)

Amala felt that her Tamil proficiency improved at home where she used it more than she used it at university.

On the contrary, Thinesan felt differently. He said that when he went back home he used Tamil so much that he was afraid that he might lose his proficiency in English. He explained that it was always difficult for him to switch into English once he returned to the university:

However whenever I went back home, I spoke in Tamil. This did not help me to improve my English. It was difficult to start talking in English again when I went back to campus. No one spoke in English at home - only Tamil. Perhaps it was not necessary because all of us were Tamils. So if I returned home for holidays for at least a week, this short interval made it harder for me to get back into English speaking mode again. I needed to switch into English immediately in Uni. This was difficult - switching immediately from Tamil to English. (Thinesan)

The participants felt that in using Tamil at home and with their family members, they were able to maintain close family relationships. Their strong affiliation to their HL was born out of the desire to be included in family gatherings and outings. It was during these occasions they were able to be themselves without having to take on a multilingual identity. They felt relaxed and happy in the company of family members 
and relatives. For Darshini it was the family's annual holiday trips together which strengthened their familial bond. "We always spoke in Tamil when we were together. We felt so close" (Darshini).

Speaking in Tamil was also important as a means to connect with the older generation. Darshini said that during family social gatherings, she made sure that her cousins spoke in Tamil to their grandmother as she could not understand English. "My grandmother can't understand English at all. The older aunties and uncles understand English a bit. It's not nice you know" (Darshini).

She felt that it was disrespectful to ignore the older generation by not speaking in Tamil. Her comment suggested that Tamil was seen as an intergenerational language that bridged the generation gap between the grandparents and grandchildren.

For Mahes Rajendran, those times when he was with his family on holiday trips were the happiest. He talked of how he felt during those moments. "We were speaking in Tamil mostly. Sometimes we spoke in English may be one or two words. That's all. Never in Malay. I felt happy and free. I can say what I like. I can be myself" (Mahes Rajendran).

He felt that he was able to express himself freely without fear of making mistakes in pronunciation or using right choice of words. He told me that if he was talking to THLU-Ms in Malay or English, he had to be careful of "grammar, tenses and sentence construction" (Mahes Rajendran). The freedom of expressing his feelings in Tamil brought him comfort. In the company of his family members, he was able to let his guard down and project his heritage language identity. He felt comfortable and relaxed when he connected to his family's linguistic and cultural heritage.

Most participants felt that using Tamil established strong family ties and the use of other languages were not welcomed within the family circle. For example, the time when Munesan spoke in English during a family picnic. A sudden call from his Malay friend caused Munesan to switch from Tamil to Malay and English. When Munesan switched languages (from Tamil to Malay/English) it briefly disrupted the jovial mood. "It sort of disturbed the fun mood" (Munesan). Munesan's cousins were not happy that he spoke in a language other than Tamil. For them English and Malay were seen as language of intrusion at that moment which disturbed the happy family atmosphere. 
The participants' narratives suggested that Tamil fostered close family relationships. When their HL was used during family social events, they felt that they were able to connect to their family members and relatives. This suggested that the world the THLU-Ts lived in with their family members and relatives was primarily constructed in Tamil and that English was not relevant for sustaining family relationships. Darshini described how she felt when she attended social gatherings hosted by her father's side of the family:

I hate going for these functions. My cousins they all studied in national secondary schools. The bond between us is not strong. My cousins the younger ones ... the youngsters will group together. I will be sitting alone. There will be two groups. My cousins will all be talking in English and I will be alone. It's ok for my parents because they will be talking to people of their age. My cousins who are younger they will all be talking in English. I will be sitting alone. So at that point of time I will feel very, very depressed. (Darshini)

This illustrated how speaking in English affected family relationships. When her cousins spoke in English, Darshini felt excluded because her cousins came from national primary school where the medium of instruction was in Malay. On the other hand, Darshini felt more comfortable using Tamil especially during family events. It had always been the norm to use Tamil whenever she attended social gatherings organised by her maternal relatives. Speaking in Tamil brought the maternal side of the family closer and enhanced family bonding; but alienated her from her father's side of the family.

The participants also developed a strong awareness of their heritage identity when they used Tamil at home. Thinesan was grateful to his parents for having sent him to Tamil school as this nurtured in him a love for Tamil language and Tamil culture. "Actually I have to thank my parents, that they sent me to Tamil school and taught me Tamil" (Thinesan). Nadesh and Suria explained that their parents chose to send them to Tamil school so that their children "would not lose touch with Tamil". Darshini's father encouraged her to use Tamil at home so that their heritage culture can be kept alive. "He told us that we must continue speaking in Tamil. Otherwise we may lose our culture" (Darshini). It can be seen that the participants' parents valued their HL as a resource and had taken positive actions to maintain their HL in the next generation. As a result almost all the participants were motivated to enrol their children in Tamil primary school in the future. "In future, I will definitely send my kids to Tamil primary school. Knowing 
Tamil will be an asset. Knowing an extra language is always an advantage. More important, our culture and language will not be lost" (Amala).

The high value the participants had placed on their HL and the responsibility they felt to pass their HL to the next generation were not surprising given that their (participants') parents had played a prominent role in promoting HL maintenance from an early age.

On the contrary, there was one participant who was not in favour of sending his children to Tamil school in future even though he valued Tamil language. Nadesh did not want his children to experience the problems he had faced while he was in secondary school. "I had a tough time at secondary school" (Nadesh). However, he also wanted his future children to learn Tamil. So to overcome this, he said, "I will hire personal tutors to teach them how to read and write Tamil at home or I will send them for tuition" (Nadesh). Vimal, however, had a different take on this aspect. He told me that he would prepare his children ahead before they entered secondary school. "I know they will face language problems so I will make sure that they brush up their English and Malay speaking skills" (Vimal).

It was also interesting to note that some participants' parents encouraged their children (the participants) to use English at home. Amala's father for example, made sure that Amala spoke in English so that she could polish her English speaking skills. He saw this as necessary because it would help her in the transition process from Tamil primary school to secondary school:

Because we used Tamil daily at home to communicate, my father advised me to use English to improve my proficiency. He will always talk to me in English. He said since you are in secondary school now, you need to speak in English more. (Amala)

One participant's parent had a different reason for encouraging his daughter to speak in English. Darshini's father wanted her to use English more at home because he wanted to prove to his relatives that Darshini was proficient in English although she had gone to a Tamil primary school:

My father's relatives thought that if you studied in Tamil school, my English will not be fluent. They compared me to my cousins who had gone to national primary schools. So my father motivated me to speak in English at home. (Dharshini) 
It can be concluded that although most participants considered their homes and Tamil primary schools to be the places of their heritage survival and continuity, yet there were a few exceptions.

The next section explores participants' experiences at Tamil school.

The participants reported that they felt at home when they were in Tamil school. All the nine participants had positive things to say of their Tamil primary schools. They talked about their experiences at Tamil primary school with exuberance and expressions of joy on their faces. They shared good memories with me and spoke fondly of their experiences in Tamil primary school. For Mahes Rajendran it was a place he longed to return. "I wish I was back in my school again. I miss my Tamil school” (Mahes Rajendran).

The participants pointed out their reasons why they could not forget their primary school experiences. According to Vimal and Nadesh it was because of the common language they shared.Vimal commented that he felt comfortable in a Tamil school environment because his classmates were all Tamils and they would all speak in Tamil. He missed this when he went to national secondary school. "I had no problems communicating with them (Tamil school mates). I was so happy" (Vimal). Nadesh compared the Tamil school environment to home. "Everywhere there were Tamil speaking people. I felt at home" (Nadesh).

Amala did not enjoy her first three years in national secondary school because she did not have many Tamil friends who could speak in Tamil. "Besides me, there was only one other Tamil girl and it took me a long time to make friends with the other races" (Amala). She missed the friendship she had enjoyed with her school mates in Tamil primary school. "We used to be a gang moving and doing things together. It was not like before" (Amala).

Darshini, Suria, Thinesan and Menaga enjoyed close relationships with their teachers in Tamil primary school and the pastoral care they were given. They thrived and performed well academically under the guidance and supervision of their teachers. The participants spoke about the intense training received in Tamil primary school which played such a big role in their academic achievement. Menaga said that her teachers in Tamil primary school were so committed to the students' academic progress. "They always gave 100\% effort to help the students succeed. They give the students a 
lot of practice to help them improve. Sometimes they scold and discipline the students but it is out of concern" (Menaga).

Menaga felt that the motivation and encouragement enjoyed in Tamil primary school were lacking in national secondary school. "We (the Tamils) won't have the same support in secondary school (Menaga). Their teachers in Tamil school helped the students achieve excellent results in UPSR (Primary School Achievement Test). Eight of the nine participants interviewed scored a maximum number of seven As in UPSR. Only one participant, Suria, scored six As. To illustrate how dedicated their teachers were, Nadesh told me that a month before UPSR, his teachers organised weekend extra classes to expose students to exam strategies and answering techniques. The students stayed at school over the weekend and the teachers took turns to prepare food for them. "They were more like our parents. We studied together, ate together and slept together" (Nadesh).

The participants acknowledged that they did not receive such care and attention in national secondary school. There was little supervision or guidance in national secondary school unlike Tamil primary school. In retrospect, Thinesan contrasted his school experiences as follows: "UPSR was not a major public exam, yet the Tamil school teachers showed great concern and they took care of us so much. I did not receive such care and attention in secondary school. He informed me that he did well at SPM level although he did not receive much support from teachers at secondary school. "This could be because of my Tamil school teachers. They had prepared us so well to sit for exams. We knew what we had to do to succeed" (Thinesan).

Menaga summarised her Tamil school experience in this way. "This is the beauty of Tamil school. You are provided with a platform to do well. All you got to do is work hard" (Menaga).

The participants kept referring to their deep attachment and affection for the Tamil teachers who had played such a big role in their academic achievement and stayed in touch with their Tamil primary school teachers.

The next sub-theme dealt with how the participants expressed their bonding to their wider heritage community. 


\section{Birds of a feather flock together}

The desire to stick together as a form of solidarity among the participants was so strong when they were in secondary school. They felt safe as long as they were in a group because they were in an unfamiliar environment. Munesan highlighted the contrasting differences between Tamil school and secondary school contexts:

I suffered a lot during my first year (form one). Coming from an environment speaking Tamil all the time and all the subjects were in Tamil. And now having to speak in BM (Malay) and English were very difficult. (Munesan)

His new surrounding where Malay and English were being used as the only languages of communication posed a problem to Munesan, and the other participants after spending six years immersed in a Tamil environment. This transition process was challenging, especially during the first year in secondary school.

Vimal spoke of another possible underlying reason for the THLU-Ts to group together in secondary school:

After 6 years in a Tamil school, I was going to a new environment with majority Malays. I tried to continue like the way I was in the Tamil school but got into some problems. I couldn't adapt to their (Malay) culture. (Vimal)

He had to face a predominantly Malay community at secondary school whose language and culture were different from his. Making the necessary adjustments posed some challenges.

However in Amala's case, it was different. Amala said that she felt brave when she was with her group of Tamil friends who had come from Tamil primary school. "We moved together in a gang during recess time. In class I sat together with my Tamil friend" (Amala). She had other reasons for seeking the support of fellow THLU-Ts as she was often bullied by her Malay classmates initially. She was often frightened by them:

And then some Malay girls will come and they will be like bullying me you know. They will come and say "oh you are from Tamil School". The tone they took up was not good. Sometimes they will call me ..... use the word ( She did not mention the word). So at that time I was scared to be in that school. And then I went and told my father "please send me to another school. I will not survive here. I really cannot take it". I was depressed. (Amala)

Like the other participants, Amala felt alienated when she entered secondary school. She was overwhelmed by the new environment as she was not used to interacting with different communities other than THLU-Ts. Furthermore, the school 
language rules did not encourage HL use. "It was because I did not come from national primary school like them" (Amala). So, she found herself being socially excluded from participating in the discursive practices of the secondary school. Tamil was viewed as an impediment to inclusion into the mainstream (those who came from national primary schools).

She countered this hostility by drawing strength from other THLU-Ts in the secondary school. She overcame her fear by staying close to her Tamil friends because she felt protected in their company. After some time the bullying stopped as she grew more confident and learned how to handle her bullies, thanks to her Tamil friends.

In addition, Amala preferred the company of other THLU-Ts as it gave her the opportunity to use Tamil. This kept her connected to her heritage community which made her feel comfortable and safe. However, this was misconstrued by the rest of her classmates. She said that this act of grouping together of the THLU-Ts was perceived as though the THLU-Ts wanted to exclude the others (Malays, Chinese and THLU-Ms):

Because they (the Malays and Chinese) think if you come from Tamil school you would not want to mix around with other people groups. It's not like that it's just that we give priority for our own language. I feel happy and safe. (Amala)

Amala sometimes regretted that she had gone to Tamil school because of the reception she received from her Malay and Chinese classmates at secondary school. "I always felt they were looking down at me. Somehow I have the feeling that people have a bad impression on us" (Amala). Another participant (Darshini) also expressed the same view. She said she received pitying looks from her classmates that made her feel uneasy:

They looked down at me; like they were sorry I came from Tamil school. They felt that those who came from Tamil school cannot speak good Malay or English. So they left me alone. Because of this we Tamils who came from Tamil school grouped together. (Darshini)

She highlighted that lack of proficiency in Malay and English impeded much communication with her Malay and Chinese classmates. As a result, the Tamils grouped together. Amala and Dharshini differed in their views as to why they were not included in classroom interactions by the Malays and Chinese. 
In contrast, some participants like Suria and Nadesh took a defiant attitude when they were confronted by the other communities on their use of their HL in secondary school. Nadesh had this to say:

We did not care. Later on when we used to meet more Tamil speaking students, we got together in a group and spoke in Tamil. Even in the class if there are Tamils we will talk among ourselves in Tamil. (Nadesh)

However, Nadesh was a THLU-T who stood out from the rest of his counterparts. Not only did Nadesh stand his ground in using Tamil with his group of Tamil speaking friends, he was able to initiate changes in the way THLU-Ts were perceived by THLU-Ms as well as the other communities. He questioned why he should be embarrassed speaking in his mother tongue. It was only natural that he would speak in Tamil whenever he was with other THLU-Ts. "People should realise this and learn to accept it" (Nadesh). In fact, Nadesh managed to "convert" the THLU-Ms and soon the Tamil speaking group started growing. "At first they (THLU-Ms) started talking in English. But later on after looking at us they started talking in Tamil. Soon there were lots of us speaking in Tamil. We managed to convert them almost" (Nadesh). Even his Malay and Chinese schoolmates accepted this. "My Chinese and Malay friends were ok with this. It didn't matter since I could communicate with them in English or Malay" (Nadesh).

The last example illustrates how heritage community members came to the Suria's assistance when he encountered problems at university. It was interesting that Suria spoke of both THLU-Ts and THLU-Ms. He saw these two groups as being part of the greater Tamil community.

Suria had learnt that it was important for Tamils to stick together, because "being a Tamil, we can depend on one another, should a problem crop up" (Suria). He talked of the time his Tamil friends (THLU-Ts and THLU-Ms) rallied around him when he faced difficulties in organising the annual science exhibition for the university. He was grateful for the support received from them:

All my Tamil friends who were not in the committee they came and helped me. They helped me (with emphasis). They said, "Surya ok let's do this together." ... Yeah the Tamils they came and helped me to set up the hall get the sponsors, science equipment and all the rest. They helped me a lot. They were there for me. (Suria) 
The event was such a success that the head of school and the Vice-Chancellor congratulated him. "I don't think I would have made it without them (the THLU-Ts and THLU-Ms)" (Suria). He was convinced that his success was the result of support from his heritage community which had stood by him in his moment of need.

The next sub-theme reflected my participants' strong affiliation to their ethnic and cultural identity. The special bond they felt with their HL and the socio-cultural values that it embodied is evident in their narratives.

\section{My “Mother Tamil” (என் தமிழ் தாய் ).}

I found that in their narratives the participants spoke of a special bond with or tie to Tamil language. They were so loyal to their HL that the love they had for Tamil was almost bordering on reverence. Thinesan, Suria and Amala referred to the teachers who taught them Tamil as their "Mother Tamil"/“Tamil Tay" with awe and respect in their voices. The concept of "Tamil Tay" or "Mother Tamil" illustrated this special bond.

Amala was inspired by her teacher to know more about her HL. She told me that she learnt to appreciate the beauty of her HL and culture from him. She looked up to him for initiating her into the literary works of Tamil:

He was truly a remarkable example as to how a Tamilian should be. He changed the way I use to think. He was my "mother Tamil” (என் தமிழ் தாய்). He opened my eyes. He made me realise that Tamil was a rich language. (Amala)

Likewise, Suria and Thinesan extolled the virtues of their teachers who taught them Tamil:

She taught me like a mother would. She was very patient and trained me. She showed so much love and concern. She was so concerned that I should be fluent in Tamil that she gave me lot of incentives. She used to sit together with me and fed me with sweets and food so that I would be motivated. (Suria)

She was more like a mother to me. I have never met anyone like her. She inspired me to love Tamil. She taught me for 3 years. A lot of teachers have come and gone but she still remains in my memory. She was like a mother figure. My knowledge in Tamil increased because of her. She insisted that I should not give up learning Tamil even in secondary School. "You must continue learning Tamil.” (Thinesan)

Their stories suggested the concept of "Tamil Tay"/ "Mother Tamil" was as a cultural symbol which connected them to their HL. By using this, they evoked a powerful image of a mother-child relationship. Tamil language was their mother and my 
participants were her loyal and devoted children. Three of the participants saw in their teachers the personification of their HL.

The following account illustrated how the various attributes of a mother were evoked by the participants as they alluded to the concept of "Mother Tamil/Tamil Tay.

Mahes Rajendran spoke of his connection to Tamil as though it was his birthright. He considered it a privilege to which he was entitled by birth. "Tamil came with me the moment I was born. It is in my blood. It comes naturally to me". Once again, I saw the metaphor of a mother -child bonding. "Mother Tamil" / "Tamil Tāy" had given birth to him and he saw himself as a loyal and devoted Tamil speaker. This same sentiment was echoed by Vimal.

Tamil was "close to my heart and it is a part of me" (Vimal). His words reflected a deep emotional attachment to Tamil and at the same time referred to something he was endowed with at birth. Just like Mahes Rajendran, Vimal spoke of a blood connection to Tamil. This again highlighted the blood tie between a mother and her child.

Darshini brought out the attributes of a mother as one who nourishes and cares for her children. She said that Tamil was her mother tongue and that "Tamil is giving me (her) rice". She explained that how being educated in a Tamil school has helped her to enhance her personal development. She has grown to be resilient, hardworking and a determination to succeed. She saw "Mother Tamil"/ "Tamil Tāy" as providing the nourishment necessary to grow. Rice has the property of sustaining life. "Mother Tamil"/ "Tamil Tāy" is seen here as a life giver.

The concept of mother-child relationship was so strongly felt by the participants that they considered any lack of respect for Tamil was an act of betrayal. This is illustrated in Menaga's comment, “when Tamils don't give importance to Tamil and don't want to speak in Tamil but instead try to master another language like English. It is like losing your culture, your race". It was like a child denying its relationship with its mother.

One participant saw Tamil as a language that teaches family, cultural and moral values. This conception of Tamil was as a mother who teaches her children respect, moral values, familial obligations and duties:

It teaches us to be respectful. For example in Tamil we need to add a suffix to pronouns as a mark of respect especially when you talk to your elders like "vangga", "pongga". Where else in English, it is the pronoun "you" or "I" for 
everyone irrespective of age. This is part of Tamil culture so Tamil teaches me more of my culture. I also feel family values are taught through Tamil language. Tamil teaches us to respect. I feel the great epic Thirukkural which was written 2000 years ago till today is so relevant which teaches on moral values. (Nadesh)

The section on "Tamil is in my blood" concludes with the last sub-theme.

\section{"If we don't speak, who else will?"}

In this section, the participants talked about their loyalty to their cultural heritage. All of them insisted that speaking in Tamil to both THLU-Ts and THLU-Ms was vital if they wanted to keep their culture and traditions alive:

If you don't talk in Tamil our generation will be gone. No one will speak the language. We would have lost everything. (Dharshini)

Menaga felt strongly that it was the duty of every Tamil to learn Tamil and to continue using it. This was important to preserve their identities as Tamils. In fact, "no one else will help to propagate the Tamil language" (Menaga). The heritage practices of the Tamil community would only be kept alive by continuous use of Tamil which she considered to be the primary responsibility of every Tamil. Thinesan suggested that Tamil parents should send their children to Tamil primary school if they wanted to prevent language loss.

The participants kept their language traditions alive by ensuring that they spoke in Tamil with their Tamil friends in public places. Sometimes they received disapproving looks from people around them but this did not seem to bother them. "We don't care. We will just talk in Tamil. Because it's our language. If we are not using who else is going to use the language. So we just use tamil whenever we go out" (Amala).

Thinesan on the other hand, was proud to speak in Tamil in public because he was aware of the rich cultural tradition associated with his HL. "Tamil is an ancient language and it has a rich past and culture" (Thinesan). He was grateful to his parents for having sent him to Tamil primary school.

The participants also felt that they need not be embarrassed to use Tamil in public as the other communities also used their own HLs. "Whenever they go out (referring to the other races) they talk in their language (their HLs) especially like the Chinese and Malay. So it's not something new. If they can do this so can we" (Amala). 
Finally, one participant felt sorry for the Tamils who lacked proficiency in their HL. Such Tamils were unable to appreciate their rich HL culture. It was interesting to hear how she described herself as being "blessed" and "enlightened". These were powerful adjectives:

I feel I am blessed because I can read, appreciate and enjoy the treasures of Tamil literature like the Bagavadgita, Tamil classics etc. So if you can't read and write Tamil you miss the opportunity to be enlightened and appreciate these great works. (Menaga)

\section{Summary}

Overall, the participants exhibited a strong affiliation to their ethnic and cultural identity. This was reflected in the way they talked about their HL in relation to their Tamil primary school; HL and family relationships, HL and the Tamil community network and lastly HL and socio-cultural values. They enjoyed a unique bond with their HL- which they revered as "Mother Tamil"/ "Tamil Tay". They saw in their HL the different attributes of a mother, that of a care-giver, one who nourishes, imparting knowledge and a teacher of moral values.

Next, I describe the third theme that emerged after analysis of their interview transcripts.

\section{"What is it about us?"}

This theme dealt with how the participants positioned themselves during social interactions with the various communities including the THLU-Ms. It also looked at how the participants were perceived by these communities (Malays, Chinese and THLUMs). This theme ("What is it about us?"), expresses how the participants saw themselves as being uniquely positioned in a multilingual setting. This was their cry reverberating throughout their narratives. "Are we different because we come from a Tamil school? What is it about us?'(Amala). Table 4 illustrates this theme with its relevant subthemes. 
Table 4. Theme three and its related sub-themes

\begin{tabular}{ll}
\hline Theme Three & Sub-themes (in vivo coding) \\
\hline "What is it about us?" & • "You don't eat bread and butter. You eat rice \\
& and lentils, don't you? \\
Perception of themselves & - "Shame on you! After all, we can speak three \\
and how they felt others & languages". \\
saw them as THLU-Ts & - "Tamil schools, nothing good came out of it". \\
& - How do others see my HL? \\
\hline
\end{tabular}

\section{"You don't eat bread and butter. You eat rice and lentils, don't you?"}

To begin with, I will consider how my participants viewed those THLU-Ms who did not or hardly use their HL. From their narratives, it could be seen the participants had little tolerance for any Tamil (whether THLU-T or THLU-M) who did not speak in their HL. They felt disappointed and considered this as an act of dishonour against their heritage identity. "If a Tamil can't speak in Tamil, his mother tongue, it brings shame to him as he is not appreciative of his identity" (Menaga).

Some participants felt that the THLU-Ms were embarrassed to use their HL in public because the other communities would ridicule them. They concluded that the THLU-Ms did not value their HL, and that THLU-Ms had little respect for their HL or even their heritage altogether. "Maybe they feel that speaking in Tamil will affect their image or lower their dignity or that it will make others look down on them. That is one thing that I don't understand" (Munesan).

Amala brought up the issue of the perception of other communities towards their HL. She felt that it would be futile to expect the Malays and Chinese to respect Tamil if the THLU-Ms hardly used their HL.

The problem is when Tamils (THLU-Ms) themselves do not value Tamil. Some Tamils (THLU-Ms) refuse to speak in Tamil. The other races feel that if we Tamils ourselves do not respect our own language so why bother (Amala).

Although, Munesan offered reasons why the THLU-Ms rarely spoke in Tamil, he did not seem to be convinced. He was of the view that as a Tamil (whether a THLU-T or THLU-M), one should know how to speak in Tamil and need not be embarrassed speaking it. After all it was their mother tongue. He was used to seeing Tamils (THLUTs) using their HL while he was in Tamil primary school. However, he soon realised that they did not share his unique experience at Tamil school. "But many of them are not 
from Tamil primary (referring to THLU-Ms), so that could be a reason. When I speak to them (THLU-Ms) in Tamil they are not comfortable and struggle to reply in Tamil” (Munesan). He was aware that the THLU-Ms lacked proficiency in their HL and he excused them. So he made the necessary adjustments by speaking to them (the THLUMs) in English. "After all I can speak both languages (Tamil and English)” (Munesan).

Suria and Mahes Rajendran on the other hand, stated that whenever they spoke in English to THLU-Ms; they earned the disapproval of the other THLU-Ts. By speaking in English to the THLU-Ms, they were often reminded rather satirically "not to become a Peter" (Suria \& Mahes Rajendran). Suria also pointed out that he was often asked rather mockingly whether he ate "bread and butter" or "rice and lentils" (Suria).

This suggested that the THLU-Ts were offended when the participants (who were also THLU-Ts) interacted in English with THLU-Ms. Whenever the participants spoke in English to THLU-Ms, the other THLU-Ts felt that the participants were disassociating themselves from their heritage identity. Hence, the images of "bread and butter" and "rice and lentils" were juxtaposed indicating a non-HL identity and a HL identity respectively.

\section{"Shame on you! After all, we can speak three languages"}

In this section, the participants related how they contrasted themselves with the THLUMs. Seven participants positioned themselves favourably when compared to the THLUMs because of their proficiency in their HL. Menaga considered herself to be in a position of advantage. Menaga felt that being competent in Tamil and English would enhance the image of a THLU-T. Unlike a THLU-M who is competent only in English. "If you are fluent in both Tamil and English that would be better. If you (referring to THLU-M) speak only in English, this does not improve his image” (Menaga).

Having proficiency in their HL as well as in English and Malay made the participants feel powerful. They had the option of selecting Tamil, Malay or English in their social interaction with the THLU-Ms. In comparison, the THLU-Ms had fewer language choices. It was either English or Malay. Vimal spoke in a patronising tone about the THLU-Ms: "We try not to make their (THLU-Ms) lives difficult by speaking in Tamil. After all we (THLU-Ts) can speak in both English and Malay" (Vimal). The participants felt that they were in a superior position when compared to the THLU-Ms as 
they (the participants) could use three languages (Tamil, Malay and English) compared to the THLU-Ms who knew only two (Malay and English).

Nadesh recalled those times when he felt empowered during his secondary school days. Some of his classmates who were THLU-Ms approached him for some help in solving a math problem. He chose to explain in Tamil. He smiled cheekily at me. "I just wanted to have some fun. I reverted to Tamil when I saw the looks on their faces" (Nadesh).

For these seven participants, it did not matter if the THLU-Ms refused to speak in Tamil to them. Nadesh's and Menaga's accounts illustrated the stance the participants took:

It is ok if they don't want to speak in Tamil but choose to speak in English. Maybe they feel ashamed to speak in Tamil and usually they will form their own group with other Tamils who prefer to speak in English. I have no grudges or bad feelings about them as it is their choice. (Menaga)

Nadesh felt that, "if they (THLU-Ms) don't want to speak in Tamil that's entirely up to them. I will just leave them alone. If they need us they will come to us. They know that we can speak in English" (Nadesh).

Their remarks suggested that the participants positioned themselves as equals or sometimes higher than the THLU-Ms. They felt that their proficiency in their HL added value to their multilingual repertoire. This facilitated a powerful position in which they could choose to interact with the THLU-Ms not only in Tamil but also in English or Malay if they (the participants) desired.

It was also interesting to note that some participants spoke of the lack of heritage cultural values amongst the THLU-Ms. As a result, they seldom interacted with the THLU-Ms. They had a negative perception towards them. Amala said that the THLUMs lacked respect for their heritage culture which was demonstrated in the way the THLU-Ms dressed and behaved. "They chose to dress however they liked. Often not appropriate. They said and did whatever they liked. Not bothered by what people thought of them" (Amala).

Amala took an authoritative and judgemental stance as she felt that she had more knowledge of their heritage culture and practices and she could inform others about them. To Amala, the THLU-Ms who were not appreciative of their ethnic and cultural values and tradition and did not observe them were outsiders. They (the THLU-Ms) 
were not included as members of their HL community. By giving little value to HL cultural values and practices, the THLU-Ms distanced themselves from their heritage community.

Suria observed that his flat mates who did not come from Tamil school (THLUMs) behaved in a manner unbefitting to their heritage cultural values. He said the boys (THLU-Ms) from the university used to get drunk and became loud. "They think that if you speak in English, there is a social life. They party, drink, smoke and become very noisy. We (the THLU-Ts) don't behave in this way. Although we speak in English, we know our limits" (Suria). It was interesting to note that Suria and Amala kept referring to the THLU-Ts "knowing their level" and "knowing their limit" as markers of heritage identity.

His sense of entitlement to HL cultural values allowed him to adopt a position that was critical of the THLU-Ms. The examples suggested that Amala and Suria saw themselves in a privileged position to criticise and mock the THLU-Ms by virtue of both their perceived ownership of their HL. Thus they drew a distinction between THLU-TS like themselves and THLU-Ms based on whether heritage values and practices were observed. The failure of the THLU-Ms to practice their heritage cultural values and traditions was seen as an impediment which made the participants view the THLU-Ms as outsiders and the THLU-Ts as insiders.

Unlike the other participants, Dharshini said that she was afraid to speak in Tamil if she was in the company of THLU-Ms. She was constantly aware of her surroundings. Since she was in an international university, this meant that she had to use English which was an international language. Dharshini considered her position as a THLU-T had little value in an international context. Thus, she was hesitant to use Tamil and always started her conversation in English with the THLU-Ms. Furthermore, she felt that the THLU-Ms would "look down" (Dharshini) if she were to speak in Tamil. She chose to "play safe" (Dharshini) by inserting a few words in Tamil to see what kind of reception she got. If it was favourably received, then she would continue in her HL otherwise it would be English all the way. This suggested that Dharshini was not willing to take risks. She even spoke in English to other THLU-Ts at the expense of her HL. This was because she placed more importance on the social context which warranted English use. English was the medium of instruction at the university as such she abided 
by the university regulations which stipulated the use of English in the classroom. Her obedience in observing this rule even extended to outside the classroom. Thus she spoke in English first, to both THLU-Ts and THLU-Ms even outside the classroom and only ventured to use Tamil fully if the other party (the THLU-Ts and THLU-Ms) was encouraging.

In Thinesan's case however, he used his HL when in the company of THLU-Ts and THLU-Ms. His THLU-M friends always tried their best to respond in Tamil and this was appreciated. As Thinesan commented, "I admire people like this. I have many friends who did not come from Tamil school (THLU-Ms). They did not go to Tamil school yet they want to speak in Tamil" (Thinesan). He said that these friends (THLUMs) regretted not going to Tamil schools and they wanted Thinesan to teach them Tamil. This suggested that although the THLU-Ms lacked expertise in their HL, yet Thinesan felt that his position as that of a HL expert enabled him to share his expertise with the THLU-Ms. The THLU-Ms valued his HL proficiency and thus looked up to him. For Thinesan his HL competency was valued as a linguistic asset. Tamil empowered him.

Suria and Munesan observed that there were two different groups of Tamils (THLU-Ts and THLU-Ms) both at secondary school and also at university. They divided these groups based on the languages they spoke. The first group of Tamils came from national primary schools and they spoke in English (THLU-Ms). While the second group of Tamils spoke in their HL and they came from Tamil primary schools (THLUTs). Although Munesan acknowledged the existence of these two groups, he was not affected by this- unlike Suria. "So basically there are two groups of Tamil friends, one group speaks in English and the other speaks in Tamil". (Munesan). However, this was not a problem to him, “after all I can speak both languages (Tamil and English). I'm okay with this" (Munesan).

Suria explained the position he took:

There were two groups here. One group of Tamils spoke in English those who came from national schools (THLU-Ms) and the other spoke in Tamil those who came from Tamil primary school (THLU-Ts). We (THLU-Ts) will be talking in Tamil and we won't mix much with them. We don't normally go out together. I was not interested. I will help if they (THLU-Ms) ask. That's about it. They (THLU-Ms) won't talk much to me. Like those of us who speak in Tamil (THLUTs) they (THLU-Ms) will segregate us. (Suria) 
Munesan positioned himself equally between these two groups; in contrast, Suria chose to position himself with other THLU-Ts. He stepped out of a HL identity reluctantly if he saw a need, like the times when the THLU-Ms approached him for help.

Like Suria, Dharshini was unhappy with the cold reception she received from THLU-Ms whenever she spoke in Tamil. However, the position she took when interacting with the THLU-Ms was different. She would start off talking in Tamil initially and once she saw "weird expressions" (Dharshini) on their faces (THLU-Ms), she would immediately switch to English or Malay. She knew then that the THLU-Ms were not happy. In doing this, Darshini voluntarily stepped out of her HL identity momentarily and adopted a position which accommodated a multilingual identity.

Nadesh was able to change the initial perception that the THLU-Ms had regarding THLU-Ts. He narrated to me how he made the THLU-Ms in his school speak in Tamil. "They (THLU-Ms) had no choice but to speak in Tamil if they wanted to become our friends" (Nadesh). "Why would they want to become your friend?" I asked. To which he replied, "I was in charge of a lot of school activities, like debates and public speaking competitions" (Nadesh).

Nadesh was able to exercise power over his classmates because of his language proficiency. Participation in debates and public speaking competitions required language competency. Furthermore, in his capacity as the person in charge of running these school activities, he was able to enjoy the special privileges that were associated with this responsibility. The THLU-Ms had the duty to listen to him as they had limited rights as ordinary members in comparison to Nadesh who was positioned as more knowledgeable.

\section{"Tamil schools, nothing good came out of it"}

Some participants felt that their positions as THLU-Ts were further disadvantaged when their relatives viewed quality of education at Tamil schools poorly when compared to national primary schools. Amala vividly recollected the scene that took place in her house, a long time ago. Her paternal uncles objected to her being sent to Tamil school. They had doubts regarding the quality of education received. "She's not going to succeed. You think she's going to come up in life?" (Amala). Darshini and Thinesan had similar experiences. Thinesan's relatives were concerned that "the Tamil schools were not on par with national primary schools" (Thinesan). 
This unequal positioning of the THLU-Ts by their relatives when compared to the THLU-Ms increased the divide between these two groups. Thus when the THLU-Ts entered secondary schools, they were perceived negatively by the THLU-Ms. This misconception continued to exist until some of the participants challenged the inferior positions they (the participants) were assigned to.

The earlier section focused on the positioning of the participants with the THLUMs. This section then emphasises on how the participants positioned themselves with the different communities during social interactions. The positions they took up is discussed in relation to the how these communities (Malays and Chinese) positioned them when the THLU-Ts spoke in their HL in the classroom as well as outside the classroom.

\section{How do others see my HL?}

Some participants felt that using their HL was not accepted by their classmates and they were often ridiculed. "My classmates laugh at us. If you speak in Tamil, people look down. That's it" (Darshini). Other participants also reported similar experiences. Vimal often received disapproving looks from the rest of his classmates whenever he spoke in Tamil in class. "They looked at us as though we were speaking a bad language" (Vimal). Suria said that he was often called a "racist" (Suria) for speaking in Tamil with other THLU-Ts outside the classroom. Although the participants were upset at the remarks, they continued speaking in their HL. They resisted this negative labeling. Darshini expressed this clearly when she said "I came from Tamil school and I will speak in Tamil. I am not embarrassed. Why should I be?" (Darshini).

This suggested that these participants found it difficult to express their HL identities at secondary school where the desirable languages were either Malay or English. The imposed language norms seemed to hinder HL use. Some of the participants took a defiant stance when they felt that their HL identity was threatened.

Other participants were able to negotiate their HL identity without openly defying the academic language and literacy practices at school. This is exemplified in Vimal's account:

We continued speaking in Tamil but we do it differently. Before that we used to talk so loud that the whole class could hear us. But now we speak softly and also look around first to make sure it is safe to speak in Tamil. (Vimal) 
Nevertheless, there were a few participants who narrated unique experiences. In fact, they did not feel that they were positioned negatively when they spoke Tamil. Munesan for instance, said that although his Malay and Chinese school mates stared at him and his friends (THLU-Ts) whenever they spoke in their HL, yet none of his classmates teased them. "They seemed to be happy once I translated our conversation into Malay. They knew we were not saying anything bad about them" (Munesan). He explained that his Malay and Chinese friends were even willing to participate in the discussion once Munesan had translated. "Sometimes they (the non-Tamils) would join in" (Munesan). If they had any mistrust or suspicion earlier on, Munesan's translation had removed these.

For Nadesh, Menaga and Suria, some of their Malay and Chinese classmates showed interest in learning Tamil. There were a few Malays who attended the Tamil class conducted in the secondary school with Menaga. She often conversed with them in Tamil so that they could pick up Tamil quickly. Suria commented that a few of his Malay friends were interested in learning Tamil because they loved to watch Tamil movies. This seemed to suggest that popular Tamil culture had also impacted other communities living in Malaysia. Suria had a tinge of pride in his voice when he reported that his Malay friends were familiar with the leading Tamil artistes in the Tamil film industry. As a result, Suria, Nadesh and Menaga were recognised as being knowledgeable in their HL and culture which positioned them as a source of reference for the language (Tamil). This suggested that that their non-Tamil classmates also recognised that Tamil was not only spoken by the Tamils in Malaysia but had a broader use.

In contrast, Nadesh was unhappy with the unfriendly and critical reception he received from other communities whenever he used Tamil in public. He told me there were times when he was embarrassed to use his HL in the campus because of the way he was judged. "The moment I speak in Tamil, people look down. They thought a Tamilian who spoke Tamil does not know much. They judged me the way I spoke and what language I spoke” (Nadesh). When he became fluent in English they (non-Malay and THLU-Ms) revised their opinion of him. As a HL user, Nadesh felt that he was positioned unfavourably if he spoke in Tamil. Nadesh felt that having proficiency in 
English and Malay empowered him. He was respected by the various communities including the THLU-Ts:

They made me the spokesperson. I became part of their group (THLU-Ts) and they accepted me as one of them. They felt proud of me. Here is one guy who can represent us. They started to respect me. I think this is quite common in our community. Tamils respect when we speak English well compared to other races. I feel if a person knows more languages he has more advantages over others who do not know as many. Knowing a lot of languages helps. (Nadesh)

Whenever Nadesh used English in his social interaction with the others, he immediately positioned himself in a central or dominant role because of his language choice. He was especially admired by his counterparts (fellow THLU-Ts) because he was respected for his expertise in English, Malay and Tamil. This enabled him to actively participate in a range of academic contexts.

\section{Summary}

Generally, the participants reported that they were positioned positively when their HL was recognised and valued by others (the non-Tamils and THLU-Ms). However, when their HL was not valued, participants challenged the way they were positioned and learnt to negotiate their HL identity in a multilingual setting. Participants considered their HL as an important marker of their identity and thus positioned themselves as experts in their heritage culture. They placed great value on being able to display knowledge about their cultural heritage, religion, festivals, and rituals and considered themselves as cultural gatekeepers of their community. This position allowed them to speak with an authoritative voice on HL cultural values and practices including educating the THLUMs and others.

\section{"I shouldn't have opened my mouth"}

The next theme described the competing language ideologies in different educational contexts (at secondary school and at university). The participants talked about how Tamil was viewed in relation to English and Malay in multilingual environments. I have labeled this theme: "I shouldn't have opened my mouth" because the participants felt that they were stigmatised the moment they started talking to the non-Tamils and THLU-Ms. Table 5 shows how this theme is categorised into sub-themes. 
Table 5. Theme four and its related sub-themes

\begin{tabular}{ll}
\hline Theme Four & Sub-themes (in vivo coding) \\
\hline "I shouldn't have & $\bullet \quad$ "For me it's Tamil first and then English". \\
opened my mouth" & $\bullet \quad$ Malay is not really an important language \\
$\begin{array}{l}\text { Competing language } \\
\text { ideologies }\end{array}$ \\
\hline
\end{tabular}

Participants frequently reported feelings of inferiority ("putting you down") due to their perceived lack of competence in Malay and English. They talked about how they felt whenever they spoke in English or Malay to their friends in secondary school and in the university. They were often teased for their mispronunciation. Coming from a Tamil school, they had hardly any exposure interacting with the other communities including the THLU-Ms. Mahes Rajendran explained that he was judged for his "Tamil accent" and it was hard to let go of it immediately:

I was still learning the languages (English and Malay). Everything was still new. So my friends will often ask me to repeat if they don't understand. Sometimes they will laugh at me and say "come on talk clearly" or "what are you saying? (Mahes Rajendran)

Episodes like this affected him so badly and he wished that he was back at his Tamil school. He was afraid to speak in either English or Malay for fear of being ridiculed openly in front of his schoolmates. Similarly, Suria, Amala, Dharshini and Vimal were also laughed at for their "funny accent" (Vimal). For this reason they seldom attempted to interact with the rest of their classmates and kept to themselves as much as possible. Suria confided that he often felt lonely as he could not communicate with the other communities. In class, they remained silent, not taking part in class discussion unless they were forced to by their teachers. They were afraid of class participation because they were often reprimanded by their teachers for not speaking clearly. Their speaking skills were considered inferior to those of their classmates; as a result they chose to remain silent:

Most of the time we did not understand what was going on in class. At least in the beginning. I used to feel very shy when asked by the teacher to stand in front of the class and do some activities, like a presentation. I stammered a bit because I was scared and that made everyone laugh. I was always scolded by the teacher because everyone couldn't understand me. I was embarrassed. (Vimal) 
Darshini described the initial few years she had to go through struggling to acquire proficiency in English and Malay. "I groped my way through like a blind person, stumbling, falling, so unsure" (Darshini).

This highlighted the early struggles the participants underwent while learning to adjust in a new academic environment which valued English and Malay over their HL. To make things worse, the participants stated that whenever they spoke in Tamil, the others (the THLU-Ms and Malays and Chinese) would make fun of them. "They would even try to mimic the way we spoke" (Munesan). Consequently, some of these participants felt unfairly treated and isolated in the classroom because of their poor linguistic skills in English and Malay and, more importantly, their Tamil learning backgrounds and experiences were not valued. The teachers and school mates saw the HL of the THLU-Ts as an impediment to the participants' learning of Malay and English. "If we use Tamil we will be punished as the teachers want us to improve our ability in Malay and English" (Menaga).

From the comments made by the participants, it can be seen that by prohibiting the use of HL in academic institutions, the THLU-Ts felt that their ethnic and linguistic backgrounds were ignored and not appreciated. Thus their (THLU-Ts') complex and, dissimilar language experiences when compared to the rest of their classmates who came from national primary schools, were considered as different and undesirable.

The next sub-theme illustrated the participants' views on the status of English when compared to their HL.

\section{"For me it's Tamil first and then English"}

Although all the participants agreed that English is an important language because of its international status and the power it wielded over its speakers, they ranked English second to their HL. They were of the view that it was crucial for Tamils to acquire competency in their HL first; followed by English and then Malay. "I believe English is very useful as it is spoken everywhere but as Tamils we must learn Tamil first before learning other languages. It is our mother tongue" (Menaga).

Menaga reiterated that Tamil was their mother tongue and as such it was the moral duty of every Tamil to be competent in the use of Tamil before they learnt any other languages. The participants' HL which functioned as their mother tongue was ranked higher than English. The participants were able to draw a clear distinction 
between Tamil which connected them culturally and English as a language which connected them globally. Menaga summarised this aspect in her remark. "Tamil is important because you will appreciate your culture. If you want to communicate with people abroad, you must be good in English" (Menaga).

However, Nadesh was an exception. He considered himself inclined more towards English when compared to his HL. For him English exuded power as it is a language of knowledge. He was driven to keep on improving his knowledge in English. He also felt that THLU-Ts, were evaluated by others according to the language they (THLU-Ts) chose to speak and how they dressed. "If I speak English and am dressed in a coat and suit, people respect me. But if I am dressed in traditional clothes, they will say, "Here comes the country bumpkin!"(Nadesh). His comment implied that if a THLU-T wanted to make a positive impression, he or she needed to speak in English and don professional attire.

Some participants stated that they saw English as the language of the internet which brought the world right into their homes. "When I use the internet, it is always in English. I get to know more about what is happening globally like world events and news" (Thinesan).

A few of the participants also indicated that they might pursue education abroad and for this they needed to invest in English proficiency:

Somehow I feel that if you have an overseas qualification it is always better. You see my cousins all of them studied in England and Australia. People respect them. Someday, I will do my postgraduate studies there. Because of this I need to be good in English. I can hold high jobs. (Daarshini)

This suggested that English played a powerful role in establishing them as global citizens and was considered prestigious. At the same time English also contributed towards upward social mobility through career enhancement.

The participants acknowledged the importance of English as a global language. Its international use superseded their use of Tamil. Thus they felt that the other communities respected them if they were able to speak English proficiently. "Talking in English commands more respect. More people understand English. So it is easier to be understood by others" (Munesan).

Menaga, Vimal, Amala and Suria felt that interacting in English fluently would make the other communities sit up and take notice of them (THLU-Ts). They considered 
this as one way of projecting a more positively perceived heritage identity. This was true in Nadesh's experience. When Nadesh first entered secondary school like the rest of his fellow THLU-Ts, he lacked English speaking skills for which he was often looked down. However, when his English proficiency improved rapidly, he gained the admiration of his classmates:

Then when I started to score better marks than them in English, they said "Hey you are great man even getting better marks than us in English." At first they refused to believe. They thought I was just lucky. But this cannot be happening all the time. So later on they accepted the fact. I felt I had proved something coming from Tamil school. Now they wanted to become my friends. (Nadesh)

This also indicated that improving English proficiency helped Nadesh to gain acceptance from his classmates. Furthermore, many of his Malay and Chinese classmates approached him for help if they encountered any problems with their school work. This placed him in a position of advantage. He felt empowered. "If you know English it's a great advantage. It becomes an asset and it makes you powerful" (Nadesh). Thus English became a language of power.

The last sub-theme looks at the status of Malay in comparison to Tamil and English

\section{“It's (Malay) not really an important language"}

Participants generally expressed the opinion that Malay was not an important language when compared to Tamil and English:

Malay when compared to Tamil and English is not really important. You see now in the university Malay usage is not there anymore. Now we are in an international university, there is no Malay. Malay was only relevant up to a certain level. When we were in secondary school, Malay was important. After that nothing. (Darshini)

This suggested that Malay had outlived its purpose in the participants' academic lives. They were no longer at secondary school. As a result most participants complained that their proficiency in Malay had dropped. All of them felt that Malay had been important while they were at secondary school. Malay was the medium of instruction then. However, being at an international university, they found Malay to be irrelevant as the medium of instruction was now in English. It was interesting that none of the participants accorded Malay its status as the national language.

Nadesh informed me that he was no longer interested in using Malay anymore at university because everyone understood English including the Malays. His Malay friends spoke to him in English in the university. When I reminded him that Malay 
language is still the national language, to which he replied, "but I can survive without using it" (Nadesh). Tamil linked him to his heritage community whereas English linked him to the various communities living in Malaysia. English now acquired status as a national lingua franca and an international lingua franca.

Menaga, Thinesan, Munesan and Vimal used Malay when they went shopping. They spoke in Malay to the traders and shop keepers. According to Vimal this does not require great proficiency in Malay. "I think you can survive just speaking street Malay. You don't have to master the language with all the grammar. So it is really not an important language" (Vimal). Malay national language was now relegated to a "shopping language".

In comparison to their HL, Malay ranked lower. Malay was no longer seen to be useful as it had fulfilled its objective when they completed their SPM which heralded the end of their secondary school education. Unlike Tamil which connected them to their heritage community, Malay no longer held any significant relevance to their current lives. Although the participants were aware that it was still the national language, they felt that the Malay proficiency they had acquired earlier on was adequate enough to interact with the other communities especially with the Malays if they (the Malays) desired this.

\section{Summary}

A strong pull towards English was definitely evident when compared to Malay. This pointed towards the privileged status that English enjoyed as an international language. Participants felt that when they spoke in English it connected them to the rest of the world. In contrast, Malay was very localised and temporal. Malay only remained important when they were at secondary school after which it became irrelevant. However, when it came to their HL all but one participant ranked Tamil higher than English. This did not mean that they considered Tamil more important than English; instead they valued both the languages for different reasons. Their strong affiliation to their heritage identity tipped the balance.

\section{"You got to come out of the box."}

This is the last theme that emerged from the thematic analysis. It provided insights into how the participants managed to negotiate their heritage identity in a multilingual 
setting. In so doing, they learnt to take on multilingual identities and at the same time not relinquishing their heritage identity. In their search for recognition as a multilingual THLU-T, they adopted various strategies to overcome the challenges they faced as THLU-Ts. In labeling this theme as "You got to come out of the box" I sought to depict an image of THLU-Ts breaking out of the stereo-typed mould they were cast into by their peers. Table 6 outlines this theme and categorises the sub-themes under it.

Table 6. Theme five and the related sub-themes

\begin{tabular}{|c|c|}
\hline Theme Five & Sub-themes (in vivo coding) \\
\hline "You got to come out of the box" & • "We should not give up" \\
\hline $\begin{array}{l}\text { In search for recognition as a multilingual } \\
\text { THLU-T }\end{array}$ & $\begin{array}{l}\text { - "I have made it!" } \\
\text { - Tamil an international experience-"It opened } \\
\text { my eyes". }\end{array}$ \\
\hline
\end{tabular}

According to Amala, as a THLU-T you need "to show who you are" and learn "to come out of the box". It was a clarion call for THLU-Ts to work hard and secure a good future. Nadesh supported Amala's view. He felt that the THLU-Ts would not be relegated to an inferior position by the THLU-Ms and other communities if they were willing to acquire competency in both English and Malay. To illustrate this he talked of how an improved proficiency in Malay and English elevated his position as a THLU-T. "I was admired by my classmates (the Malays, Chinese and THLU-Ms)" (Nadesh). Munesan grabbed the trophy for best actor in an English drama organised at his secondary school.

All the participants indicated that the use of English accorded them a privileged status amongst their classmates. It symbolised prestige in the academic context. The participants talked of various methods they employed to increase proficiency in English and Malay. For example jotting down English and Malay words which expanded their vocabulary and interacting with Malay students to polish Malay speaking skills. In Mahes Rajendran's case it was different. He turned to THLU-Ms to help him with his English in return he taught them Tamil. "I had a few friends (THLU-Ms) who were interested in learning Tamil. So I taught them Tamil and they taught me English" (Mahes Rajendran). In this case, Mahes Rajendran used his HL proficiency which was an asset as a means to improve English proficiency. 
The participants realised that to adapt to a multingual setting they needed to be fluent in Malay and English which were the languages used in educational institutions. They were able to fit in and be accepted by the rest of their classmates when they showed competency in these languages. Although this was not an easy task both Menaga and Darshini acknowledged that it was the hard work and discipline which were instilled upon them during their Tamil primary school years that stood them in good stead. "We were used to working hard. Our Tamil school teachers were very committed" (Menaga). The participants constantly referred to their heritage language education which made them strive for excellence. "Perhaps we were successful because of the strong base built in Tamil school" (Darshini).

\section{"We should not give up"}

There were also instances when some of the participants felt demotivated when their attempts at speaking in English or Malay were poked fun at. "I used to feel discouraged when my Malay, Chinese and Tamil classmates (THLU-Ms) laughed at the way we spoke English and Malay. But I reminded myself and my friends that this is a learning period for us. We should not give up easily" (Darshini). Her encouraging remarks proved how badly the participants wanted to be accepted by the rest of the academic community. At the same time they wanted to occupy a position that boosted their selfesteem by displaying competent use of the academic languages (Malay and English) at school and university.

The question of maintaining a heritage identity was frequently invoked by the participants. Several of them explained that they talked in Tamil outside the classroom during break time. Tamil was seen as an important aspect of their cultural heritage which helped to strengthen their communal bond. Sometimes they were reprimanded by the school prefects and duty teachers if they happen to be conversing in Tamil. Amala and Darshini informed me that she and her friends were often fined but this did not deter them from speaking in Tamil. "They should realise that we came from Tamil school. So it's natural for us to speak in Tamil. Why stop now?" (Amala). The same sentiments were also echoed by Suria, Mahes Rajendran and Munesan.

Vimal had found a way to speak in Tamil during class. He told me that he would lower his voice if he wanted to speak in Tamil to other THLU-Ts. He did this for fear of being ridiculed by the rest of his classmates. Furthermore, the class monitor would 
report this to their class teacher and he was afraid of being punished. This indicated that the participants were willing to take risks although this act meant that they were disobeying school rules regarding language policies. Thus they exhibited their perceived right to use their HL as its authentic owners. This also gave them the opportunity to prove themselves as potentially authentic, loyal and committed members of their community.

There were several other ways that participants held on to their heritage identity. The following paragraphs illustrated how they managed to do this.

Suria, Amala, Munesan Nadesh, Vimal demonstrated their heritage identity by participating in cultural events organised by their secondary school and the university. During occasions like these they felt they were able to preserve their cultural heritage and maintain its continuity.

Suria and Amala often wrote articles for Tamil periodicals. Suria told me that a few of his articles had been published. They were proud of their ability to write well in Tamil. Thinesan read Tamil newspapers and had surfed the internet on history and development of Tamil language and culture. He informed me that he had done a lot of research in this area. This helped him to take pride in his heritage language and culture. He found that equipping himself with knowledge on Tamil language and culture had enabled him to confront negative views regarding Tamil. "I tell them (Malays, Chinese and THLU-Ms) that Tamil is an ancient language and has a rich tradition and history"

(Thinesan). This suggested that it was important for him to display a positive disposition to his HL in the context of the university.

Menaga read Tamil novels and recited verses in Bhagavadgita and other Tamil religious texts. This helped her to connect with her religion. "Tamil is so important in worship. The philosophical thoughts of Tamil saints have enlightened me" (Menaga). Suria took part in Bhajans (Tamil worship songs) singing competitions in the temple. Participating in these religious rituals and practices ensured that their HL identities continue to thrive.

\section{“I have made it!"}

When reflecting on their language experiences while they were in secondary school, all the participants expressed a sense of satisfaction at what they have achieved so far. They were happy with the progress they had made in terms of fluency in English and Malay. 
"I can now speak better English than before. My friends who knew me from secondary school have said that I had improved a lot" (Vimal). While Mahes Rajendran commented that, “I don't have a thick accent now when I speak in Malay or English. Compared to last time I have certainly improved a lot" (Mahes Rajendran).

Recalling the struggles they had gone through initially, learning to negotiate in a multilingual environment, the participants felt that "they have made it" (Amala). This can be seen in the way they were elected to responsible positions in the university. Suria was elected as student leader in the university and Nadesh was the president of the English Language Club. Munesan was the organising chairperson for sports and cultural events. Vimal was able to conduct class presentations in English fairly well. Before this, he used to fare badly. Menaga was congratulated for excellent science projects by the dean of the engineering faculty. As for Thinesan, Amala and Dharshini they were no longer "looked down" (Dharshini) by their relatives who had thought that "nothing good came out from Tamil school" (Thinesan). Amala summed up by saying "we have proved ourselves. You know it is difficult to qualify for this course, chemical engineering. Not many people are selected" (Amala).

The participants also commented that their circle of friendship had extended to include the various communities not just the THLU-Ts. "Before I only had Tamil friends from Tamil school. Now I have many, Malay, Chinese and Tamil friends who did not come from Tamil school" (Nadesh). This illustrated that when language proficiency in English and Malay increased their (the participants') sphere of influence among their peers also increased.

The last section under this theme discusses how certain events in the participants' lives helped them to value their HL culture and tradition even more. They were aware of the existence of an international community of THLUs with whom they could identify.

\section{Tamil an international language-"It opened my eyes"}

Amala and Suria talked of two cultural events in which they had participated which had impacted them greatly. When they shared their experiences there was pride and awe in their voices. For Amala, it was an international level Tamil debate competition:

It opened my eyes and made me aware, that were lots of things that can be done using Tamil, a lot of opportunities to be explored. During that event everyone 
spoke in Tamil, a lot of knowledge was shared in Tamil. I met so many Tamil speaking people from different countries. It made me realise that Tamil can be so useful. (Amala)

In Suria's case, it was an international Tamil singing competition. He was so happy meeting other Tamil speaking people from different countries. “I didn't know there were so many Tamils. Everyone was talking in Tamil. It was purely a Tamil world. I didn't want this experience to end" (Suria). They took pride at the fact that their HL was showcased in an international arena.

For one participant however, her experience in the classroom at the university drove home the fact that Tamil is an academic language. Darshini related an episode which had greatly impacted her. She explained how her Math lecturer who was from India started explaining concepts in Tamil to her when she had approached him for help. "I didn't know Tamil can be used this way. Everyone was staring at us" (Darshini). This indicated that for the THLU-Ts Tamil was seen to function more as a social language which was used mainly to connect to their heritage community. Tamil as a language of knowlede ceased at Tamil primary school. It stopped once they transitioned to secondary school. Later at secondary school a thin life line was extended - Tamil was offered as an additional language. Beyond this Tamil had no place in the academia in Malaysia.

\section{Chapter Summary}

I have illustrated how the participants were able to take on multilingual identities while at the same time preserving their heritage identities. In their search for recognition from non-Tamils and THLU-Ms, they adopted various methods to improve their competency in Malay and English. As a THLU-T they managed to hold on firmly to their heritage socio-cultural values. Their stories spoke of their challenges throughout this process.

The five themes using in vivo headings that arose from the thematic analysis were: Which language to use? Tamil is in my blood, What is it about us? I shouldn't have opened my mouth and You got to come out of the box. In the next chapter, I integrate these five themes with literature under new headings which reflect the connections made to broad theoretical framework. These are: Diverse linguistic practices, Affiliation to heritage identity, Positioning, Linguistic hegemony and Quest for a positive linguistic identity. Upon further analysis, I collapsed the theme Affiliation 
to heritage identity under the theme Quest for a positive linguistic identity for the following reasons:

1. to examine how THLU-Ts maneuvered multilingual identities both a heritage identity and a multilingual identity.

2. to know how both these identities impacted them as multilingual THLU-Ts in Malaysian context.

3. to highlight the role of a heritage identity in a multilingual Malaysia.

The four themes Diverse linguistic practices, Positioning, Linguistic hegemony and Quest for a positive linguistic identity will be used as a framework to integrate the findings and to explain how these findings relate to each other. In the next chapter I discuss each theme drawing upon the conceptual framework described earlier (refer to Chapter Three). 


\section{Chapter Seven}

\section{Discussion}

\section{Overview}

In this chapter I will summarise my responses to the research questions. The first section contains the major findings of my study. The next part of this chapter will be a discussion of the four major themes that emerged from the previous chapter. These major themes are diverse linguistic practices, linguistic hegemony, positioning and a quest for a positive linguistic identity. I have already explained the rationale behind collapsing the initial five themes into four in the previous chapter (refer to summary section on Thematic Analysis Chapter). I will relate each theme to the major theoretical framework used in this study (Blommaert, 2007, 2010a, 2010b; Blommaert \& Variis, 2013).

\section{Summary of findings}

Table 7 provides a summary of the findings in relation to the research questions posed in chapter One.

Table 7. Table on summary of findings.

\begin{tabular}{ll}
\hline Research questions & \multicolumn{1}{c}{ Findings } \\
\hline $\begin{array}{l}\text { How do nine THLU-Ts tertiary } \\
\text { students from an international } \\
\text { university in Malaysia: }\end{array}$ & $\begin{array}{l}\text { 1. The participants felt comfortable in the Tamil school } \\
\text { environment as their HL was the medium of } \\
\text { instruction and they saw this as an extension of their } \\
\text { home language (Tamil). There was equal status at } \\
\text { relation to English and Malay? } \\
\text { both home and school }\end{array}$ \\
& $\begin{array}{l}\text { 2. The status of HL decreased in relation to English and } \\
\text { Malay because it was not used as the medium of } \\
\text { instruction in secondary and tertiary contexts. HL was } \\
\text { not well received or encouraged in formal academic } \\
\text { contexts (secondary school and university). }\end{array}$ \\
& $\begin{array}{l}\text { 3. HL status was maintained only within informal and } \\
\text { family contexts. }\end{array}$ \\
\hline $\begin{array}{l}\text { 1. The participants perceived that their (non-Tamils and } \\
\text { THLU-Ms) peers positioned them unfavourably } \\
\text { beceive that they are positioned }\end{array}$ & $\begin{array}{l}\text { because they lacked proficiency in Malay and English. } \\
\text { THLU-Ms) when they use Tamil? }\end{array}$ \\
& $\begin{array}{l}\text { 2. The participants perceived that the THLU-Ms did not } \\
\text { appreciate their HL and culture. }\end{array}$ \\
& $\begin{array}{l}\text { 3. The participants had little respect for THLU-Ms who } \\
\text { did not value their HL and culture. }\end{array}$ \\
\hline
\end{tabular}


Research questions

3. perceive the role of their families in the language choices they (the participants) make?
Findings

1. The participants reported that their families encouraged Tamil in their homes.

2. The participants perceived that their families preserved and maintained Tamil language and culture at home and during family events and community gatherings, and wished them to use Tamil to participate in these events.

3. The participants' families also motivated them to increase English proficiency.

4. Malay was hardly ever spoken at home.

\section{An overall framework of the theories and themes}

Next, I will discuss the major themes that emerged from the thematic analysis (presented in chapter 6). Four major themes emerged and they are discussed in relation to Blommaert's (2010a) sociolinguistics scales and Blommaert and Variis' (2013) dynamic identity process. These theories help to explain how the movement of people across spaces and time may have influenced the linguistic practices of a group of THLU-Ts (the participants of this study) studying at an international university in Malaysia. They allow me to explore the underlying reasons for, as well as the identities derived from, those practices. Table 8 below provides a brief description of the four themes and the theoretical framework used.

Table 8. Table showing themes, findings and theoretical framework used in this study

\begin{tabular}{|c|c|c|}
\hline Themes & Findings & Theory \\
\hline $\begin{array}{l}\text { Diverse } \\
\text { linguistic } \\
\text { practices }\end{array}$ & $\begin{array}{l}\text { Participants used different languages in different academic spaces. Their } \\
\text { linguistic repertoires were organized indexically in relation to layered and } \\
\text { stratified spaces on the sociolinguistic scales at different points in time. } \\
\text { They used Tamil in Tamil school, either Malay or English at secondary } \\
\text { school, and mostly English at the international university. }\end{array}$ & $\begin{array}{l}\text { Blommaert's } \\
(2010 \mathrm{a} ; 2010 \mathrm{~b}) \\
\text { sociolinguistic } \\
\text { scales }\end{array}$ \\
\hline $\begin{array}{l}\text { Linguistic } \\
\text { hegemony }\end{array}$ & $\begin{array}{l}\text { The academic spaces they entered were influenced by dominant language } \\
\text { ideologies. Certain languages (English and Malay) occupied a higher } \\
\text { status on the sociolinguistic scales compared to HLs (Tamil). At } \\
\text { secondary school, Malay was ranked higher than English and Tamil. At } \\
\text { the international university, participants ranked English first followed by } \\
\text { Tamil and then Malay. Participants rescaled the languages according to } \\
\text { what was viewed as prestigious and valid in different academic contexts. }\end{array}$ & $\begin{array}{l}\text { Blommaert's } \\
(2010 \mathrm{a}) \\
\text { sociolinguistic } \\
\text { scales }\end{array}$ \\
\hline
\end{tabular}




\begin{tabular}{|c|c|c|}
\hline Themes & Findings & Theory \\
\hline Positioning & $\begin{array}{l}\text { Different spaces required competencies in different languages (English, } \\
\text { Malay and Tamil). Their positions were affected because the value of } \\
\text { their linguistic resources shifted in these spaces. So the participants } \\
\text { invested in acquiring competency in dominant languages (Malay and } \\
\text { English) which demonstrated their agency. By gaining proficiency in } \\
\text { Malay and English they repositioned themselves as powerful } \\
\text { multilinguals and gained respect from the others. This led the non-Tamils } \\
\text { and THLU-Ms to reposition the participants higher than the initial } \\
\text { negative labeling. }\end{array}$ & $\begin{array}{l}\text { Blommaert's } \\
(2010 \mathrm{a}) \\
\text { sociolinguistic } \\
\text { scales }\end{array}$ \\
\hline \multirow[t]{2}{*}{$\begin{array}{l}\text { Quest for a } \\
\text { positive } \\
\text { linguistic } \\
\text { identity }\end{array}$} & $\begin{array}{l}\text { Participants oriented towards entirely different sets of linguistic patterns, } \\
\text { norms and values in different segments of their academic lives. The } \\
\text { participants' linguistic biographies became a dynamic (i.e. perpetually } \\
\text { adjustable) complex of micro-hegemonies within which they situated } \\
\text { their linguistic practices and behavior. }\end{array}$ & $\begin{array}{l}\text { Blommaert and } \\
\text { Variis (2013) } \\
\text { dynamic identity } \\
\text { process }\end{array}$ \\
\hline & $\begin{array}{l}\text { They projected a heritage language identity when they were with other } \\
\text { THLU-Ts and their community members (Tamil held power here). They } \\
\text { assumed multilingual identities when they were with THLU-Ms and non- } \\
\text { Tamils. }\end{array}$ & \\
\hline
\end{tabular}

\section{Towards the construction of heritage identities and multilingual identities}

Having given an overview of the theoretical framework and shown how each theme is related to the theories used in this study, I will now explain how my participants as THLUTs perceived that using their HL (Tamil) impacted their identities as multilingual speakers in Malaysia (the overarching research question of this study). Figure 38 represents how the identities of my participants were impacted through linguistic hegemony and positioning which created multilingual identities and heritage identities.

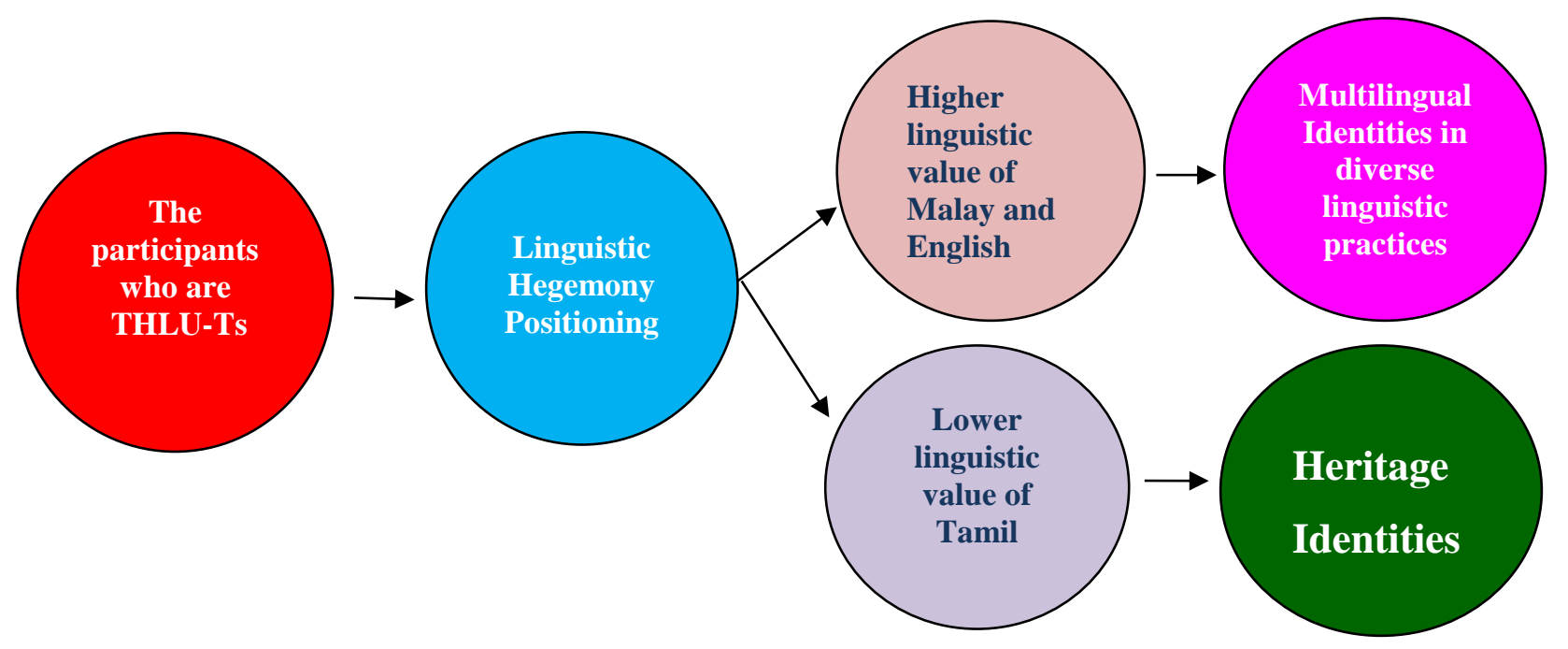

Figure 38. How the identities of the participants are impacted as multilingual speakers in Malaysia. 


\section{The participants}

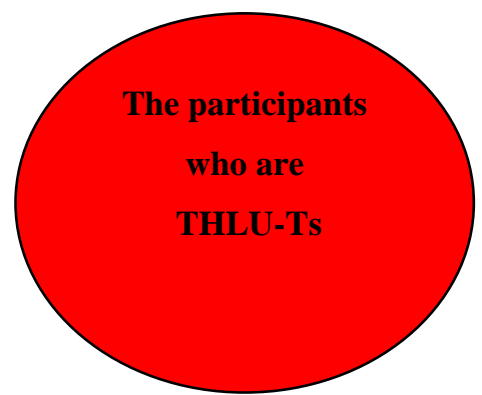

Figure 39. The participants who are THLU-Ts (from Tamil primary schools)

The discussion begins with the group of nine THLU-Ts who were the participants of this study (figure 39). Their voices were storied into narratives as they used photographs to recall their language experiences as they travelled through different academic contexts at different points in time in their academic journey.

These participants were selected based upon the criteria set out in the methodology section of this study. I refer to them as Tamil Heritage Language Users (THLUs) and not using terms such as Heritage Language Learners (HLLs) or Heritage Language Speakers (HLSs) used by other heritage language researchers (Kelleher, 2010; Valdes, 2001; Weiyun He, 2010; Wiley, 2001). This distinction was made to reflect their degree of proficiency in their HL both in oral and writing skills. A HLS speaks a HL to different levels of proficiency, and a HLL is actively learning a HL in a classroom setting (Seals, 2013). All my participants had already formally acquired a high level of competency in Tamil, were accomplished fluent users of their HL and were no longer in the process of acquiring proficiency in their HL (thus no longer learners).

The next section will trace the language learning trajectories of the participants (THLU-Ts) which are markedly different from those of THLU-Ms and non-Tamil (Malay and Chinese) peers.

\section{Learning trajectories of the participants}

It is important to pay attention to the language learning trajectories of the participants as their linguistic competencies index the places and spaces they have been to and travelled through (Blommaert \& Backus, 2011). The participants learnt languages through their involvement in the discursive linguistic practices of the various academic institutions they entered and also through social interactions using a particular language with a 
specific academic community. These trajectories show how the participants' linguistic identities evolved as they interacted with different academic communities across different spaces and time (THLU-Ts at Tamil primary school, Malays and Chinese and THLU-Ms at secondary school and at an international university).

Furthermore, the path the participants travelled was different from that of their peers. For the first six years of their academic lives they were fully immersed in Tamil education as compared to their peers (THLU-Ms, Malays and Chinese) who attended national primary schools where the medium of instruction was Malay. The THLU-Ts academic journey was also different as compared to the Chinese students who went to Chinese primary schools where the medium of instruction was Mandarin.

\section{The notion of a linguistic biography of the participants}

I looked at the participants' linguistic resources (Tamil, Malay and English) which were acquired formally at different points of time in their academic lives. Expanding on this notion, Backus and Blommaert (2011) emphasised the importance of examining linguistic repertoires of multilingual users in a biographical sense:

Repertoires are ... indexical biographies and analyzing repertoires amounts to analyzing the social and cultural itineraries followed by people, how they manoeuvered and navigated them, and how they placed themselves into the various social arenas they inhabited or visited in their lives. (p. 22)

The notion of a linguistic biography presented in Blommaert and Backus' work demonstrates how repertoires are biographically organised complexes of linguistic resources, and they follow the rhythms of human lives. The linguistic biographies of multilingual users may often index their complex social trajectories.

In Table 9, I reported the participants' linguistic practices according to their history of access to resources in academic and community life (biographies). The languages are aligned with the practices they represent. The following table illustrates the participants' linguistic biographies. The participants' choice of language depended on the ethnicity of the interlocutors, and the time and social and academic spaces they were in. 
Table 9. The linguistic biographies and practices of the participants

\begin{tabular}{lll}
\hline Tamil & $\begin{array}{l}\text { Academic Life } \\
\text { Six years formal education in Tamil } \\
\text { primary school (age 6 to 12 years). } \\
\text { English and Malay were taught as } \\
\text { subjects. }\end{array}$ & $\begin{array}{l}\text { Community Life } \\
\text { Communication with family members, } \\
\text { relatives and with Tamil friends and peers. } \\
\text { Community gatherings and religious } \\
\text { events. }\end{array}$ \\
\hline Malay & $\begin{array}{l}\text { Medium of instruction in national } \\
\text { secondary school (age 13 to 17 years). }\end{array}$ & $\begin{array}{l}\text { Communication with Malay friends and } \\
\text { peers, THLU-Ms and Chinese. }\end{array}$ \\
& $\begin{array}{l}\text { Communication with teachers and } \\
\text { classmates in the classroom. }\end{array}$ & $\begin{array}{l}\text { Language used for shopping and at local } \\
\text { restaurants. } \\
\text { English is taught as a subject. }\end{array}$ \\
& $\begin{array}{l}\text { Generally used to communicate with older } \\
\text { generation of Malay and Chinese descent. }\end{array}$ \\
\hline English & Medium of instruction at international & $\begin{array}{l}\text { Communication with other races } \\
\text { especially Chinese. }\end{array}$ \\
& university (ages 18 onwards). & Communication with foreigners. \\
& Communication with lecturers and & \\
\hline
\end{tabular}

The linguistic biography of the participants chronologically traces their access to multilingual resources. They acquired proficiency in their HL when they were at Tamil primary school. When they entered secondary school, they had to be competent in Malay as it was the medium of instruction. Finally at the university, the dominant language was English. The table also highlights both formal (academic life) and informal interaction (community life) of the participants with the various communities in Malaysia. They were socialised into the various dominant institutional and community practices (cultural, linguistic, values, norms and ethos). It was in the social spaces both inside and outside of the classroom they learnt to accept, negotiate, subvert and assess societal structures through the languages that they had learnt and through what they had learnt about language use (Canagarajah, 1999, 2006; Pennycook, 2001, 2010).

\section{Summary}

Thus far, I have described who my participants are and have also illustrated the complex language learning trajectories that they had travelled through.

The next part will describe what happened when they entered secondary schools and university. 


\section{Linguistic hegemony and positioning in relation to identity}

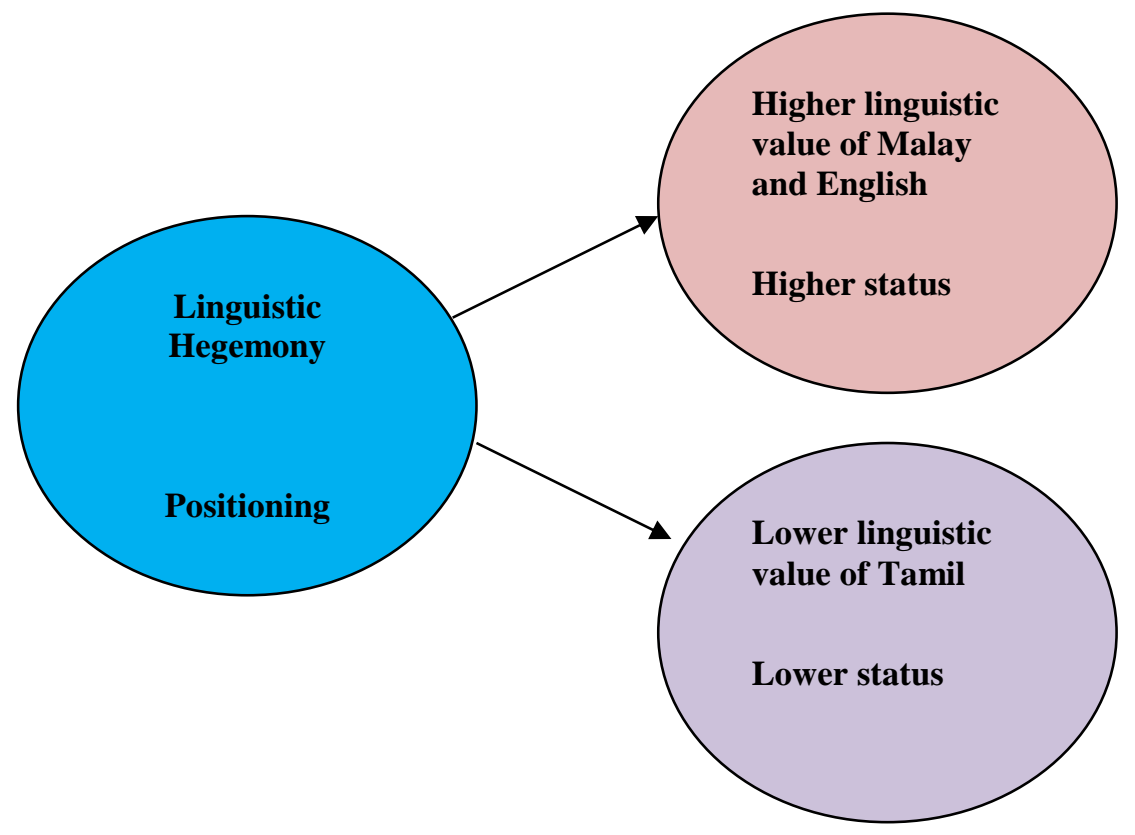

Figure 40. Linguistic hegemony and positioning in relation to identity

Two themes (linguistic hegemony and positioning) impacted the identities of the participants when they entered secondary schools and university. (Refer to figure 40) The participants' choice of assuming either a multilingual or a heritage identity was influenced by linguistic hegemony and positioning.

I will discuss each theme separately in relation to Blommaert's sociolinguistic scales (2010a). I begin with linguistic hegemony.

\section{Linguistic hegemony and sociolinguistic scales}

According to Blommaert (2010a) when social interactions take place within a specific social context and at a specific time, the linguistic practices that occur in this space and time are placed on a vertically layered scale which is hierarchical. The sociolinguistic scales offer a vertical image of spaces and time which are stratified.

There is a hierarchical ordering of languages at different scales based on the social, cultural and political context in which they (the languages) are used (Agha, 2007; Blommaert, 2005; Silverstein, 2006). The status attributed to a language is closely tied up with the social structure and value systems of society. Thus, languages are located within social hierarchies of values (Blommaert, 2010a; Bucholtz \& Hall, 2004; Heller, 2010). Blommaert (2010a) uses the metaphor of sociolinguistic scales to represent these 
hierarchies. The scales allow us to envision how, practices, norms and standard for languages exist in strata informed by political, social and cultural factors.

At the higher end of the vertical scale are languages that are valued highly by society and are considered prestigious; while those at the lower end of the scales are considered to less prestigious (Dong \& Blommaert, 2009). For example, English as a global language is widespread (space) and timeless (time). It is the language used in higher educational institutions and operates in an international space that transcends the local therefore it is power-invested. At the lower end of the scale are languages that are not valued by mainstream society, for example heritage languages/minority languages. These languages are considered to be local in terms of space as they involve the heritage communities only, and in terms of time these languages are temporal because their use is restricted to specific events. The context of HL use by the participants was bounded and restricted by its transient nature because the HL functioned only in personal, localised spaces like in the home or during family events over short and intermittent (sporadic) periods of time.

In between the higher end and lower end of the scales are intermediary levels and Malay occupied this level for the participants. Because Malay was the national language and also the medium of instruction in secondary schools, it was the next most important language after English for the participants while they were at secondary school.

I have used Blommaert's sociolinguistic scales to rank languages in Malaysia which is illustrated in Table 10.

Table 10. Using Blommaert's sociolinguistic scales to rank languages in Malaysia

\begin{tabular}{llll}
\hline \multicolumn{2}{l}{ Lower Scale } & \multicolumn{1}{c}{ Intermediary } & \multicolumn{1}{c}{ Higher Scale } \\
\hline Time & Momentary & Momentary & Timeless \\
Space & $\begin{array}{l}\text { Extremely local } \\
\text { and situated } \\
\text { (within HL } \\
\text { communities) }\end{array}$ & $\begin{array}{l}\text { Situated at a national level } \\
\text { (within Malaysian context) }\end{array}$ & $\begin{array}{l}\text { Global and widespread } \\
\text { (international context) }\end{array}$ \\
& & & \\
Languages & Tamil & Malay & English \\
\hline
\end{tabular}

\section{Applying sociolinguistic scales at Tamil primary school}

When the participants entered Tamil primary school where Tamil was the medium of instruction, they gained academic linguistic competence in their heritage language (Tamil) to supplement their informal and oral use at home. For six years they were immersed in a heritage language environment and experienced the values and social patterns attached to 
their heritage language. The Tamil school environment nurtured in them a love for Tamil language and Tamil culture. The participants used Tamil in and from a space that projected HL values, HL socio-cultural structure and affective attributes (strong sense of emotional attachment) to HL (Blommaert, 2005b; Scollon \& Scollon, 2003). In such a space the participants strengthened their bonds with their heritage language through social and linguistic interactions with their community members (Blommaert, 2005a; Butler, 1990; Goffman, 1981). The community extended to their teachers and classmates at school. They learnt to connect with family and community members through their heritage language experiences. Thus, a deep emotional attachment to their heritage language was reinforced which contributed to a strong bonding to heritage culture and values.

In applying the sociolinguistic scales within this space (Tamil primary school) and time (six years of primary schooling), Tamil language ranked the highest against Malay and English. Both the academic and social language at use was Tamil. Malay or English was only used during classes when these languages were taught as subjects.

Furthermore, there were no Malay or Chinese students. During the first six years of the participants' academic lives, there was very little place for English and Malay. in. Moreover, as young children their social lives revolved around their families and the Tamil community. They would not have much need to go outside of the family to shop or to do business. There were very few opportunities for them to be exposed to Malay or English as there were ample Tamil programmes broadcast on national TV. There was even a 24 hour Tamil channel which most Malaysian Tamils subscribed to. The language scale at this time in their lives is illustrated in figure 41.

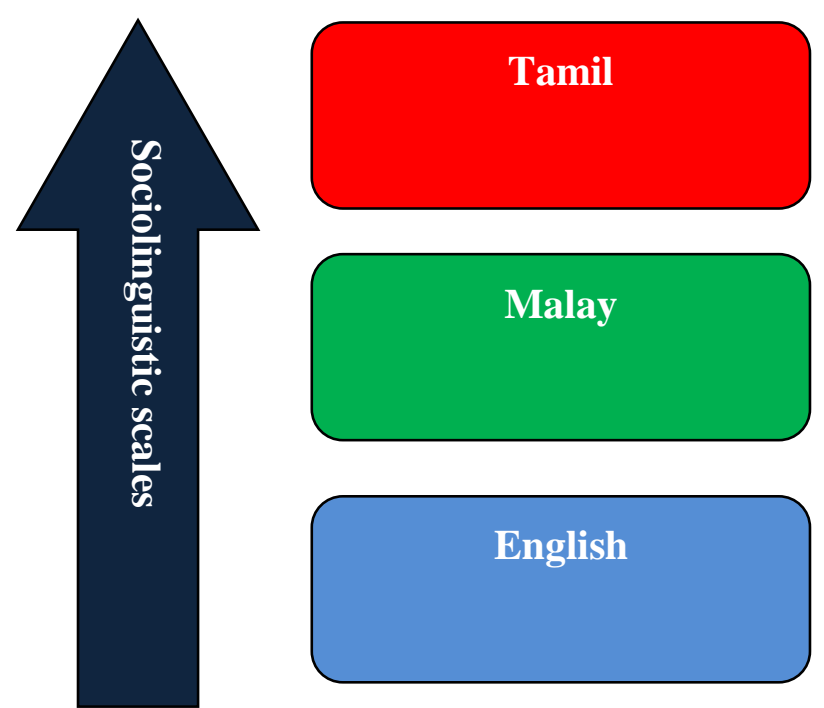

Figure 41. How participants perceived languages were scaled in Tamil primary school. 


\section{Applying sociolinguistic scales at secondary school}

When they entered national secondary schools, they were in an unfamiliar linguistic space (refer to figure 42). The sole medium of instruction here was Malay which was also the national language. They needed to interact with students who came from different racial and cultural backgrounds (Malays and Chinese) and also THLU-Ms who did not come from Tamil school. Their linguistic repertoire was extended to include linguistic competence in Malay which was now both a social and academic language. English became the second language of importance followed by their heritage language which was now relegated to the lowest rank. Their social interaction was governed by different language ideologies, social patterns and norms that were considered appropriate within this new linguistic community. As a result, they had to realign and reposition themselves as heritage language users in this new linguistic environment. Because their heritage language was placed at the lowest end of the scale and considered unprestigious, the participants confronted negative attitudes to their HL and cultural biases (Kagan \& Dillon, 2011) when communicating with the other races which they sometimes perceived as confrontational. This lack of respect for Tamil HL and culture may have stemmed from their classmates' reluctance to embrace linguistic and cultural diversity as diversity was not promoted in the school curricula. Language policies in Malaysia prioritised the use of Malay language as the official national language and the medium of instruction in public schools, and English as the second most important language. Malay language was seen as essential for the political purpose of uniting the various linguistic groups in Malaysia, and English was seen as the language of modernisation, knowledge transfer and international communication (Kirkpatrick, 2009). These language planning decisions attempted to reduce linguistic and cultural diversity in order to promote linguistic unity so ethnic languages in Malaysia were pushed to the background despite the existence of multiple languages (Hamidah Yamat et al., 2014).

International research continues to illustrate how assimilationist policies and practices lead to experiences of alienation by learners from diverse groups and backgrounds (McKinney, 2010; Tihanyi, 2007; Vandeyar, 2008). In their analysis of literacy practices in Dutch classes for immigrants in Belgium, for example, Blommaert, Creve, and Willaert (2006) argued that in order to "understand objectively the schoolchild's communicative world" (p. 36), it is necessary to take into account the 
particularities of cultural contexts that gave rise to specific meanings, images and constructions of what counted, and what did not. Thus language policies in a society are strongly tied to political and ideological arguments about what society should (ideally) look like, and who can count as a (full) citizen in such a society. "These connections [are] indexical: forms of literacy [provide] extremely strong indexes of identity, social status, and perceived relations between people" (Blommaert, Creve, \& Willaert, 2006, p. 35).

The HL of the Tamils in Malaysia was thus deemed to be institutionally undesirable when compared to institutionally valuable linguistic resources (Malay and English languages) because of the bilingual language policies that did not encourage the practice of HLs in academic institutions. This also implied that linguistic and cultural diversities were not embraced and heritage languages and cultures were marginalised. On the other hand, the THLU-Ts were required to assimilate into mainstream Malaysian society through the use of Malay and English in their daily social interactions with Malays, Chinese and THLU-Ms.

Since languages are "stratified and layered", the scaling process affected the participants' language choice and identity construction in these interactions (Dong \& Blommaert, 2009, p. 5). The participants used more Malay and less of their HL at secondary school. They had to observe the "social and cultural itineraries" (Blommaert \& Backus, 2011, p. 22) dictated by the time (a period of five years from forms one to five) and space (secondary school) they were in. As they maneuvered and navigated in this new social arena, they increased linguistic competency in Malay and English and decreased their HL use. In occupying the new social spaces of secondary school, the participants learnt to acquire new material and symbolic resources (such as acquiring new language structures, and observing new social norms, new ways of acquiring knowledge, new patterns of social interaction) that were considered valuable in the new context (Darvin \& Norton, 2014). Hence new linguistic competencies were gained and old ones either dropped or maintained (Backus \& Blommaert, 2011) in this new language learning trajectory. The participants only used their HL to communicate with other THLU-Ts outside the classroom in informal contexts as it was considered inappropriate in the formal context of the classroom. This conversion (HL as the dominant language of institutional practice in Tamil primary school now being replaced 
by Malay in secondary school) was always a site of struggle, given that what may be valued in one place may be radically under-valued in another (Darvin \& Norton, 2014).

So, for the next five years (time) of their academic lives at secondary school (space), Malay was at the top end of the scale. This concept is illustrated on the sociolinguistic scales (see figure 42).

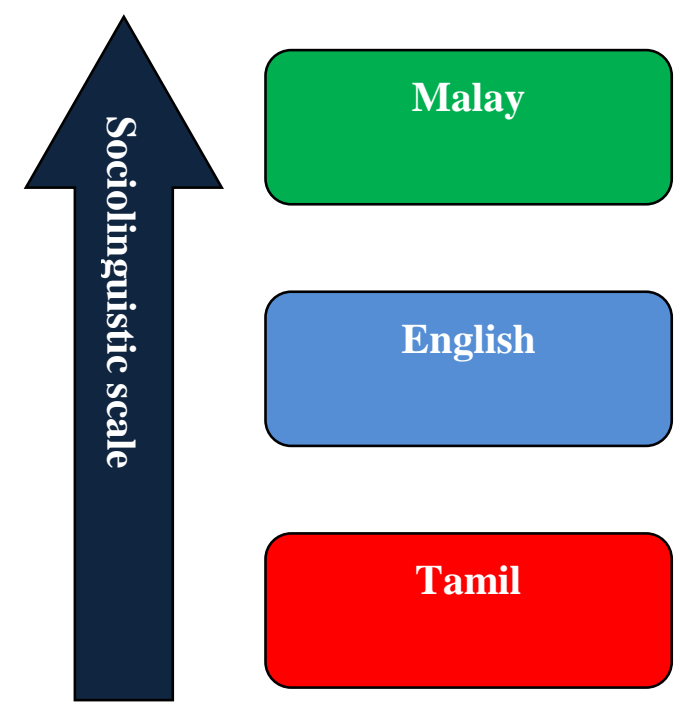

Figure 42. How participants ranked languages in secondary school.

\section{Applying sociolinguistic scales at the international university}

At the international university, the participants were exposed to English as the medium of instruction. Their linguistic repertoire expanded to include proficiency in English. So, in the university context (space) where they were currently studying (time), English occupied the top end of the sociolinguistic scale. As an international language, English transcended the local and situated (both Tamil and Malay). Malay was repositioned in a national space since it was the national language.

Tamil was the next most important language after English for the participants in the university. Compared to Malay, Tamil functioned more widely in the university. After leaving secondary schools where it was strictly forbidden to use Tamil both in and outside classrooms, they found the university environment more relaxed. They could use Tamil freely outside the classroom. This gave the participants more opportunities to interact in Tamil. Hence Malay was no longer perceived to be relevant and held very little value at this stage of their academic lives. Figure 43 illustrates this concept. 


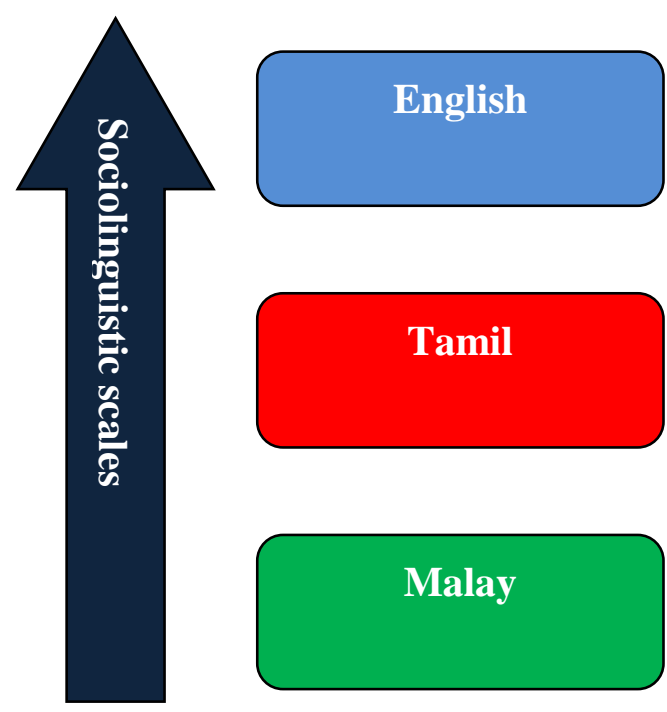

Figure 43. How the participants scaled the languages at the university.

\section{Summary}

Overall, the scales show how certain languages enjoyed power and prestige over others for the participants at different stages of their academic lives because of the value accorded them by society. Outside Tamil primary school, English and Malay were valued highly compared to their HL. As the participants moved across different academic spaces their linguistic resources shifted in value, meaning and function. When a language (Tamil, Malay or English) was no longer the language of instruction in a specific academic context, it lost its relevance and its value decreased. Therefore, participants had to continuously rescale their linguistic resources based on their validity, relevancy and status in particular academic contexts. The only exception was English which remained constant as the second most important language both at Tamil primary school and at secondary school. English became the most important language of communication at university.

\section{Positioning}

I will now move on to the next theme, positioning, which was reflected in the way the participants took different positions during their social interactions with the THLU-Ts, THLU-Ms and non-Tamils as they travelled through different spaces (academic contexts) from Tamil primary school to secondary school and finally to an international university. These spaces were not passive backgrounds but agentive forces in sociolinguistic processes, notably in the assessment of linguistic competences 
(Blommaert, Collins \& Slembrouck (2005a, 2005b). Using the sociolinguistic scales, I will show how spaces are also stratified.

\section{Sociolinguistic scales and spaces}

The sociolinguistic scales help to address power relations when linguistic resources are negotiated in shifting contexts (Canagarajah, 2013a). The linguistic resources that participants carried with them shifted in value, meaning and function according to the social and linguistic norms dictated by the different academic spaces.

The participants moved from one academic space to another during their academic lives within different educational settings. These academic spaces were polycentric and stratified in that people continuously needed to observe orders of indexicality that were attached to different centres of authority (Blommaert, Creve \& Willaert, 2006). The participants moved from one centre of authority to another. For example, Tamil was powerful while participants were at Tamil primary school. However, once they transitioned to secondary school, they had to observe rules laid down by a different centre of authority. Malay language dominated at this centre. Then, when they moved to a different centre again (university), the linguistic values shifted once more. It was a different centre of authority again where the linguistic value assigned to Malay decreased and English became powerful.

The vertical dimension of the scales projects an image of hierarchical ordering and power differentiation in these spaces. Some spaces (like the international university) were centres of authority that held more power than the others (secondary school and Tamil school) because they were more structured and ordered (Billings, 2014). So when the participants left Tamil school and moved to secondary schools and university they were moving towards (academic) spaces or centres which were higher up on the sociolinguistic scales which denoted more power and prestige.

Since (academic) spaces/centres are stratified, the languages used within the different spaces/ centres are also stratified. The participants' HL was valued at Tamil school but not at secondary school or at university. Malay presided over HL at secondary school, however, at the university English ranked the highest. According to Blommaert, minority languages or HLs are "placed resources" (2010a, p. 23) because they do not "travel well" in comparison to dominant languages (English and Malay) which are "high mobility resources" (2010a, p. 24). HL was functional in Tamil school 
but became dysfunctional as soon as the participants moved to secondary school and university. Likewise, Malay was functional at secondary school, and at university it was English. The process of mobility or movement to different (academic) spaces/ centres affected the value of each linguistic resource. What was valued at a certain (academic) space/ centre was devalued in another. Thus when participants moved upwards from one (academic) space/ centre to another, they were also moving across scales of social structure (Blommaert et al., 2005a) because some (academic) spaces/ centres had more power and prestige over others. For example, being an undergraduate at an international university was considered more prestigious than a secondary school leaver. The language learning trajectories of the participants traced their upward social mobility as they moved up the sociolinguistic scales from one (academic) space/ centre to a more powerful (academic) space/ centre. These (academic) spaces can be seen as centres of authority which were hierarchical.

Finally, participants also moved from rural areas (where most Tamil schools are located) towards urban areas (where secondary schools and universities are found). Such a move in space (geographical) signified a movement towards centres of power in terms of infrastructure, technology, administration and control. They had to reposition themselves according to different value systems operating at different centres.

Academic institutions/ centres legitimised dominant linguistic practices while disqualifying or constraining marginal or heritage linguistic practices. Additionally, they (academic spaces/ centres) attached different values and functions to participants' linguistic repertoires. In essence, participants were forced to continuously readjust their linguistic patterns and behavior to conform to the practices of the different academic spaces/ centres they were in. These reasons shaped how the participants positioned themselves, and how they were positioned / ascribed positions by others (Blommaert et al., 2005a).

In taking different positions, the participants became active agents in social interactions with THLU-Ms and non-Tamils. They created and modified spaces and social arrangements through semiotics (Blommaert, 2005a; Norton \& Toohey, 2001; Toohey \& Norton, 2003). As the participants moved from one academic context to another, they either gained or lost power during their social interactions with their peers (THLU-Ts, THLU-Ms and non-Tamils) as the "value of their linguistic capital shifted" 
(Darvin \& Norton, 2014, p. 43). Since academic spaces or contexts assign values and statuses to the linguistic codes that people take with them, this led the THLU-Ts to take up a position of either "dominance, contestation or compliance" (Darvin \& Norton, p. 43). To enter into academic spaces that valued particular linguistic practices over the others, the participants invested in acquiring proficiency in languages (Malay and English) with a higher linguistic market value.

They adopted the following strategies for meaningful communication with their peers (non-Tamils and THLU-Ms): the participants worked hard in improving proficiency skills in the dominant languages (Malay and English), restrained from using their HL in formal situations, and even translated whenever HL was used if desired by their non-Tamil peers. They also started socialising more with non-Tamils than with other THLU-Ts at secondary school and at university. On the other hand, they associated with other THLU-Ts and used their HL in informal contexts (outside classrooms).

The next section will discuss the different positions taken by the participants towards the various communities (non-Tamils and THLU-Ms).

\section{Positioning non-Tamils}

Blommaert (2013) believes that to move fluidly across (academic) spaces, it requires the communicative competence of shifting effortlessly from one set of communicative norms to another. In order to do this, the participants had to comply with the language policies and structures laid down by sites of control (formal academic institutions and government educational organisations) which were legitimated authorities that managed resources and regulated and implemented systems. It is these authorities that constructed modes of inclusion and exclusion (Darvin \& Norton, 2014). Because of this, these THLU-Ts were already positioned in multiple ways before they even spoke: they were marginalised and their HL was devalued. This restricted their entry into new academic spaces. The participants fought this academic battle by increasing communicative competence in Malay and English (which were the dominant languages in these academic institutions). By doing so, the participants gained social power and valuable linguistic capital that was operational in these academic institutions. 
The section that follows illustrates how by investing in acquiring proficiency in the dominant discursive practices at formal academic institutions, the participants demonstrated their agency. This in turn affected their positioning.

\section{Investment, agency and positioning}

The participants sought to claim their rights to speak, refute and contest certain identities or dispositions imposed upon them. In doing so, they became active agents who had the capacity to act in a particular communicative event (Ahearn, 2001). To demonstrate their agency the participants had to invest time and effort in acquiring proficiency in Malay and English so that they could communicate efficiently with their peers (non-Tamils and THLU-Ms) and achieve academic success by complying with the social norms observed in these academic spaces. The desire to be accepted as part of the academic community; to become a legitimate member, propelled the participants to increase proficiency in English and Malay. It was this desire that pushed them to invest in gaining proficiency in the dominant linguistic practices; not only because they desired specific material or

symbolic benefits, but also because they recognized that the capital they possessed could serve as an affordance to their learning (offering access to books, computers, devices and infra-structure). Their linguistic capital now included an extended multilingual repertoire (Malay, English and Tamil) and was an affirmation of their identity, a legitimation of their rightful place in different learning contexts (Darvin and Norton, 2014). Their linguistic capital which now included English increased their market value as THLU-Ts in the global linguistic market.

In an effort to acquire greater competency, the participants purposefully communicated more with non-Tamil classmates, observing how they interacted. Some even carried note books around and jotted down points. They spent time reading books and materials in English and Malay. Besides this, the parents of some of the participants encouraged them to improve their proficiency in English and Malay by subscribing to English newspapers. Those parents who did not attend Tamil schools, in particular, were active in motivating their children to speak in English at home.

Agency was now exercised when the participants were able to take part and contribute in social interactions with the non-Tamils and THLU-Ms using Malay or English. They could even refute ideas when they gained proficiency in Malay and English. Two participants even reported that so greatly improved was their proficiency 
in English and Malay, that some of their non-Tamil and THLU-M peers approached them for help. Recognising that they had the agency to assert their own identities, the participants were able to negotiate symbolic capital from their multilingual repertoire, reframe relations of power, and challenge normative ways of thinking, in order to claim the right to speak (Darvin \& Norton, 2014). This was successfully carried out when the participants were able to shed the initial negative labeling of HLUs by their peers (nonTamils and THLU-Ms). They were now repositioned as powerful multilinguals.

A complex and dynamic interplay between investment and agency was evident in the way the participants socially interacted with their non-Tamil and THLU-M peers. The more they invested, the greater was their agency. For example, three participants held leadership positions at the university and secondary school. Their investment in gaining competency in the dominant languages allowed them entry and greater access to the powerful academic structures which gave the participants a strong sense of agency. They were now able to claim the identity of a powerful and knowledgeable multilingual proficient in three languages.

\section{Process of upscaling: demonstrating agency}

The participants countered their unequal status on the sociolingustic scales through the process of upscaling (Blommaert, 2007, p. 6). This was a power move where the participants consciously repositioned their language use the scales from the local (HL) up to the translocal (Malay/English).

Figure 44 illustrates how the participants moved higher on the sociolinguistic scales through the process of upscaling (Blommaert, 2007) as indicated by the arrows curving right. By increasing their proficiency in Malay, the participants were able to assume a higher status because of the linguistic value attached to Malay as compared to their HL. Acquiring competency in English elevated them to an even higher position. 


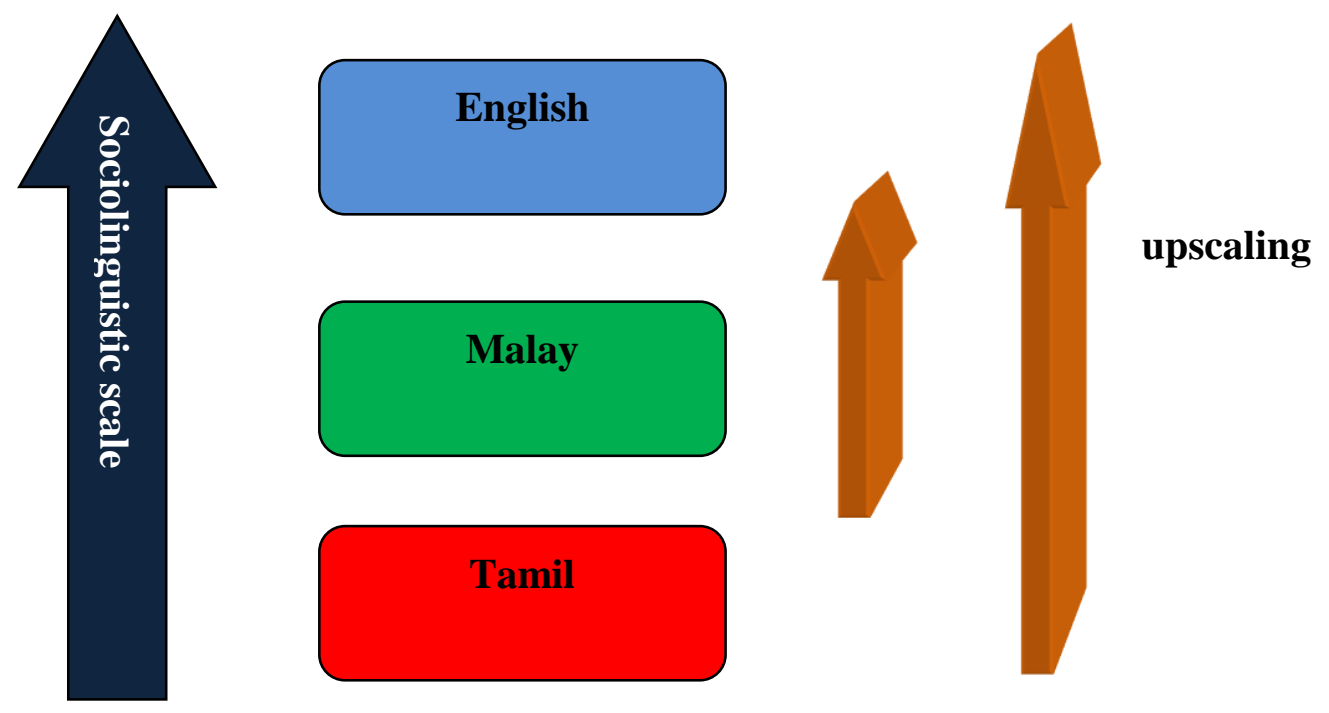

Figure 44. The process of upscaling

Through the process of upscaling the participants redefined their status as THLUTs which had initially been stereotyped as negative. Most participants spoke of how their status as THLU-Ts improved once they had gained proficiency in Malay and English while they were in secondary school. They referred to this as their breakthrough because they felt accepted by their peers (non-Tamils and THLU-Ms) and were socially included.

At the international university, the participants were exposed to English as the medium of instruction. Their linguistic repertoire expanded to include proficiency in English. They made another vertical move further up the scales. This "scale jumping" (Uitermark, 2002, p. 750) or upscaling required a further conscious effort by the participants to develop the linguistic competence to move higher than before in a stratified, hierarchically layered system, in which higher scale-levels (institutional and community norms and rules) prevailed over lower scale-levels (Blommaert, 2010b). The participants realised that a good command of English was more prestigious now and enhanced their social mobility across scales. So in the university context (space) where they were currently studying (time), English occupied the top end of the sociolinguistic scale.

When the participants invested in acquiring competency in Malay and English and thereby initiated greater agency in social interactions with their peers (non-Tamils and THLU-Ms), they actually repositioned themselves. This upward scaling of languages in the sociolinguistic scales earned them a legitimate place in the new academic spaces they entered (secondary schools and at the university) (Blommaert, 
2007). The process of upscaling is seen as part of their agency and allowed their voices to be heard within these powerful academic spaces.

The participants gained respect from their non-Tamil and THLU-M peers when they began to interact with them in either English or Malay. Becoming competent users of Malay and English raised their self esteem. This was displayed when a few of the participants even chose to translate their conversations from Tamil to Malay or English if the non-Tamils desired. By adopting the translation strategy, they were powerfully positioned as proficient multilinguals. This worked to their advantage in two ways. Firstly, they were able to include the non-Tamils in their social interaction. Secondly, by accommodating the non-Tamils, the participants were made aware of the fact that most Malays and Chinese were linguistically limited (non-Tamils' linguistic proficiency was limited to Malay and English). Their positions were fortified even further because now it was up to them whether they wanted to include or exclude the non-Tamils in their social interaction (Bucholtz \& Hall, 2008).

Sometimes the participants even resisted the dominant practices and ways of thinking that had become systemic within the different institutions. A few participants chose to contest the inferior positioning as THLU-Ts by the non-Tamils and THLU-Ms by speaking in their HL in the classroom. The dominant linguistic practices at secondary school and at the university did not encourage the use of HLs either in or out of the classroom. So by using their HL in these spaces (academic contexts), the participants asserted their right to speak in their HL. Thus the participants became active agents who navigated these social spaces where competing language ideologies (the dominant Malay and English) versus the marginal (Tamil) existed by asserting their right to use their HL. The participants chose to subvert dominant ideological practices by creating spaces where they used their HL. In this way they challenged hegemonic practices at schools and university and formed HL peer groups which enabled them to establish their heritage identities (Miller, 2003; Gibbons \& Ramirez, 2004; Heller, 2006).

The following section deals with how the participants positioned the THLU-Ms.

\section{Positioning of THLU-Ms}

The THLU-Ts positioned the THLU-Ms at secondary school and at university in two ways that differed with the positioning of non-Tamils. The participants felt that both the non-Tamils and THLU-Ms positioned them negatively because the participants lacked 
proficiency in the dominant languages (Malay and English) and therefore their HL was devalued in these academic spaces However, the participants also positioned the THLUMs as inferior because of their lack of proficiency in Tamil and their resistance to HL usage at secondary school and at $\mathrm{t}$ university. HL proficiency was regarded as a prerequisite for heritage identity and allowed complete access to the heritage community. Thus the THLU-Ms were considered to be less authentic members of the heritage community (Jaspal \& Coyle, 2010; You, 2005). The participants took an authoritative position against the THLU-Ms as they felt more knowledgeable than them about heritage language and culture (Preece, 2010).

Although in these academic spaces HL was not encouraged, the participants were driven by a desire to create for themselves an environment where they felt at home and in which they could "achieve that fulfillment of [their] desire to be which [they] [identified] with happiness" (Bourdieu, 2000, p. 150). Having left the safe environment of the Tamil school where their HL was valued, the participants were compelled to act and exercise their agency, because they sought to recreate the Tamil school environment once again at secondary school and at the university. This they did by grouping together and maintaining HL use among other THLU-Ts.

Blommaert (2005) identifies this as an innovative practice performed by language learners within a dominant prevailing language ideology. The participants exercised greater agency within a spectrum of consent and dissent without necessarily subscribing to dominant language ideologies. This is because sustaining a dominant culture requires both coercion and consent from the participants (Darvin \& Norton, 2014; Gramsci, 1971; Philips, 1998).

The participants complied with the hegemonic practices imposed by the academic institutions, yet at the same time showed their dissent or resistance by maintaining pockets of HL usage (like outside classrooms, during breaks) in these academic spaces. "The observance of institutional norms does not, in itself, point to the acceptance of linguistic hegemony; standard practices may accompany resistant consciousness "as a form of accommodation to coercion ..." (Woolard, 1985, p. 741). Thus participants created spaces of dissension or resistance where they spoke in their HL to other THLU-Ts.

Therefore when the THLU-Ms rejected the idea of using HL because it went against dominant ideology practiced in these academic spaces, the participants who were 
THLU-Ts in turn positioned the THLU-Ms who showed no attempt to speak in Tamil outside their circle of interaction and refused them entry. Most participants reported that they kept to themselves and hardly ever interacted with THLU-Ms in Tamil. THLU-Ms were only permitted entry if they chose to speak in Tamil. It is through such mechanisms that power is manifested and ideologies are challenged (Norton, 2013). Social inclusion was determined on the participants' terms, "guided by their sympathies and antipathies, affections and aversions, tastes and distastes" (Bourdieu, 2000, p. 150).

Thus the THLU-Ms were socially excluded and the position taken by the participants took a dominant position as they felt powerful being experts in the heritage language, values and culture.

\section{Summary}

Participants' positions were impacted by prevailing dominant ideologies practised in academic institutions which devalued their HL. They countered this negative labeling (from both the non-Tamils and THLU-Ms) through investment and agency in the dominant discursive practices at secondary schools and at the university which was demonstrated through the upscaling process. They also positioned themselves as HL experts with the THLU-Ms.

\section{Quest for a positive linguistic identity}

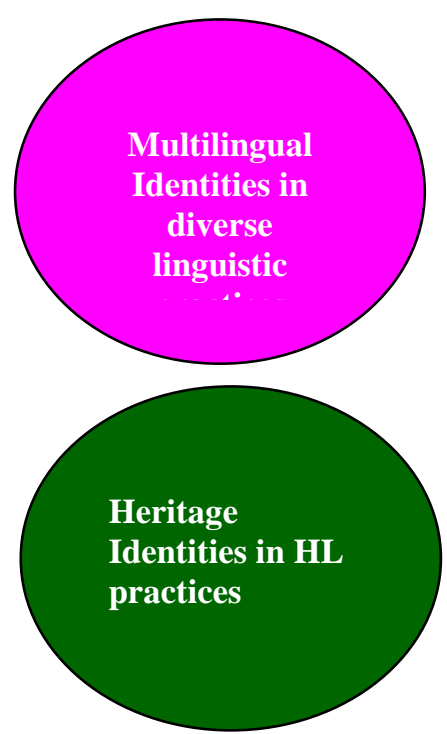

Figure 45. Quest for a positive linguistic identity 
In their search for a positive linguistic identity (refer to figure 45), the participants as multilingual users had to shuffle between multilingual identities and heritage identities. This was displayed in their diverse linguistic practices with the nonTamils and THLU-Ms (assuming multilingual identities) and HL practices with other THLU-Ts like themselves (with heritage identities). When they were with the nonTamils and THLU-Ms they distanced themselves from their heritage identities and assumed multilingual identities which were determined by linguistic hegemony and positioning based on sociolinguistic scales. Likewise, when they were with other THLU-

Ts, they took on heritage identities while distancing themselves from multilingual identities. Their identities were fluid (Norton, 2013) in nature as they were continually projecting them (multilingual and heritage identities) as they moved from multilingual context to heritage context.

\section{Contemporary identity practices in a multilingual environment}

Next, I will relate how my participants flexibly negotiated multilingual identities and heritage identities through social interactions with the different communities in Malaysia (non-Tamils, THLU-Ms and THLU-Ts). This will be done using Blommaert and Variis' (2013) dynamic identity process.

To understand the contemporary identity practices in a multilingual environment Blommaert and Variis (2013) proposed a schematic general framework for investigating the complex and dynamic identity processes of multilinguals. Identity discourses and practices can be described as discursive orientations towards sets of features that are seen (or can be seen) as emblematic of particular identities. These features can be manifold and include artefacts, styles, forms of language, places, times, forms of art or aesthetics, ideas and so forth. These emblematic features presented together reflect and emphasise the authenticity of a particular identity. The notion of degree of authenticity is defined as whether one has enough of the emblematic features so that he or she is recognised as a legitimate member of a specific identity category. Thus, dynamic identity processes become highly contestable because the configurations of features and criteria of enoughness can be adjusted, reinvented amended. Table 11 illustrates how this framework is applied to the participants. 
Table 11. An application of Blommaert and Variis (2013)'s framework of contemporary identity practices to the participants

\begin{tabular}{lll}
\hline $\begin{array}{l}\text { Contemporary Identity } \\
\text { Practices }\end{array}$ & Multilingual Identities & Heritage Identities \\
\hline Emblematic features & $\begin{array}{l}\text { 1. Dominant languages used (Malay and } \\
\text { English). } \\
\text { 2. Social norms, values and behaviours } \\
\text { prescribed by dominant linguistic } \\
\text { practices. }\end{array}$ & $\begin{array}{l}\text { 1. Heritage language used } \\
\text { (Tamil). }\end{array}$ \\
$\begin{array}{l}\text { Malays, Chinese and THLU-Ms } \\
\text { Targeted speakers }\end{array}$ & $\begin{array}{l}\text { Social norms, values and } \\
\text { behiours prescribed by } \\
\text { heritage communities. }\end{array}$ \\
Authenticity decided by: & Proficient dominant language users & $\begin{array}{l}\text { community members } \\
\text { Proficient HL users }\end{array}$ \\
\hline
\end{tabular}

When participants produced sets of features that were emblematic of particular identities (either multilingual or heritage identities), they were judged as to whether these sets of features were sufficient to produce a particular targeted identity. They (the participants) were identified as real, authentic members of a particular community (multilingual community or heritage community) by competent users of dominant languages or heritage languages.

Next I will discuss the two types of identities (multilingual and heritage identities) displayed by the participants in their diverse and monolingual practices.

\section{Assuming multilingual identities in diverse linguistic practices}

Identities are constructed when participants make a choice of which language to use from their multilingual repertoire (Blommaert, 2009). In their diverse linguistic practices with their non-Tamil and THLU-M peers, the participants projected their multilingual identities. The participants understood that they had to select from multiple languages to communicate effectively with other ethnic groups. By choosing to speak English, Malay or Tamil, the participants flexibly negotiated multilingual identities through social interactions with the different communities in Malaysia.

\section{Assuming heritage identities in monolingual practices}

The Tamil school environment nurtured in the participants a love for Tamil language and Tamil culture. Although they used their HL at homes and within their heritage communities, it was in these academic spaces (Tamil schools), a deep emotional attachment to their heritage language was reinforced which in turn impacted their identities. The participants developed a strong affiliation to their heritage language and 
culture. The Tamil school provided a common, cultural and ideological background of shared beliefs with other THLU-Ts. For the participants, the sociocultural values of their HL and entered their consciousness and influenced their ideological becoming and positioning as Tamils (Maguire et. al., 2007).

Speaking in Tamil was seen as demonstrating loyalty to their linguistic tradition. Tamil use was a symbol of the participants' heritage identities that bonded them with other Tamils. The Tamil primary schools provided opportunities for the participants to strengthen their identity and cultural positioning as Tamils and drew them together as a community. It was also an ideological environment where the participants aligned themselves with Tamil culture, and expressed their loyalty to Tamil language.

Some emblematic features strongly identified the participants as authentic members of their heritage community. Firstly, it was the concept of "Mother Tamil" / "Tamil Tāy" (refer to chapter on thematic analysis). This concept encouraged the participants as THLU-Ts to relate to their language with a mixture of reverence, love and deep devotion which they would accord to their mother. "Mother Tamil" is a personification of the Tamil language that is central to the Tamil heritage identity. Thus, Tamil Tāy is looked upon, as their (the THLUs') mother who gave birth to them and raised them to be loyal and devoted THLU-Ts (Ramaswami, 1998).

Secondly, the participants' HL taught them good conduct, traditions and granted them good values and knowledge (Ramaswami, 1998). For example, the participants spoke of how Tamil women were encouraged to conduct themselves appropriately through their attire and demeanour and Tamil men were taught to refrain from indulging in smoking, drinking and partying (which Tamils view as characteristic of a permissive lifestyle).

Thirdly, strong familial ties to the heritage community were established through heritage culture. Learning HL was seen as an ideological obligation towards their families and an important part of their heritage identity. This was demonstrated when the participants' parents chose to send their children to Tamil primary schools. During family gatherings and community events, the participants used their HL to foster closer bonding especially with older family members and community members. THLU-Ts' parents give a lot of importance to familial bonds, interdependence and loyalty to the 
family, obedience, religious beliefs and academic and career achievements (Karkar, 1978; Mishra, 1994; Saraswathi \& Pai, 1997).

These emblematic features that projected an authentic heritage identity distinguished the participants from the THLU-Ms. If a THLU-M did not display these emblematic features they were socially excluded and were viewed as inauthentic members of their heritage community. Participants generally expressed a desire to maintain continuity of their heritage sociocultural values, primarily through the maintenance of their heritage language usage.

The next part explains how the participants were able to assume multilingual identities and at the same also project heritage identities when required.

\section{Micro hegemonies and multiple identities (multilingual and heritage identities}

As participants travelled across different language learning trajectories, they were able to deploy particular linguistic competencies which were required in specific academic contexts. Through their linguistic repertoires, the participants invested in the necessary linguistic resources (Tamil, Malay and English) to construct a multilingual identity and a heritage identity. They managed several micro hegemonies within their language learning trajectories when they rescaled the languages according to what was valued in particular academic spaces and time. The participants' linguistic biographies became a dynamic complex of micro hegemonies within which they situated diverse linguistic practices and monolingual practices. The complex of micro hegemonies provided a different type of order, a complex order composed of different niches of ordered linguistic behaviour (Blommaert \& Variis, 2013). Therefore the participants were not at all confused about the linguistic choices they made. Nor did they appear to be caught between different cultures. Participants reported using Malay or English to their nonTamil peers and Tamil to other THLU-Ts. In doing so they projected multilingual identities and at the same time maintained their heritage identities.

\section{Chapter Summary}

It can be seen that in their quest for a positive linguistic identity, the participants realised that projecting themselves as competent multilinguals (proficient in Malay and English) as well as experts in their HL redefined their status as THLU-Ts in Malaysia. The initial stigma of inadequate multilinguals lacking in proficiency in Malay and English was no 
longer valid once they became fluent speakers of Malay and English. This impacted their identities as THLU-Ts positively as it boosted their self esteem. They now considered themselves as multilinguals proficient in three languages (Tamil, Malay and English). 


\section{Chapter Eight \\ Conclusion}

\section{Overview}

This study examined how the identities of a small group of multilingual THLU-Ts were shaped by their educational experiences in Malaysia. In this concluding chapter, I consider the issues of maintaining heritage language and culture within a context where the national language and English dominate. I summarise the study and provide a synthesis of the findings in relation to each research question. Next, I consider how my study has contributed to the field of the sociolinguistics of mobility (Blommaert, 2010a, p. 5), by analysing the THLU-Ts' deployment of language resources as they moved from one academic setting to another. Then I review the limitations of the study and describe the implications for tertiary educators and policy makers. I look at the possibilities for future research to build on the findings of this study.

\section{Summary of the study}

The study explored how a group of THLU-Ts studying at an international university reported negotiating their identities in multilingual academic contexts. It revealed how using multiple languages (English, Malay and Tamil) in different academic settings impacted their identities as multilingual Malaysians. For this purpose I employed a photovoice methodology over a six month period to support the construction of narratives of nine participants. The major criterion for their selection was that they had studied at a Tamil primary school where they were fully immersed in their HL for the first six years of their academic lives. The nine participants used photographs to recall their language experiences in this multilingual setting and these recollections were storied into narratives. I used three narrative inquiry strategies - broadening, burrowing and restorying to write the participants' narratives (Clandinin \& Connelly, 1990, 2000) and this process enabled themes to emerge from their interview transcripts. These themes were then analysed in the light of relevant literature in order to understand why and when the THLU-Ts made language switches and how these impacted their identities during social interaction with the various linguistic communities in Malaysia which 
included HLUs (from national primary schools) and non - Tamils. Through their individual stories, I sought to answer the three research questions framed in Chapter One.

I will now provide a synthesis of the findings from the study with respect to the individual research questions.

\section{Research question one}

How do nine THLU-Ts tertiary students from an international university in Malaysia perceive the status of their HL in relation to English and Malay?

Qualitative data from in-depth interviews with the participants indicated their HL use thrived within a heritage language context; for example, in Tamil primary schools and among heritage community members (other THLU-Ts). Participants responded that they felt comfortable speaking in Tamil as it was encouraged by heritage community members, parents and relatives. However, the participants felt that using HL was disapproved by non-Tamils and THLU-Ms at secondary school and at university. The participants reported that they often felt isolated as they were not included in social interactions with their classmates and peers (Malays, Chinese and THLU-Ms). This led them to bond with other THLU-Ts as a form of solidarity. They used their HL outside classrooms as a form of counter- discourse against prevailing dominant language ideologies implemented in formal academic contexts.

\section{Research question two}

How do nine THLU-Ts tertiary students from an international university in Malaysia perceive that they are positioned by their peers (non-Tamils and THLU-Ms) when they use Tamil?

The participants considered that they were looked down upon by non- Tamils and THLU-Ms when they used their HL at secondary school. The participants reported that they were sometimes reprimanded by their teachers and told to speak in either Malay or English. They (the participants) felt that their HL was devalued because it was not used in academic contexts in Malaysia outside Tamil primary school. Therefore it appeared to hold no significant value in the formal academic settings of secondary school and at university. Another reason why the participants perceived themselves to be positioned lower than their non- Tamil and THLU-Ms classmates was that initially the 
participants were not as fluent as them in the dominant discursive practices of the academic institutions. They felt that the Chinese and THLU-Ms especially ridiculed the way they spoke English. Perhaps in response to this, the participants positioned THLUMs as being disloyal to their heritage language and culture. They felt that the THLU-Ms betrayed their heritage identity by refusing to speak in their HL. They did not mind if the non-Tamils were unable to show respect to their HL and culture by speaking in Tamil. However, they were offended when THLU-Ms showed little support for their status as HLUs.

\section{Research question three}

How do nine THLU-Ts tertiary students from an international university in Malaysia perceive the role of their families in the language choices they (the participants) make?

The participants felt that their families supported the maintenance and growth of their HL and culture. For example during family events speaking in their HL appeared to foster relationships with the older generation. Participants also reported taking part in community events which promoted heritage culture. On one hand, HL and culture were

encouraged: on the other hand families of the participants also encouraged proficiency in English. The participants perceived that this was due to the status of English as a global language of power and prestige. In contrast, Malay held little significance for the participants' families and was hardly ever used at home.

Next I explain how my study has contributed to existing literature.

\section{Contributions to literature}

In the thematic review of literature found in Chapter Two, three major themes were identified. These were linguistic hegemony, self positioning and positioning by others, and affiliation to heritage identity. The purpose of this section is to consider how this study contributes to these three streams of research.

\section{Linguistic hegemony}

The analysis of the findings of my study adds to an understanding of linguistic hegemony. My study highlights the uniqueness of the multilingual Malaysian context. Earlier research on linguistic hegemony indicated that HLUs had linguistic demarcations 
or boundaries; one for public use (the dominant language) and the other for private use (HLs) (Jaspal, 2010; Pujolar \& Gonzalez, 2013; Wong \& Xiao, 2010).

In contrast the findings from my study revealed that the THLU-Ts coped with the language policies at secondary schools and at university by shuttling between public (formal) and private (informal) spheres. They deployed the appropriate language (Malay, English or Tamil) during interaction with different linguistic groups in Malaysia. Therefore the use of their HL was not limited to their home context. I argue that they possessed the appropriate linguistic resources to constantly adjust and readjust their language boundaries. As a result there were no rigid language boundaries set by the participants. This was possible because of their language learning experiences at Tamil primary school (they became fluent in Tamil both socially and academically), at secondary school (they became fluent in Malay both socially and academically) and at the international university (they became fluent in English both socially and academically).

In the Malaysian context (Lee Su Kim, 2003; Rajadurai, 2009), the participants adhered to the language policies of public and private universities, using English and Malay in formal and informal academic contexts. The non-Malay classmates (Chinese and Tamils) in their studies did not come from HL schools. Hence they were not fluent in their HL.

The THLU-Ts (the participants in my study) selected from their multilingual repertoire to interact with the various linguistic communities they encountered. As a result, they were deliberate in their language choices. With other THLU-Ts they used Tamil, with the Malays and Chinese and THLU-Ms they used either Malay or English.

In my study, the THLU-Ts constructed shifting language boundaries according to space and time (Blommaert, 2010a). These shifting language boundaries were constructed based on the linguistic value assigned to the multiple languages (Tamil, Malay and English) in a specific academic context. The THLU-Ts possessed mobile language resources which they continuously manipulated as they moved from one academic environment to another. Therefore, the THLU-Ts indexed the value of each language according to the period of their life (academic life) and space (academic context), illustrating how order of indexicality influences sociolinguistic mobility patterns. 
These findings emphasise how HL education at Tamil primary school, the national language as the medium of instruction and English as a second language at secondary school, and English as the medium of instruction at the international university prepared these participants to become fluid multilinguals. Unlike the language learning trajectories of HLUs in other contexts (Jaspal \& Coyle, 2010 ; Gua \& Patkin, 2013; Preece, 2010), these THLU-Ts positioned themselves as fluent speakers of English, Malay and Tamil which earned respect from their classmates. Their linguistic repertoires included micro hegemonies (ordered sets of linguistic patterns) which were active during social interaction with the non-Tamils and THLU-Ms (Blommaert \& Variis, 2013). There seemed to be almost a seamless transition from one micro hegemony to another.

The second theme from the review of literature was positioning. I highlight here how the findings of my study contributed to the existing literature.

\section{Positioning}

In my study, the THLU-Ts positioned themselves as having their "feet in both worlds" (Wallace, 2001 p. 124) - a multilingual world and a heritage language world. It was interesting to note that in the multilingual environment of Malaysia the participants projected a multilingual identity, and in a heritage setting they projected a heritage identity. They were able to separate their identities (multilingual and heritage) according to space and time. They maintained their heritage identities at Tamil school, at home and with other community members. They projected a multilingual identity with their nonTamil and THLU-M classmates, peers and friends. They were able to select from a complex set of micro hegemonies within their linguistic repertoire. They did not appear to be caught between their heritage culture and dominant culture. They did not consider their identities as mixed or multifaceted as reported in Wylegala's (2010) study. They positioned themselves as proficient THLU-Ts with heritage community members and equally as skilled multilinguals (proficient in Malay and English) with non Tamils and THLU-Ms. My study revealed that they were certain of their identities and knew when to project a multilingual or heritage identity.

Findings from my study have expanded the notion of positioning to include social positioning in academic settings. Aydar's (2014) study reported positioning of HLUs within the classroom context by their teachers and classmates. During classroom 
observations, the participants' involvement in classroom activities was influenced by how they were positioned by others in the classroom. My study also describes how the participants felt they were positioned by others in multilingual academic settings. The research methodology employed in this study allowed a glimpse into their world as THLU-Ts. Their perception of themselves as how others (THLU-Ms and non-Tamils) saw them.

As they narrated their stories of being multilingual Malaysians, the THLU-Ts felt that they were perceived favourably by others when they became proficient users of Malay and English. They managed to reposition themselves by increasing their investment in gaining fluency in Malay and English. This was demonstrated through their agency. The dynamic interplay of agency and investment worked together to contribute towards a more favourable perception of them (THLU-Ts) by others.

To be multilingual in the Malaysian context, the THLU-Ts in my study had to be competent in both English and Malay. In contrast, in other contexts throughout the world; HLUs were empowered only by increasing their fluency in English (EduBuandoh \& Otchere, 2012; Gua \& Patkin, 2013; Jaspal \& Coyle, 2010; Preece, 2010). This provides a unique context. My study indicated that the Chinese and THLU-Ms preferred the THLU-Ts to speak to them in English. Their Malay classmates, however, expected the participants to be fluent in Malay. Therefore I conclude that increasing English competency alone is not enough to be a powerful multilingual Malaysian; acquiring fluency in Malay is a necessity.

The next section considers the contribution of this study in relation to the last theme.

\section{Affiliation to heritage identity}

The THLU-Ts in my study demonstrated a very strong and deep emotional attachment to their HL (Mother Tamil). Personification of the HL has not been reported in studies of the Tamil diaspora living in Canada, USA and the UK (Canagarajah, 2012; Jaspal \& Coyle, 2010; Preece, 2010). The Malaysian context is unique because Tamil parents have the opportunity of sending their children to Tamil primary schools. Tamil migrants in other contexts attend HL schools during weekends.

My study highlights this interesting relationship; a deep loyalty almost bordering on reverence which was evident in the participants' description of their HL. It appears 
that six years of full immersion during the early part of their school life in Tamil primary school contributed to and intensified their love for their HL which was used both as an academic language and a social language. As their HL bonded the THLU-Ts together, any Tamil (THLU-Ms, in this case) who did not use his or her HL was considered an outsider and thus positioned as betraying their heritage identities. Earlier studies (Chinen \& Tucker, 2006; Noels, 2005; Shibata, 2000; You, 2005) explained how researchers found a positive relationship between HL competency and attending HL schools which were run during weekends. My study seems to show that the six year immersion in a completely Tamil academic and cultural environment nurtured a strong affiliation to heritage identity.

The next section describes how language use impacted the THLUs' identities.

\section{Impact on identity}

The participants had two different sets of emblematic features (characteristics of a particular identity) (Blommaert \& Variis, 2013); one for a multilingual identity and the other for a heritage identity. My participants renegotiated their identities as they moved between heritage identities and multilingual identities. When they invested in the discursive practices at school and at university, they acquired emblematic features of a multilingual identity. Yet, they also projected a heritage identity to other THLU-Ts and THLU-Ms, because they had sufficient characteristics that represented a heritage identity. In doing so, the participants demonstrated their agency and became adaptable multilinguals shuttling across a heritage identity and a multilingual identity. This reiterates the concept that identities are fluid and take shape according to context.

I now highlight how my study may be of relevance to education policymakers, practitioners and researchers in Malaysia.

\section{Implication of this study on educational policies}

This study has used empirical findings to show that THLU-Ts in an international university in Malaysia repositioned themselves at different points in time throughout their multilingual academic life. They engaged in this process of linguistic accommodation in response to the tensions and conflicts they faced at the intersection of institutional values, varied language policies and program structures, and their (THLUTs') own linguistic and cultural resources. 
In a multilingual setting, different values are ascribed to different language systems and HLs often do not share equal status (Ahearn, 2001) with academic languages like English and in the Malaysian context, Malay. This can be a source of identity conflict for THLU-Ts (Brown, 2010) as they go through the transition process from Tamil primary school to secondary school. Learning to adapt to a new academic environment is rarely an easy process because THLU-Ts face challenges as they struggle to negotiate and renegotiate their status as THLUs among non-Tamils and THLU-Ms. Thus, it would assist educators and policy-makers to be mindful of the adjustments a THLU-T has to make when he or she makes the transition from a HL academic environment to a multilingual academic context.

Current language policies prohibit students from using their HLs within academic contexts (only Malay and English are allowed). The existing language policies do not acknowledge the HL resources of the THLU-Ts. Studies (Hollobow, Genesee \& Lambert, 1991; Swain \& Lapkin, 1982) have shown that bilingualism results in positive or additive consequences if the first language (Tamil) is well-developed and if this language is valued by the community and is not in danger of being replaced by a second language (Malay at secondary school and English at the international university). Furthermore, multilinguals' language learning is maximised when they are allowed and enabled to draw from across all their existing language skills (including in theirL1) rather than being constrained and inhibited from doing so by monolingual instructional assumptions and practices (Baker, 2011; Cummins \& Swain, 1986; Garcia, 2008; Grosjean, 1982; Hamers \& Blanc, 2000; Heller, 2007a; Hornberger, 2008). These researchers claim that the stronger the foundation and continuing development in the L1, the greater the potential for enhanced learning of L2.

Existing research argues convincingly that preserving or cultivating the language/literacy skills and cultural capital of HL users while they become fully proficient in dominant languages (Malay and English) through additive bilingualism or multilingualism is an important educational priority in an increasingly global marketplace and diversified society (Cummins, 2004; Tavares, 2000). However, in Malaysian secondary classrooms a bilingual policy which ignores HL use is practised. Language policies as outlined in the Malaysian Education Blueprint (2013-2025) 
advocate the use of Malay and English only. These language policies may limit the possibilities for THLU-Ts' educational success and achievement.

It would support THLU-Ts in general if there were language policies and practices that were sensitive to the language learning trajectories of HLUs. The THLUTs in this study reported that their first year at secondary school was the most trying period in their academic lives as they learnt to position themselves in the dominant culture and linguistic practices. Implementing policies that consider the different language learning paths taken by the THLU-Ts would help the THLU-Ts settle more quickly into secondary school. The transition process from Tamil school to secondary school may be less difficult for THLU-Ts, and they may find it easier to adjust to a multilingual academic setting if several changes in educational policies take place. I have outlined these policies in the subsequent paragraphs.

It may support THLU-Ts if there were more flexible language policies in the academic environment. Although Malay is the academic language at secondary schools, THLU-Ts might be allowed restricted use of their L1 or HL as they learn to adjust to new discursive practices at school. For example, in allowing THLU-Ts to exchange ideas in their HL with other THLU-Ts during group discussions, and translating to academic languages (Malay or English) when required. Canagarajah (2013a) terms these translingual practices (the ability to merge different language resources in situated interactions for new meaning construction) (pp. 1-2). Translingual practices have the potential to encourage active classroom participation and it may reduce fear and tension among the THLU-Ts if heterogeneity (heteroglossia) is treated as a norm rather than an exception.

The existing educational policies need to be reviewed against the objectives of the 1Malaysia concept introduced by the Prime Minister, Najib Abdul Razak on September 16, 2010. 1Malaysia encourages respect and valuing of the linguistic identities of each community as an asset that forefronts Malaysia's uniqueness. The Prime Minister's department has encouraged programmes and policies that promote, enhance and preserve the linguistic and cultural diversities of its people. For example, the National Civics Bureau organises courses and seminars that promote national unity. Secondary schools are potentially important multilingual sites where young people from the various linguistic communities meet and interact. Our schools should capture the 
essence of 1Malaysia and project a miniature Malaysia where linguistic and cultural diversities are recognised and celebrated; a snapshot of the bigger Malaysian picture. This means allowing HL languages to thrive alongside the national language and English.

This study highlighted how the THLU-Ts were capable of perpetually adjusting their multilingual repertoire (moving between HL usage and Malay and English use). Adopting classroom strategies that encourage translingual practices would enable THLU-Ts to access their available multilingual resources to address their communication needs. It would support both learning and social coherence if educators were able to recognise the value of the linguistic and cultural diversity of their students and view translingual practices as crucial processes for making meaning in a multilingual Malaysian classroom.

Secondly, it may validate their identity as THLU-Ts if they are allowed to use their HL outside the classroom as this would acknowledge that their HL is valued at secondary school. This could be done by creating "safe spaces" (Conteh et. al., 2007; p.10) condoned by the school administration for the THLU-Ts to use their HL freely.

Next, the teaching of HLs within the school time-table alongside other subjects could balance the hegemonic positions of Malay and English. At present HLs are only taught after school hours or during weekends. This further isolates the THLU-Ts from Malay students at secondary school. HL use will become more accepted in academic settings if it is scheduled within the main school timetable.

Finally, school authorities often cite lack of full-time trained secondary school HL teachers as the major cause for excluding HLs from the mainstream school timetable. Many schools employ HL teachers on a part-time basis from Tamil primary schools. One way to overcome the issue of timetabling would be for the Education Ministry to recruit more HL teachers who are trained to teach HL at secondary level. This calls for local universities to include Tamil education as part of their undergraduate programmes.

The Malaysian Education Blueprint (2013-2025) remains silent on its commitment to support and improve HL education. The blueprint stresses that all Malaysian students must acquire bilingual proficiency (in Malay and English). The Ministry also encourages all students to learn an additional language (Tamil, Mandarin or Arabic). However, there is no acknowledgement of the roles played by existing 
Tamil and Chinese primary schools. Such a scenario does not augur well for HL education in Malaysia. This goes against the spirit of 1Malaysia concept which strongly emphasises unity in diversity. If there is no support and commitment from the Education Ministry to promote and develop the growth of HL schools, the gap among the THLUTs, non-Tamils and THLU-Ms will widen.

\section{Summary}

It is my contention that efforts in this direction will contribute to more effective and rewarding educational experiences for linguistic minority students. Linguistic majority students and teachers may become more sensitive to the struggles and challenges faced by the linguistic minority students (THLU-Ts) as they learn to position themselves in the dominant discursive practices. As Malay administrators learn to appreciate the linguistic and cultural resources present in the Malaysian classroom, the socio-cultural gap between THLUs and THLU-Ms and non-Tamils may be reduced. The linguistic and cultural diversities that exist in our classroom are a part of the unique Malaysian heritage. Such policies may encourage our students to connect and network with the different linguistic groups in the multilingual classroom. As multilingual Malaysians, pooling our economic, social and intellectual resources together can promote a vibrant society in line with the government's much touted 1Malaysia concept.

I recommend some areas of research that could be explored in relation to HLUs.

\section{Directions for future research}

Several issues emerge from this study that might be addressed in future research. Firstly, the multilingual experiences of THLU-Ts studying in public universities in Malaysia where the medium of instruction is in Malay could be explored. There are many other THLU-Ts' stories waiting to be heard and understood. For example, how do other THLU-Ts negotiate their identities in a public university where Malay is the medium of instruction? Do they experience similar tensions and conflicts? How are their identities impacted? More research in this area may add depth through a discussion of similarities, differences and peculiarities of the multilingual experiences of THLU-Ts studying in Malaysian public and private universities. Findings from these future studies may offer possible solutions for developing, enabling and empowering teaching and learning environment for THLU-Ts in the Malaysian academic context. 
Secondly, longitudinal studies of THLU-Ts could be conducted to gain a full understanding of their multilingual lives as they journey through different spaces and time. For example, observing THLU-Ts' language choices at home, at Tamil school, at secondary school and at university could inform the long term planning of educational policies. Ethnographic research can provide rich insight into THLU-Ts as multilingual users. Such an approach can be used to identify new linguistic behaviours, patterns and constraints among the THLU-Ts as they negotiate multiple identities. There is still relatively little linguistic research on how language is used in everyday interaction in multilingual communities (Degi, 2010; Willoughby, 2010). A study of this nature highlights the importance of considering the ways in which multilingual users learn and draw on their multilingual resources for social interaction. Instructional goals in language education should be reviewed and adjusted to the needs of a multilingual society. Thus, an understanding of the ethnic composition and internal dynamics of the school community can shed new light on how linguistic practices evolve as they do.

Finally, research might also be conducted with THLU-Ts who did not pursue studies at university. These might be THLU-Ts who were low achievers at secondary school. An investigation of their multilingual experiences could shed some light on how they negotiated their identities during interaction with non-Tamils and THLU-Ms at secondary schools. Perhaps important information can be gleaned from their coping strategies as they learnt to adapt (or did not adapt) to new linguistic demands at secondary schools, and how we as educators and language planners might help. Are we as educators responsive to the HL students we serve? Findings from studies like this can help to answer these questions and may support higher levels of academic achievement for HLUs in general. I hope that in the future, additional studies will continue to consider how teachers work for the benefit of their HL students.

In the next section, I reflect on the limitations of my study.

\section{Limitations of the study}

One of the limitations of this small-scale study is the particularity of successful individual THLU-Ts' multilingual experiences, and the fact that their stories are situated within the particular contexts and particular phases of their language learning trajectories. For instance, all the participants were already first year undergraduates at an 
international university when this study was conducted. These participants reflected back on their much earlier multilingual experiences at Tamil primary school and secondary school. However their language experiences at the university were current. While I have been writing this thesis, they may have completed their three year degree programmes. Their language experiences may have continued to change and as a result impact the way they see themselves now as multilingual users at this point in time. This reflects the dynamic process of identity formation (Norton, 2013) which is constantly being transformed by experiences through social interactions with diverse communities.

Therefore, this study cannot make any generalisable claims beyond presenting these stories from specific participants as they navigated their journey through various academic contexts. My study has limited transferability because of the unique research context. My hope is that the THLU-Ts' stories will stimulate more discussions about teaching and learning of HLUs among teachers, tertiary educators, scholars and policymakers in the contemporary Malaysian academic context.

The final limitation is related to the subjectivity of the narratives, as my interpretations of the THLU-Ts' stories are from my own epistemological standpoint as a THLU-M and educator. To balance my own perspectives, I constructed participants' narratives using Clandinin and Connelly's (1990, 2000) narrative inquiry approach, and did a thematic analysis of their transcribed interviews. Triangulation of data analysis increased the trustworthiness of my study. Furthermore, using a photovoice methodology helped to reduce researcher bias. The participants narrated their stories based on the pictures they had selected. They initiated the conversation during interview sessions by describing events related to the photos. The trustworthiness of my study was further increased through member checking, feedback from supervisors and my own reflexivity.

Finally, I offer concluding thoughts on my study.

\section{Concluding thoughts}

I hope to raise awareness through this study that the participants (the THLU-Ts) had an agentive capacity to evaluate and negotiate the constraints and opportunities of their positioning in a multilingual academic context. While there were policy structures that seemed to position them as inferior compared to dominant language users who came 
from national primary schools, the THLU-Ts' agency in investing in dominant linguistic practices helped them to challenge hegemonic practices. This allowed the THLU-Ts to not only participate in but also transform the multiple spaces and time they travelled through within their language learning trajectories. The results of this study emphasise that identities are fluid, taking shape according to the space and time the THLU-Ts occupy in a dynamic and diverse multilingual society. To recognise this fact, academic institutions are encouraged to revise policies and implement strategies that make it easier for THLU-Ts to participate in different academic contexts.

It is time both government and language policy-makers started envisioning a multilingual Malaysia in the true sense of the word. We cannot deny the fact that THLUTs carry with them mobile multilingual repertoires as they travel across (academic) space and (academic) time. This is inevitable in a multilingual Malaysian society. Policies should reflect this linguistic flexibility and value the diverse linguistic practices of its people. So, as the THLU-Ts move from context to context, their multilingual practices can be seen as components of the Malaysian sociolinguistics of mobility. There is a need to educate Malaysian society as a whole and build awareness that identities are multidimensional. In a multilingual and multicultural society like Malaysia, HLUs do not only project heritage identities but also multilingual identities. When THLU-Ts communicate in Malay, they project a national identity and when they communicate in English, they project an international identity. Support for the maintenance and enhancement of heritage language education in Malaysia, I believe, would encourage linguistic minorities to feel included and their heritage identities be acknowledged and valued. This sense of belonging as a part of the greater Malaysian identity may in turn spur and enhance loyalty for the national language of the nation. If seen in this manner, linguistic diversities need not be viewed as causing divisiveness but promoting unity in diversity.

This raises the issue of a delicate balance that needs to be maintained for the development of a national identity, a heritage identity and an international or global identity. Language planning and policies formulated need to assist Malaysia’s multilingual and multicultural population in establishing these identities. We need educational policies that capitalise on our rich linguistic resources for this to happen. Only through these crucial considerations can heritage identities flourish alongside national and global identities. 


\section{References}

Adams, J. L., \& Harre, R. (2001). Gender positioning: A sixteenth/seventeenth century example. Journal for the Theory of Social Behaviour, 31(3), 331-338. doi.org/10.1111/1468-5914.00162

Agha, A. (2007). Language and social structure. Cambridge: Cambridge University Press.

Ahearn, L. M. (2001). Agency. In A. Duranti (Ed.), Key terms in language and culture (pp. 7-10). Oxford, UK: Blackwell.

Alkin, M. C., Daillak, R., \& White, P. (1979). Using evaluations: Does evaluation make a difference? Sage Library of Social Research Series: Vol. 76. Beverly Hills: Sage.

Amtaika, A. (2014). The power and authority of the dominant to name: A case study of selected Nyanja and isiZulu linguistic expressions regarding 'national assets'. Journal of African Cultural Studies, 26(1), 99-115. www.tandfonline.com/doi/abs/10.1080/13696815.2013.823856.

Arumugam, K. (2008) 'Tamil School Education in Malaysia: Challenges and Prospects in the New Millennium', in Rising India and Indian communities in East Asia (pp. 399-421). ISEAS-Yusof Ishak Institute.

Asmah Haji Omar, (2007). Malaysia and Brunei. In A. Simpson (Ed.), Language and national identity in Asia (pp. 337-359). Oxford: Oxford University Press.

Azirah Hashim. (2009). Not plain sailing. Malaysia's language choice in policy and education. AILA Review, 22, 36-51.

Bailey, A. J., Canagarajah, S., Lan, S., \& Powers, D. G. (2016). Scalar politics, language ideologies and the sociolinguistics of globalization among transnational Korean professionals in Hong Kong. Journal of Sociolinguistics, 20(3), 312-334. doi.org/10.1111/josl.12186

Baker, C. (2011). Foundations of bilingual education and bilingualism (Vol. 79). Bristol, UK: Multilingual Matters.

Baker, C., \& Jones, S. P. (1998). Encyclopedia of bilingual education and bilingualism. Clevedon, UK: Multilingual Matters.

Barbour, R. (2008). Introducing qualitative research: A student guide to the craft of doing qualitative research. London: Sage.

Barth, F. (Ed.). (1982). Ethnic groups and boundaries: The social organization of cultural difference. Oslo: Universitetsforlaget.

Bartlett, L. (2007). Bilingual literacies, social identification, and educational trajectories. Linguistics and Education, 18(3-4), 215-231.

doi.org/10.1016/j.linged.2007.07.005 
Bastos, L. C., \& Oliveira, M. C. L. (2006). Identity and personal/institutional relations: People and tragedy in a health insurance customer service. In A.de Fina, D. Schiffrin, \& M. Bamberg (Eds.), Discourse and identity (pp. 188-212). Cambridge: CUP.

Bell, J. S. (2002). Narrative inquiry: More than just telling stories. TESOL Quarterly, 36(2), 207-213. doi.org/10.2307/3588331

Belle, C. V. (2015). Tragic orphans: Indians in Malaysia. Singapore: Institute of Southeast Asian Studies.

Ben-Rafael, E., Shohamy, E., Amara, M. H., \& Trumper-Hecht, N. (2006). Linguistic landscape as symbolic construction of the public space: The case of Israel. International Journal of Multilingualism, 3, 7-30.

Berard, T. J. (2005). On multiple identities and educational contexts: Remarks on the study of inequalities and discrimination. Journal or Language, Identity, and Education, 4(1), 67-76. doi.org/10.1207/s15327701jlie0401_4

Billings, S. (2014). Language, globalisation and the making of a Tanzanian beauty queen. Bristol, UK: Multilingual Matters.

Blackledge, A., \& Creese, A. (2008). Contesting 'language' as 'heritage': Negotiation of identities in late modernity. Applied Linguistics, 29(4), 533-554. doi:10.1093/applin/amn024

Blackledge, A., \& Pavlenko, A. (Eds.). (2002). Ideologies of language in multilingual contexts. Multilingua: Special Issue, 21, (pp. 2-3).

Block, D. (2007a). Second language identities. London: Continuum.

Block, D. (2007b). The rise of identity in SLA research: Post Firth and Wagner (1997). Modern Language Journal, 91, 863-876. doi.org/10.1111/j.15404781.2007.00674.x

Blommaert, J. (2005a). Discourse: A critical introduction. Cambridge: Cambridge University Press.

Blommaert, J. (2005b). In and out of class, codes and control. In M. Baynham \& A. De Fina (Eds.), Dislocations/relocations: Narratives of displacement (pp. 127-143). Manchester, UK: St Jerome.

Blommaert, J. (2007). Sociolinguistic scales. Intercultural Pragmatics, 4(1), 1-19. doi.org/10.1515/IP.2007.001

Blommaert, J. (2010a). The sociolinguistics of globalization. Cambridge: Cambridge University Press.

Blommaert, J. (2010b). Policy, policing \& the ecology of social norms: Ethnographic monitoring revisited. Working Papers in Urban Language \& Literacies: Paper 63. Retrieved from www.kcl.ac.uk/ldc

Blommaert, J. (2013). Ethnography, superdiversity and linguistic landscapes: Chronicles of complexity. Bristol, UK: Multilingual Matters. 
Blommaert, J., \& Backus, A. (2011). Repertoires revisited: 'Knowing language' in superdiversity. Working Papers in Urban Language and Literacies: Paper 67. Retrieved from www.kcl.ac.uk/ldc.

Blommaert, J., \& Variis, P. (2013). Enough is enough: The heuristics of authenticity in superdiversity. In J. Duarte \& I. Gogolin (Eds.), Linguistic superdiversity in urban areas: Research approaches (pp. 143-160). Hamburg: Studies on Linguistic Diversity, 2.

Blommaert, J., Creve, L., \& Willaert, E. (2006). On being declared illiterate: Languageideological disqualification in Dutch classes for immigrants in Belgium. Language and Communication, 26(1), 34-54. doi.org/10.1016/j.langcom.2005.03.004

Blommaert, J., James, C., \& Stef, S. (2005a). Spaces of multilingualism. Language and Communication, 25(3), 197-216. doi.org/10.1016/j.langcom.2005.05.002

Blommaert, J., James, C., \& Stef. S. (2005b). Polycentricity and interaction regimes in 'global neighborhoods'. Ethnography, 6(2), 205-235. doi.org/10.1177/1466138105057557

Bochner, A. P., \& Ellis, C. (1996). Talking over ethnography. In C. Ellis \& A. P. Bochner (Eds.), Composing ethnography: Alternative forms of qualitative writing (pp. 13-45). Walnut Creek, CA: Alta Mira Press.

Bochner, A. P., \& Ellis, C. (Eds.). (2002). Ethnographically speaking: Autoethnography, literature and aesthetics. Walnut Creek: Alta Mira Press.

Bogdan, R. C., \& Biklen, S. K. (2003). Qualitative research for education: An introduction to theories and methods ( ${ }^{\text {th }}$ ed.). New York: Pearson Education.

Bourdieu, P. (2000). Pascalian Meditations. (trans. N. Rice). Cambridge: Polity Press.

Bourdieu, P. in J. Thompson (Ed.). (1991), Language and symbolic power. (G. Raymond., \& M. Adamson. trans.). Cambridge, MA: Polity Press.

Bourdieu, P. in J. Thompson (Ed.). (1999). Language and symbolic power. (G. Raymond., \& M. Adamson. trans.). Cambridge, MA: Harvard University Press.

Bratlinger, E., Jiminez, R., Klinger, J., Pugach, M., \& Richardson, V. (2005). Qualitative studies in special education. Exceptional Children, 71, (pp.195-207). doi.org/10.1177/001440290507100205

Braun, V., \& Clarke, V. (2006). Using thematic analysis in psychology. Qualitative Research in Psychology, 3(2), 77-101. Retrieved from http://eprints.uwe.ac.uk/11735

Brown, C. L. (2009). Heritage language and ethnic identity: A case study of KoreanAmerican college students. International Journal of Multicultural Education, 11(1), 1-16.

Bryman, A. (1988). Quantity and quality in social research. London: Unwin.

Bucholtz, M., \& Hall, K. (2004). Theorizing identity in language and sexuality research. Language in Society, 33, 469-515. doi.org/10.1017/S0047404504334020 
Bucholtz, M., \& Hall, K. (2005). Identity and interaction: A sociocultural linguistic approach. Discourse Studies, 7(4-5), 585-614.

doi.org/10.1177/1461445605054407

Bucholtz, M., \& Hall, K. (2008). All of the above: New coalitions in sociocultural linguistics. Journal of Sociolinguistics, 12(4), 401-431. doi:10.1111/j.14679841.2008.00382.x.

Budach, G. (2013). From language choice to mode choice: How artefacts impact on language use and meaning making in a bilingual classroom. Language and Education, 27(5), 451-468. http://dx.doi.org/10.1080/09500782.2012.720688.

Butler, J. (1990). Gender trouble: Feminism and the subversion of identity. New York: Routledge.

Canagarajah, A. S. (1996). From critical research practice to critical research reporting. TESOL Quarterly, 30, 321-331. doi.org/10.2307/3588146

Canagarajah, A. S. (2004). Multilingual writers and the struggle for voice in academic discourse. In A. Pavlenko \& A. Blackledge (Eds.), Negotiation of identities in multilingual contexts (pp. 266-289). Clevedon, UK: Multilingual Matters.

Canagarajah, A. S. (2006). Globalization of English and changing pedagogical priorities: The postmodern turn. In B. Beaven (Ed.). IATEFL 2005 Cardiff conference selections (pp. 15-25). Canterbury, UK: IATEFL.

Canagarajah, A. S. (2012). Styling one's own in the Sri Lankan Tamil diaspora: Implications for language and ethnicity. Journal of Language, Identity \& Education, 11(2), 124-135. doi:10.1080/15348458.2012.667309.

Canagarajah, S. (2013b). Reconstructing heritage language: Resolving dilemmas in language maintenance for Sri Lankan Tamil migrants. International Journal of Sociology of Language, 222, 131-155. doi.org/10.1515/ijsl-2013-0035

Canagarajah, S. (2013a). Translingual practice: Global Englishes and cosmopolitan relations. New York: Routledge.

Carreira, M. (2004). Seeking explanatory adequacy: A dual approach to understanding the term "heritage language learner." Heritage Language Journal, 2(1), 1-28.

Castells, M. (2004). The power of identity (2 ${ }^{\text {nd }}$ ed.). (pp. 5-70)Maiden, MA: Blackwell.

Cavallaro, F. (2005). Language maintenance revisited: An Australian perspective. Bilingual Research Journal, 29(3), 561-582. doi.org/10.1080/15235882.2005.10162852

Centre for Public Policy Studies (ASLI). (2012, April 23). Round table discussion on vernacular schools in Malaysia: A heritage to be celebrated or a hindrance to nation building? Retrieved from http://www.cpps.org.my/upload/VERNACULAR\%20SCHOOLS\%20IN\%20MA LAYSIA\%20REPORT\%202012.pdf.

Chang, Y. J. (2011). Picking one's battles: NNES doctoral students' imagined communities and selections of investment. Journal of Language, Identity and Education, 10(4), 213-230. doi.org/10.1080/15348458.2011.598125 
Chen, X. (2010). Identity construction and negotiation within and across school communities: The case of one English-as-a-new-language (ENL) student. Journal of Language, Identity and Education, 9, 163-179. doi.org/10.1080/15348458.2010.486274

Chinen, K., \& Tucker, R. G. (2005). Heritage language development: Understanding the roles of ethnic identity and Saturday school participation. Heritage Language Journal, 3(1). Retrieved from http://www.heritagelanguages.org. doi.org/10.1075/sibil.32.09chi

Chio, C. M., \& Fandt, P. M. (2007). PhotoVoice in the diversity classroom: Engagement, voice, and the "eye/I" of the camera. Journal of Management Education, 31, 484-504. doi.org/10.1177/1052562906288124

Cho, G. (2000). The role of heritage language in social interactions and relationships: Reflections from a language minority group. Bilingual Research Journal, 24(4), 369-384. doi.org/10.1080/15235882.2000.10162773

Cho, S. (2013). Disciplinary enculturation experiences of three Korean students in U.S.based MATESOL programs. Journal of Language, Identity, and Education, 12, 136-151. doi.org/10.1080/15348458.2013.775881

Cincotta-Segi, A. (2011). Talking in, talking around and talking about the L2: Three literacy teaching responses to L2 medium of instruction in the Lao PDR. Compare: A Journal of Comparative and International Education, 41, 195209. http://dx.doi.org/10.1080/03057925.2011.547285.

Clandinin, D. J., \& Connelly, F. M. (2000). Narrative inquiry: Experience and story in qualitative research ( $1^{\text {st }}$ ed.). San Francisco: Jossey-Bass.

Connelly, F. M., \& Clandinin, D. J. (1990). Stories of experience and narrative inquiry. Educational Researcher, 19(5), 2-14. doi.org/10.3102/0013189X019005002

Conteh, J., \& Brock, A. (2011). 'Safe spaces'? Sites of bilingualism for young learners in home, school and community. International Journal of Bilingual Education and Bilingualism, 14(3), 347-360. doi:10.1080/13670050.2010.486850

Corson, D. (1999). Community-based education for indigenous cultures. In S. May (Ed.), Indigenous community-based education (pp. 8-19). Clevedon, UK: Multilingual Matters.

Coulmas, F. (2005). Sociolinguistics: The study of speaker's choice. Cambridge: Cambridge University Press.

Crawshaw, R., Callen, B., \& Tusting, K. (2001). Attesting the self: Narration and identity change during periods of residence abroad. Language and Intercultural Communication, 1(2), 101-119. doi.org/10.1080/14708470108668067

Creese, A., \& Blackledge, A. (2011). Separate and flexible bilingualism in complementary schools. Journal of Pragmatics, 43, 1196-1208. doi.org/10.1016/j.pragma.2010.10.006 
Creese, A., \& Martin, P. W. (Eds.). (2006). Introduction: Special issues of language and education on 'interaction in complementary school contexts: Developing identities of choice'. Language and Education, 20(1), 1-4.

Creswell, J. W. (2009). Research design qualitative: Quantitative, and mixed methods approaches ( $3^{\text {rd }}$ ed.). Los Angeles: Sage.

Creswell, J. W., \& Miller, D. L. (2000). Determining validity in qualitative inquiry. Theory into Practice, 39(3), 124-131. doi.org/10.1207/s15430421tip3903_2

Crystal, D. (2003). English as a global language. Cambridge: Cambridge University Press.

Cummins, J. (2000). 'This place nurtures my spirit': Creating contexts of empowerment in linguistically-diverse schools. In R. Phillipson (Ed.), Rights to language: Equity, power and education (pp. 249-258). Mahwah, NJ: Lawrence Erlbaum.

Cummins, J. (2005). A proposal for action: Strategies for recognizing heritage language competence as a learning resource within the mainstream classroom. Modern Language Journal, 89(4), 585-591.

Cummins, J. (Ed.). (2004). Language, power and pedagogy: Bilingual children in the crossfire. Clevedon UK: Multilingual Matters.

Cummins, J., \& Swain, M. (1986). Bilingualism in education: Aspects of theory, research and policy. London: Longman.

Davies, B., \& Harré, R. (1991). Positioning. Journal for the Theory of Social Behaviour, $21,1-8$.

De Costa, P. I. (2010). Reconceptualizing language, language learning, and the adolescent immigrant language learner in the age of postmodern globalization. Language and Linguistics Compass, 4(9), 769-781. doi.org/10.1111/j.1749$\underline{818 X .2010 .00229 . \mathrm{X}}$

Degi, Z. (2010). Effects on the linguistic awareness of foreign language learners. Acta Universitatis Sapientiae, Philologica, 2(2), 299-311.

Delgado, M. (2015). Urban youth and photovoice. Visual ethnography in action. NY: Oxford University Press.

Denzin, N. K., \& Lincoln, Y. S. (Eds.). (2000). Handbook of qualitative research (2 ${ }^{\text {nd }}$ ed.). Thousand Oaks, CA: Sage.

Denzin, N. K., \& Lincoln, Y. S. (2003). The landscape of qualitative research: Theories and issues ( $2^{\text {nd }}$ ed.). Thousand Oaks, CA: Sage.

Deters, P., Gao, X., Miller, E., \& Vitanova, G. (Eds.). (2015). Theorizing and analyzing agency in second language learning. Clevedon, UK: Multilingual Matters.

Djité, P. G. (2006). Shifts in linguistic identities in a global world. Language Problems \& Language Planning, 30(1), 1-20. doi.org/10.1075/1plp.30.1.02dji

Dong, J., \& Blommaert, J. (2009). Space, scale and accent: Constructing migrant identity in Beijing. Multilingua, 28(1), 1-24. doi.org/10.1515/mult.2009.001 
Dressler, R. (2010). “There is no space for being German": Portraits of willing and reluctant heritage language earners of German. Heritage Language Journal, 7(2). $1-21$.

Duff, P. (2012). Identity, agency and SLA. In A. Mackey, \& S. Gass (Eds.), Handbook of second language acquisition (pp. 410-426). London: Routledge.

Edu-Buandoh, D. F., \& Otchere, G. (2012). "Speak English!" A prescription or choice of English as a lingua franca in Ghanaian schools. Linguistics and Education: An International Research Journal, 23, 301-309. doi.org/10.1016/j.linged.2012.06.003

Edwards, J. (1988). Language, society, and identity. Language in Society, 17(1), 103108. doi:http://dx.doi.org/10.1017/S0047404500012628.

Eisner, E. W. (1991). The enlightened eye: Qualitative inquiry and the enhancement of educational practice. New York, NY: Macmillan.

Ellis, C. S. (1995). Final negotiations: A story of love, loss, and chronic illness. Philadelphia: Temple University Press.

Etherington, K. (2000). Narrative approaches to working with adult male survivors of childhood sexual abuse. London: Jessica Kingsley.

EWRF News. (2013, October,). Education Forum 2013. Issue 85 (pp. 22-23).

Ex-government official calls for closure of Tamil medium schools. (2013, May 14). Retrieved from http://ibnlive.in.com.

Fishman, J. A. (1991). Reversing language shift: Theoretical and empirical foundations of assistance to threatened languages. Clevedon, UK: Multilingual Matters.

Francis, B., Archer, L., \& Mau, A. (2009). Language as capital, or language as identity? Chinese complementary school pupils' perspectives on the purposes and benefits of complementary schools. British Educational Research Journal, 35(4), 519538. doi.org/10.1080/01411920802044586

Gao, X., Cheng, H., \& Kelly, P. (2008). Supplementing an uncertain investment? Mainland Chinese students practising English together in Hong Kong. Journal of Asian Pacific Communication, 18(1), 9-29. doi.org/10.1075/japc.18.1.02gao

Garcia, O. (2008). Bilingual education in the 21st century: A global perspective. Malden, MA: Wiley-Blackwell.

Gaudart, H. (1987). English language teaching in Malaysia: A historical account. The English Teacher, 16, 17-36.

Gaventa, J. (2003). Power after Lukes: A review of the literature. Brighton, UK: Institute of Development Studies.

Geertz, C. (2004). What is a state if it is not a sovereign? Reflections on politics in complicated places. Current Anthropology, 45(5), 577-593. doi.org/10.1086/423972 
Giampapa, F. (2004). The politics of identity, representation, and the discourses of selfidentification: Negotiating the periphery and the center. In A. Pavlenko \& A. Blackledge (Eds.), Negotiation of identities in multicultural contexts (pp. 192218). Clevedon, UK: Multilingual Matters.

Gibbons, J., \& Ramírez, E. (2004). Maintaining a minority language: A case study of Hispanic teenagers. Clevedon: Multilingual Matters.

Gkaintartzi, A., \& Tsokalidou, R. (2011). 'She is a very good child but she doesn't speak': The invisibility of children's bilingualism and teacher ideology.

Journal of Pragmatics, 43(2), 588-601. doi:http://dx.doi.org/10.1016/j.pragma.2010.09.014.

Goffman, E. (1981). Forms of talk. Pennsylvania: University of Pennsylvania Press.

Goodhart, F. W., Hsu, J., Baek, J. H., Coleman, A. L., Maresca, F. M., \& Miller, M. B. (2006). A view through a different lens: Photovoice as a tool for student advocacy. Journal of American College Health, 55, 53-56. doi.org/10.3200/JACH.55.1.53$\underline{56}$

Gu, M. M., \& Patkin, J. (2013). Heritage and identity: Ethnic minority students from South Asia in Hong Kong. Linguistics and Education, 24(2), 131-141. doi.org/10.1016/j.linged.2012.12.008

Gu, M. M., \& Tong, H. K. (2012). Space, scale and languages: Identity construction of cross-boundary students in a multilingual university in Hong Kong. Language and Education, 26(6), 575. doi.org/10.1080/09500782.2012.734686

Guardado, M. (2010). Heritage language development: Preserving a mythic past or envisioning the future of Canadian identity? Journal of Language, Identity \& Education, 9(5), 329-346. doi.org/10.1080/15348458.2010.517699

Guba, E. G. (1981). Criteria for assessing the trustworthiness of naturalistic inquiries. ERIC/ECTJ Annual Review Paper, 29(2), 75-91.

Guba, E. G., \& Lincoln, Y. S. (1989). Fourth generation evaluation. Newbury Park: Sage.

Hall, J. K. (2011). Teaching and researching language and culture (2 ${ }^{\text {nd }}$ ed.). London: Pearson.

Hamers, J. F., \& Blanc, M. H. A. (2000). Bilinguality and bilingualism (2 ${ }^{\text {nd }}$ ed.). Cambridge, UK: Cambridge University Press.

Hansen-Thomas, H. (2007). Language ideology, citizenship, and identity: The case of modern Germany. Journal of Language and Politics, 6(2), 249-264. doi.org/10.1075/jlp.6.2.07han

Harré, R., \& Moghaddam, F. M. (2003). The self and others. Westport, CT: Praeger.

Harré, R., \& van Langenhove, L. (1999). The dynamics of social episodes. In R. Harré, \& L. van Lagenhove (Eds.), Positioning theory: Moral contexts of intentional action (pp. 1-12). Malden, MA: Blackwell. 
He, A.W. (2006). Toward an identity theory of the development of Chinese as a heritage language. Heritage Language Journal, 4(1). Retrieved from http://www.heritagelanguages.org/.

He, A.W. (2010). The heart of heritage: Sociocultural dimensions of heritage language learning. Annual Review of Applied Linguistics, 30, 66-82. doi:http://dx.doi.org/10.1017/S0267190510000073.

He, M. F., Phillion, J., Chan, E., \& Xu, S. J. (2008). Immigrant students' experience of curriculum. In F. M. Connelly, M. F. He, \& J. Phillion (Eds.), Handbook of curriculum and instruction (pp. 219-239). Thousand Oaks, CA: Sage.

Heller, M. (2006). Linguistic minorities and modernity ( $2^{\text {nd }}$ ed.). London: Continuum.

Heller, M. (2007a). Linguistic minorities and modernity: A sociolinguistic ethnography ( $2^{\text {nd }}$ ed.). London, UK: Continuum.

Heller, M. (2007b). Bilingualism as an ideology and practice. In M. Heller, \& E. Pennington (Eds.), Bilingualism: A social approach (pp. 1-17). Hampshire: Palgrave Macmillan.

Heller, M. (2010). The commodification of language. Annual Review of Anthropology, 39, 101-114. doi:10.1146/annurev.anthro.012809.104951

Heller, M., \& Martin-Jones, M. (2001). Introduction: Symbolic domination, education, and linguistic difference. In M. Heller \& M. Martin-Jones (Eds.), Voices of authority: Education and linguistic difference (pp. 1-28). Westport, CT: Ablex.

Hornberger, N. H. (2008). Continua of biliteracy. In A. Creese, P. Martin, \& H. N. H. Hornberger (Eds.), Encyclopedia of language and education: Vol. 9. Ecology of language ( $2^{\text {nd }}$ ed., pp. 275-290). Boston: Springer Science+Business Media.

Hornberger, N., \& Wang, S. (2008). Who are our heritage language learners? Identity and biliteracy in heritage language education in the United States. In D. Brinton, O. Kagan, \& S. Bauckus (Eds.), Heritage language education: A new field emerging (pp. 3-35). New York: Routledge.

House, J. (2003). English as a lingua franca: A threat to multilingualism? Journal of Sociolinguistics, 7, 556-578. doi:10.1111/j.1467-9841.2003.00242.x

Huhtala, A., \& Lehti-Eklund, H. (2012). Language students and emerging identities. Journal of Applied Language Studies, 6(2), 5-17.

Hurworth, R. (2003). Photo-interviewing for research. Social research UPDATE, Issue 40. Department of Sociology, University of Surrey, U.K.

Jaspal, R., \& Coyle, A. (2010). 'My language, my people': Language and ethnic identity among British-born South Asians. Journal of South Asian Diaspora, 2(2), 201218. http://dx.doi.org/10.1080/19438192.2010.491299

Jaspers, J. (2004). Stylizing standard Dutch by Moroccan boys in Antwerp: Linguistics and Education, 17, 131-156. doi.org/10.1016/j.linged.2006.09.001. 
Jorgensen, J. N. (2008). Polylingual languaging around and among children and adolescents. International Journal of Multilingualism, 5(3), 161-176. doi:10.1080/14790710802387562

Joseph, C. (2008). Ethnicities and education in Malaysia: Differences, inclusions and exclusions. In G. Wan (Ed.), The education of diverse student populations. A global perspective (pp. 182-202). USA: Springer.

Joseph, C. (2014). Growing up female in multi-ethnic Malaysia. Women in Asia Series. New York: Routledge.

Joseph, J. E. (2004). Language and identity: National, ethnic, religious. Hampshire: Palgrave Macmillan.

Joseph, J. E. (2006). Linguistic identities: Double-edged swords. Language Problems \& Language Planning, 30(3), 261-267. doi.org/10.1075/lplp.30.3.04jos

Kagan, O., \& Dillon, K. (2011. Heritage languages and L2 learning. In S. Gass. \& A. Mackey (Eds.), Handbook of second language acquisition (pp. 491-505). New York: Routledge.

Kang, S. K., \& Bodenhausen, G. V. (2015). Multiple identities in social perception and interaction: Challenges and opportunities. Annual Review of Psychology, 66, 547-574. doi:10.1146/annurev-psych-010814-015025

Kang, Y. (2012). Singlish or globish: Multiple language ideologies and global identities among Korean educational migrants in Singapore. Journal of Sociolinguistics, 16, 165-183. doi.org/10.1111/j.1467-9841.2011.00522.x

Kanno, Y. (2003). Negotiating bilingual and bicultural identities: Japanese returnees betwixt two worlds. Mahwah, NJ: Lawrence Erlbaum.

Kanno, Y. (2008). Language and education in Japan: Unequal access to bilingualism. Basingstoke, UK: Palgrave Macmillan.

Karkar, S. (1978). The inner worlds: A psycho-analytic study of childhood and society in India. New Delhi: Oxford University Press.

Karrebæk, M. S. (2013). 'Don’t speak like that to her!': Linguistic minority children's socialization into an ideology of monolingualism. Journal of Sociolinguistics, 17(3), 355-375. doi.org/10.1111/josl.12035

Kayi-Aydar, H. (2014). Social positioning, participation, and second language learning: Talkative students in an academic ESL classroom. TESOL Quarterly, 48(4), 686-714. doi:10.1002/tesq.139.

Kelleher, A., Haynes, E., \& Moore, S. (2010). What are the similarities and differences among English language, foreign language, and heritage language education in the United States? Heritage Briefs Center for Applied Linguistics. Retrieved from http://www.cal.org /heritage /research /briefs .html

Kemmis, S., \& McTaggart, R. (2003). Participatory action research. In N. K. Denzin \& Y. S. Lincoln (Eds.), Strategies of qualitative inquiry ( $2^{\text {nd }}$ ed., pp. 336-396). Thousand Oaks, CA: Sage. 
Kirkpatrick, A. (2009). Learning English and other languages in multilingual settings: Myths and principles. Retrieved from http://libir1.ied.edu.hk/pubdata/ir/link/pub/9917.pdf

Kramsch, C. J. (2013). Afterword. In B. Norton (Ed.), Identity and language learning: Extending the conversation ( $2^{\text {nd }}$ ed., pp. 192-201). Bristol, UK: Multilingual Matters.

Krefting, L. (1991). Rigor in qualitative research: The assessment of trustworthiness. American Occupational Therapy Association, 45(3), 214-222. doi.org/10.5014/ajot.45.3.214

Kroskrity, P. (Ed.). (2000). Regimes of language: Ideologies, polities, and identities. Santa Fe, NM: School of American Research.

Kroskrity, P. V. (2010). Language ideologies: Evolving perspectives. In J. Jaspers, J. Ostman, \& J. Verschueren (Eds.), Language use and society (pp. 192-211).

Kumaravadivelu, B. (2008). Cultural globalization and language education. New Haven, CT: Yale University Press.

Kushner, E. (2003). English as a global language: Problems, dangers, opportunities. Diogenes, 50, 17-23. doi.org/10.1177/0392192103050002002

Lahiri, D. (2008). Malaysian Indian community: Victim of Bumiputera policy. ORF Issue Brief No.12. Retrieved from http://www.orfonline.org/cms/export/orfonline/modules/issuebrief/attachments/m alaysia_1203067850658.pdf.

Latz, A. O. (2012). Understanding the educational lives of community college students: A photovoice project, a Bourdieusian interpretation, habitus dissonance and Spark theory. Current Issues in Education, 15(2), 1-21.

Lee, J. J. (2008). Beyond borders: International student pathways to the United States. Journal of Studies in International Education, 12(3), 308-327. doi.org/10.1177/1028315307299418

Lee, J. S., \& Oxelson, E. (2006). "It's Not My Job": K-12 teacher attitudes toward students' heritage language. Bilingual Research Journal, 30(2), 456-477. doi.org/10.1080/15235882.2006.10162885

Lee, S. K. (2003). Multiple identities in a multicultural world: A Malaysian perspective. Journal of Language, Identity \& Education, 2(3), 137-158. doi.org/10.1207/S15327701JLIE0203_1

Leung, C., Harris, R., \& Rampton, B. (1997). The idealized native speaker, reified ethnicities, and classroom realities. TESOL Quarterly, 31, 543-560. doi.org/10.2307/3587837

Li, W. (2011). Moment analysis and translanguaging space: Discursive construction of identities by multilingual Chinese youth in Britain. Journal of Pragmatics, 43, 1222-1235. doi.org/10.1016/j.pragma.2010.07.035 
Li, W., \& Wu, C-J. (2009). Polite Chinese children revisited: Creativity and the use of codes witching in the Chinese complementary school classroom. International Journal of Bilingual Education and Bilingualism, 12(2), 193-212. doi.org/10.1080/13670050802153210

Lin, P. (2009). Dissecting multilingual Beijing: The space and scale of vernacular globalization. Visual Communication, Vol. 9 Issue 1 (pp.67-90). doi.org/10.1177/1470357209352948

Lincoln, Y. S., \& Guba, E. G. (1985). Naturalistic inquiry. Beverly Hills: Sage.

Lo'pez-Gopara, M. E., Me'ndezb, O. N., Sughruaa, W., \& Clementea, A. (2013). In pursuit of multilingual practices: Ethnographic accounts of teaching English to Mexican children. International Journal of Multilingualism, 10(3), 273-229. doi.org/10.1080/14790718.2013.769557

Lopez, J., Frawley, W., \& Peyton, J. K. (2010). "Se puede conservar la cultura y también se puede aspirar": Language and cultural identities among the Cora of Mexico. Heritage Language Journal, 7(2), 21-44.

Ma, W. (2010). Bumpy journeys: A young Chinese adolescent's transitional schooling across two sociocultural contexts. Journal of Language, Identity, and Education, 9, 107-123.

MacKenzie, I. (2010). English as a lingua franca in Europe: Bilingualism and multicompetence. International Journal of Multilingualism, 9(1), 83-100. doi.org/10.1080/14790718.2011.610506

Maguire, M. H., \& Curdt-Christiansen, X. L. (2007). Multiple schools, languages, experiences and affiliations: Ideological becomings and positionings. Heritage Language Journal, 5(1), 50-78.

Malaysia Today. (20 Dec, 2013). Dong Zong repeats criticism of education blueprint,

Malaysian Demographics Profile 2014. Retrieved from www.indexmundi.com/malaysia/demographics_profile.html.

Manickam, J. R. (2010). The Malaysian Indian dilemma: The struggles and agony of the Indian community in Malaysia ( $2^{\text {nd }}$ ed). Klang: Nationwide Human Development and Research Centre.

Marimuthu, T. (1993). The Plantation School as an agent of social reproduction. In K. S. Sandhu, \& A. Mani (Eds.), Indian communities in Southeast Asia (pp. 465-481). Singapore: Institute of Southeast Asian Studies (ISEAS).

Marshall, S., Hayashi, H., \& Yeung, P. (2012). Negotiating the multi in multilingualism and multiliteracies: Undergraduate students in Vancouver, Canada. The Canadian Modern Language Review, 68(1), 28-53. doi.org/10.3138/cmlr.68.1.028

Martin, N., Garcia, A. C., \& Leipert, B. (2010). Photovoice and its potential use in nutrition and dietetic research. Canadian Journal of Dietetic Practice and Research, 71, 93-97. doi.org/10.3148/71.2.2010.93 
Martin, P. (2010). 'They have lost their identity but not gained a British one': Nontraditional multilingual students in higher education in the United Kingdom. Language and Education, 24(1), 9-21. doi.org/10.1080/09500780903194028

Martin, P., Creese, A., Bhatt, A., \& Bhojani, N. (2004). Final report on complementary schools and their communities in Leicester. University of Leicester/University of Birmingham (Unpublished document) (ESRC R200223949). Retrieved from http//www.uel.ac.uk/education/staff/documents/omplementery_schools.pdf.

Massimiliano, S. (2007). 'What lies beneath?' Immigrant minority pupils' identity construction in a multicultural Flemish primary classroom. Journal of Language, Identity and Education, 6, 31-51.

Maykut, P., \& Morehouse, R. (1994). Beginning qualitative research: A philosophic and practical guide (pp. 90-91). London: The Falmer Press.

McCarty, T. L. (2002). A place to be Navajo: Rough rock and the struggle for selfdetermination in indigenous schooling. Mahwah, NJ: Lawrence Erlbaum.

Merriam, S. B. (1998). Qualitative research and case study applications in education. San Francisco: Jossey-Bass.

Miles, M. B., \& Huberman, A. M. (1994). Qualitative data analysis: An expanded sourcebook ( $2^{\text {nd }}$ ed.). California: Sage.

Miller, C. (2003). Linguistic policies and language issues in the Middle East. In A. Usuki, \& H. Kato (Eds.), Islam in the Middle Eastern studies: Muslims and minorities (149-174). Osaka, Japan: JCAS Symposium Series 7.

Milner, H. R. (2007). Race, culture and researcher positionality: Working through dangers seen, unseen and unforeseen. Educational Researcher, 36(7), 388-400. doi:10.3102/0013189X07309471

Mishra, R. C. (1994). Individualist and collectivist orientations across generations. In U. Kim, \& H. C. Triandis (Eds.), Individualism and collectivism: Theory, method, and applications (pp. 225-238). Thousand Oaks: Sage.

Montrul, S. (2008). Second language acquisition welcomes the heritage language learner: Opportunities of a new field. Second Language Research, 24, 487-506. doi.org/10.1177/0267658308095738

Morse, J. C., Barrett, M., Mayan, M., Olson, K., \& Spiers, J. (2002). Verification strategies for establishing reliability and validity in qualitative research. International Journal of Qualitative Methods, 1(2), 13-22.

Mulder, C., \& Dull, A. (2014). Facilitating self-reflection: The integration of Photovoice in graduate work education. Social Work Education, 33(8), 1017-1036. doi:10.1080/02615479.2014.937416

Ncoko, S. O. S., Osman, R., \& Cockroft, K. (2000). Code switching among multilingual learners in primary schools in South Africa: An exploratory study. International Journal of Bilingual Education and Bilingualism, 3(4), 225-241. doi.org/10.1080/13670050008667709 
Noels, K. (2005). Orientations to learning German: Heritage language learning and motivational substrates. The Canadian Modern Language Review, 62(2), 285312. doi.org/10.3138/cmlr.62.2.285

Norton, B. (1997). Language and identity. TESOL Quarterly Special Issue, 31(3), 409439.

Norton, B. (2000). Identity and language learning: Gender, ethnicity, and educational change. Essex, UK: Longman.

Norton, B. (2013). Identity and language learning: Extending the conversation ( $2^{\text {nd }}$ ed.). Bristol, UK: Multilingual Matters.

Norton, B., \& Darvin, R. (2014, May). Towards a model of investment in language learning: The intersection of identity, capital, and ideology. Paper presented at the Dialogues autour de la notion d'investissement dans l'appropriation langagiere, Lausanne, Switzerland.

Norton, B., \& Toohey, K. (2001). Changing perspectives on good language learners. TESOL Quarterly, 35(2), 307-322. doi.org/10.2307/3587650

Norton, B., \& Toohey, K. (2003). Critical pedagogies and language learning. Cambridge: Cambridge University Press.

Novak, D. R. (2010). Democratizing qualitative research: Photovoice and the study of human communication. Communication Methods Measures, 4, 291-310. doi.org/10.1080/19312458.2010.527870

Oketani, H. (1997). Additive bilinguals: The case of post-war second generation Japanese Canadian youths. Bilingual Research Journal, 21(4), 334-354. doi.org/10.1080/15235882.1997.10162710

Ollerenshaw, J. A., \& Creswell, J. W. (2002). Narrative research: A comparison of two restorying data analysis approaches. Qualitative Inquiry, 8, 329. doi:10.1177/10778004008003008

Olsen, K., \& Olsen, O. (2010). Language use, attitude and linguistic identity among Palestinian students in East Jerusalem. International Multilingual Research Journal, 4(1), 31-54. doi.org/10.1080/19313150903501018

Oriyama, K. (2010). Heritage language maintenance and Japanese identity formation: What role can schooling and ethnic community contact play? Heritage Language Journal, 7(2), 76-111.

Ornelas, I. J., Amell, J., Tran. A. N., Royster, M., Armstrong-Brown, J., \& Eng, E. (2009). Understanding African American men's perceptions of racism, male gender socialization, and social capital through photovoice. Qualitative Health Research, 19(4), 552-565. doi.org/10.1177/1049732309332104

Osman, M N. M. (2007). Marginalisation and the Indian community in Malaysia. RSIS Commentaries,(131/2007). Singapore: Nanyang Technological University. Retrieved from http://dr.ntu.edu.sg/bitstream/handle/10220/6011/rsisc13107.pdf? sequence $=1$. 
Palmer, D. K. (2009). Code-switching and symbolic power in a second-grade two-way classroom: A teacher's motivation system gone awry. Bilingual Research Journal, 32(1), 1-39. doi:10.1080/15235880902965854.

Park, J. S-Y. (2009). The local construction of a global language: Ideologies of English in South Korea. Berlin, Germany: Mouton de Gruyter.

Patton, M. Q. (1990). Qualitative evaluation and research methods (pp. 169-186). Beverly Hills, CA: Sage.

Patton, M. Q. (2002). Qualitative research and evaluation methods (3 ${ }^{\text {rd }}$ ed.). Thousand Oaks, CA: Sage.

Pavlenko, A. (2005). Emotions and multilingualism. Cambridge, UK: Cambridge University Press.

Pavlenko, A., \& Blackledge, A. (2004). Introduction: New theoretical approaches to the study of negotiation of identities in multilingual contexts. In A. Pavlenko, \& A. Blackledge (Eds.), Negotiation of identities in multilingual contexts (pp. 133). Clevedon, UK: Multilingual Matters.

Pavlenko, A., \& Lantolf, J. B. (2000). Second language learning as participation and the (re)construction of selves. In J. B. Lantolf (Ed.), Sociocultural theory and second Language learning (pp. 155-177). Oxford, UK: Oxford University Press.

Pennycook, A. (2001). Critical applied linguistics. New Jersey: Lawrence Erlbaum.

Pennycook, A. (2010). Language as a local phenomenon. London: Routledge.

Peyton, J. K., Ranard, D. A., \& McGinnis, S. (2001). Heritage languages in America: Preserving a national resource. Washington, DC: Center for Applied Linguistics \& Delta Systems.

Phillips, S. (1998). Language ideologies in institutions of power: A commentary. In B. Schieffelin, K. Woolard, \& P. Kroskrity (Eds.), Language ideologies: Practice and theory (pp. 211-222). New York: Oxford University Press.

Phinney, J. S. (1990). Ethnic identity in adolescents and adults: Review of research. Psychological Bulletin, 108(3), 499-514. doi.org/10.1037/0033-2909.108.3.499

Phinney, J., Romero, I., Nova, M., \& Huang, D. (2001). The role of language, parents and peers in ethnic identity among adolescents in immigrant families. Journal of Youth and Adolescence, 30(2), 135-153. doi.org/10.1023/A:1010389607319

Pietikäinen, S., \& Dufva, H. (2006). Voices and discourses: Dialogism, critical discourse analysis and ethnic identity. Journal of Sociolinguistics, 10(2), 205-224. doi.org/10.1111/j.1360-6441.2006.00325.x

Polinsky, M., \& Kagan, O. (2007). Heritage languages: In the 'wild' and in the classroom. Language and Linguistics Compass, 1(5), 368-395. doi:10.1111/j.1749-818x.2007.00022.x.

Polkinghorne, D. E. (1998). Narrative knowing and the human sciences. Albany: State University of New York Press. 
Preece, S. (2010). Multilingual identities in higher education: Negotiating the 'mother tongue', 'posh' and 'slang'. Language and Education, 24(1), 21-39. doi.org/10.1080/09500780903194036

Prins, E. (2010). Participatory photography: A tool for empowerment or surveillance? Action Research, 8, 426-443. doi.org/10.1177/1476750310374502

Pujolar, J., \& Gonzalez, I. (2013). Linguistic 'mudes' and the de-ethicization of language choice in Catalonia. International Journal of Bilingual Education and Bilingualism, 16(2), 138-152. doi.org/10.1080/13670050.2012.720664

Rajadurai, J. (2009). Crossing borders: The linguistic practices of aspiring bilinguals in the Malay community. International Journal of Multilingualism, 4(4), 282-299.

Ramaswamy, S. (1998). Passions of the tongue: Language devotion in Tamil India, 1891-1970. Berkeley, Los Angeles: University of California Press.

Reissman, C. K. (1993). Narrative analysis. Newbury Park, CA: Sage.

Reissman, C. K. (2008). Narrative methods for the human sciences. London: Sage.

Ricento, T. (2005). Considerations of identity in L2 learning. In E. Hinkel (Ed.), Handbook of research in second language teaching and learning (pp. 895-910). Mahwah, NJ: Lawrence Erlbaum.

Ritchie, J., \& Lewis, J. (2003). The application of qualitative methods to social research In J. Ritchie, \& J. Lewis (Eds.), Qualitative research practice. London: Sage.

Robinson-Pant, A. (2005). Cross cultural perspectives on educational research. Maidenhead: Open University Press.

Rolfe, G. (2006). Validity, trustworthiness and rigour: Quality and the idea of qualitative research. Journal of Advanced Nursing, 53(3), 304-310. doi.org/10.1111/j.13652648.2006.03727.x

Ronai, C. R. (1995). Multiple reflections of childhood sex abuse: An argument for a layered account. Journal of Contemporary Ethnography, 23(4), 395-426. doi.org/10.1177/089124195023004001

Ros i Solé, C. (2004). Autobiographical accounts of L2 identity construction in Chicano literature. Language and Intercultural Communication, 4(4), 229-241. doi.org/10.1080/14708470408668874

Rutland, A., Cameron, L., Jugert, P., Nigbur, D., Brown, R., Watters, C., ... Le Touze, D. (2012). Group identity and peer relations: A longitudinal study of group identity, perceived peer acceptance, and friendships amongst ethnic minority English children. British Journal of Developmental Psychology, 30, 283-302.

Sanagavarapu, P. (2010). Voices of Bangladeshi parents in Sydney: Australia children's transition to school. Australian Journal of Early Childhood, 35(4), 21-29.

Sandelowski, M. (1986). The problem of rigor in qualitative research. Advances in Nursing Science, 8(3), 27-37. doi.org/10.1097/00012272-198604000-00005 
Saraswathi, T. S., \& Pai, S. (1997). Socialization in the Indian context. In H. S. R. Kao \& D. Sinha (Eds.), Asian perspectives on psychology (pp. 74-92). Thousand Oaks: Sage.

Sathisan, D. (2009). Speaking for the diaspora: Tamil newspapers in Malaya and Singapore as instruments of modernity, reform and change, 1930-1940. The Heritage Journal, 4, 74-96.

says vernacular schools in jeopardy. Retrieved from http://www.malaysiatoday.net/dong-zong-repeats-criticism-of-education-blueprint-says-vernacularschools-in-jeopardy/

Schiffman, H. F. (2002). Malaysian Tamils and Tamil linguistic culture. Language and Communication, 22, 159-169.

Schwandt, T. A. (2007). The Sage dictionary of qualitative inquiry ( $3^{\text {rd }}$ ed.). Los Angeles: Sage.

Scollon, R., \& Scollon, S. (2003). Discourses in place: Language in the material world. London: Routledge.

Seals, C. (2013). Heritage language, acquisition and maintenance. Retrieved from ethniccommunities.govt.nz/.../DAY\%202\%20Heritage\%20Language\%20Axquisi tion...

Shannon, S. M. (1995). The hegemony of English: A case study of one bilingual classroom as a site of resistance. Linguistics and Education, 7, 175-200. doi.org/10.1016/0898-5898(95)90022-5

Shenton, A. K. (2004). Strategies for ensuring trustworthiness in qualitative research projects. Education for Information, 22, 63-75.

Shi, X. (2006). Gender, identity and intercultural transformation in second language socialization. Language and Intercultural Communication, 6(1), 2-17. doi.org/10.1080/14708470608668905

Shibata, S. (2000). Opening a Japanese Saturday School in a small town in the United States: Community collaboration to teach Japanese as a heritage language. Bilingual Research Journal, 24(4), 465-474. doi.org/10.1080/15235882.2000.10162778

Silverstein, M. (2006). Pragmatic indexing. In K. Brown (Ed.), Encyclopaedia of language and linguistics ( $2^{\text {nd }}$ ed., Vol. 6, pp. 14-17). Amsterdam: Elsevier.

Sithraputhran, T. (1998). Creative thinking as a function of bilingualism: A study of Malay-English bilinguals at the MARA Institute of Technology, Shah Alam. Gemilang UKM Library Catalogue. Bangi, Malaysia.

Skutnabb-Kangas, T. (2001). The globalisation of (educational) language rights. International Review of Education, 47(3), 201-219.

Song, J. (2012). The struggle over class, identity, and language: A case study of South Korean transnational families. Journal of Sociolinguistics, 16, 201-217. doi.org/10.1111/j.1467-9841.2011.00525.x 
Soto, L. D. (2002). Young bilingual children's perceptions of bilingualism and biliteracy: Altruistic possibilities. Bilingual Research Journal, 26(3), 599-610. doi.org/10.1080/15235882.2002.10162580

South Asian Voice. (2008). Malaysia: "truly Asia"? Or a cynical marketing ploy? Retrieved from http://india_resource.tripod.com/malaysia.html

Spolsky, B. (2009). Language management. New York, NY: Cambridge University Press.

Stavenhagen, R. (1996). Ethnic conflicts and the nation-state. London: Macmillan Press.

Strack, R. W., Magill, C., \& McDonough, K. (2004). Engaging youth through PhotoVoice. Health Promotion Practice, 5(1), 49-58. doi.org/10.1177/1524839903258015

Strauss, A., \& Corbin, J. (1990). Basics of qualitative research: Grounded theory, procedures and techniques. Newbury Park, CA: Sage.

Suarez, D. (2002). The paradox of linguistic hegemony and the maintenance of Spanish as a heritage language in the United States. Journal of Multilingual and Multicultural Development, 23(6), 512-530. doi.org/10.1080/01434630208666483

Swain, M., \& Lapkin, S. (1982). Evaluating bilingual education: A Canadian case study. Clevedon, UK: Multilingual Matters.

Swartz, D. (1997). Culture and power: The sociology of Pierre Bourdieu. Chicago: The University of Chicago Press.

Tate, M. D. (2008). The Malaysian Indians: History, problems and future. Petaling Jaya: SIRD.

Tavares, A. J. (2000). From heritage to international languages: Globalism and Western Canadian trends in heritage language education. Canadian Ethnic Studies, 22(1), 156-171.

Thornborrow, J. (2004). Language and identity. In J. Peccei \& I. Singh (Eds.), Language, society and power ( $2^{\text {nd }}$ ed.). London: Routledge.

Tihanyi, K. (2007). Racial integration in the USA and South Africa: Lessons in a comparative perspective. International Journal of Inclusive Education, 11(2), 177-197. doi.org/10.1080/13603110500480265

Toohey, K. (2000). Learning English at school. Clevedon, UK: Multilingual Matters.

True, G. (2015). Using photovoice and photo elicitation interview methods in VA research: Addressing questions around ethics, practice and meassurement. Retrieved from www.hsrd.research..va.gov/for_researchers/cyber_seminars/4/16/2015

Tse, L. (1997). Ethnic identity formation and its implications for heritage language development. In S. Krashen, L. Tse, \& J. McQuillan (Eds.), Heritage language development (pp. 15-29). Culver City: Language Education. 
Uitermark, J. (2002). Re-scaling, 'scale fragmentation' and the regulation of antagonistic relationships. Progress in Human Geography, 266, 743-765.

doi.org/10.1191/0309132502ph4010a

Val, A., \& Vinogradova, P. (2010). What is the identity of a heritage language speaker? Heritage Briefs. Center for Applied Linguistics. Retrieved from www.cal.org/heritage

Valdés, G. (2001). Heritage language students: Profiles and possibilities. In J. K. Peyton, D. A. Ranard, \& S. McGinnis (Eds.), Heritage languages in America: Preserving a national resource (pp. 37-77). Washington, DC \& McHenry, IL: Center for Applied Linguistics \& Delta Systems.

Valdes, G. (2005). Bilingualism, heritage language learners, and SLA research: Opportunities lost or seized? The Modern Language Journal, 89(iii), 410-426. doi:10.1111/j.1540-4781.2005.00314.x.

Van Deusen-Scholl, N. (2003). Toward a definition of heritage language: Sociopolitical and pedagogical considerations. Journal of Language, Identity, and Education, 2, 211-230. doi.org/10.1207/S15327701JLIE0203_4

Van Maanen, J. (1983). The fact and fiction in organizational ethnography. In J. Van Maanen (Ed.), Qualitative methodology (pp. 37-55). Beverly Hills: Sage.

Vandeyar, S. (2008). Changing student-teachers' beliefs and attitudes in South African classrooms. In E. Weber (Eds.), Educational change in South Africa: Reflections on local realities, practices and reforms (pp. 113-126). Rotterdam: Sense.

Victoria University of Wellington. (2007). Human ethics policy. Wellington: Author.

Wallace, K. R. (2001). Relative/outsider: The art and politics of identity among mixed heritage students. Westport, CT: Ablex.

Wallace, K. R. (2004). Situating multiethnic identity: Contributions of discourse theory to the study of mixed heritage students. Journal of Language, Identity \& Education, 33, 195-213. doi:10.1207/s15327701jlie0303_2.

Wang, C. C., \& Burris, M. A. (1997). Photovoice: Concept, methodology, and use for participatory needs assessment. Health Education and Behavior, 24, 369-387. doi.org/10.1177/109019819702400309

Wang, C. C., \& Redwood-Jones, Y. A. (2001). Photovoice ethics: Perspectives from Flint photovoice. Health Education and Behavior, 28, 560-572. doi.org/10.1177/109019810102800504

Warschauer, M. (2000). Language, identity, and the Internet. In B. Kolko, L. Nakamura, \& G. Rodman (Eds.), Race in cyberspace (pp. 151-170). New York: Routledge.

Whyte, W. F. (1991). Participatory action research. Newbury: Sage.

Wiley, T. G. (2001). On defining heritage languages and their speakers. In J. K. Peyton, D. A. Ranard, \& S. McGinnis (Eds.), Heritage languages in America: Preserving a national resource (pp. 29-36). Washington, DC \& McHenry, IL: Center for Applied Linguistics \& Delta Systems. 
Wiley, T. G. (2005). Literacy and language diversity in the United States (2 $\left.{ }^{\text {nd }} \mathrm{ed}.\right)$. Washington, DC: Center for Applied Linguistics.

Willoughby, L. (2009). Language choice in multilingual peer groups: Insights from an Australian high school. Journal of Multilingual and Multicultural Development, 30(5), 421-435. http://dx.doi.org/10.1080/01434630902999174

Wilson, N., Dasho, S., Martin, A. C., Wallerstein, N., Wang, C. C., \& Minkler, M. (2007). Engaging young adolescents in social action through PhotoVoice. Journal of Early Adolescence, 27(2), 241-243.

Wong Fillmore, L. (1991). When learning a second language means losing the first. Early Childhood Research Quarterly, 6, 323-346.

Wong Fillmore, L. (2000). Loss of family languages: Should educators be concerned? Theory into Practice, 39, 203-210. doi.org/10.1016/S0885-2006(05)80059-6

Wong, K. F., \& Xiao, Y. (2010). Diversity and difference: Identity issues of Chinese heritage language learners from dialect backgrounds. Heritage Language Journal, 7(2), 152-187.

Woolard, K. (1985). Language variation and cultural hegemony: Toward an integration of sociolinguistic and social theory. American Ethnologist, 12, 738-748.

Wylegala, A. (2010). Minority language as identity factor: Case study of young Russian speakers in Lviv. International Journal Sociology of Languages, 201, 29-51. doi.org/10.1525/ae.1985.12.4.02a00090

Yamat, H., Umar, N. F. M., \& Mahmood, M. I. (2014). Upholding the Malay language and strengthening the English language policy: An education reform.

International Education Studies, 7(13), 197-205. doi.org/10.5539/ies.v7n13p197

Yeung, Y. S., Marsh, H. W., \& Suliman, R. (2000). Can two tongues live in harmony? Analysis of the National Education Longitudinal Study of 1988 (NELS88) longitudinal data on the maintenance of home language. American Educational Research Journal, 37(4), 1001-1026. doi.org/10.3102/000283120370041001

Yi, Y. (2013). Adolescent multilingual writer's negotiation of multiple identities and access to academic writing: A case study of a Jogi Yuhak student in a US high school. The Canadian Modern Language Review, 69(2), 207-231. doi.org/10.3138/cmlr.1381

Yin, R. K. (1994). Case study research: Design and methods Applied Social Research Methods Series (2nd ed., Vol. 5). Thousand Oaks: Sage.

You, B. (2005). Children negotiating Korean American ethnic identity through their heritage language. Bilingual Research Journal, 29(3), 711-721. doi.org/10.1080/15235882.2005.10162860

Zakaria, F. (2011). The post-American world: Release 2.0. New York, NY: W. W. Norton. 
Zenkov, K., \& Harmon, J. (2009). Picturing a writing process: PhotoVoice and teaching writing to urban youth. Journal of Adolescent \& Adult Literacy, 52(7), 575-584. doi.org/10.1598/JAAL.52.7.3

Zentz, L. (2015). Is English also the place where I belong? Linguistic biographies and expanding communicative repertoires in Central Java. International Journal of Multilingualism, 12(1), 68-92. doi:10.1080/14790718.2014.943233

Zhang, D., \& Slaughter-Defoe, D. T. (2009). Language attitudes and heritage language maintenance among Chinese immigrant families in the USA. Language, Culture and Curriculum, 22-(2), 77-93. Retrieved from http://dx.doi.org/10.1080/07908310902935940. 


\section{Appendix 1: Interview Consent Forms}

\section{$\underline{\text { Research Project-Student Consent Form }}$}

\section{Negotiating multiple identities in educational contexts : Stories of Tamil Heritage Language Users as multilingual Malaysians}

Please read the following:

I agree to be interviewed by the researcher Thilegawathy Sithraputhran.

$>$ I understand that interviews will be recorded and transcribed.

$>$ I understand that my participation is entirely voluntary.

$>$ I understand that my identity will be protected using a pseudonym. .

$>$ I understand that the analysis obtained may be used for a thesis, for conference papers and/or publication by the researcher Thilegawathy Sithraputhran.

$>$ I understand that I can withdraw from the research project for any reason within two weeks after interview and that any data provided would then be destroyed.

$>$ I understand that the researcher may ask me for further follow-up interviews to ensure that my stories have been fully understood.

$>$ I understand that the researcher will ask me to share photographs that I have collected or taken based on instructions given by the researcher during interviews.

$>$ I understand that these photographs should not contain facial images of person/persons.

$>$ I understand that I will have a chance to check the accuracy of the interview/s.

$>$ I understand that transcripts and tapes and raw data will be kept for five years, after which they will be destroyed. 
Please indicate your preference for involvement in the research (tick as appropriate):

- I have had the project explained to me and have had the chance to ask any questions. I agree to take part in the above research.

Name

Name of university

I wish to receive feedback from this project by being sent a summary of the research.

$\begin{array}{cc}\square & \text { Yes } \\ \square & \text { No }\end{array}$

Email address

Signature

Date

This project has been reviewed and approved by the Victoria University Human

Ethics Committee (number) 


\section{-UNIVERSITY CONSENT FORM-}

\section{$\underline{\text { Research Project - Head of Department Consent Form }}$}

Project Title: “How do Tamil Heritage Language Users (THLU) perceive using Tamil impacts their identities as multilingual speakers in Malaysia?"

I have read the Information Sheet for students and have understood the nature of research and why the Tamil Heritage Language Users from this university have been selected in this study.

- I agree to allow the researcher to approach undergraduate students who are Tamil Heritage Language Users from my university for research purposes.

- I understand that participation is entirely voluntary and will take place only with the consent of all participants.

- I understand that data will be kept for 5 years, after which they will be destroyed.

- I understand that the participants can withdraw from the research for any reason within two weeks after interview and that any data provided would then be destroyed.

- I understand that neither the participants' names nor the university's name will be used in any publications or presentations based on the data from this research.

Name:

Signature: 
I wish to receive feedback from this project by being sent a summary of the research. This will not be available until (date)

$\square \quad$ Yes
$\square \quad$ No

Email address

Signature

Date

This project has been reviewed and approved by the Victoria University Human Ethics Committee (number) 


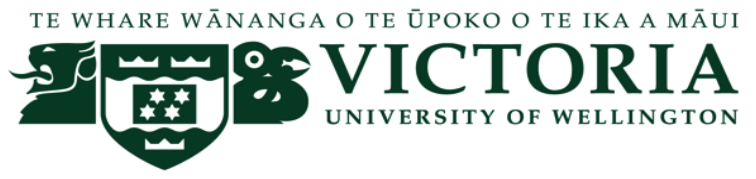

\section{Appendix 2: Information Sheets}

\section{Information Sheet to Participants}

\section{Negotiating multiple identities in educational contexts: Stories of Tamil Heritage Language Users as multilingual Malaysians}

I am Thilegawathy Sithraputhran, a PhD student in the, Faculty of Education, Victoria University of Wellington, New Zealand. I am conducting a study on how Tamil Heritage Language Users (THLUs) perceive using Tamil impacts their identities as multilingual speakers in Malaysia. I want to explain this study and invite you to take part.

This information sheet may contain words that you do not understand. Please ask me to stop as we go through it and I will take time to explain. If you have questions later, you can ask them at any time.

\section{Research Project}

My research project is entitled "Negotiating multiple identities in educational contexts: Stories of Tamil Heritage Language Users as multilingual Malaysians". A Tamil Heritage Language User is someone who has studied in a Tamil Primary School in Malaysia and whose ethnicity is Tamil and who is able to read, write and speak Tamil. The study will explore how using multiple languages (English, Malay and Tamil) in their daily lives impacts the identities of THLUs and affects their motivation to maintain their Heritage Language (HL) which is Tamil. The participants for this study will be THLUs like you, who are studying in a university in Malaysia. I want to find out how you perceive the status of your heritage language (Tamil) in relation to English and Malay and how you perceive you are positioned by your peers and families when you use Tamil. I want to invite you to take part in this research because I feel that your experience as a THLU can contribute much to the understanding and knowledge of heritage language identity of Tamils in Malaysia.

Research Method

This research will ask you to bring photographs and talk about these in interviews with me. This process is called photovoice. You will be given a two week time frame to bring photos of objects, events and places which you think capture your language experiences as a multilingual user. These photographs can be sent online to me. However, the photographs must not show people's faces. Throughout this study there will be two interviews, one at the beginning of the trimester and the second one towards the end of the trimester. Each interview will take about one hour. All interviews will be digitally recorded and transcribed. I will check the recording with you. In the analysis stage, I will rewrite the themes from your interviews into a narrative and again check with you that this story faithfully captures your main ideas.

All information collected will be strictly confidential. Your identity will be protected using a pseudonym. You have the right to withdraw from the study for any reason within two 
weeks of the first interview. There is no penalty for participating or not participating in this research.

If you consent to participate in the interview, you have the following rights

- to decline to answer any particular questions;

- to withdraw from the study for any reason within two weeks after the first interview;

- to ask any questions regarding the study at any time during participation;

- to provide information on the understanding that your name will not be revealed;

- to have the interview transcriptions and narratives sent to you by email and have a chance to verify and change any part of these;

- to be given access to a summary of the study findings when it is concluded if you wish. This will be sent to you by email.

This research will have no impact on your grades. Your name and university will not be identified in any publications resulting from the research. Access to the data is restricted to my supervisors and me. All data will be stored in password protected files and will be kept for 5 years, after which they will be destroyed.

If you have any questions or you would like additional information, please contact me at Thilegawathy.Sithraputhran@vuw.ac.nz, janetsith@gmail.com or my supervisors, Dr. Margaret Gleeson, at Margaret.gleeson@vuw.ac.nz and/or Dr. Carolyn Tait at Carolyn.tait@vuw.ac.nz, telephone +64-4-463-9590. If you have any concerns about the ethics of this project, please contact the head of the ethics committee Allison Kirkman at Allison.kirkman@vuw.ac.nz.

This project has been reviewed and approved by the Victoria University Human Ethics Committee (number)

This project has been reviewed and approved by the Victoria University Human Ethics Committee (number)

If you are happy to participate, please complete the attached consent form and return it to me. 


\section{UNIVERSITY PARTICIPATION- Assistant Registrar/Head of School Information Sheet Negotiating multiple identities in educational contexts: Stories of Tamil Heritage Language Users as multilingual Malaysians}

\section{Researcher}

I am Thilegawathy Sithraputhran, a PhD student from the Faculty of Education, Victoria University of Wellington. Prior to this, I held the position of an Associate Professor at the MARA University of Technology, Malaysia. I was teaching English at the Academy of Language Studies, MARA University of Technology for 26 years. My doctoral study is designed to explore how Tamil Heritage Language Users use multiple languages (English, Malay and Tamil) in different spheres of their daily lives and how this impacts their identities and motivation to maintain their heritage language. This research has ethical approval from the Victoria University Human Ethics Committee (No. \#\#\#\#\#).

This sheet gives you information regarding this study as I am seeking your permission to recruit students from your faculty for my study.

\section{The purpose of my PhD research}

This research aims to contribute to an understanding of how the identities of multilingual Heritage Language Users are defined. In addition, the findings are likely to be of interest to educators like you, language policy and curriculum planners, and families trying to promote heritage language maintenance and development.

\section{The research questions}

How do nine THLU-Ts tertiary students from an international university in Malaysia:

1. perceive the status of their HL in relation to English and Malay?

2. perceive that they are positioned by their peers (non-Tamils and THLU-Ms) when they use Tamil?

3. perceive the role of their families in the language choices they (the participants) make?

\section{Research Process}

I wish to recruit students from your university in Malaysia because students from Tamil Heritage backgrounds attend courses here which are taught in English. Data will be gathered through photovoice interviews. Students bring or take photographs on events, objects or places that capture their multiple language experiences and discuss these with me during the interview sessions. There will be two interviews; one early in the trimester and the second one towards the end. Each interview will be conducted individually and will take approximately one hour. The interviews will be digitally recorded and transcribed, and the key themes emerging will be written in a narrative form. At other times I will communicate with the participants by email. 


\section{Research Participants}

I plan to select eight to ten participants who are first-year students from your university. They will be Tamil Heritage Language Users who are defined as ethnic Tamils, having had six years primary schooling in Tamil primary schools and come from homes where Tamil is spoken. Participants are chosen through snow ball sampling and only those who express their willingness to participate in my study will be invited. They may withdraw from the research project for any reason up to the conclusion of the first interview and any data provided would then be destroyed. I am seeking permission to interview the selected participants.

The participation for the students would involve:

- Participating in the interviews and being available for follow-up interviews.

- Agreeing that the information given can be used by the researcher, Thilegawathy Sithraputhran for the study.

\section{Confidentiality and Access to Information}

The information provided is strictly confidential. Your university and participating students will not be identifiable. Data and information collected will be kept confidentially by the sole researcher, Thilegawathy Sithraputhran.

\section{Publication of Results}

The information gained in this research will be used for publication purposes including academic or professional journals, conference papers and appropriate articles. The finished thesis will be deposited at the Victoria University of Wellington library.

If you have any questions or would like to receive further information regarding this project, please contact me at Thilegawathy.Sithraputhran@vuw.ac.nz. You can also contact my supervisors, Dr. Margaret Gleeson, Senior Lecturer at Margaret.gleeson@vuw.ac.nz. and/or Dr. Carolyn Tait, Senior Lecturer at Carolyn.tait@ vuw.ac.nz, Phone: +64-4-463-9590 Any ethical concerns regarding the research should be directed to Dr. Allison Kirkman, chair of the Victoria University of Wellington Human Ethics Committee by emailing Allison.kirkman@vuw.ac.nz.

This project has been reviewed and approved by the Victoria University Human Ethics Committee (number)

Your consent for this study is highly valued. If you are willing for me to recruit students from your university, please complete the attached form.

Thank you for your consideration.

Yours sincerely, Thilegawathy Sithraputhran 


\section{Appendix 3: Sample Interview Questions}

\section{Indicative ways of helping participants tell their stories (Broadening)}

(Adapted from Etherington, K. (2009)).

1. Tell me about this photo you took/Tell me what is happening here.

2. Who were you with? (inviting other characters into the story)

3. What happened then ...? How long did that go on? (inviting the temporal nature of stories).

Historical continuity: the need to understand the participant as coming from somewhere (contextual information) and going somewhere.

4. What was happening in the rest of your life at that time?

\section{Feeling Questions (Burrowing)}

Embodied nature of the teller and their engagement in the events, their senses, feelings, thoughts, attitudes and ideas; thus locating the narrative in the experience of a real life.

1. What could you see/hear? How did it look to you?

2. What was your sense of what was going on?

3. How did that affect you/make you feel/think?

4. How did you feel about what s/he did?

5. Did you have any ideas about this at the time?

Metaphors, symbols, and creative, intuitive ways of knowing: these create pictures that capture

vivid representations of experiences.

1. What was that like?

2. Do you have an image of that?

3. Did that put you in mind of something?

4. Couldyou draw me a picture of that in words?

\section{Meaning Questions (Restorying)}

Significance of other people: how does participant's network of relationships impact on events?

1. Who were the other characters?

2. What did your family think of that?

3. Who told you?

Choices and actions of the participant who is an active participant in the events, making choices

based on values, beliefs and aims.

1. What made you decide to go there?

2. Why did you want to do that?

3. What were you intending?

4. What did you want to happen?

5. When did you decide that?

6 . When did you realise that it couldn't go on? (turning point)

7. What kind of sense did you make of all that? (meaning-making) 
The researcher needs to ask questions that pay attention to cultural contextual: giving details of

values, beliefs, habits etc

1. How did you know that...?

2. Why do you think that happened?

3. What did you think about that?

4. Was that something you usually did?

5. Was that OK with you?

\section{Some questions that will help in building a beginning, middle and an end}

Beginning, middle and an end: a story needs recognisable parameters or it will seem chaotic or meaningless. It starts with an event or decision or some recognisable trigger. The plot then develops toward some form of completion.

1. Where does your story begin?

2. How did that situation arise?

3. What happened after that?

4. What do you think about that now? 